Acquisitions and

Bibliographic Services Branch

395 Wellington Street

Ottawa, Ontario

K1A ON4
Bibliothèque nationale

du Canada

Direction des acquisitions et

des services bibliographiques

395. rue Wellington

Ottawa (Ontario)
Your thet Votre reterence

Ourfice Notreselerence

NOTICE

AVIS

The quality of this microform is heavily dependent upon the quality of the original thesis submitted for microfilming. Every effort has been made to ensure the highest quality of reproduction possible.

If pages are missing, contact the university which granted the degree.

Some pages may have indistinct print especially if the original pages were typed with a poor typewriter ribbon or if the university sent us an inferior photocopy.
La qualité de cette microforme dépend grandement de la qualité de la thèse soumise au microfilmage. Nous avons tout fait pour assurer une qualité supérieure de reproduction.

S'il manque des pages, veuillez communiquer avec l'université qui a conféré le grade.

La qualité d'impression de certaines pages peut laisser à désirer, surtout si les pages originales ont été dactylographiées à l'aide d'un ruban usé ou si l'université nous a fait parvenir une photocopie de qualité inférieure.

Reproduction in full or in part of this microform is governed by the Canadian Copyright Act, R.S.C. 1970, c. C-30, and subsequent amendments.
La reproduction, même partielle, de cette microforme est soumise à la Loi canadienne sur le droit d'auteur, SRC 1970, c. C-30, et ses amendements subséquents.

\title{
Canadä
}




\section{APPLICATION OF ELECTRIC POLARIZATION TO CONTAMINANT DETECTION IN SOILS}

$$
\text { by }
$$

\section{EDWARD J. HOPPE}

Department of Civil Engineering and Applied Mechanics

McGill University

Montreal, Canada

February 1994

A thesis submitted to the Faculty of Graduate Studies and Research in partial fulfillment of the requirements for the degree of Doctor of Philosophy

() Edward J. Hoppe 1994 
National Library

of Canada

Acquisitions and

Bibliographic Services Branch

395 Wellington Street

Ottawa, Ontario

K1A ON4
Bibliotheque nationale

du Canada

Direction des acquisitions et

des services bibliographiques

395, nue Wellington

Ottawa (Onlario)

K1A ON4
Your the Votre reterence
Oux tile Notre reterence
THE AUTHOR HAS GRANTED AN IRREVOCABLE NON-EXCLUSIVE LICENCE ALLOWING THE NATIONAL LIBRARY OF CANADA TO REPRODUCE, LOAN, DISTRIBUTE OR SELL COPIES OF HIS/HER THESIS BY ANY MEANS AND IN ANY FORM OR FORMAT, MAKING THIS THESIS AVAILABLE TO INTERESTED PERSONS.
L'AUTEUR A ACCORDE UNE LICENCE IRREVOCABLE ET NON EXCLUSIVE PERMETTANT A LA BIBLIOTHEQUE NATIONALE DU CANADA DE REPRODUIRE, PRETER, DISTRIBUER OU VENDRE DES COPIES DE SA THESE DE QUELQUE MANIERE ET SOUS QUELQUE FORME QUE CE SOIT POUR METTRE DES EXEMPLAIRES DE CETTE THESE A LA DISPOSITION DES PERSONNE INTERESSEES.

L'AUTEUR CONSERVE LA PROPRIETE DU DROIT D'AUTEUR QUI PROTEGE

SA THESE. NI LA THESE NI DES EXTRAITS SUBSTANTIELS DE CELLECI NE DOIVENT ETRE IMPRIMES OU AUTREMENT REPRODUITS SANS SON AUTORISATION.
THE AUTHOR RETAINS OWNERSHIP OF THE COPYRIGHT IN HIS/HER THESIS. NEITHER THE THESIS NOR SUBSTANTIAL EXTRACTS FROM IT MAY BE PRINTED OR OTHERWISE REPRODUCED WITHOUT HIS/HER PERMISSION. 


\begin{abstract}
A new field measurement technique for the determination of the lateral extent of subsurface contamination is proposed. It is applicable to tracing contaminant migration from underground storage tanks and waste disposal sites. The proposed approach involves adaptation of the time-domain reflectometry (TDR) concept and relies on the interaction of matter with an electric field. Analysis of the TDR data collected from soil-contaminant mixtures indicates the feasibility of a subsurface contaminant detection.

The proposed contaminant detection technique relies on matching an unknown TDR waveform with a number of known waveforms stored in a computerized database. The analysis is performed in the frequency-domain through the use of the Fast Fourier Transform (FFT). It is proposed that the matching process utilize the coherence function.

Application of the proposed technique requires a signal generator, a digital waveform recorder, a portable computer, and a coaxial cable terminated with a soil probe. The main advantage of the proposed system is the capability of on site analysis, thus reducing the time and the expense associated with the subsurface contaminant detection and delineation.
\end{abstract}




\section{RÉSUMÉ}

Une nouvelle technique de mesure champêtre pour déterminer l'étendue de contamination latérale souterraine st proposée. Elle est applicable à la migration de contaminants provenant de sources telles que les réservoirs souterrains ainsi que les dépotoirs. L'approche proposée implique l'adaptation du concept du domaine de temps de réflectométrie (DTR) et se fie sur l'interaction de matière avec un champ électrique. L'analyse des données DTR rassemblées provenant de mélanges terre-contaminants démontre que cette méthode de détection est réalisable.

La technique de détection proposée se fie sur la comparaison d'un signal DTR inconnu avec un nombres de signaux connus en réserve dans la base de données d'un ordinateur. L'analyse est accomplie dans le domaine de fréquence. Il est suggéré que la procédure de comparaison implique la fonction de cohérence.

L'application de la technique recommandée requiert un générateur de signaux, un enregistreur de signaux digitaux, un ordinateur portatif, et un cable coaxial muni d'une sonde souterraine. L'avantage principal qu'offre ce système est lia capacité d'analyse sur site, donc la réduction de temps et de dépenses associés à la découverte de contaminants. 


\section{ACKNOWLEDGMENTS}

The author would like to thank Prifessor Raymond Yong for his support and patience throughout this study. In addition, the author wishes to express his gratitude to Dr. Ryszard Malewski of Hydro-Québec Research Institute (IREQ) for his constructive comments and helpful guidance. The technical assistance of Messr. Jean Douville and Louis Lavallée of IREQ is gratefully acknowledged. Critical comments from Mr. Daniel Tschudi of Asea-Brown Boveri (ABB) are also appreciated. Thanks are extended to Dr. William Cook for his expert computer help in the use of the PC TEX typesetting program and to Mr. Randy Combs of VTRC for his assistance with graphics. This study was supported by Grants from the Québec Ministry of Education (FCAR/MESST) and the Natural Sciences and Engineering Research Council of Canada Grant No. A-882. 


\section{TABLE OF CONTENTS}

1 INTRODUCTION . . . . . . . . . . . . . . . . . . . . 1

1.1 STATEMENT OF THE PROBLEM

1.2 OBJECTIVES . . . . . . . . . . . . . . . . . . . . . 4

1.3 APPROACH PURSUED BY THIS STUDY . . . . . . . . . . . 5

1.4 ORGANIZATION OF THESIS . . . . . . . . . . . . . . . . 7

2 REVIEW OF PREVIOUS RESEARCH . . . . . . . . . . . . 8

2.1 APPLICABLE DETECTION TECHNIQUES . . . . . . . . . . 8

2.2 ELECTRICAL RESISTIVITY . . . . . . . . . . . . . . . 9

2.3 INDUCED POLARIZATION . . . . . . . . . . . . . . . . 12

2.4 TIME-DOMAIN REFLECTOMETRY . . . . . . . . . . . . 14

2.5 ELECTROMAGNETIC TECHNIQUES . . . . . . . . . . . . 16

2.6 HIGH FREQUENCY PULSE TECHNIQUES . . . . . . . . . . 18

2.7 SEISMIC TECHNIQUES . . . . . . . . . . . . . . . . . 20

2.8 ACOUSTIC EMISSION MONITORING . . . . . . . . . . . . 21

2.9 SOIL GAS SURVEY . . . . . . . . . . . . . . . . . . . 21

2.10 ASSESSMENT OF EXISTING TECHNIQUES . . . . . . . . . 22

3 THEORETICAT ASPECTS . . . . . . . . . . . . . . . . 29

4 EXPERIMENTAL STUDY . . . . . . . . . . . . . . . . . 43

4.1 EXPERIMENTAL PROCEDURE . . . . . . . . . . . . . . 43

4.2 DATA ACQUISITION . . . . . . . . . . . . . . . . . . 49

4.3 DATA ANALYSIS . . . . . . . . . . . . . . . . . . . . 63

4.4 DISCUSSION OF RESULTS . . . . . . . . . . . . . . . . . 91

4.5 PRACTICAL IMPLEMENTATION . . . . . . . . . . . . . 103

5 CONCLUSIONS . . . . . . . . . . . . . . . . . . . . . 104

STATEMENT OF ORIGINALITY . . . . . . . . . . . . . . . 106

APPENDIX 1 - Computer Source Code Listings . . . . . . . . 107

1.1 Data Transfer from TEK 11402 to IBM PC . . . . . . . . . . . 108

1.2 Processing of Acquired Waveforms . . . . . . . . . . . . . . 109

1.3 Display of Time-Domain Waveforms . . . . . . . . . . . . . 114

1.4 Display of Frequency-Domain Waveforms . . . . . . . . . . . 117

1.5 Matching of Database and Test Waveforms . . . . . . . . . . . 123 
APPENDIX 2 - Previously Published Material . . . . . . . . 130

REFERENCES . . . . . . . . . . . . . . . . . . . . . . 147 


\section{LIST OF FIGURES}

2.1 Electrical Resistivity Arrays (Wait, 1971) . . . . . . . . . . . . 10

2.2 Wave Tilt (Wait, 1971) . . . . . . . . . . . . . . . . . . . 17

3.1 Polarization of a Dielectric . . . . . . . . . . . . . . . . . . 30

3.2 Dispersion and Absorption in Dielectrics . . . . . . . . . . . . . 32

3.3 Locus of the Dielectric Constant in the Complex Plane . . . . . . . 34

3.4 Typical Setup for the TDR Method . . . . . . . . . . . . . . 40

3.5 Typical TDR Responses . . . . . . . . . . . . . . . . . . 41

4.1 Experimental Setup . . . . . . . . . . . . . . . . . . . . 44

4.2 Effect of Pulse Propagation Through Coaxial Cable on Attenuation . . . 46

4.3 Oscilloscope Trace - Butyl Alcohol . . . . . . . . . . . . . . . 50

4.4 Oscilloscope Trace - Methyl Alcohol . . . . . . . . . . . . . . 51

4.5 Oscilloscope Trace - Phenol (1000 ppm) . . . . . . . . . . . . . 52

4.6 Oscilloscope Trace - Kerosene . . . . . . . . . . . . . . . . 53

4.7 Acquired Time-Domain Data : $\mathrm{H} 2 \mathrm{O}, \mathrm{H} 2 \mathrm{O}-40, \mathrm{H} 2 \mathrm{O}-60$. . . . . . . 56

4.8 Acquired Time-Domain Data : CACL, CACL-40, CACL-60 . . . . . . 57

4.9 Acquired Time-Domain Data : PB, PB-40, PB-60 . . . . . . . . . 58

4.10 Acquired Time-Domain Data : CEZ, CEZ-40, CEZ-60 . . . . . . . . 59

4.11 Acquired Time-Domain Data : KAH1, KAH1-40, KAH1-60 . . . . . . 60

4.12 Acquired Time-Domain Data : OPEN, BENZENE, ETHANOL . . . . 61

4.13 Acquired Time-Domain Data : LACHENAIE, NACL . . . . . . . . 62

4.14 Processed Time-Domain Data: H2O, H2O-40, H2O-60 . . . . . . . 65

4.15 Processed Time-Domain Data : CACL, CACL-40, CACL-60 . . . . . $\$ 6$

4.16 Processed Time-Domain Data : PB, PB-40, PB-60 . . . . . . . . . 67

4.17 Processed Time-Domain Data : CEZ, CEZ-40, CEZ-60 . . . . . . . 68

4.18 Processed Time-Domain Data : KAH1, KAH1-40, KAH1-60 . . . . . 69

4.19 Processed Time-Domain Data : OPEN, BENZENE, ETHANOL . . . . 70

4.20 Processed Time-Domain Data : LACHENAIE, NACL . . . . . . . . 71

4.21 Transfer Function : PB, CEZ, KAH, CACL, H2O . . . . . . . . . . 72

4.22 Transfer Function : BENZENE, ETHANOL . . . . . . . . . . . 73

4.23 Transfer Function : H2O, H2O-40, H2O-60 . . . . . . . . . . . . 74

4.24 Transfer Function : KAH1, KAH1-40, KAH1-60 . . . . . . . . . . 75

4.25 Transfer Function : CEZ, CEZ-40, CEZ-60 . . . . . . . . . . . . 76

4.26 The Influence of Phase Angle on Coherence . . . . . . . . . . . 78

4.27 The Influence of Magnitude on Coherence . . . . . . . . . . . . 79 
4.28 Soil 1: Time-Domain Data and FFT of Input . . . . . . . . . . . 80

4.29 Soil 1: FFT of Output and Power Spectra . . . . . . . . . . . . 81

4.30 Soil 1: Cross Spectrum and Transfer Function . . . . . . . . . . . 82

4.31 Soil 2: Time-Domain Data and FFT of Input . . . . . . . . . . . 83

4.32 Soil 2: FFT of Output and Power Spectra . . . . . . . . . . . . 84

4.33 Soil 2: Cross Spectrum and Transfer Function . . . . . . . . . . . 85

4.34 Coherence Function Between Dry Soil 1 and Dry Soil 2 . . . . . . . 86

4.35 Proposed Contaminant Match Procedure . . . . . . . . . . . . 89

4.36 Coherence Function Between KAH1-40, KAH1 and LACHEN . . . . . 101 


\section{LIST OF TABLES}

3.1 Ionic Lowering of the Dielectric Constant (Hasted et al., 1948) . . . . 36

4.1 Chemical Characteristics of "Contaminants" . . . . . . . . . . . 54

4.2 Contaminant Match Results : $\mathrm{H} 2 \mathrm{O}, \mathrm{H} 2 \mathrm{O}-40, \mathrm{H} 2 \mathrm{O}-60$. . . . . . . . 94

4.3 Contaminant Match Results : CACL, CACL-40, CACL-60 . . . . . . 95

4.4 Contaminant Match Results : PB, PB-40, PB-60 . . . . . . . . . 96

4.5 Contaminant Match Results : CEZ, CEZ-40, CEZ-60 . . . . . . . . 97

4.6 Contaminant Match Results : KAH1, KAH1-40, KAH1-60 . . . . . . 98

4.7 Contaminant Match Results : OPEN, BENZENE, ETHANOL . . . . 99

4.8 Contaminant Match Results : LACHENAIE, NACL . . . . . . . . 100 


\section{LIST OF SYMBOLS}

$\begin{array}{ll}\epsilon^{\prime} & \text { dielectric constant } \\ \epsilon^{\prime \prime} & \text { dielectric loss } \\ C & \text { capacitance } \\ E & \text { electric field } \\ f & \text { frequency } \\ \omega & \text { angular frequency } \\ F_{x} & \text { Fast Fourier Transform } \\ F_{x x} & \text { power spectrum } \\ F_{x y} & \text { cross spectrum } \\ \Gamma & \text { coherence function } \\ H & \text { transfer function } \\ I & \text { current } \\ k & \text { Boltzmann constant } \\ R & \text { resistivity } \\ T_{r} & \text { risetime } \\ \mu & \text { magnetic permeabilty } \\ \sigma & \text { conductivity } \\ \tau & \text { relaxation time } \\ V & \text { voltage } \\ Z & \text { impedance } \\ & \end{array}$




\section{CHAPTER 1 \\ INTRODUCTION}

\subsection{STATEMENT OF THE PROBLEM}

The problem that this study addresses is the detection of a contaminant leakage. Product leakage from underground storage tanks and migration of leachates from waste disposal sites have been known to create acute health risks and require substantial expenditures of funds to clean up. The Environmental Protection Agency (EPA) regulates approximately 2 million underground storage tanks at 750,000 facilities across the United States (Tarrer, 1993). It is estimated that 80 percent of the underground tanks are constructed of bare, unprotected steel, susceptible to corrosion and subsequent leakage. The EPA has identified 175,000 confirmed tank releases that are potential threats to public health and the environment, and that number is expected to rise.

According to the EPA, the American industry produces approximately 35 million metric tons of toxic waste each year. Much of this waste is disposed of in land impoundments. While recently constructed facilities appear to contain the waste in an environmentally sound manner, numerous older disposal sites continue to pollute their surroundings. By some calculations about six billion tons of chemicals have been disposed of since 1950, some in impoundments situated on permeable soils (Boraiko, 1985).

Current detection procedures rely mainly upon monitoring wells, lysimeters, and leachate underdrains. Wells are the most common means of monitoring the ground- 
water contamination. This approach tends to be expensive and time consuming to implement. Timely detection of the contaminant plume is obviously dependent on the initial layout and a number of monitoring wells. Unfortunately, wells can sample only a small volume of the acquifer. If samples collected from wells are not representative of the area or conditions for which they are intended, misleading and erroneous conclusions may result. Experience has shown that by the time a contaminant becomes detected in a monitoring well, a substantial volume of the surrounding soil and groundwater has already been polluted (Waller and Davis, 1984).

The risk of drilling wells and exploratory holes in unknown hazardous waste sites can be substantial. As the number of holes needed to define a problem area increases, so does the possibility of puncturing buried containers. Toxic fumes and liquids may be released. Explosions and fire may occur in extreme cases.

Lysimeters are commonly installed in the unsaturated zone. They include a ceramic cup into which a pore liquid is drawn. The sample is subsequently forced to the surface for collection and analysis. As in well monitoring, the contaminant plume must intersect the lysimeter. Common problems with lysimeters include clogging and degradation of ceramic cups.

The urderdrain system serves to intercept the fluid seeping below an impoundment site. Although this system allows the leak to be detected and managed, it also has some significant drawbacks. It can't be installed at an existing site. It requires daily inspection. Finally: it can't identify the location of a leak.

The limitations associated with present monitoring techniques underscore the need for an alternate approach. Undeniably, early detection and characterization of ensuing subsurface contamination can minimize its negative impact. Therefore, there is a demand for a field diagnostic procedure which allows a rapid determination of the extent of pollutants present in the soil substrate. The method should assist in locating a leak in the impounding boundary so that a corrective action can be taken to alleviate the 
problem. It should also be adaptable to a wide range of chemicals, as opposed to being ion specific. Currently there are about 60,000 substances classified as hazardous by the EPA (Waller and Davis, 1984). 


\subsection{OBJECTIVES}

The objective of this research is to develop a new field procedure for the detection and delineation of soil contaminants. This study concentrates on a detection method that will improve the efficiency and reduce the costs associated with the current procedures. Both data gathering and data analysis techniques are examined from the standpoint of the applicability to the on-site contaminant characterization and subsurface mapping. The application of digital data acquisition instruments and portable computers to an automated measurement and analysis process is explored. It is envisioned that the proposed contaminant match procedure will minimize the current need to conduct site characterization studies in several stages of monitoring well installation, groundwater sampling, and laboratory analysis. 


\subsection{APPROACH PURSUED BY THIS STUDY}

A study conducted by the U.S. Environmental Protection Agency (EPA) identified a number of existing methodologies that can potentially be applied to subsurface contaminant detection (Waller and Davis, 1984). Most promising candidates include resistivity soundings, electromagnetic (EM) techniques, ground penetrating radar (GPR), time-domain reflectometry (TDR), acoustic enissions (AE) and seismic methods. These approaches typically relate the extent of soil contamination to a change in electrical properties of materials. Seismic techniques may be used to detect a contaminant indirectly by measuring a change in the velocity of sound propagation in a saturated material (Winter, 1973). The propagation velocity of sound in unsaturated soils is about one half the velocity in saturated soils. Therefore, it is theoretically possible to detect a leak that is located in the unsaturated zone.

The approach pursued by this study originates from a measurement method called time-domain reflectometry (TDR). It involves sending a fast risetime electrical impulse into a coaxial cable terminated by a sample material and analyzing the reflected signal. Although this approach necessitates an invasive probing, as opposed to a surface based electromagnetic techniq̣ue, it is considerably less susceptible to a cultural noise commonly present in the field EM measurements.

The main thrust of this study involves an adaptation of the TDR technology to the in-situ detection of subsurface contaminants by measuring and analyzing the variation of soil-contaminant dielectric properties as a function of frequency. Data gathered by the TDR method is analyzed in the frequency-domain through the use of the Fast Fourier Transform. A contaminant match procedure is developed, whereby a data record obtained from an unknown soil-contaminant system is matched with a computerized database of known records. The matching procedure relies on the coherence function which provides a measure of similarity between the unknown signals. A single parameter match descriptor is proposed. By utilizing a digital recording 
instrumentation and a portable computer for data acquisition and signal processing this study concentrates on a method which allows an automated measurement and analysis process. 


\subsection{ORGANIZATION OF THESIS}

This thesis contains descriptions of various geophysical techniques that may be adapted to a subsurface contaminant detection. The measurement principles associated with each technique are discussed. The approach selected for subsequent experimental studies is proposed and the background theoretical aspects are elaborated upon. The experimental setup adopted in this study is described and the results from measurements on various soil-contaminant mixtures are presented. A contaminant match procedure based on the coherence function is advanced and tested with the acquired data. The results are analyzed with respect to the applicability of the proposed method to the subsurface contaminant detection. 


\section{CHAPTER 2}

\section{REVIEW OF PREVIOUS RESEARCH}

\subsection{APPLICABLE DETECTION TECHNIQUES}

A satisfactory contaminant detection system should be capable of pinpointing a leak position and be as nondestructive as possible. The goal set by the U.S. EPA is the ability to pinpoint the leakage in the liner material to within 30 square centimeters (Waller and Davis, 1984). Such accuracy is yet unattainable.

Contaminants propagate through soils principally by advection and dispersion. The advection is a movement with a mean groundwater flow while dispersion refers to spreading through diffusion and mixing. In the unsaturated zone above the water table contaminants percolate downward under the influence of gravity. Accumulation of contaminants typically causes alteration of the transmission, adsorption and diffusion properties of soils (Yong et al., 1992). These processes may in turn affect the electric conductivity, dielectric constant and seismic velocity of the soil. For example, the introduction of an organic liquid into a soil lowers the dielectric constant, increases the resistivity and increases the hydraulic conductivity (Olhoeft, 1986). Thus, a change in soil properties may be exploited to detect contaminants.

The majority of potential detection methodologies represent an outgrowth of the general area of geophysics, as applied to oil, gas, and mineral exploration. Some are extensions of techniques used in the laboratory environment or in agriculture. Typically, 
a change in electrical properties of a soil is correlated with a potential contamination. Each measurement technique routinely involves two distinct stages: measurement and analysis. An effective in-situ method should perform these tasks quickly and accurately. It should also be relatively easy and economical in implementation. Applicable detection techniques, other than a direct sampling from a monitoring well, are as follows:

\subsection{ELECTRICAL RESISTIVITY}

This method relies on the fact that any subsurface variation in resistivity alters the form of current flow within the soil. It is therefore possible to obtain some information about subsurface distribution of various bodies from the potential measurements conducted at the surface. The resistivity of soil is influenced by the porosity, moisture content, electrical conductivity of the pore fluid, and the clay content. Typically, the higher the porosity, moisture content, salinity of pore fluid, and clay content, the lower the electrical resistivity of the subsurface soil. The presence of inorganic contaminants generally decreases the resistivity while most organic contaminants cause an increase in resistivity (Olhoeft, 1986). Their influence has not been found equal and opposite. Given the same quantity, most inorganic contaminants exert a much larger effect on resistivity than the organic compounds.

Effective use of the resistivity method can be traced to the pioncering studies of Schlumberger and Wenner in the early 1900's (Schlumberger, 1920). Due to its simplicity and a relatively low cost, a direct current sounding method has become popular in carrying out subsurface studies. Various electrode arrangements are shown in Figure 2.1.

In the Schlumberger method four electrodes are placed along a common line, with the outer two serving as the current electrodes and the inner two as the potential electrodes. The current electrodes are used to provide the input signal while the potential

electrodes are used to record the response. In studying the resistivity as a function of 


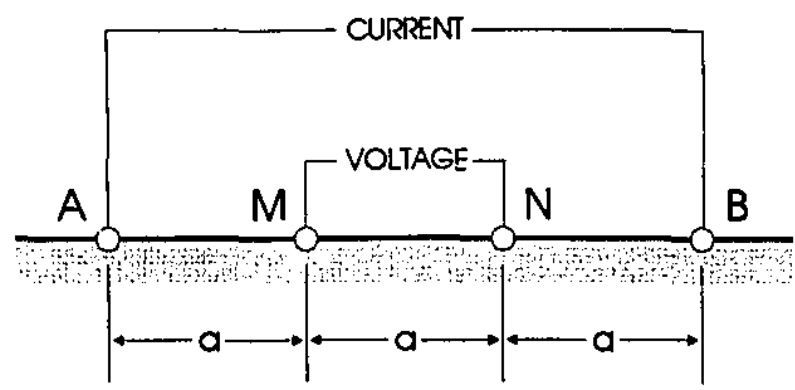

WENNER

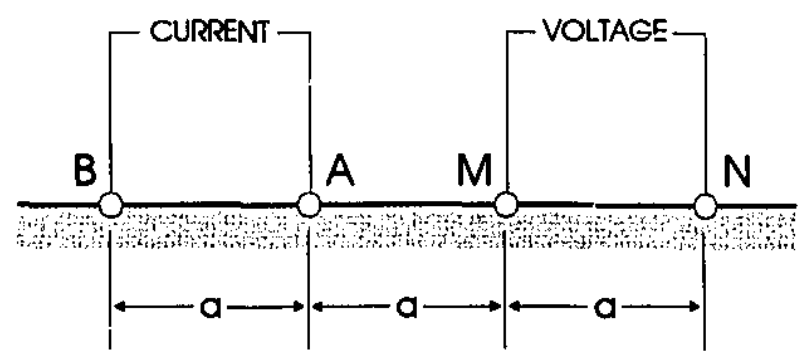

\section{ELTRAN}

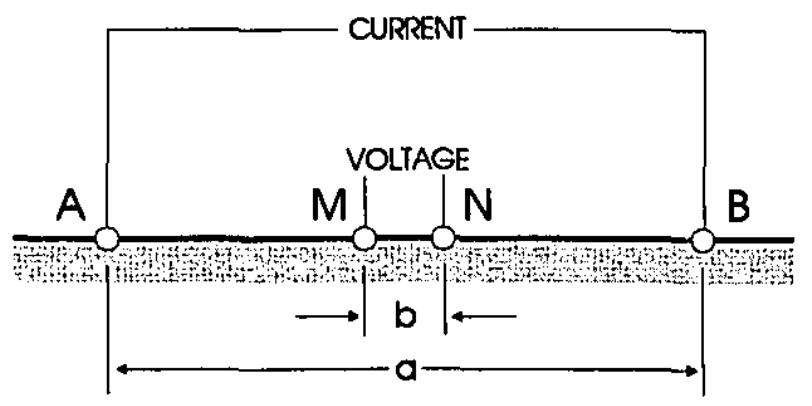

\section{SCHLUMBERGER}

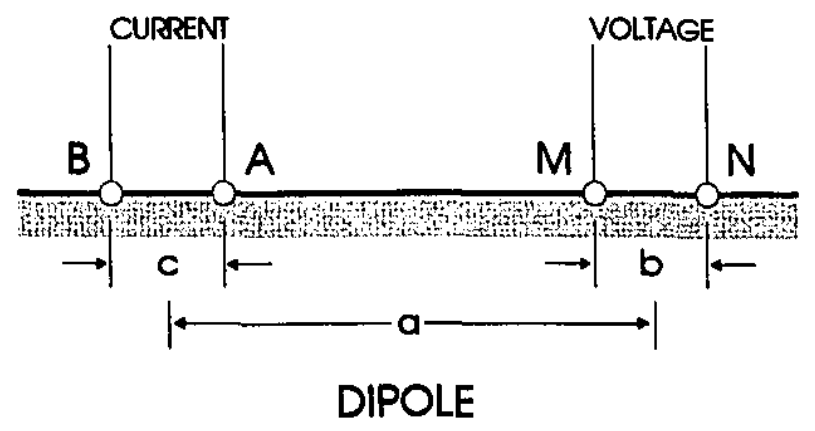

Figure 2.1 Electrical Resistivity Arrays (Wait, 1971). 
depth, the current electrode separation is increased in a series of steps while maintaining the spacing on the measuring electrodes. It is assumed that the ratio of the measured voltage to the potential electrode spacing is equal to the gradient of the voltage under the soil surface.

With the Wenner array configuration four equally spaced and colinear electrodes are used. The outer two electrodes are normally used to provide current to the ground, while the inner two are used to measure the voltage drop caused by this current. If the resistivity is being measured as a function of depth, the center point of the array is held fixed and the array spacing is expanded about the midpoint. All four electrodes are separated by an equal distance at all times. The subsurface bulk resistivity $R$ is computed from the measured voltage $V$, current $I$ and array spacing $a$ :

$$
R=\frac{K V}{I}
$$

where $K=2 \pi a$

A variation of the Wenner array is the Eltran array where the two adjacent electrodes at one end of the line are used to provide current. This array came into widespread use in the 1930's as means for reducing the electromagnetic coupling between the current circuit and the measuring circuit. With the usual Wenner array, the capacitive coupling between the wires leading to the current electrodes and wires leading to measuring electrodes tends to produce larger transient voltages than those produced by the current flow in the ground. In the Eltran array this coupling is reduced by not placing the two circuits adjacent to each other.

Most arrays currently in use belong either to the Wenner class in which the potential difference is measured between two widely spaced electrodes or to the Schlumberger class in which the gradient of the potential is determined from closely spaced measuring electrodes. A third category of arrays is the dipole-dipole class as originally described 
by Al'pin and Berdichevskii (1966). Four electrodes are used with a dipole array but they do not necessarily occupy positions along a common line. The diagnostic characteristic of a dipole array is the fact that the distance between the center of the current electrode pair and the center of the measuring electrode pair is large compared to the separation within each pair. This condition permits two approximations in the theory of dipole arrays: 1) the ratio of the measured voltage to the potential electrode separation is approximately equal to the the gradient of the voltage, and 2) the voltage ficld is proportional to the current moment of the current electrode pair, defined as the product of the current and the distance between electrodes.

The resistivity survey is performed at grid points covering the area of interest. The layout of the electrode arrays determines the depth of investigation. Resistivity soundings are used to locate an anomaly in the subsurface resistivity, thus indicating a potential presence of contaminants. Further exploration is usually necessary to confirm that the resistivity contrast is in fact traceable to a contaminant.

\subsection{INDUCED POLARIZATION}

Induced polarization (IP) is a technique closely related to the resistivity survey. It is sometimes referred to as a complex resistivity since it can measure resistivity both in magnitude and in phase as a function of frequency. A traditional way of measuring IP effects, whether employing frequency-domain or time-domain approach, involves detecting differences in time and/or amplitude between the waveforms of the applied current and the measured (induced) voltage. The actual measurement is conducted with the electrode arrangement similar to that used in the resistivity survey. A predetermined, time-varying current waveform is applied at one set of electrodes and the resultant earth voltage is measured across the other set.

The IP effect is also observed when the current in any of the standard four electrode DC resistivity arrays is suddenly interrupted. The voltage across the potential 
electrodes is found to decay slowly after an initial rapid drop from the steady state value. The effect was first observed by Schlumberger in 1912 and it was ascribed by him to the polarization of earth material by the current. A comprehensive study of this technique was made by Bleil (1953) who was primarily interested in applying it as a prospecting tool for metallic minerals. The IP method has been actively and successfully applied in mineral explorations since 1948 (Wait, 1959). It is accepted as a basic electrical prospecting method, particularly in the detection of sulphide ore deposits of low conductivity, such as porphyry copper and bedded lead-rinc doposits (Sumner, 1976). Various refinements to the IP method have been studied over the years. The approach pursued by Zonge and Hughes (1980) involved monitoring the phase difference between the applied current and the measured voltage at several distinct frequencies.

The IP effect is due to several sources. Electrode polarization at the boundaries of metallic conductors, such as sulphide ore deposits, is most predominant. The next most important effect is the membrane polarization, resulting from the movement of ions through the pore spaces of the subsurface material. This diffusion phenomenon is most pronounced in the presence of clay minerals, due to the small pore size, large number of ions forming a diffuse double layer and minimal advective forces.

The IP measurement was reported by Olhoeft (1985) as an indicator of the subsurface chemical activity associated with a contaminant presence. Inorganic processes of oxidation-reaction and of cation exchange may be detected. Relatively high IP phase angles were correlated with the presence of active chemical processes. For example, petroleum hydrocarbons are known to react with clays during migration. Baizer and Lund (1983) reported on a variety of organic processes that may be detected with the induced polarization technique. 


\subsection{TIME-DOMAIN REFLECTOMETRY}

Essentially the time-domain reflectometry (TDR) is a technique that measures a reflected voltage as a function of time. Typically a rapid electrical pulse is generated in a coaxial cable and is subsequently reflected from a point of change in the electrical properties along the transmission path. Processing of the acquired data, consisting of the voltage versus time record, is dependent on the physical phenomenon under study.

Originally the TDR was developed for the telecommunications industry. Its major practical application was in locating faults in the underground or undersea cavles. This was accomplished by measuring the time that the reflected signal took to travel back to the measurement point. Knowing the velocity of pulse propagation in a cable, the distance to the fault point can be readily established.

A variation of the TDR method is a technique called Corrtex, which stands for continuous reflectometry for radius versus time experiment. The U.S. relies on this technique for monitoring underground nuclear explosions (Adam, 1988). A typical setup includes placement of a cable in drill hole near a nuclear device. When the explosion occurs, the rate at which the cable is crushed by the expanding shock wave is measured by the diminishing time it takes to reflect the pulses from the rapidly dwindling length of cable. That rate of expansion of the shock wave corresponds to the explosion's yield. Corrtex TDR data is typically analyzed from some 4000 electronic pulses after the explosion.

The TDR has also been applied to the measurement of a soil moisture content in the laboratory and field experiments. Laboratory applications of the TDR were reported by Hoekstra and Delaney (1974) and Davis and Annan (1977). Look and Reeves (1992) developed a TDR system to monitor the moisture content of in-situ soils. Satisfactory results were obtained in determining moisture conditions within an expansive clay embankment. In principle, the system relies on the dependence of the static dielectric constant on the moisture content. Since the sand and most aggregates have a dielectric 
constant of approximately 2 to 4 , while the water has a dielectric constant of about 80 , the water content essentially dominates the measurement. The test is conducted with a coaxial cable terminated by a soil probe consisting of exposed electrodes of a known length. An electrical pulse is applied to the coaxial cable and recorded on the oscilloscope as it reflects from the soil probe surrounded by a material under study. The time that the pulse travels along the known distance (probe length) determines the propagation velocity and allows the computation of the dielectric constant as follows:

$$
K_{a}=\left(\frac{c t}{L}\right)^{2}
$$

where: $K_{a}=$ apparent dielectric constant, $c=$ velocity of light, and $\frac{L}{t}=$ propagation velocity.

An empirical relationship between the volumetric moisture content and the apparent dielectric constant was proposed by Topp et al. (1980):

$$
\theta_{v}=-5.3+2.92 K_{a}-5.5 \times 10^{-2} K_{a}^{2}+4.3 \times 10^{-4} K_{a}^{3}
$$

where: $\theta_{v}=$ volumetric moisture content.

The relationship between the gravirnetric and the volumetric moisture contents is obtained from:

$$
w=\theta_{v} * \frac{\gamma_{w}}{\gamma_{d}}
$$

where $w=$ gravimetric moisture content, $\gamma_{w}=$ density of water, and $\gamma_{d}=$ dry density of soil.

The application of the TDR in physical chemistry was introduced by FellnerFeldeg (1969), who proposed a laboratory use of the TDR in studying dielectric properties of materials as a function of frequency. This application demands a precise recording of the shape of the reflected pulse. Bose et al. (1986) reported measurements 
on biological substances where the dielectric properties are often masked by the presence of large DC conductivities. The TDR technique allows differentiation of contributions due to a DC conductivity and a complex dielectric constant. Treatment of the transient experimental data obtained by such a method may be divided into two categories: the time-domain analysis and the frequency-domain analysis. The time-domain analysis provides a time dependent polarization response function directly from the TDR data, in contrast to the frequency-domain approach which requires a numerical Fourier transform to obtain dielectric data as a continuous function of frequency.

The underlying link between the TDR and the contaminant detection in soils is the influence of a contaminant on the dielectric constant and the conductivity of a soilcontaminant system. The measurement of these electrical properties as a function of time or frequency may be used to infer the presence and the character of a contaminant.

\subsection{ELECTROMAGNETIC TECHNIQUES}

Electromagnetic techniques for measuring the electrical parameters of a substrate soil generally involve measurement of a wave propagating through or reflecting from an analyzed material. One of the most commonly used methods is the wave tilt, which involves launching an electromagnetic wave near the earth surface and measuring the tilt of the wavefront at a moderate distance from the transmitter, as shown in Figure 2.2. The wave tilt is defined as the ratio of horizontal to vertical components of the electric field measured at the earth surface (Wait, 1971).

The electric field vector near the earth surface traces an ellipse. The orientation of the major axis of the ellipse and the relation between the major and the minor axis are influenced by the vertical and horizontal components of the electric field. Typically, the ratio of the major to the minor axis is recorded, together with the angle of inclination of the major axis. These measurements allow calculation of a dielectric constant and conductivity of the underlying soil. One approach that offers high vertical 

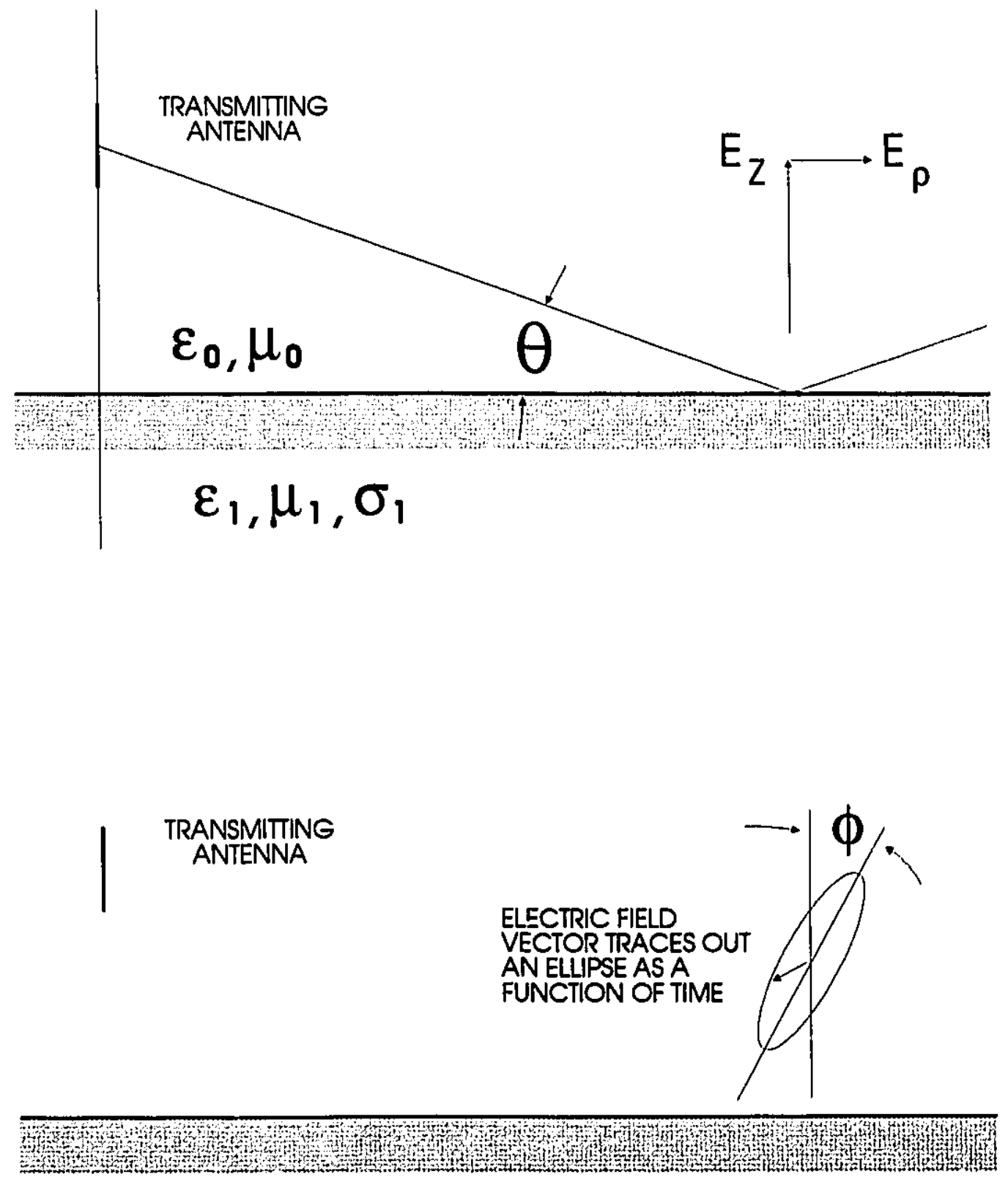

Figure 2.2 Wave Tilt (Wait, 1971). 
resolution and deep sounding is the EM method employing a sweep-frequency source. Ryu et al. (1972) used 14 discrete frequencies between $200 \mathrm{~Hz}$ and $10 \mathrm{kHz}$ to measure tilt angle ellipticity and the modulus of wave tilt to explore for ground water in the Santa Clara Valley, California.

Another commonly used EM technique is the mutual inductance. A terrain conductivity survey is performed by placing a small transmitter coil on or close to the earth's surface. This coil is then energized with an alternating current, typically at the zudio frequency. An alternating magnetic field is generated, which, following Faraday's law, causes the electrical current to be induced in the earth. The induced current generates a secondary magnetic field. Both the primary and the secondary fields are detected by receiver coils located at a fixed distance from the transmitter coil. The comparison of the strengths of the primary and secondary fields is used to determine the conductivity of the subsurface. Field surveys are carried out by running the equipment on a grid, with coils at different separations to measure conductivity as a function of depth. A portable instrument can also be used in a preliminary reconnaissance survey.

The subsurface conductivity map that the EM technique generates can be utilized to assess the uniformity of a subsurface soil. The interpretation of data is essentially the same as the one obtained from the resistivity survey (conductivity being the inverse of resistivity). A conductivity variation signifies a potential contaminant location.

\subsection{HIGH FREQUENCY PULSE TECHNIQUES}

A high frequency pulse technique called ground penetrating radar (GPR) operates by emitting short bursts of radar waves, which are monitored by the receiving antenna. When operated from the ground surface, a radar antenna is manually towed over a site or puiled by a vehicle, to produce a continuous mapping. In the transillumination mode (borehole-to-borehole), the transmitter and the receiver are placed in adjacent boreholes. 
This method is similar in principle to the seismic reflection technique, except that it is the electromagnetic waves that are propagated into the soil. Most of the subsurface probing at shallow depths has been based on transmittirg pulsed waves in the frequency range of 1 to $900 \mathrm{MHz}$ (Ulriksen, 1982). The transmitted pulse travels througin a soil or water until it encounters a material with different electrical characteristics. Part of the pulse is then reflected back to the ground surface where its time of travel is recorded. The depth $d$ at which the interface is located is calculated from:

$$
d=\frac{v t}{2}
$$

where: $v=\frac{c}{\sqrt{\epsilon}}=$ wave velocity $\frac{m}{s}, c=$ velocity of light, and $\epsilon=$ dielectric constant

GPR measurements are sensitive to the dielectric constant and conductivity. Changes in these electrical properties may be indicative of a contaminant presence. Olhoeft (1986) observed that the conductivity is affected to a large extent by the inorganics, while the dielectric constant is more influenced by the orgaric contaminants. Since there is a contrast in the dielectric constant of many organics as compared with that of a soil, a contaminant detection is possible. GPR has been found to be most. sensitive to changes in the dielectric properties in the unsaturated zone.

Radar measurements conducted by Ulriksen (1982) attest to a fairly high resolution profiling in sandy and gravelly soils. GPR soundings up to approximately 30 meter depth are possible. Excellent radar records are also obtained in a freshwater due to its low conductivity. In contrast, highly conductive, clay rich soils often result in penetrations of less than a meter. The resolution of a sounding depends on the radar operating frequency. A typical radar resolution at $100 \mathrm{MHz}$ is approximatcly 10 centimeters up to a depth of about 30 meters in a clay-free coarse sand (Olhoeft, 1986).

A variation of a pulsed high frequency technique is the Time-Domain Electromagnetic Sounding (TDEM). Significant advancements in the applicability of the TDEM 
have been reported by Hoekstra et al., (1988). The TDEM technique employs transmitting and receiving antennas consisting of square loops of insulated wire laid on the ground surface. The receiving coil is placed in the center of the transmitting loop. In the TDEM approach currents are induced by a time varying magnetic field of a transmitter. The current driven through the transmitter loop creates a primary magnetic field. During the rapid current cut-off this primary field varies in time and in accordance with Faraday's Law the resulting electromagnetic induction produces eddy currents in the subsurface soil. The intensity of these currents at a given time and depth is dependent on the subsurface resistivity, hence the TDEM can infer the presence of a contaminant with a sufficient resistivity contrast. The receiver measures the electromotive force (emf) caused by the ground eddy currents. At early times following the primary current shutoff the eddy currents are concentrated near the ground surface. With increasing time, as currents are induced at greater depth the measured emf's are progressively more influenced by the electrical properties of deeper layers.

\subsection{SEISMIC TECHNIQUES}

Acoustic waves appear to provide a promising approach to the subsurface probing of contaminants. The propagation velocity in unsaturated soils is about half of the velocity in the saturated zone. Moreover, the seismic waves are not as acutely attenuated in a conductive environment as the electromagnetic waves.

Seismic techniques have been employed for a number of years by the petroleum industry. Some applications to map a site stratigraphy have also been made. In a traditional seismic reflection method an impulse (hammer blow, explosion, etc.) is generated in the ground. The elastic waves emanating from the source are picked up by a series of geophones installed on the surface. A characteristic series of return echoes is recorded. The travel time of a wave along with the velocity of propagation through the soil indicates the depth to a dissimilar stratum. This dissimilar stratum 
may potentially include a contaminant.

In a related method called refraction surveying the time it takes for the echo to reach a transducer is measured for a varying transducer to impact distance. The time is plotted as a function of a distance and if a well defined layer exists below the surface, it results in a characteristic break in the response curve, allowing a determination of the depth of the layer.

\subsection{ACOUSTIC EMISSION MONITORING}

An entirely different approach to leak detection involves the use of acoustic cmission monitoring (AE) techniques. It has been observed that sound emissions occur from a structural distress and from a liquid flow through the porous media. These sounds can be monitored using a microphone or an undamped accelerometer coupled to the ground. Some recent applications relating to leakage detection under existing dams are reported by Koerner et al. (1981). It must be realized, however, that certain acoustic emissions, occurring naturally from a decomposition of the waste material or a settlement and deformation of the liner may obscure emissions from liner failures. Fundamentals of the $\mathrm{AE}$ process need to further researched before the techniquc can be optimally applied in the field.

\subsection{SOIL GAS SURVEY}

The soil gas survey ia a field monitoring technique that has gained an acceptancc in site characterization studies. This technique has been applied effectively to detect and define the location and the extent of volatile organic contaminants (VOC) in the soil substrate. Soil gas surveys have been used to estimate the extent of the VOC contamination and to select the optimum locations for groundwater monitoring wells (Karably and Babcock, 1989). The soil gas sampling is typically performed by us-

ing driven perforated probes, driven hollow probes, surface static trapping (SST), and 
augered permanent stations. Probes can be inserted in the ground with a hammer or with a hydraulic ram, reaching depths of tens of meters in some soils. Augered permanent stations offer repeatable sampling locations over an extended period, however, the installation of probes takes a significant amount of time.

The SST sampling technique involves the use of activated carbon which accumulates vapors over a period of time and is subsequently subjected to a chemical analysis. Once the soil gas is extracted, it is analyzed in the field or sent to a laboratory. Analysis methods range from hand held photoionization detectors and organic vapor analyzers to sophisticated field gas chromatographs and mass spectrometers. Sampling depth, soil moisture, permeability, and constituent specific factors commonly influence the results. The real time data analysis in the field allows a more detailed mapping of volatile hydrocarbons.

\subsection{ASSESSMENT OF EXISTING TECHNIQUES}

Indirect methods of contarninant detection in soils rely on sensing the alterations in soil properties. The properties that easily lend themselves to indirect probing are mainly electrical. The choice of a suitable remote sensing method needs to be evaluated in the context of an initial data collection and a subsequent data analysis. An undue level of complexity at each of these stages can render a particular approach ineffective and impractical.

The introduction of a contaminant into a soil alters its electrical conductivity (or resistivity) if the concentration exceeds certain levels. The degree of that alteration, however, strongly depends on a given soil-contaminant system. Existing studies indicate that the organics tend to increase the resistivity, while the inorganics decrease the resistivity of soils. The impact of inorganics is generally stronger, but on sites where both organic and inorganic contaminants are present the net effect on resistivity may be negligible. A sole reliance on the conductivity survey is further complicated in the 
areas of a complex lithology where the influence of a soil type needs to be uncoupled from the infiuence of a contaminant.

Another electrical property which is commonly affected by the introduction of a contaminant into a soil is the dielectric constant. Studies indicate that the organic contaminants exert a substantially greater impact on the dielectric constant than the inorganics, in contrast with the effect on electrical conductivity. It is therefore attractive from the detection point of view to employ a technique wh:ch is sensitive to both conductivity and a dielectric constant.

When considering a detection method based on analyzing the electrical properties various measurement approaches are possible. The electrical phenomena occurring in a soil-contaminant system may be studied at a zero frequency (DC), at a particular frequency (f) or at a range of frequencies of the electric or the electromagnetic field. Study of the phenomena occurring at a wide range of frequencies is obviously more technically challenging but it may supply additional valuable data. Some materials may exhibit essentially identical resistivities and/or dielectric constants at a particular frequency but may differ in the distribution of these parameters over a wide frequency range.

DC resistivity methods have been applied in locating leachates from waste impoundments with varying degrees of success. The primary factors influencing their performance are the geology and hydrogeology of the area and the resistivity contrast between the leachate and the host material. Cultural features, such as buried pipes, metal fences, and power lines also play a significant role. Combination of the above factors often limits the resistivity survey to sites with a simple and well defined geologic cross section and a highly conductive leachate. Moreover, at most hazardous sites both organic and inorganic contaminants are present, causing opposite effects on the resistivity. Among the most important constraints in the use of the resistivity techniques are the following: 
- complex stratigraphy, making the results ambiguous.

- cultural objects, such as electrical lines, fences, roads, and buried pipes, causing undue conductivity fluctuations.

- insufficient conductivity contrast of the leachate. A ratio of at least 2:1 between conductivities of leachate and groundwater greatly aids in the interpretation of field data.

Similar limitations apply to the electromagnetic techniques. They generally produce a measurement of a bulk electrical conductivity of the subsurface. Data collection is markedly faster with the EM approach as compared to the resistivity survey, however, data processing is significantly more complex and the nearby utilities, power and telephone lines, can greatly interfere with the measurements. A common problem involves masking of conductivity variations at greater depths by the presence of a highly conductive surface layer. Electromagnetic waves attenuate exponentially as they propagate through the earth. The distance that the wave must travel before its amplitude decreases to $\frac{1}{e}$ of its surface amplitude is called the skin depth and represents an effective depth of exploration. The skin depth decreases substantially with increasing conductivity due to the excessive signal attenuation.

Some successful applications of EM techniques have been reported. Greenhouse and Harris (1980) employed the EM conductivity survey to evaluate the leachate flow at the abandoned Bose-Borden waste impoundment in Ontario. Often the interpretation of results is complicated by localized site conditions. Saunders and Germeroth (1986) used a portable EM probe to determine a hydrocarbon thickness under the aprons at Newark International Airport. They concluded that slight variations in the terrain conductivity result in significant changes in the interpreted hydrocarbon thickness.

The sensitivity study of the GPR, conducted by Bowders et al. (1982), concluded that a small variation in the soil density will cause a detectable return signal. Since nonhomogeneous situations prevail in the field, and minor density changes abound, it 
can be concluded the GPR traces will often be cluttered with return signals. Data analysis in such situations becomes complex and requires sophisticated signal enhancement techniques to uncouple the influence of the soil density from the impact of the contaminant. On the other hand, data collection associated with the GPR can be extremely efficient, since the actual measurement is very fast.

Seismic techniques are not as rapid as the EM and the GPR. They work best in very dense materials and perform poorly in loose soils. The problems encountered with the fine detail resolution are similar in nature to those associated with the electromagnetic propagation. As smaller wavelengths are applied for enhanced resolution, excessive scattering and reflections become difficult to uncouple. Typically, in selecting the equipment frequency range a compromise is made between the depth of penetration and the resolution.

Existing acoustic imaging systems typically require that the sound source be separated from the receivers. However, in a layered soil there are many sound paths between any two points in addition to the path due to reflection from the object. The net result is that there will appear to be as many reflectors as there are sound paths. It is a common experience in the seismic field work to observe that a single seismic impulse produces a train of impulses lasting for a number of seconds.

There have been efforts made to develop acoustical imaging systems based on the principle of acoustic holography. It appears that the main obstacles to any kind of sophisticated imaging in soils are severe velocity gradients and multipath conditions (Winter, 1973). The principal factors affecting the velocity are the confining pressure and the water content. The behavior of the acoustic velocity affects any imaging system in three ways. First, it modifies the amount of energy available to illuminate the reflector. Second, it greatly influences refraction. Due to refraction, the ray paths are also irregular and unpredictable. Any imaging system using wavelengths less than a meter which assumes an isotropic medium produces extremely blurred images. The 
third problem is that as wavelengths get smaller (for enhanced resolution) all of the local variations in velocity become acoustic reflectors, making data analysis extremely complex. Thus, a variation in the seismic velocity due to the contaminant presence may be effectively masked by the site lithology.

In view of the above considerations, remote sensing electromagnetic and seismic methodologies were not pursued in this study. Despite their obvious attractiveness from a data collection point of view it is believed that these techniques do not provide an adequate resolution of a contaminant plume in the heterogeneous environment. In contrast to potential mineral locations, the majority of contaminated sites routinely contain a multitude of cultural features generating a significant level of a background noise. Fences, pipes, underground and overhead power lines typically exert a substantial impact on electromagnetic measurements, often resulting in a low signal to noise ratio. Moreover, remote electromagnetic sensing has met with little success in petroleum exploration mainly because of insufficient resistivity resolution in the oil bearing strata (Keller and Frischknecht, 1966). Yet petroleum products constitute one of the most widespread subsurface pollutants in need of detection. As a result, remote sensing electromagnetic and seismic techniques may be regarded as potentially useful in the initial reconnaissance work, but not very suitable for a detailed exploration.

Techniques based on a soil gas sampling are limited in applicability to the volatile organics. Any permeability variations at the site, such as those stemming from clay layers or fractures, affect the results. Ambient vapors from past operational practices and spills also make this approach difficult to implement. If a laboratory analysis of samples is required, the increased amount of manual handling renders this approach costly and time consuming. Direct probing methods based on the detection of a specific ion, $\mathrm{pH}$ or conductivity also suffer from a limited applicability.

Limitations associated with each of the above mentioned methodologies can be mitigated by employing some of these techniques together. Many researchers advocate 
the use of complementary methodologies in site characterization studies. The selection is obviously dependent on the relative ease of data collection and analysis for the intended application.

The main criteria in pursuing an effective detection methodology adopted by this study were as follows:

- minimization of a site disturbance.

- minimization of the probing and sampling time.

- capability of on-site data analysis.

- capability of an automated measurement and analysis, thus minimizing manual operations.

- capability of a contaminant detection in the unsaturated zone.

- applicability to a wide range of contaminants.

The technique pursued in this study is based on measuring dielectric propertics as a function of frequency. Two proven methodologies exploiting this phenomenon are Induced Polarization (IP) and Time-Domain Reflectometry (TDR). Existing studies indicate that the IP method has been used successfully in search of metallic ore bodies (high conductivity) and sulphide ore deposits (low conductivity). The TDR laboratory method, operating at significantly higher frequencies, has been applied to charactcrize a variety of chemicals, including biological substances, where the dielectric propertics are often masked by a high conductivity.

The TDR approach is conceptually attractive as a contaminant detection tool since the influence of an ambient cultural noise on measurements is greatly minimized due to inherent shielding properties of the coaxial transmission line. Although the field application of TDR requires an invasive probing, it allows a measurement at a particular point in the subsurface, with no interference from the adjacent strata (Gajda and Stuchly, 1983). In this respect it differs from EM techniques which tend to measure 
bulk subsurface properties. The decision to further explore the TDR approach was also motivated by the fact that relatively little research has been conducted to date in adapting this technology to a contaminant detection in soils. 


\section{CHAPTER 3}

\section{THEORETICAL ASPECTS}

In dealing with the subsurface contaminant detection it is informative to relate the level of a soil contamination to the change in electrical properties of the soil. The conductivity and the dielectric constant may be substantially affected by the introduction of a liquid contaminant into the soil pores. In the initial approach to the problem it is common to resort to the DC resistivity survey. This method offers a quick and inexpensive way of locating a subsurface contaminant, provided that the geological cross section is fairly uniform. In areas of a complex lithology, however, this approach cannot readily discern between the resistivity of a particular soil type and that of a pore fluid. In fact, a variety of chemically different materials exhibit essentially similar $\mathrm{DC}$ resistivities. To address this lack of selectivity, one may consider monitoring not, only the resistivity but also a dielectric constant and to monitor these parameters over a wide frequency range.

Non-conductive materials interacting with the electric field are called dielectrics and their behaviour is governed by the underlying phenomenon of electric polarization. From the measurement point of view most contaminated soils can be regarded as dielectric materials, with their characteristic resistivities and dielectric constants affected by the chemical nature of the contaminant. The problem entails the interaction of these dielectric materials with the electric field. 
The mechanics of polarization may be visualized with reference to Figure 3.1 which illustrates a homogeneous non-conducting material placed in the electric field. Although the atomic structure of an insulator is such that it is difficult for electrons to move from one atom to another, the electrons orbiting around each nucleus will be attracted by the $(+)$ plate and repelled by the (-) plate. As a result, the orbits of the electrons in each atom will be displaced. The effect of the positive charge being closer to one side of the atom and the negative charge being closer to the other is called polarization. Because a net movement of electrons in one direction constitutes an electric current, there is a momentary surge of the so-called displacement current, causing increased conductivity in the system while the charges are induced ie. take up their positions (Jackson, 1976). A similar phenomena occurs when the electric field is removed. With some materials a small potential difference momentarily appears between the plates. It indicates that the electron orbits did not instantly return to their original positions. This effect is called dielectric absorption.

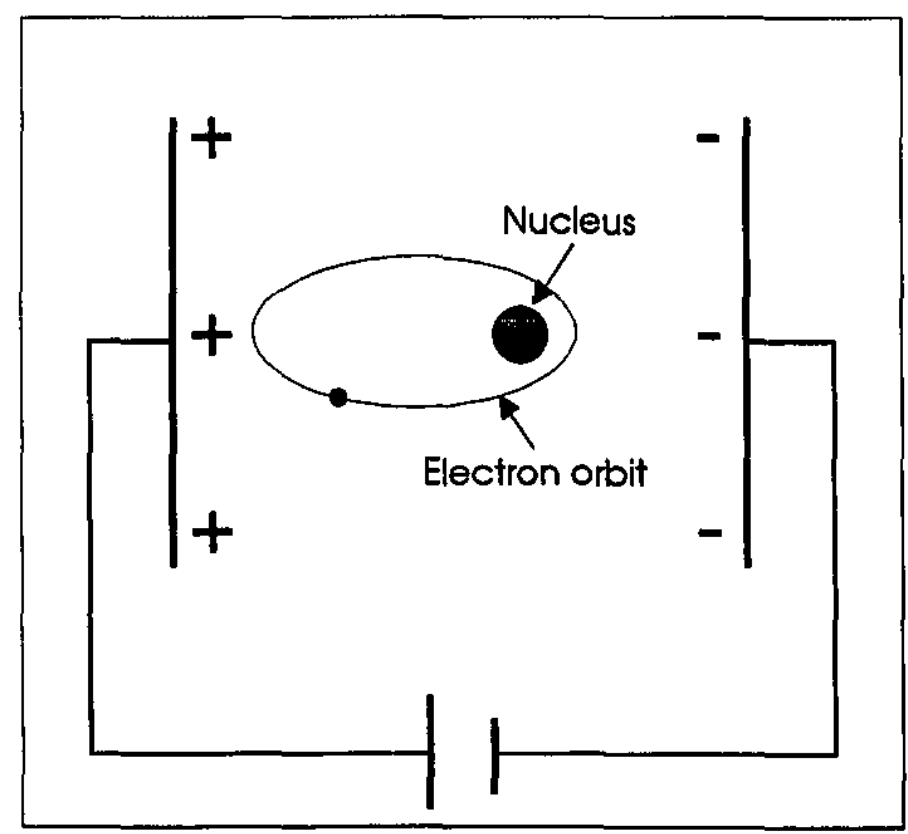

Figure 3.1 Polarization of a Dielectric. 
The behavior of a typical dieiectric material can be visualized in terms of a molecular dipole aligning or polarizing in the direction of the electric field. The extent of the observed polarization or permittivity is a function of time or frequency of a signal used in the experiments. When the field is reversed, the dipoles tend to realign themselves. As the rate of field reversal becomes faster than the rate of molecular reorientation, rotation of a dipole can no longer occur. At this relaxation frequency the material's dielectric constant drops in value since there are fewer available charges that can be displaced by the electric field. This variability of dielectric constant with frequency is known as "dispersion". In the transition region of dispersion a phenomenon known as "absorption conductivity" takes place and the resulting complex dielectric constant can be expressed by $\epsilon^{*}=\epsilon^{\prime}-i \epsilon^{\prime \prime}$ as shown in Figure 3.2. It is important to note that the Figure 3.2 illustrates the simplest case involving only one type of a dipole. Practical systems containing a collection of various dipoles display a number of steplike transition regions occurring at various characteristic frequencies. The implication of the polarization phenomenon is that as the frequency of electric field increases the material's dielectric constant drops in value and its conductivity increases in a manner characteristic of a given material. This principle forms the cornerstone of this study.

There are several mechanisms of polarization that cause a frequency dependence of electrical properties. Contributions to this polarization arise from the following (Dev et al., 1972):

- displacement of electrons relative to the nucleus of each atom (electronic polarization).

- movement of one nucleus relative to another in the same molecule (atomic polarization).

- rotation of molecular dipoles (orientation polarization).

- migration and piling up of charges within the sample (interfacial polarization).

The electronic polarization is a process requiring about $10^{-15} \mathrm{~s}$, corresponding to 


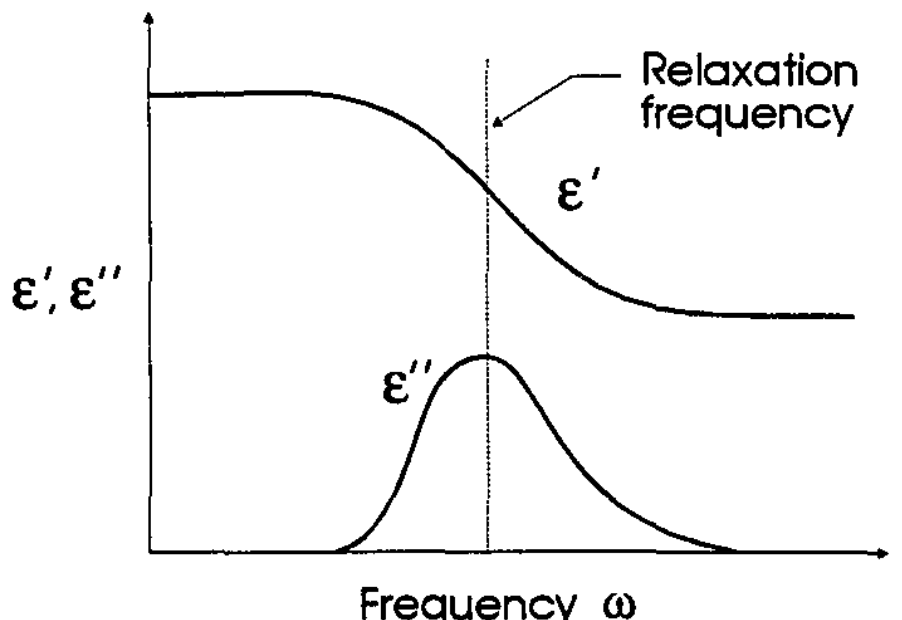

$$
\varepsilon^{\prime \prime}=\text { dlelectric loss } \quad \varepsilon^{\prime}=\text { dlelectric constant }
$$

Figure 3.2 Dispersion and Absorption in Dielectrics.

the frequency of ultraviolet light. The atomic polarization takes from $10^{-12}$ to $10^{-14}$ $s$ and corresponds to the infrared frequency. The orientation polarization in liquids ranges from $10^{-10}$ to $10^{-6} \mathrm{~s}$, corresponding to radio and microwave frequencies. In a heterogeneous material the interfacial polarization may require seconds or minutes to complete, a process observed only at very low frequencies.

The classical theory of polarization is commonly associated with Debye (1929). Dielectric properties of materials containing molecules with permanent dipole moments can be described by a modification of the Debye equation due to Cole and Cole (1941). Accordingly:

$$
\epsilon^{*}(\omega)=\epsilon_{\infty}+\frac{\epsilon_{s}-\epsilon_{\infty}}{1+(i \omega \tau)^{1-\alpha}}
$$

where $\epsilon^{*}$ is the complex dielectric constant $=\epsilon^{\prime}(\omega)-i \epsilon^{\prime \prime}(\omega)$. The real part, $\epsilon^{\prime}$, is the dielectric constant and the imaginary part, $\epsilon^{\prime \prime}$, is the dielectric loss. $\epsilon_{\infty}$ and $\epsilon_{s}$ are the "infinite frequency" and "static" limits of the dielectric constant, $\omega$ is the angular frequency, $\tau$ is the relaxation time, and $\alpha$ is the parameter indicating the width of the 
distribution of relaxation times around $\tau$. For materials with a single relaxation time, such as water, $\alpha=0$ and the equation 3-1 reduces to the form given by Debye:

$$
\epsilon^{*}(\omega)=\epsilon_{\infty}+\frac{\epsilon_{s}-\epsilon_{\infty}}{1+i \omega \tau}
$$

In this case, $\epsilon^{*}$ can be separated into real and imaginary parts as follows:

$$
\begin{gathered}
\epsilon^{\prime}=\epsilon_{\infty}+\frac{\epsilon_{s}-\epsilon_{\infty}}{1+(\omega \tau)^{2}} \\
\epsilon^{\prime \prime}=\frac{\left(\epsilon_{s}-\epsilon_{\infty}\right) \omega \tau}{1+(\omega \tau)^{2}}
\end{gathered}
$$

The difference between $\epsilon_{s}$ and $\epsilon_{\infty}$ is attributed to dipole polarization. The orientation of polar molecules in an alternating field is opposed by the effects of thermal agitation and molecular interactions. Debye represents the second effect by a picture of viscous damping, the molecules being regarded as spheres in a continuous medium having macroscopic viscosity.

Dispersion and absorption can also occur in nonhomogeneous dielectrics. The possibility of absorption in a double layer dielectric if the ratios of conductivities and dielectric constants are not equal was first pointed out by Maxwell (1854).

Cole and Cole (1941) have shown that a graphical representation of equation 3-2 gives an arc of a semicircle in the complex plane, with the diameter of the semicircle making an angle $\frac{\alpha \pi}{2}$ with the real axis as shown in Figure 3.3.

The complex dielectric constant may be defined in terms of the electric flux density and the intensity of the electric field set up in the dielectric:

$$
\epsilon^{*}=\frac{D}{E}
$$

where $E$ is the electric field applied to the sample ( $\left.\frac{\text { volts }}{\text { meter }}\right)$ and $D$ is the electric flux density or electric displacement ( $\left.\frac{\text { coulombs }}{\text { meter }^{2}}\right)$ The magnitude and phase of $D$ is governed 


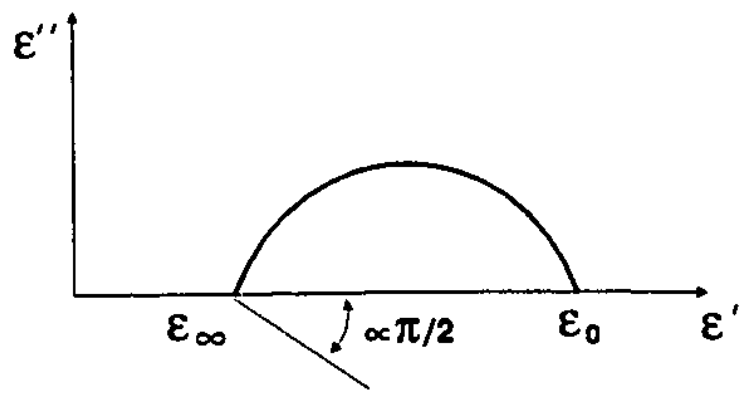

Figure 3.3 Locus of the Dielectric Constant in the Complex Plane.

by the frequency-dependent behavior of the material and is reflected in terms of real and imaginary parts of $\epsilon^{*}$.

It is possible to perform an alternate class of experiments in which the time dependence between $D$ and $E$ is compared. The quantity $D$ is proportional to charge and $E$ is the voltage gradient across the dielectric. If a step voltage is suddenly applied, the time dependence of $D$ may be used to compute $\epsilon^{*}$. It is therefore viable to employ either a sinusoidal or a step voltage approach in dielectric measurements. Thus the time or frequency dependence of the dielectric constant can be used to provide information on the chemical composition of a material. The application of the time-domain method offers a faster measurement in comparison to the 'point-by-point' approach required in the frequency-domain. Since a single impulse comprises a large frequency spectrum, transient methods are generally regarded as less time consuming than frequency-domain methods (van Gemert, 1973).

Various researchers have studied the dependence of a dielectric constant on the ionic concentration of a liquid solution. Onsanger (1936) reported that the dielectric constant of dilute solutions forms a linear function of the number of polar molecules per volume of solution. Hedestrand (1929) and Halverstadt and Kumler (1942) examined data for solutions in nonpolar solvents of over fifty polar compounds of widely different 
nature and have found in every case that the dielectric constant of the solution is a linear function of the weight fraction of a solute. Hasted et al. (1948) reported that the dielectric constants of concentrated solutions of a variety of typical electrolytes decrease with increasing concentration. Within the error of measurement, the decrease is linear up to a concentration of about $2 M$, above which it becomes gradually less pronounced.

Dielectric constant of liquids is also affected by the type of ion present in the analyzed material. Hasted et al. (1948) determined that the static dielectric constant of a solution may be written as:

$$
\epsilon=\epsilon_{H_{2} O}-\left(\delta^{+}+\delta^{-}\right) c
$$

where $\epsilon_{\mathrm{H}_{2} \mathrm{O}}$ is the static dielectric constant of water, $c$ is the concentration in moles per liter, and $\delta^{+}$and $\delta^{-}$are the contributions of the cation and anion, respectively. Individual ionic contributions to the lowering of dielectric constant per mole of ion per liter of solution are presented in Table 3.1.

Studies of the dielectric constant of soils, conducted by Okrasinski et al. (1978) in the frequency range of 0.39 to $1.5 \mathrm{GHz}$, indicate that:

- dielectric constant decreases linearly as the porosity of the soil increases.

- granular soils show a more linear relationship between the voiumetric moisture content and the dielectric constant than clay soils.

- the dependence of the dielectric constant on the temperature in the range from 0 to $25^{\circ} \mathrm{C}$ is minimal.

It is worth noting that the dielectric constant is proportional to the thickness of the diffuse double layer formed on the colloidal surface. Double layer thickness decreases as the square root of the bulk solution salt concentration and directly with increasing valence of the exchangeable cation (Yong and Warkentin, 1975). The effect of increased 


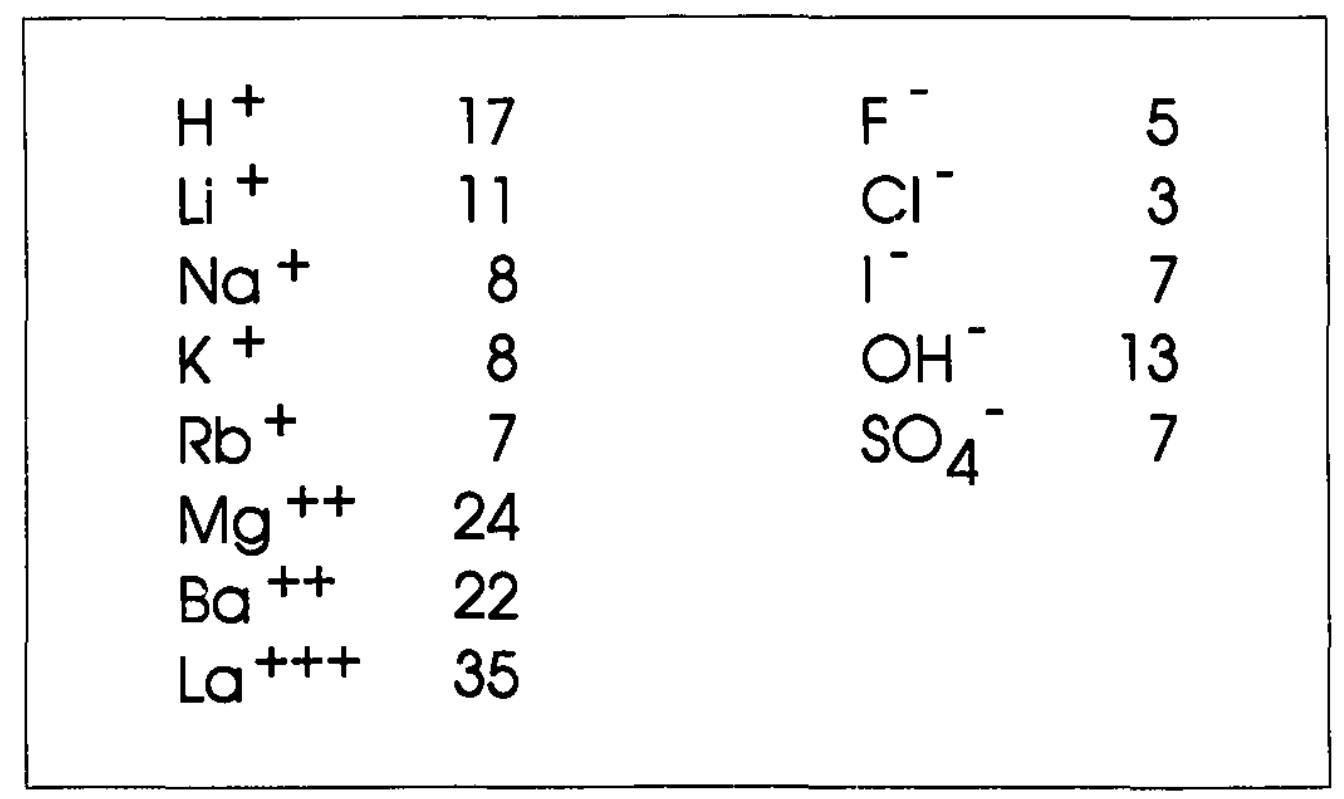

Table 3.1 Ionic Lowering of the Dielectric Constant (Hasted et al., 1948).

salt concentration arises from reduced cation diffusion from the surface toward the bulk solution and increased anion diffusion in the opposite direction. The effect of cation valence stems from the stronger attraction of higher charged cations by the colloid surface.

The theoretical distribution of ions at a negatively charged surface as a result of Coulomb and thermal forces was originally developed by Gouy (1910). The distribution of cations in the electric field at a distance $x$ from the clay surface can be expressed as (Yong and Warkentin, 1975):

$$
n_{+}=n_{o}\left(\operatorname{coth} \frac{x}{2} \sqrt{\frac{8 \pi^{2} z^{2} c_{o} N}{\epsilon k T}}\right)^{2}
$$

where $n_{+}$is the number of cations per unit volume at a distance $x$ from the surface, $n_{o}$ is the number of cations per unit volume in the pore water away from the influence of the surface, $z$ is the valence of cations, $c_{o}$ is the concentration of cations in moles away 
from the influence of the surface, $x$ is the distance from surface in $\AA$ ngstrom, $T$ is the absolute temperature, $k$ is the Boltzmann constant, and $\epsilon$ is the dielectric constant of the solution.

It can be seen from equation 3-7 that if the concentration and/or ionic valence of the pore fluid changes then the dielectric constant changes accordingly, other factors remaining constant. This interdependence may be employed to detect contaminants in soils by means of dielectric measurements. Thus the electric polarization measurements of the double layer may indicate the nature of the pore fluid chemistry.

In measuring the relaxation properties of various materials it is imperative to find a frequency range of interest, where the effects are most observable. As pointed out by Cole, this frequency range is often as awkwardly low for solids as that for liquids is high. The reason for such disparity is that the charge displacement in a solid matrix is much more constrained than in a liquid. For example, water molecules in a liquid state become aligned with an electric field in about 30 nanoseconds (Keller and Frischknecht, 1966). The amount of polarization is fairly large, as water exhibits the dielectric constant of 81.5 at low frequencies. At temperatures below the freezing point these molecules take much longer to align due to the rigid structure of ice.

A study conducted by Hoekstra and Delaney (1974) indicates that in geologic materials the soil type strongly influences dielectric measurements in the frequency range of DC up to about $1 \mathrm{MHz}$. Olhoeft (1987) reports that in clay-water systems there are significant contributions of the clay type up to $100 \mathrm{MHz}$. At higher frequencies the influence of the unbound pore fluid becomes dominant. It is also observed that the frequency of maximum dielectric loss in a soil-water mixture is appreciably lower than in a bulk water due to the constraints on charge displacement, characteristic of the double layer. A study by Bockris et al., (1966) indicates that liquid molecules comprising the double layer are severely restricted in their motion, and their relaxation frequency is lowered. Work involving measurements on packed protein powders with 
adsorbed water, conducted by Harvey and Hoekstra (1972), reports two distinct relaxation frequencies, corresponding to two layers of adsorbed water. Experiments with polyclectrolyte solutions, conducted by Sachs and Spiegler (1964), show that in the range of radio frequencies the dispersion curves are shifted to higher frequencies with increasing concentrations. Studies performed by Arulanandan and Mitchell (1968) conclude that clay-water electrolyte systems behave as anomalous dielectrics in the audio frequency and near radio frequency range.

Based on the above findings, it appears that if the polarization measurements are conducted at sufficiently high frequencies, the results would reflect predominantly pore fluid relaxations, hence a contaminant response. However, even at lower frequencies associated with the interfacial polarization, one should detect the influence of a contaminant on the double layer, although the effect of a soil type needs to be accounted for. The ion concentration in the pore fluid at equilibrium with the adsorbed cations depends on the specific surface area and the cation exchange capacity of clay minerals. The above findings also indicate that in a particular soil type, dielectric constant may be linearly dependent on the contaminant concentration.

The frequency range of interest depends on the composition of a particular soilcontaminant system, hence in the absence of any specific information it is prudent to conduct the measurements over an extensive bandwith. Instead of performing a multitude of point-by-point frequency-domain measurements it is advantageous to employ the time-domain approach using a pulse made up of a wide spectrum of harmonics. It reduces the data collection time and allows a temporary generation of a higher amplitude signal that may otherwise be possible on a continuous basis.

The geophysical technique of Induced Polarization detects mainly interfacial polarization associated with dissimilar materials. However, the traditional four-electrode arrangement used in the IP method is not capable of accurately measuring high frequency relaxations. In order to perform effective high frequency field measurements 
extending into the $\mathrm{MHz}$ range, the monitoring circuit has to be properly shielded from the electromagnetic interference. From a practical point of view it requires the use of a coaxial cable, which is designed to block the outside interference. The electric and magnetic fields are confined between the outer and the inner conductors of a conxial transmission line.

One technique that lends itself to electric polarization measurements spanning the range covered by IP and extending into the microwave frequencies is the time-domain reflectometry (TDR). In the TDR method the electrical impulse with a fast risetime is sent into a coaxial cable. Upon reaching the end of the cable embedded in the analyzed material the impulse is reflected in a manner indicating the characteristic spectral signature of the sample, as shown in Figure 3.4. The reflected signal can range in magnitude from $+100 \%$ to $-100 \%$ of the incident signal. These two extremes correspond to conditions of infinite resistivity and zero resistivity of the sample material. The measurement system is conceptually simple and relatively immune from the electromagnetic interference due to the shielding characteristics of a coaxial cable.

Typical TDR responses to a step function are shown in Figure 3.5 (bold portion), indicating the inherent capability of the TDR method to distinguish between the effects of the resistivity and the dielectric constant. The relationship between the time-domain and the frequency-domain may be regarded as reciprocal, meaning that at small timcs the waveform is described by the high frequency harmonics, while at later times it is shaped by the low frequencies of the impulse. Purely resistive termination results in the transfer of all frequencies of the input signal equally, both in magnitude and in phase. In the open-circuit termination (infinite resistance) all frequency components of the output signal appear in phase with the spectrum of the incident signal. In the short-circuit termination (zero resistance) the transfer occurs in antiphase. It can be observed that the initial time domain response (high frequency) of the capacitor corresponds to that of a short circuit $(R=0)$, while in the latter stage (low frequency) 


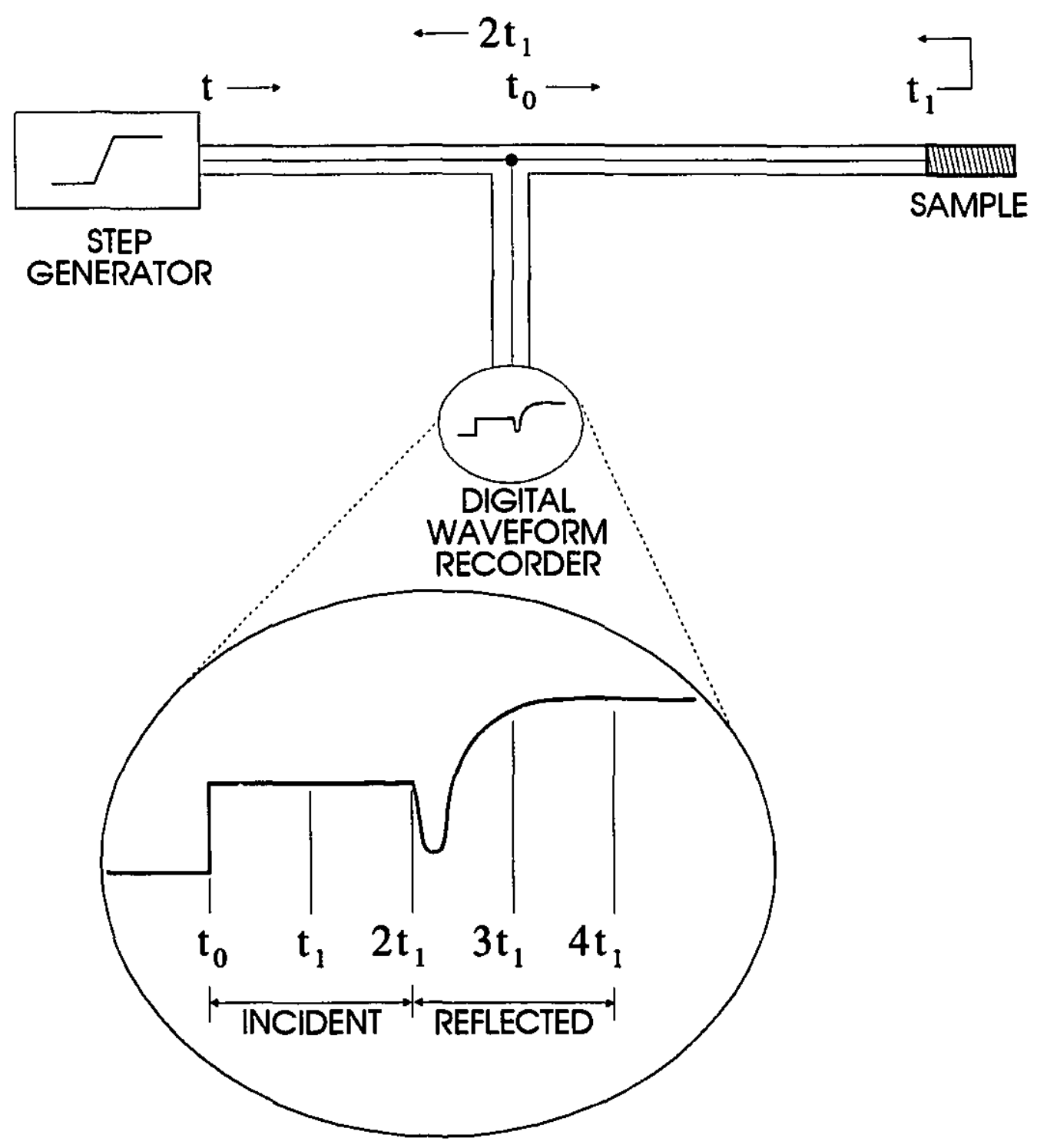

Figure 3.4 Typical Setup for the TDR Method.

it approaches exponentially the behavior of an open circuit $(R=\infty)$. The capacitor illustrated in Figure 3.1 would manifest itself in this fashion, indicating the effect of a single polarization. In a heterogeneous dielectric material the reflected signal does not exhibit a purely exponential rise due to multiple polarization phenomena and the resulting dispersion.

The measurements conducted in the time-domain can be transformed into the 


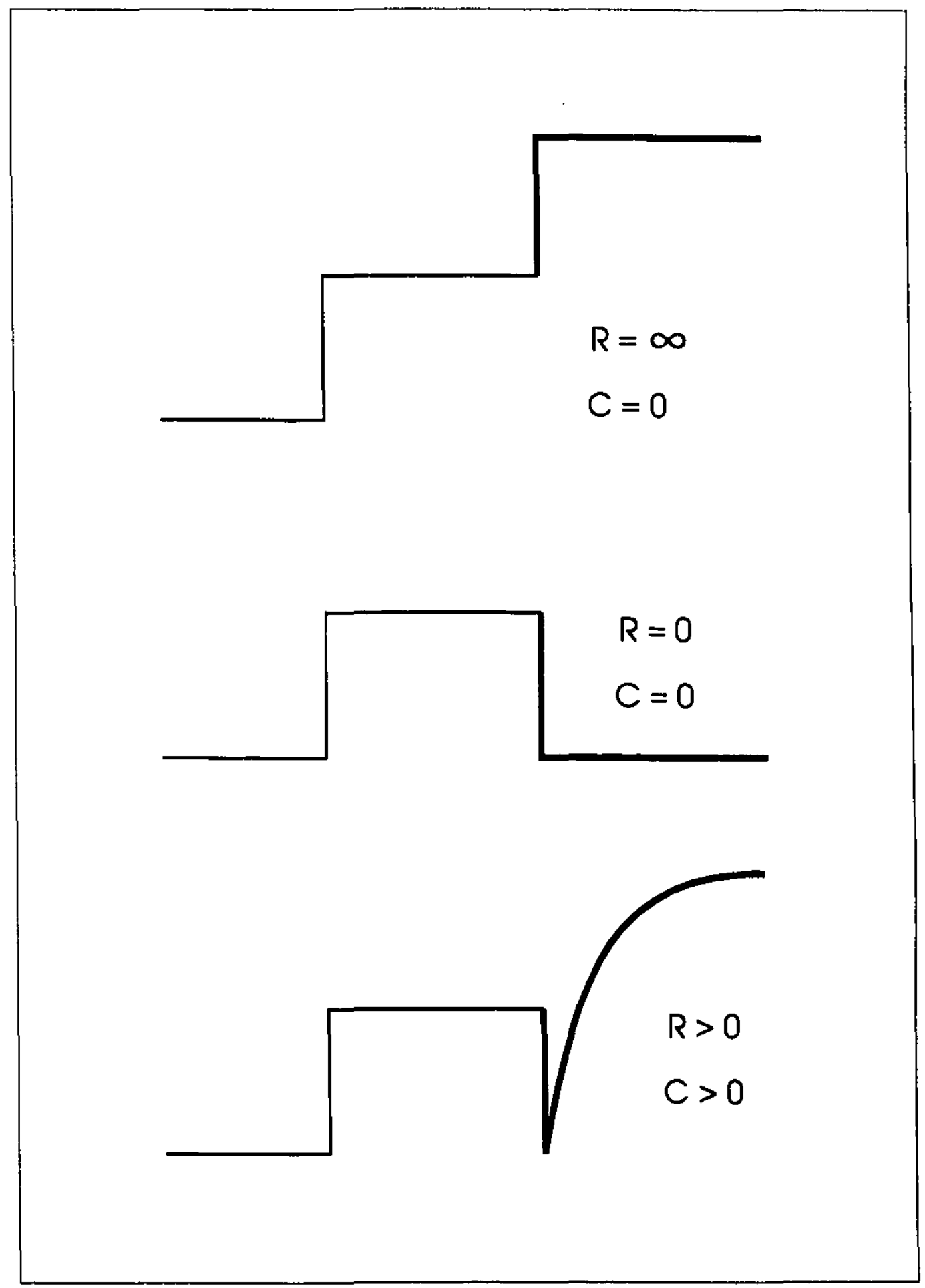

Figure 3.5 Typical TDR Responses. 
equivalent information in the frequency-domain through the use of the Fast Fourier transform. The response of a dielectric sample in the frequency-domain may be found by calculating the ratio of Fourier transforms of the reflected and the incident pulses. If $f_{i}(t)$ and $f_{r}(t)$ are the incident and the reflected signals in the time-domain then the frequency response or the transfer function $G(\omega)$ of the dielectric system is defined as:

$$
G(\omega)=\frac{F_{r}(\omega)}{F_{i}(\omega)}=\frac{\int_{-\infty}^{\infty} f_{r}(t) \exp (-i \omega t) d t}{\int_{-\infty}^{\infty} f_{i}(t) \exp (-i \omega t) d t}
$$

The above deconvolution defines $G(\omega)$ for all frequencies contained in the incident pulse, thus it forms a unique description of the analyzed material regardless of the shape of the applied pulse. The use of a transfer function automatically compensates for an irregularly shaped incident pulse. In a setup involving a relatively long sample terminating the coaxial line, the analysis of direct reflections leads to the computation of the complex dielectric constant as follows:

$$
\epsilon^{*}=\left(\frac{1-G(\omega)}{1+G(\omega)}\right)^{2}
$$

This study advocates a practical field implementation of the TDR method for the subsurface contaminant detection. It is proposed that a probe in a coaxial network configuration be inserted into the contaminated soil by pushing or drilling. Following a TDR measurement, a spectral analysis of the collected record would be performed. A broadband measurement of the frequency-dependent electrical properties of a contaminated soil would provide a characteristic "signature", which would be matched with a computerized database of known soil-contaminant "signatures". The mechanics of data analysis associated with this concept is elaborated upon in the experimental section of this study. 


\section{CHAPTER 4 EXPERIMENTAL STUDY}

\subsection{EXPERIMENTAL PROCEDURE}

To assess the practicality of applying the TDR method to the contaminant detection in soils, a series of laboratory experiments was conducted. The instrumentation setup employed in this study is shown in Figure 4.1.

The main components include a step function generator, a coaxial transmission cable terminated by a soil probe, a digital waveform recorder and a portable computer to analyze the acquired data. The impulse signal produced by the generator is split as it travels past point $\mathrm{A}$. Half of the amplitude of this voltage signal is recorded by the digitizing oscilloscope, while the other half propagates through the coaxial line and reaches the contaminated soil at point B. Subsequently, a reflection occurs due to a mismatch between the line impedance and some characteristic load impedandce at point $B$. The reflected impulse passes again through point $A$, creating a waveform indicative of the material's dielectric response. The role of the matched "T" is to prevent unwanted reflections at point $\mathrm{A}$. Each of the matching resistors has a resistance of $\frac{Z_{0}}{3}$, where $Z_{o}$ is the characteristic impedance of the coaxial line. The matched "T" was constructed with three Type $\mathrm{N}$ connectors attached to a metallic box (Pomona box), with their center conductors interconnected by three $16.5 \mathrm{ohm}$ resistors.

In order to produce a high frequency polarization the incident signal must exhibit 


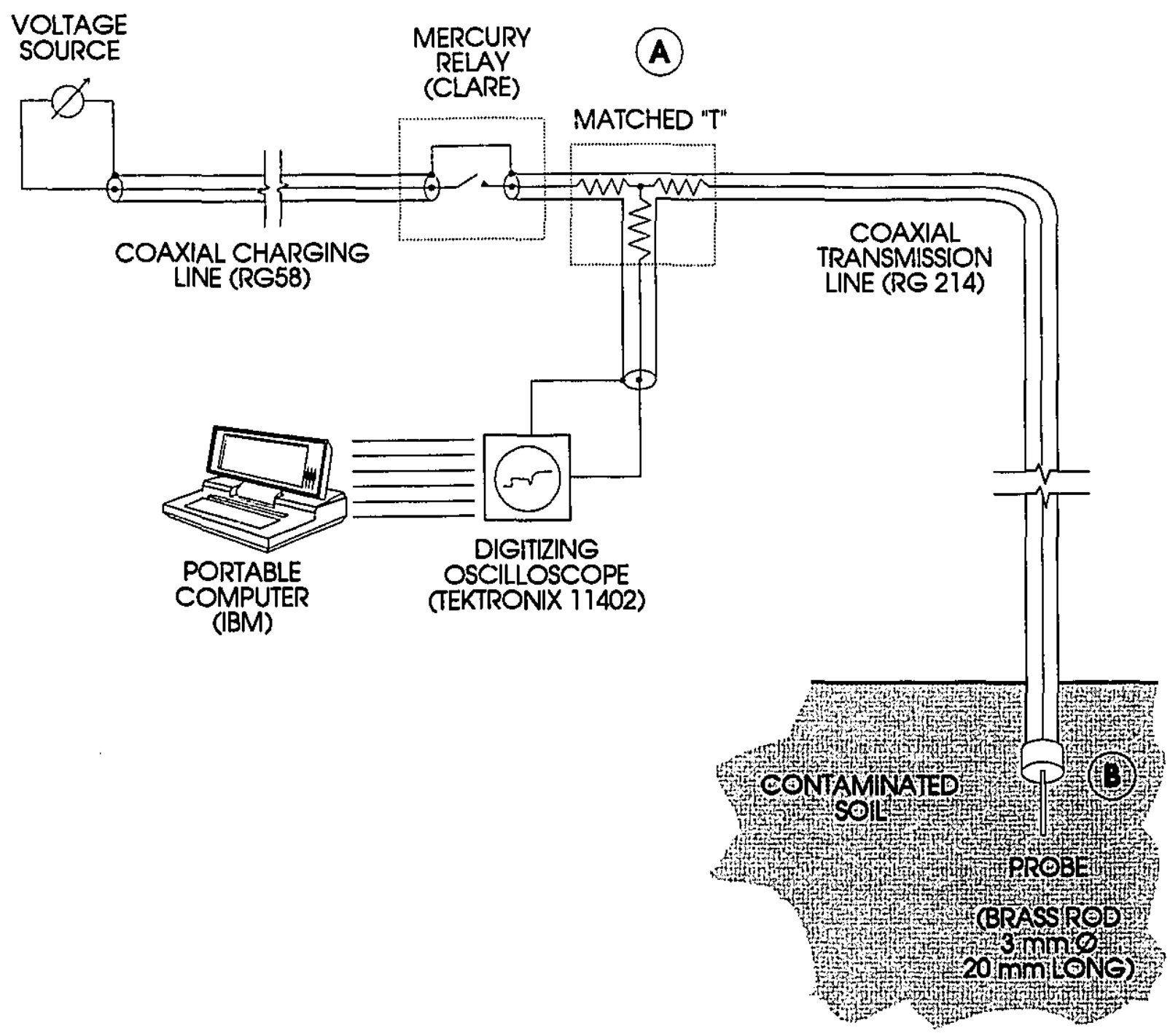

Figure 4.1 Experimental Setup.

a sufficiently fast risetime. The relationship between the signal risetime $\left(T_{r}\right)$ and its frequency bandwidth (BW) may be approximated as follows:

$$
B W=\frac{0.35}{T_{r}}
$$

Thus, the steeper the pulse risetime the wider its effective frequency spectrum. A simple switch consisting of metal contacts is not satisfactory because the contact 
bounce during closure may produce an undesirable series of pulses. Brown and Pollard (1947) addressed this problem by developing a relay in which solid platinum contacts are continuously wetted with mercury by means of a capillary connection to a reservoir. The mercury film prevents the contacts from breaking when the armature bounces. Only one pulse is accordingly produced for each relay operation. The mercury relay has been recognized for its ability to deliver reproducible pulses with subnasecond risetimes (Andrews, 1973). Its main advantage is the capability to deliver a fast risetime, high amplitude signal. In contrast, a conventional laboratory TDR setup uses a low amplitude diode for signal generation. Such a signal may not be effective in field applications due to the influence of the ambient noise.

In this study the incident signal was produced with a mercury wetted contact relay manufactured by Clare. The relay was operated at a line frequency of $60 \mathrm{~Hz}$, thus producing recurring waveforms. Each pulse was subsequently acquired by the digital waveform recorder.

The step function generator was created by alternately charging a 10 meter section of RG 58 coaxial cable with a DC voltage source and fast discharging through the mercury relay into the RG 214 coaxial cable. The length of the RG 214 cable was selected at 7 meters to simulate field conditions where the subsurface contaminant occurs at some depth.

It has been observed that a substantial length of the coaxial cable results in a noticeable impulse degradation with a resulting loss of the high frequency components. This is usually not a problem in a typical laboratory TDR setup which includes only about $30 \mathrm{~cm}$ of a coaxial line terminating in the sample material. The initial risetime of an impulse and thus its frequency spectrum degrade as the signal travels through a long cable, due to the phenomenon known as the "skin effect". One way of minimizing the pulse distortion is to select a high quality cable with inherently low loss characteristics. For this reason the RG 214 coaxial cable was chosen. It exhibits a maximum attenuation 
of $1.7 \mathrm{db} / 100$ feet at $50 \mathrm{MHz}$, increasing to $60 \mathrm{db} / 100$ feet at $11 \mathrm{GHz}$. The effect of pulse degradation is illustrated in Figure 4.2. The attenuation characteristics of the signal measured directly at the output of the step-function generator are compared with those of the same signal propagated through the coaxial cable, reflected from the shortcircuit termination at point $B$ and measured at point $A$. This comparison shows that a distortion associated with the pulse propagation in the measuring circuit begins to play a significant role only at frequencies above $200 \mathrm{MHz}$. In the range of $0-200 \mathrm{MHz}$ the RG 214 coaxial cable does not exert any appreciable effect on the signal attenuation. Furthermore, it can be seen that the $200 \mathrm{MHz}$ frequency component exhibits about $40 \mathrm{~dB}$ attenuation, which translates into the signal strength of 0.01 of the maximum. This signal level is well within the resolution capability of the TEK 11402 .

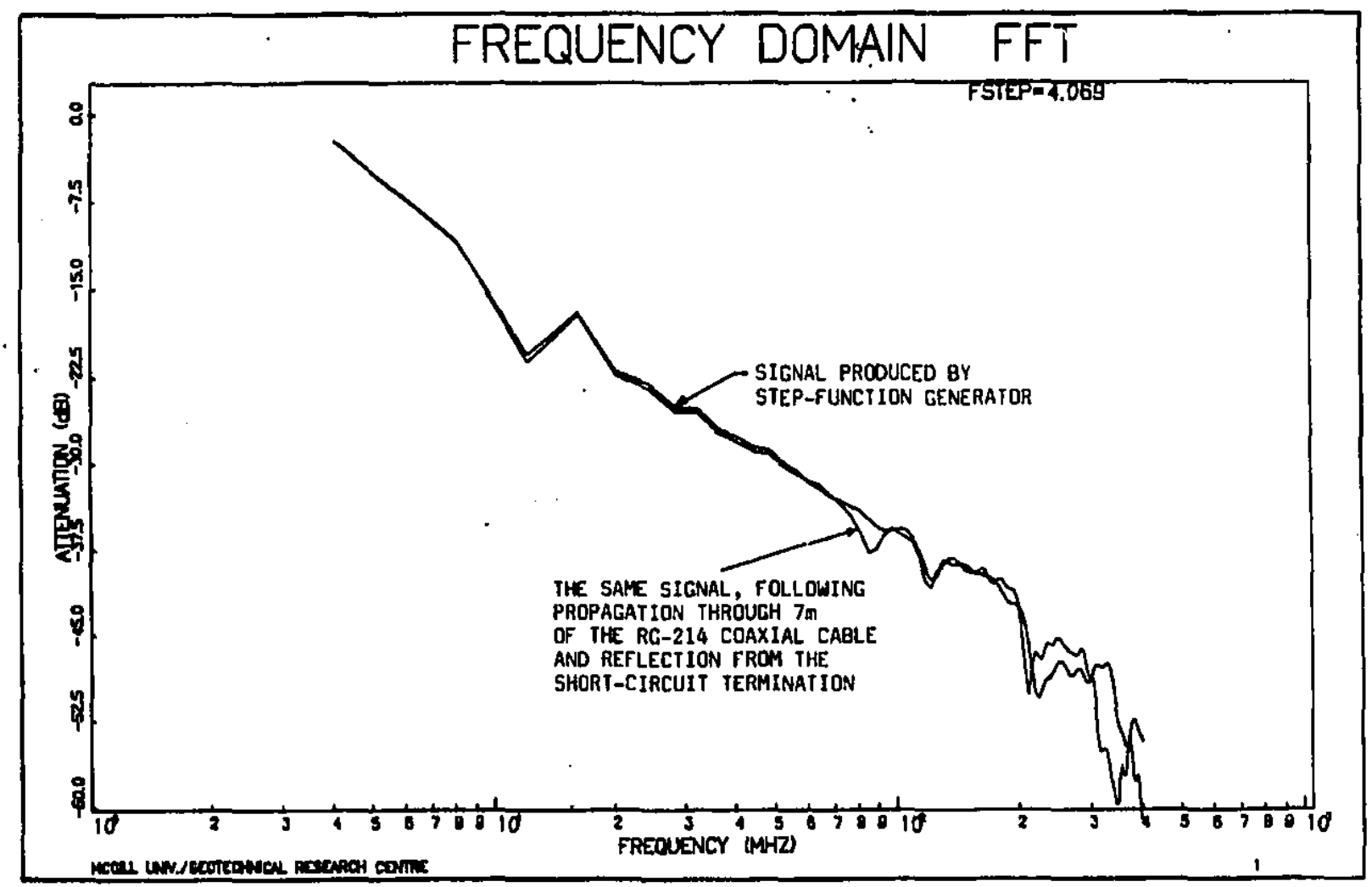

Figure 4.2 Effect of Pulse Propagation Through Coaxial Cable on Attenuation. 
It is envisioned that the field probe would be drilled or pushed into the soil, while the recording instruments collect and analyze data at the surface. One potential scenario involves hollow stem auger drilling to a test depth, followed by the probe insertion, TDR measurement and data analysis directly on site. The soil probe used in this study consisted of a modified Type $\mathrm{N}$ coaxial connector with an extended center electrode made of a machined brass rod, $3 \mathrm{~mm}$ dia. and $20 \mathrm{~mm}$ long. The concept of an extended central electrode, surrounded by a dielectric material, was adapted from the in-situ dielectric measurements on oil shales, conducted by Iskander and DuBow (1983). Electrically, at low frequencies the equivalent circuit may be represented by a shunt capacitor terminating the coaxial line. At high frequencies the influence of the fringing field capacitance becomes increasingly dominant. An expression for the input impedance of the dielectric probe which is basically a monopole antenna immersed in the material under test is given by Gooch et al. (1963):

$$
Z_{i}^{*}=\frac{\omega \mu_{o}}{j 2 k(S+C U)}
$$

where the functions $k, S, C$, and $U$ depend on the measurement frequency, the length and the diameter of the extended soil conductor and on the dielectric properties $\epsilon^{\prime}$ and $\epsilon^{\prime \prime}$. Due to the complexity of equation 4-2 the derivation of dielectric parameters is typically performed by iterative solutions involving minimization of a two-dimensional error surface, where the minimum indicates the most appropriate values of $\epsilon^{\prime}$ and $\epsilon^{\prime \prime}$ that satisfy the measured value of the input impedance.

The use of a digital waveform recording instrument provides several advantages, such as capture of transient signals, observation of signals occurring prior to the trigger event, waveform storage, and computer interfacing. The data acquisition equipment used in the study consisted of the Tektronix 11402 Digitizing Oscilloscope. This instrument is characterized by 14 -bit vertical resolution with signal averaging and a maximum 
of $10 \mathrm{ps}$ temporal resolution. The TEK 11402 can acquire up to three channels of data with $1 \mathrm{GH}$ \% frequency bandwidth concurrently. Record length is adjustable to 512, $1024,2048,4096,5120,8192$ and 10240 points. Digitized waveforms are transferred for a subsequent data analysis to a portable computer using the IEEE-488 or RS-232 interface. The process of data acquisition lends itself to a full automation. The oscilloscope settings are also saved in a data file, allowing initialization and control of the oscilloscope from the computer.

The operation of the Tektronix 11402 requires a recurrent waveform to enhance its sensitivity and to extend the frequency range. The oscilloscope functions through a random sampling process. The shape of the recurrent waveform is determined by an automatic point-by-point measurement, with each individual data point being cietermined at a different waveform repetitions. As each recurrent waveform passes the "T" it triggers the automatic signal acquisition based on the predetermined threshold level of the leading edge of the pulse. This approach makes it possible to sample a given waveform with a much greater time resolution that is otherwise available with a single-shot acquisition. Random sampling acquires signals at a random sequence in relation to where they are stored in memory. The points in time at which these samples are acquired are "remembered" in reference to the trigger point.

Rather than computing the absolute values of the complex dielectric constant, the approach pursued in this study involved the material characterization through the use of the Transfer Function, which in turn is a function of $\epsilon^{*}$. In the time-domain the input signal, the system response and the output signal are related through the Duhamel convolution integral:

$$
y(t)=\int_{-\infty}^{\infty} h(\tau) x(t-\tau) d \tau
$$

In iise frequency-domain the relationship between the input and the output corresponds to a simple multiplication. The input and the output signals can be transformed 
into the frequenc $y^{\prime}$-domain through the use of the Fast Fourier Transform (FFT). Subsequently, the Transfer Function $H(f)$ of a system may be established by dividing the spectrum of the output by the spectrum of the input waveform.

$$
\begin{aligned}
& Y(f)=H(f) * X(f) \\
& H(f)=\frac{Y(f)}{X(f)}
\end{aligned}
$$

What usually needs to be established is how a given system responds to each frequency component of an arbitrary input signal. In a linear, time invariant system, such a response offers a complete and unique circuit characterization (Ramirez, 1985). It also represents a characteristic spectral "signature" of a material under test.

\subsection{DATA ACQUISITION}

Prior to digitizing and processing large quantities of data, a small series of trial tests was conducted with a setup shown in Figure 4.1. The objective was to assess if various "contaminants" produce clearly discernible time-domain responses. Fluids selected for testing included Butyl Alcohol, Methyl Alcohol, Phenol (1000 ppm), and Kerosene. The oscilloscope traces indicating distinctly unique responses are shown in Figures 4.3 through 4.6. It is evident that the shape of the reflected signal is affected by the material examined.

Subsequent tests were conducted using the digital waveform recording capabilities of the TEK 11402. Data acquired and stored by the oscilloscope was transferred to a computer for signal processing. Tests were performed on several arbitrarily chosen "contaminants" and on "soil-contaminant" mixtures. The soil used to create these mixtures consisted of dry portions of $60 \%$ Lake Agassiz clay and $40 \%$ crushed granodiorite passing sieve \#50 and retained on sieve \#16. Soil-contaminant mixtures were prepared with $60 \%$ and $40 \%$ fluid content ("contaminant"), simulating fully saturated 


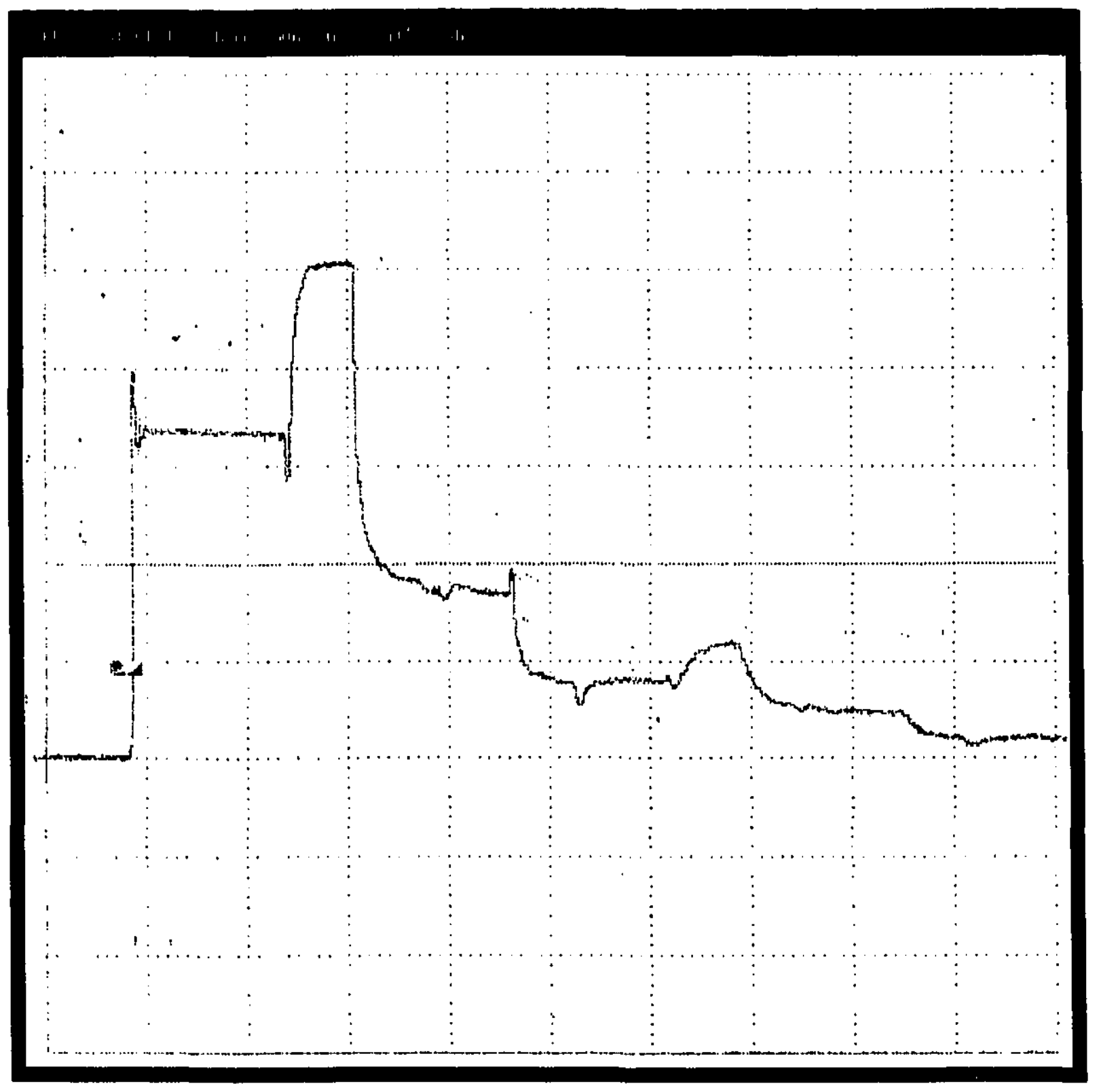

Figure 4.3 Oscilloscope Trace - Butyl Alcohol. 


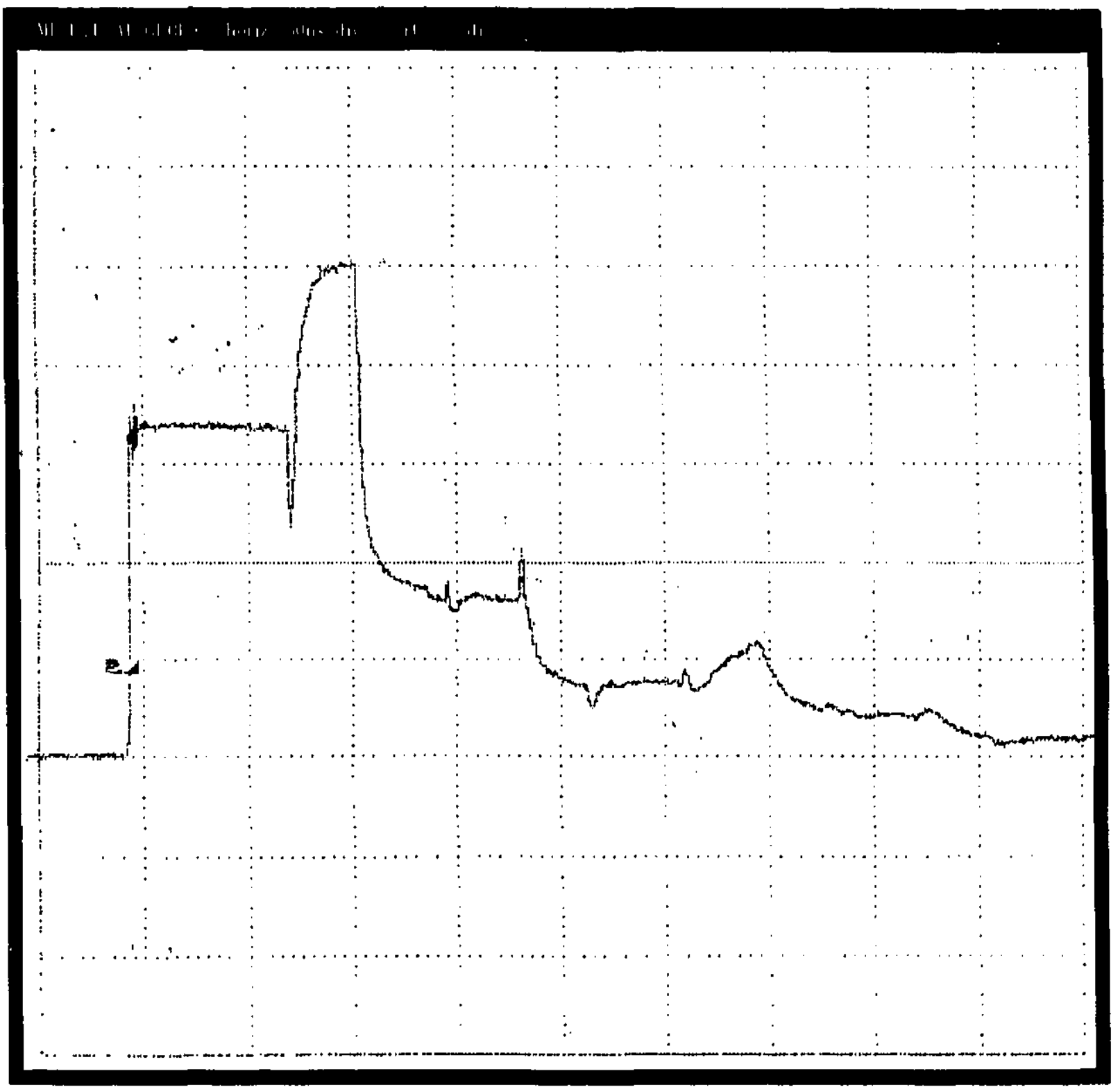

Figure 4.4 Oscilloscope Trace - Methyl Alcohol. 


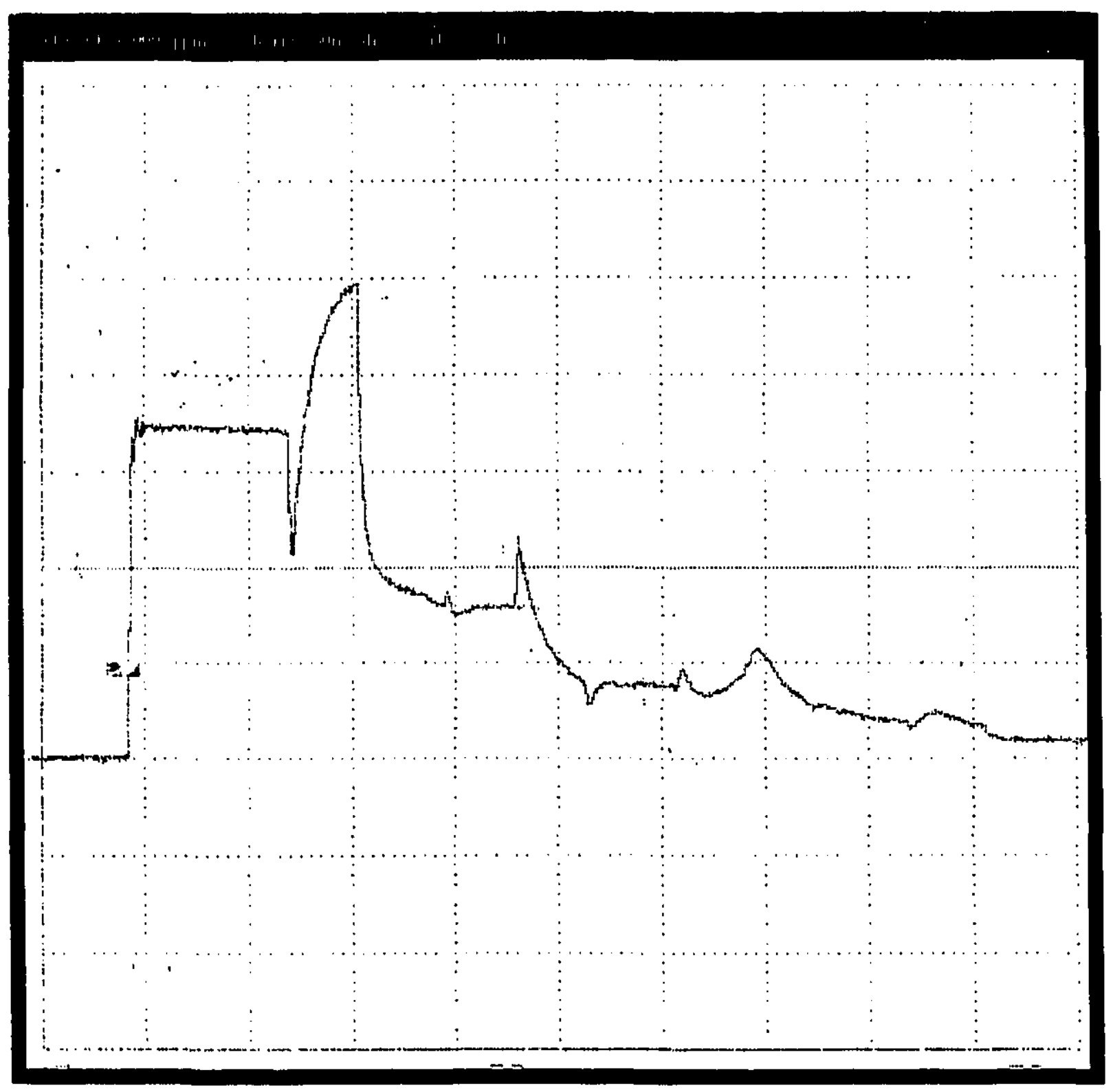

Figure 4.5 Oscilloscope Trace - Phenol (1000 ppm). 


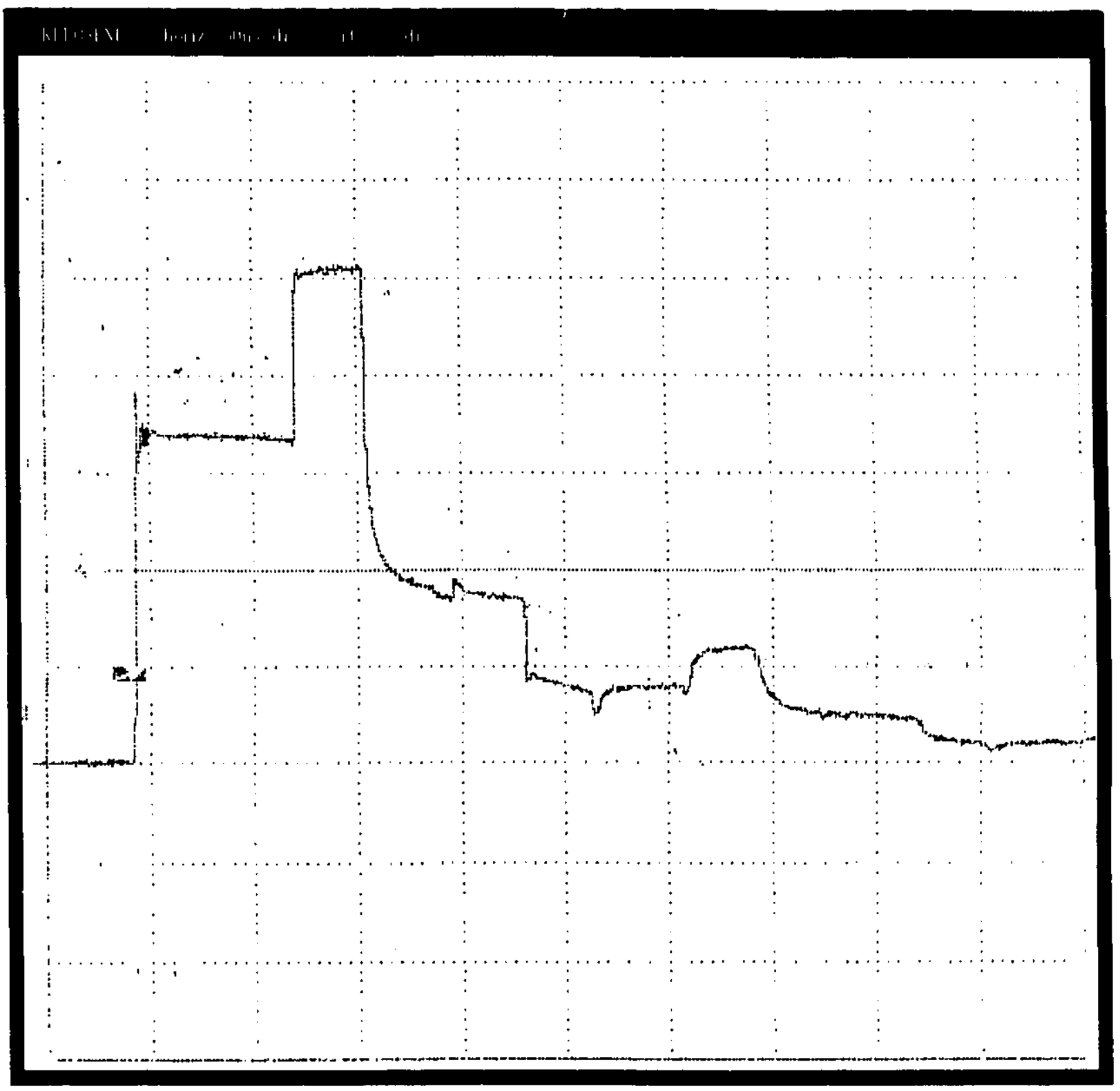

Figure 4.6 Oscilloscope Trace - Kerosene. 


\begin{tabular}{|c|c|c|c|c|c|c|c|c|c|}
\hline Pollutant & $\mathrm{pH}$ & $\begin{array}{c}S \\
(\mathrm{mS} / \mathrm{m})\end{array}$ & $\begin{array}{c}\mathrm{Na} \\
(\mathrm{ppm})\end{array}$ & $\begin{array}{c}\mathrm{Ca} \\
(\mathrm{ppm})\end{array}$ & $\begin{array}{c}K \\
(\mathrm{ppm})\end{array}$ & $\begin{array}{l}\mathrm{Mg} \\
(\mathrm{ppm})\end{array}$ & $\begin{array}{c}\mathrm{Cl}^{-} \\
(\mathrm{meq} / \mathrm{L})\end{array}$ & $\begin{array}{c}\mathrm{CO}_{3}^{2-} \\
(\mathrm{meq} / \mathrm{L})\end{array}$ & $\begin{array}{l}\mathrm{HCO}_{3}^{-} \\
(\mathrm{meq} / \mathrm{L})\end{array}$ \\
\hline $\begin{array}{l}\text { KAHI } \\
\text { CEZ } \\
\mathrm{PB} \\
\mathrm{H} 20 \\
\text { LACHENAIE }\end{array}$ & $\begin{array}{l}7.54 \\
2.73 \\
2.11 \\
5.24 \\
6.80\end{array}$ & $\begin{array}{r}23.0 \\
58.7 \\
64.7 \\
0.3 \\
2.7\end{array}$ & $\begin{array}{r}198 \\
0 \\
340 \\
1 \\
140\end{array}$ & $\begin{array}{r}54 \\
8 \\
2 \\
1 \\
180\end{array}$ & $\begin{array}{r}103 \\
2 \\
1 \\
0 \\
16\end{array}$ & $\begin{array}{r}95 \\
148 \\
0 \\
0 \\
350\end{array}$ & $\begin{array}{r}15 \\
27 \\
45 \\
0 \\
5\end{array}$ & $\begin{array}{l}0 \\
0 \\
0 \\
0 \\
0\end{array}$ & $\begin{array}{l}0 \\
1.0 \\
2.0 \\
3.0 \\
5.0\end{array}$ \\
\hline
\end{tabular}

\begin{tabular}{|c|c|c|c|c|c|c|c|c|c|}
\hline Pollutant & $\begin{array}{c}\mathrm{SO}_{4}^{2-} \\
(\mathrm{meq} / \mathrm{L})\end{array}$ & $\begin{array}{c}\mathrm{Al}^{3+} \\
(\mathrm{ppm})\end{array}$ & $\underset{(\mathrm{ppm})}{\mathrm{Cd}^{2+}}$ & $\begin{array}{c}\mathrm{Cr}^{2+} \\
(\mathrm{ppm})\end{array}$ & $\underset{(\mathrm{ppm})}{\mathrm{Cu}^{2+}}$ & $\begin{array}{c}\mathrm{Fe}^{2+} \\
(\mathrm{ppm})\end{array}$ & $\begin{array}{c}\mathrm{Ni}^{2+} \\
(\mathrm{ppm})\end{array}$ & $\begin{array}{c}\mathrm{Pb}^{2+} \\
(\mathrm{ppm})\end{array}$ & $\begin{array}{c}\mathrm{Zn}^{2+} \\
(\mathrm{ppm})\end{array}$ \\
\hline $\begin{array}{l}\text { KAH1 } \\
\text { CEZ } \\
\text { PB } \\
\text { H2O } \\
\text { LACHENAIE }\end{array}$ & $\begin{array}{r}0.02 \\
107.00 \\
0.10 \\
0.16 \\
-\end{array}$ & $\begin{array}{r}0 \\
15 \\
0 \\
0 \\
--\end{array}$ & $\begin{array}{r}0 \\
17 \\
0 \\
0 \\
--\end{array}$ & $\begin{array}{l}0 \\
0 \\
0 \\
0 \\
--\end{array}$ & $\begin{array}{c}0 \\
42 \\
0 \\
0 \\
1.7\end{array}$ & $\begin{array}{r}0 \\
47 \\
0 \\
0 \\
5\end{array}$ & $\begin{array}{l}0 \\
0 \\
0 \\
0 \\
-2\end{array}$ & $\begin{array}{r}0 \\
1 \\
63 \\
0 \\
1\end{array}$ & $\begin{array}{c}0 \\
2983 \\
0 \\
0 \\
2.5\end{array}$ \\
\hline
\end{tabular}

NOTES: S - conductivity;

$\mathrm{KAHI}$ - leachate from Kahnawaki landfill site.

CEZ - waste product from zinc manufacturing facility (diluted to $200 \mathrm{mg} / \mathrm{L}$ )

PB - laboratory solution of lead chloride

$\mathrm{H} 2 \mathrm{O}$ - distilled water

LACHENAIE - Leachate from Lachenaie landfill site.

Additional materials used in experiments included BENZENE, ETHANOL, $0.01 \mathrm{~N} \mathrm{CaCl}_{2}$, and $0.01 \mathrm{~N} \mathrm{NaCl}$.

Table 4.1 Chemical Characteristics of "Contaminants".

and unsaturated soil conditions. Table 4.1 summarizes the chemical composition of "contaminants" used in the experiments.

Lake Agassiz clay originated from St. Boniface, Manitoba. Its mineral composition, in a decreasing order of abundance, comprised montmorillonite, illite, quartz, kaolinite, feldspar, and dolomite (Yong et al., 1986). Based on the saturation extract 
analysis, the main water soluble ions were classified as: $\mathrm{Na}^{+}, \mathrm{Ca}^{2+}, \mathrm{HCO}_{3}^{-}$. The predominant extractable ion was found to be $\mathrm{Ca}^{2+}$ and the cation exchange capacity (CEC) was determined at $71.4 \mathrm{mg} / 100 \mathrm{~g}$. Liquid and plastic limits were $112 \%$ and $28 \%$, respectively. The gradation analysis indicated $61 \%$ of particles passing the \#200 sieve.

The crushed granodiorite originated from Cold Springs Quarry in Lac du Bonnet, Manitoba. Its mineralogical composition included quartz (28\%), feldspar plagioclase $(35 \%)$ and microcline $(20 \%)$.

Measurements were performed on contaminants and on soil-contaminant mixtures prepared 24 hours prior to testing. All soil specimens were initially air dry. No significant scatter in each material's response was observed during testing. Measurements were performed on the following materials:

- $\mathrm{H} 2 \mathrm{O}$ (Distilled water)

- $\mathrm{H} 2 \mathrm{O}-40$ (Soil with 40\% H2O)

- $\mathrm{H} 2 \mathrm{O}-60$ (Soil with $60 \% \mathrm{H} 2 \mathrm{O}$ )

- CACL (0.01 N calcium chloride)

- CACL-40 (Soil with 40\% CACL)

- CACL-60 (Soil with 60\% CACL)

- PB (Lead chloride)

- PB-40 (Soil with $40 \%$ PB)

- PB-60 (Soil with 60\% PB)

- CEZ (Waste product from zinc production)

- CEZ-40 (Soil with 40\% CEZ)

- CEZ-60 (Soil with 60\% CEZ)

- KAH1 (Leachate from Kahnawaki landfill site)

- KAH1-40 (Soil with 40\% KAH1)

- KAH1-60 (Soil with 60\% KAH1)

- OPEN (Empty probe) 

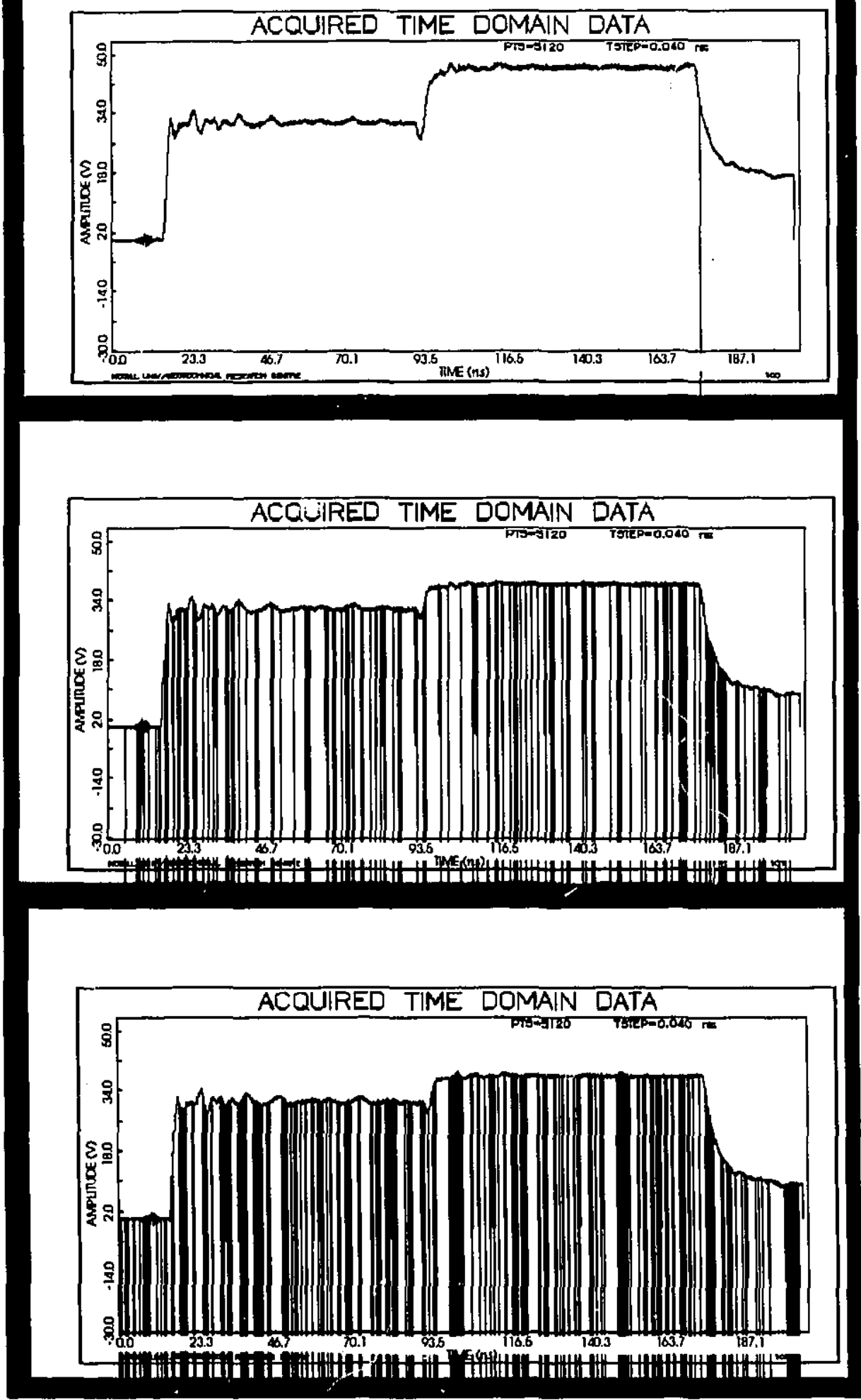

Figure 4.7 Acquired Time-Domain Data : H2O, H2O-40, H2O-60. 

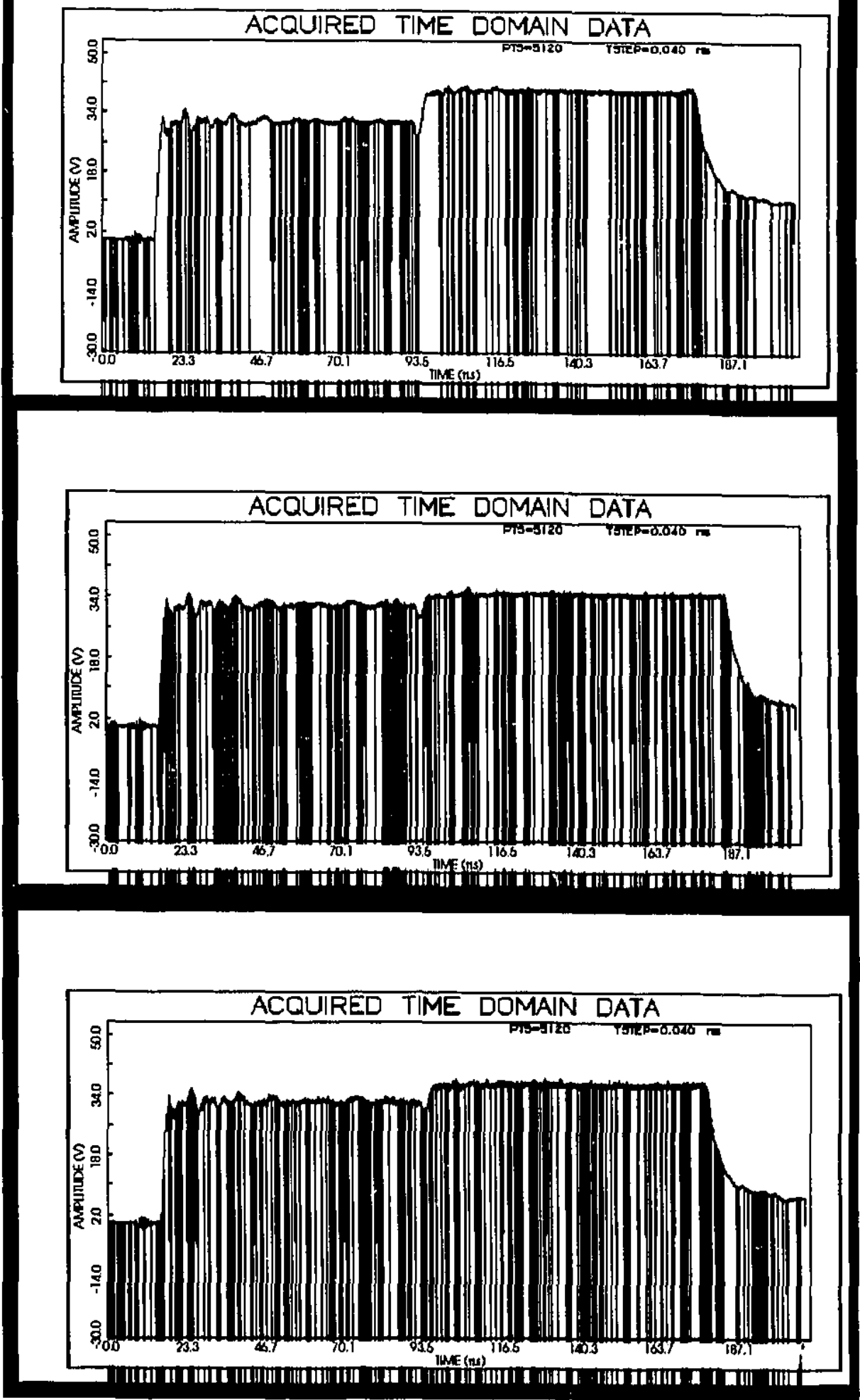

Figure 4.8 Acquired Time-Domain Data : CACL, CACL-40, CACL-60. 

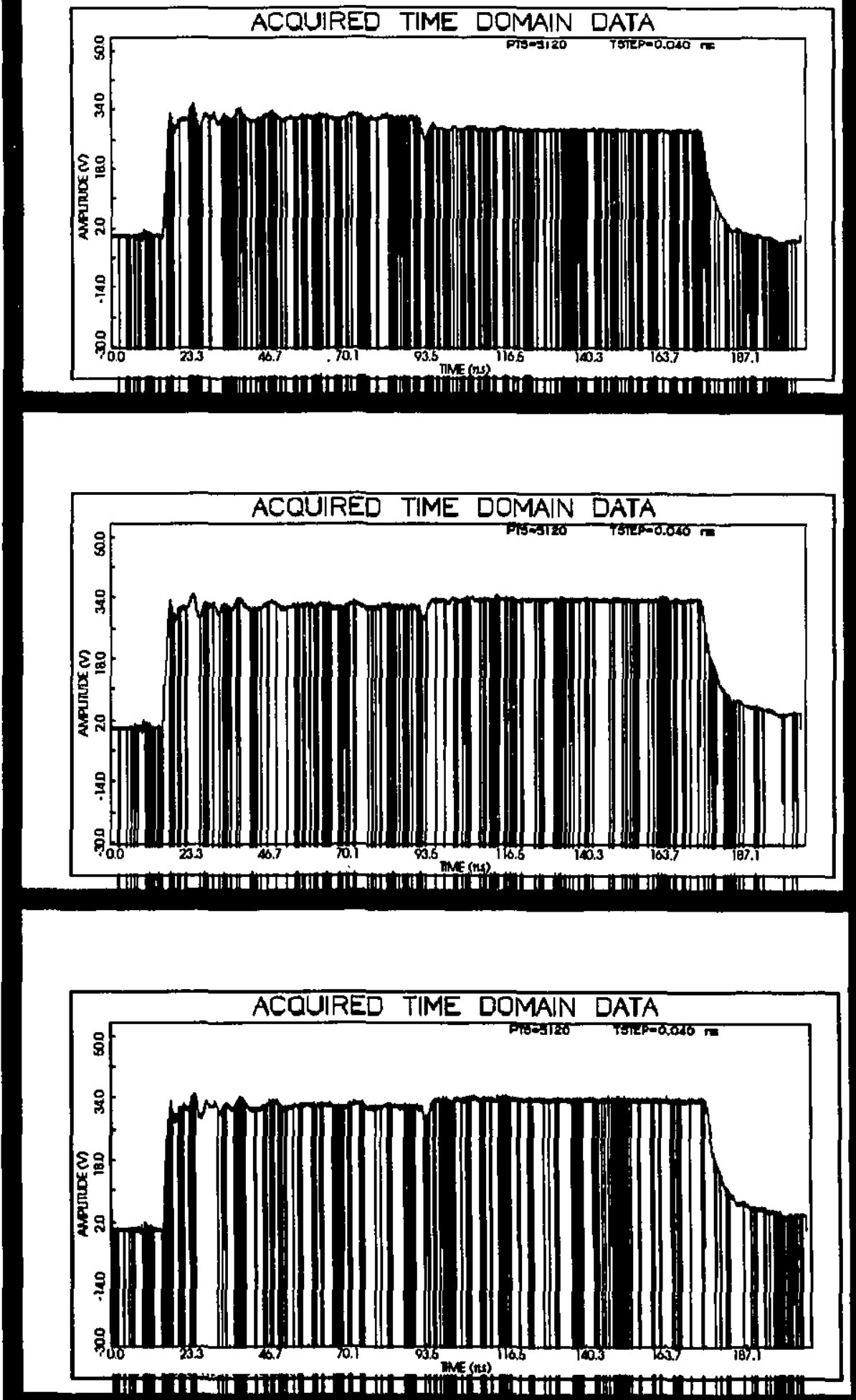

Figure 4.9 Acquired Time-Domain Data : PB, PB-40, PB-60. 

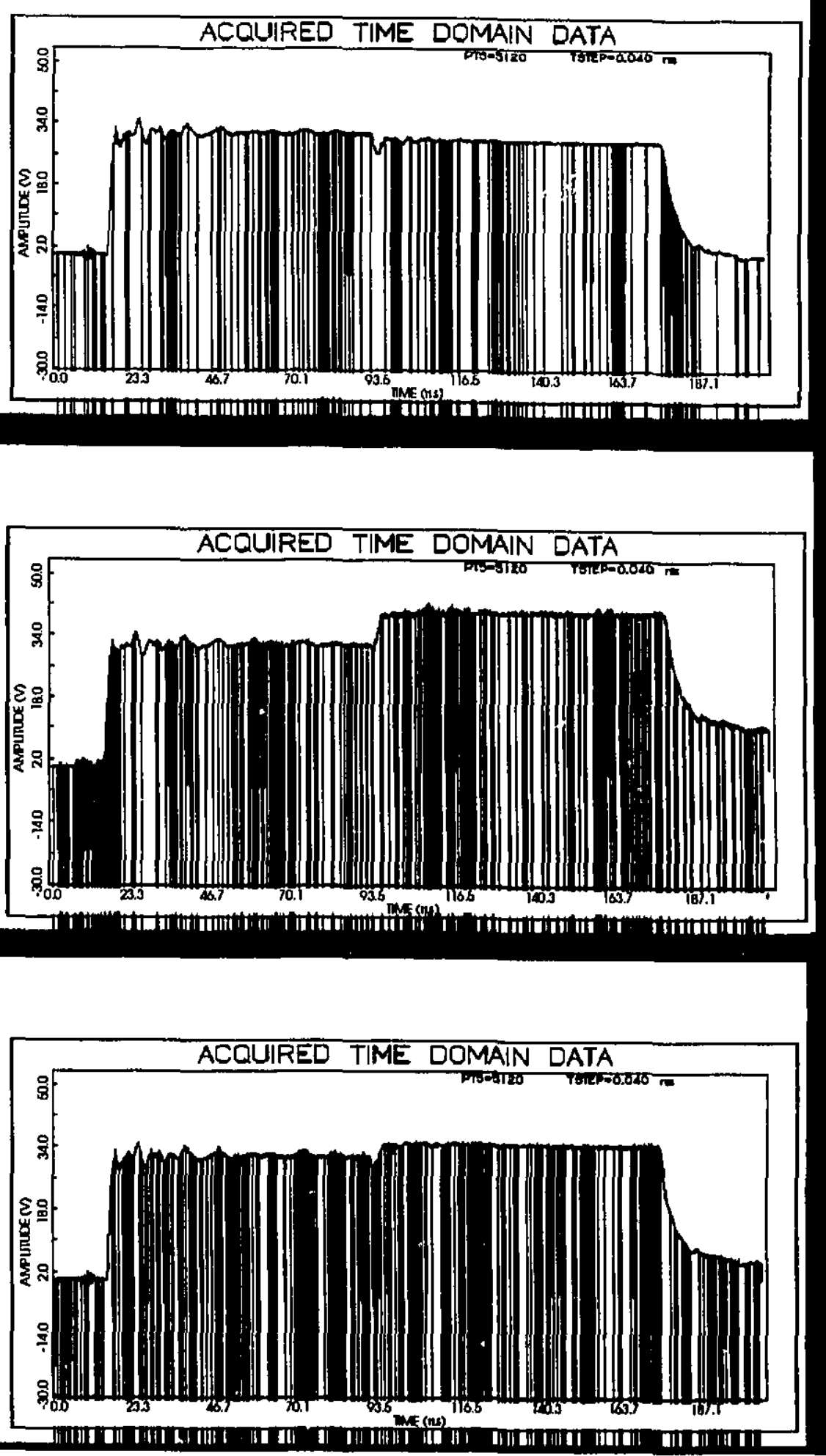

Figure 4.10 Acquired Time-Domain Data : CEZ, CEZ-40, CEZ-60. 

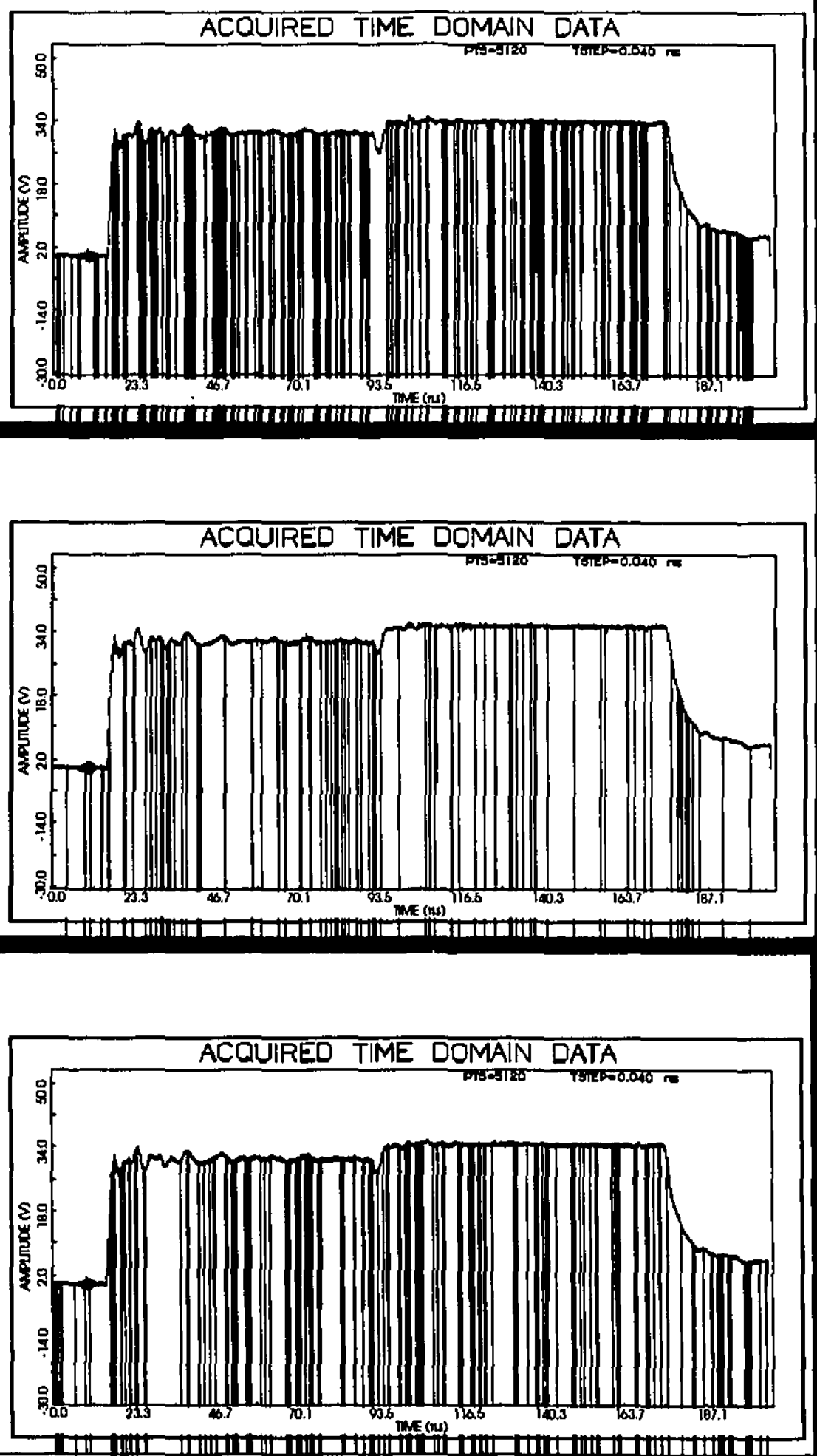

Figure 4.11 Acquired Time-Domain Data : KAH1, KAH1-40, KAH1-60. 

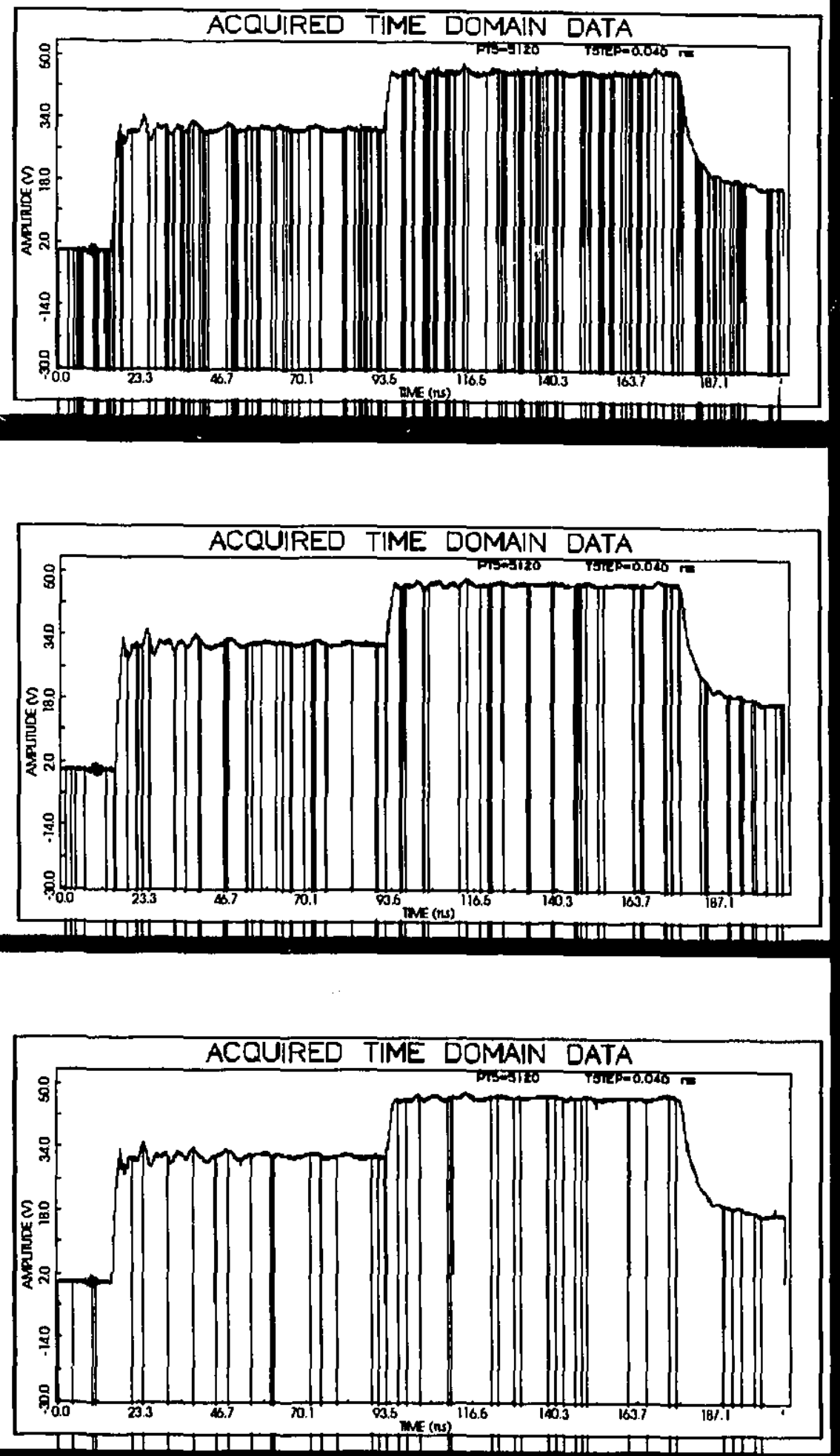

Figure 4.12 Acquired Time-Domain Data: OPEN, BENZENE, ETHANOL. 


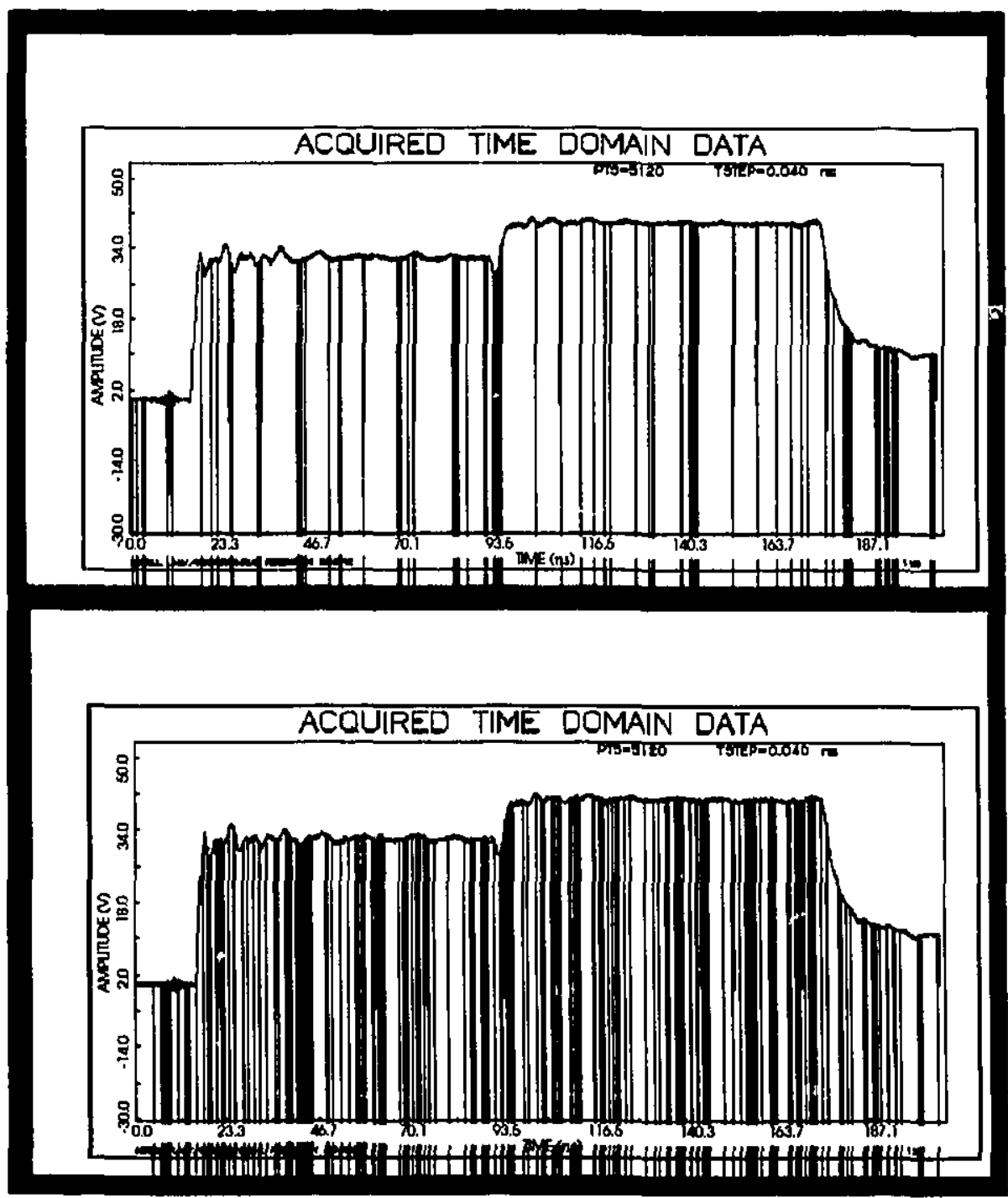

Figure 4.13 Acquired Time-Domain Data : LACHENAIE, NACL. 
- BENZENE

- ETHANOL

- LACHEN (Leachate from Lachenaie landfill site)

- NACL (0.01 N sodium chloride)

Figures 4.7 through 4.13 display the experimental data acquired with the measuring circuit shown in Figure 4.1. Each signal, sampled every 40 ps, consists of 5120 datis points and indicates the initial voltage step as the impulse reaches the digitizing oscilloscope and a subsequent reflection from the sample material. The time $t=0$ signifies the triggering point for the waveform acquisition to the digitizer's memory. The negative time range represents pre-trigger events. After about 70 nanoseconds following the start of the incident impulse acquisition, the reflected signal reaches the digitizer. This time lag is governed by the length of the cable between the sampling point and the soil probe. Sporadic vertical spikes corrupting the acquired time-domain data represent points that were missed during the random sampling process. These data points were adjusted at the signal processing stage.

\subsection{DATA ANALYSIS}

Figures 4.14 through 4.20 display processed time-domain data following splitting the acquired signal into its constituent input $x(t)$ and output $y(t)$ waveforms. Median filtering was used to eliminate the unwanted spikes in data. This method is considered particularly effective when the noise pattern consists of strong, spikclike components, and where the characteristic to be preserved is edge sharpness (Gonzales and Wintz, 1987). The effect of the median filtering operation is the rejection rather than averaging of spikes in data. Each acquired TDR record was successively divided into 25 point data groups, with the 13th largest value being the median of each group. This operation had no appreciable impact on reducing the effective frequency content 
since the signal was heavily oversampled at the acquisition stage. All output waveforms were also multiplied by 2 , to correct for the initial split of the amplitude as the signal passed through the matched " $T$ ".

Proper application of the Fast Fourier Transform (FFT) demands that a timedomain waveform begins and terminates at the same amplitude. Step-like waveforms produce a well known truncation error if they are treated by the FFT without any preprocessing. The abrupt data truncation produces a distortion of the true spectrum of the analyzed signal by introducing a series of artificial high frequency components. Several methods addressing this particular problem have been published. Waldmeyer (1980) pointed out that the three widely used techniques of Samulon, Nicolson and Gans, which originate from apparently different ideas lead to the same numerical process. The technique used for preprocessing of the time-domain data in this study involved application of a cosine window to the last $30 \%$ of each waveform, thus forming a gradual transition towards the initial amplitude level. Subsequently, a $100 \%$ zero padding was applied, so that the analyzed impulse appeared to the FFT algorithm as a repetitive waveform. Additional zeroes were appended to bring each waveform to exactly 4096 data points prior to applying the FFT. All signal processing operations were performed by developing customized programs in Fortran. Applicable source codes are included in the Appendix 1.

The transfer function $H(f)$ was calculated by dividing the FFT of the output waveform by the corresponding FFT of the input. This operation results in a set of complex numbers which may be displayed graphically for ease of interpretation. Representative results are shown in Figures 4.21 though 4.25. Transfer functions for contaminants and soil-contaminant mixtures were computed up to a maximum frequency of $200 \mathrm{MHz}$. The practical upper frequency limit was imposed by the spectral composition of the generated input signal (function of the risetime). All frequency components above $200 \mathrm{MHz}$ were ignored. 

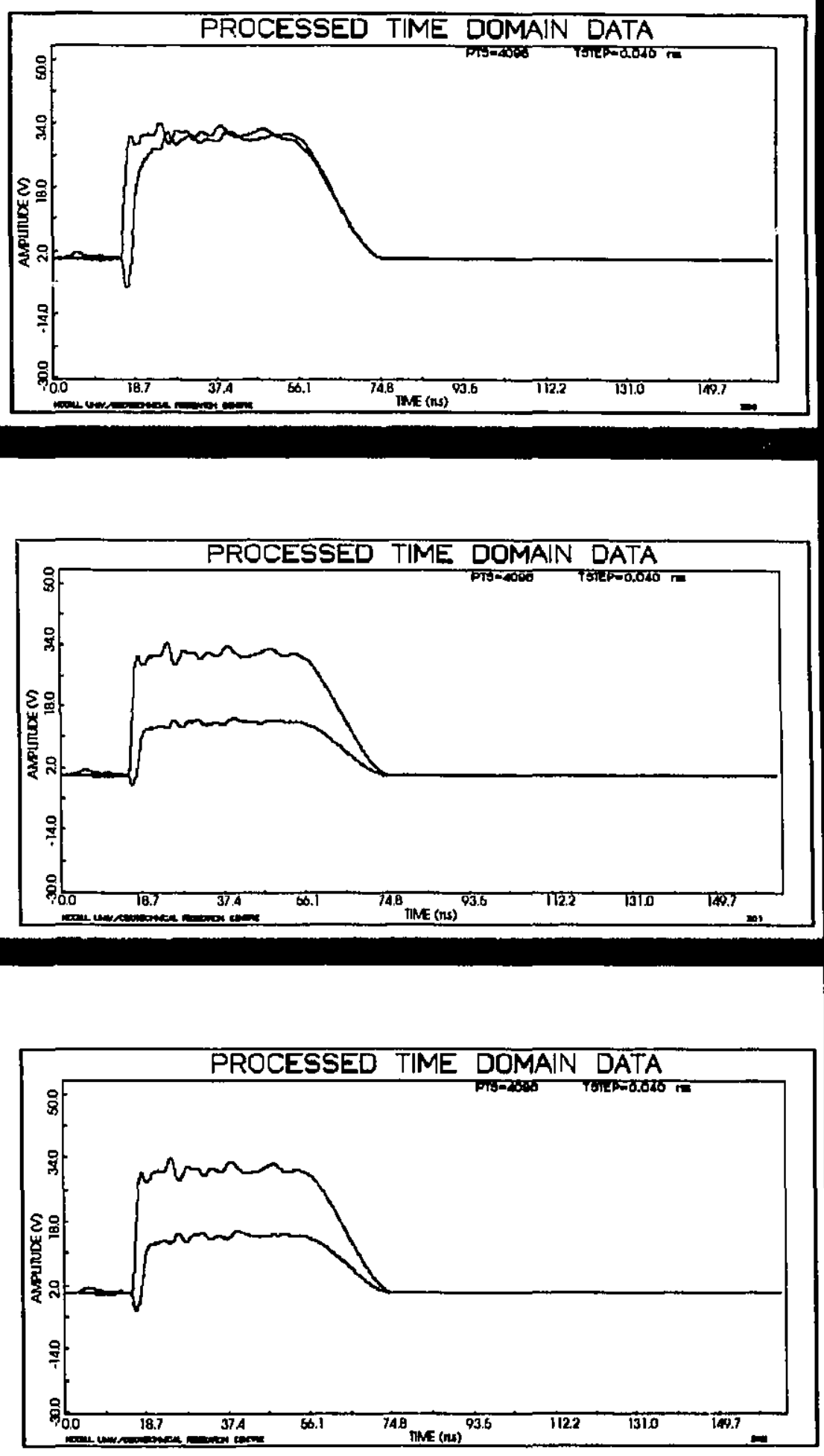

Figure 4.14 Processed Time-Domain Data : H2O, H2O-40, H2O-60. 

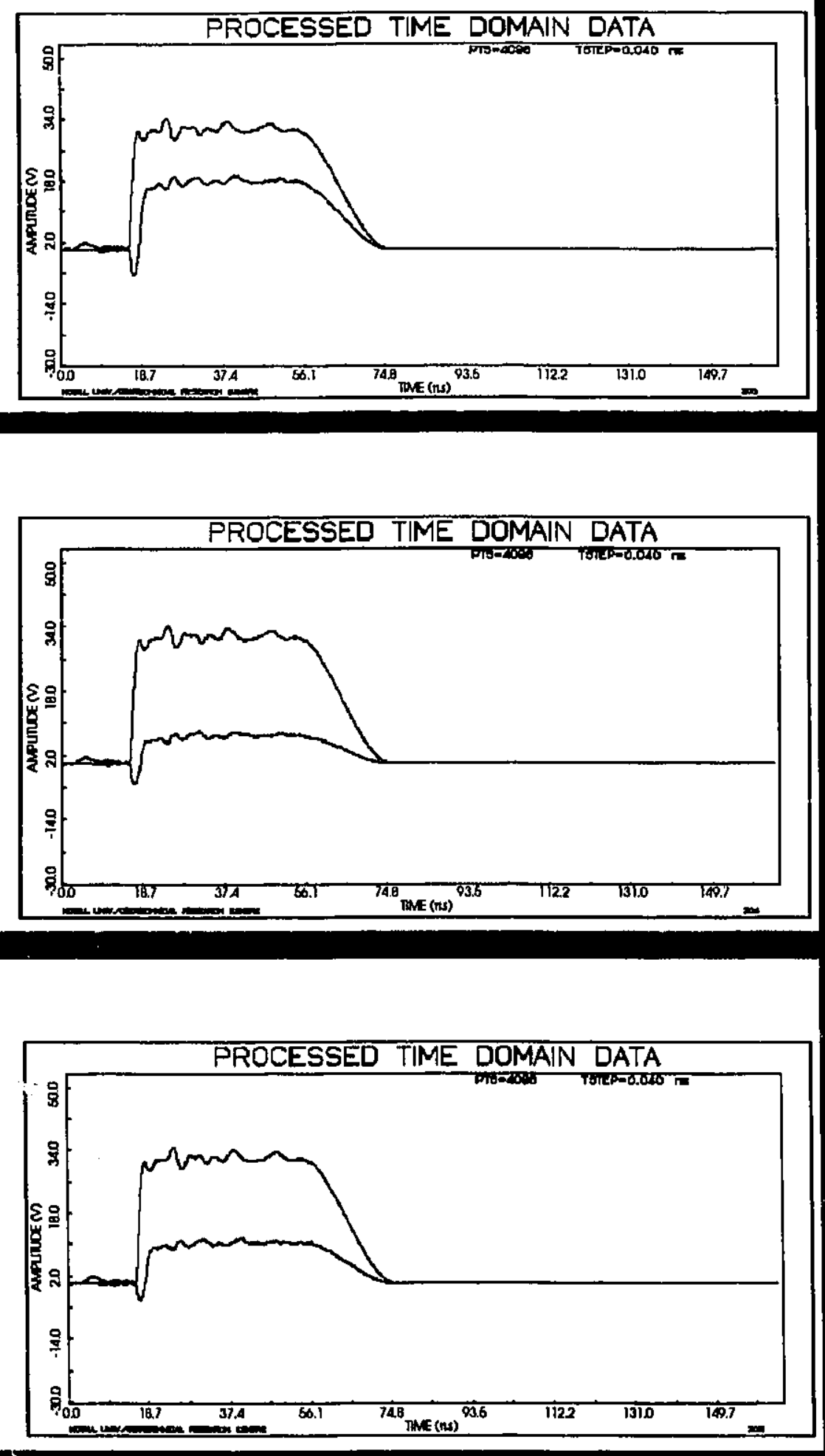

Figure 4.15 Processed Time-Domain Data : C 4 CL, CACL-40, CACL-60. 

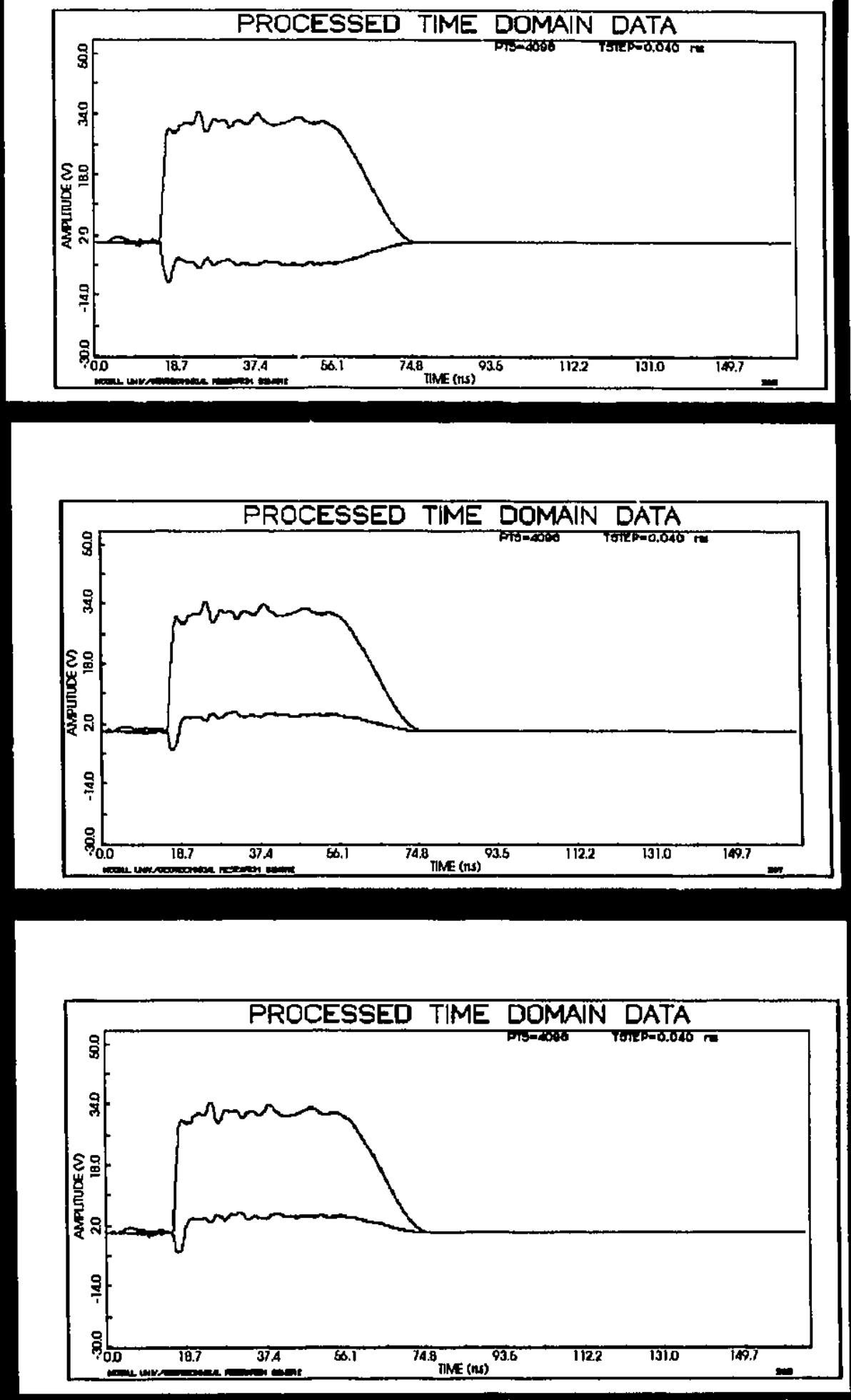

Figure 4.16 Processed Time-Domain Data : PB, PB-40, PB-60. 

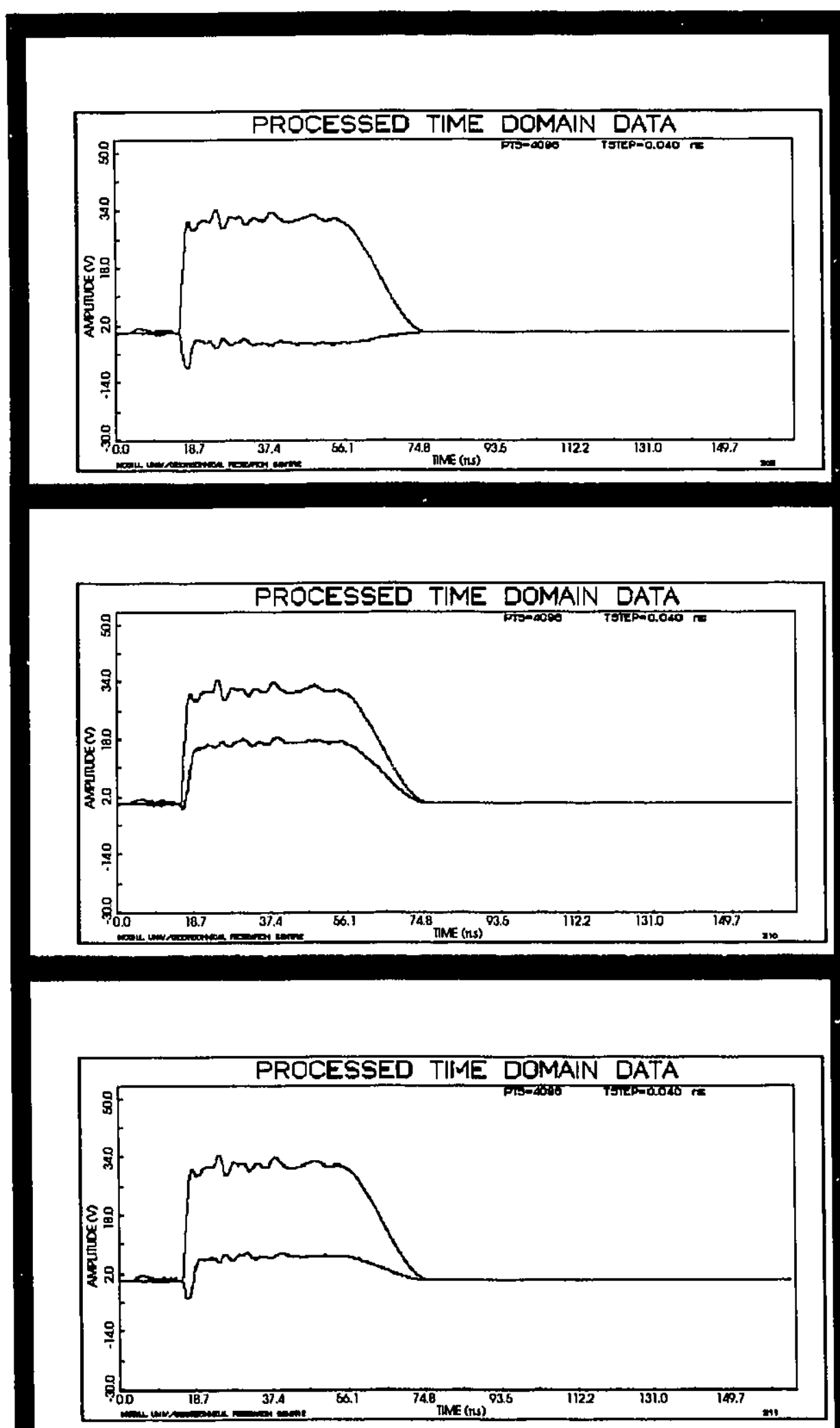

Figure 4.17 Processed Time-Domain Data : CEZ, CEZ-40, CEZ-60. 

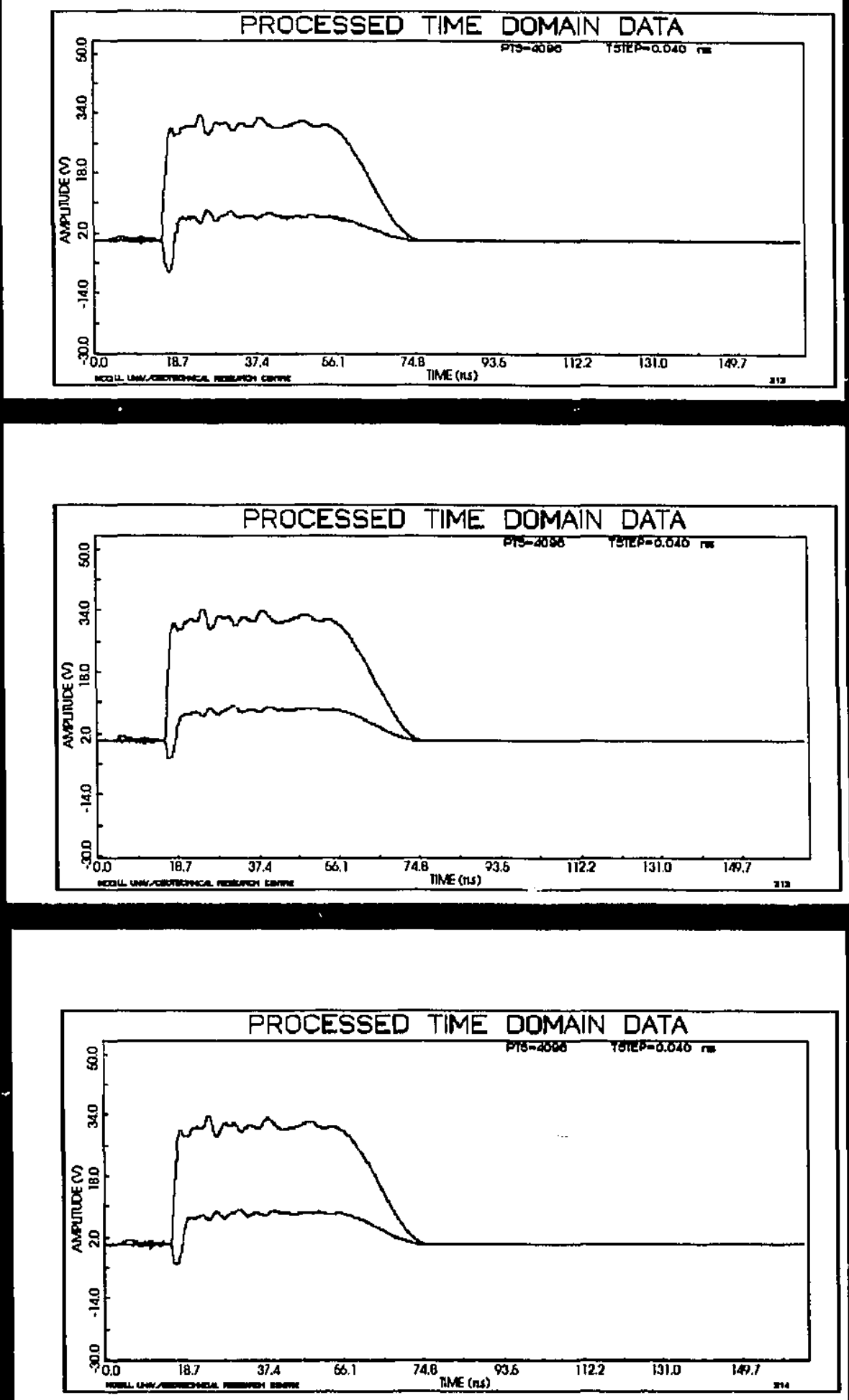

Figure 4.18 Processed Time-Domain Data : KAH1, KAH1-40, KAH1-60. 

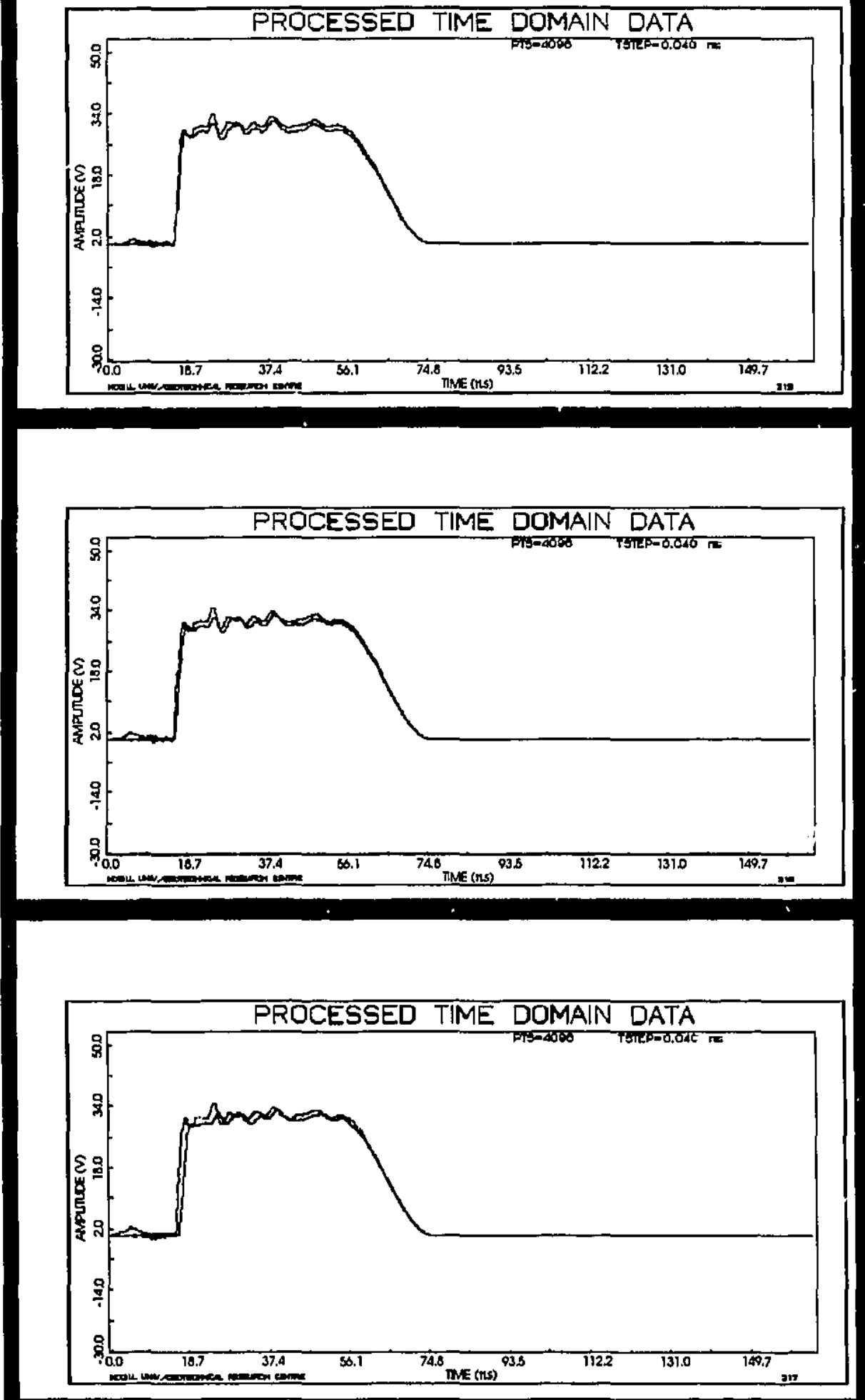

Figure 4.19 Processed Time-Domain Data : OPEN, BENZENE, ETHANOL. 


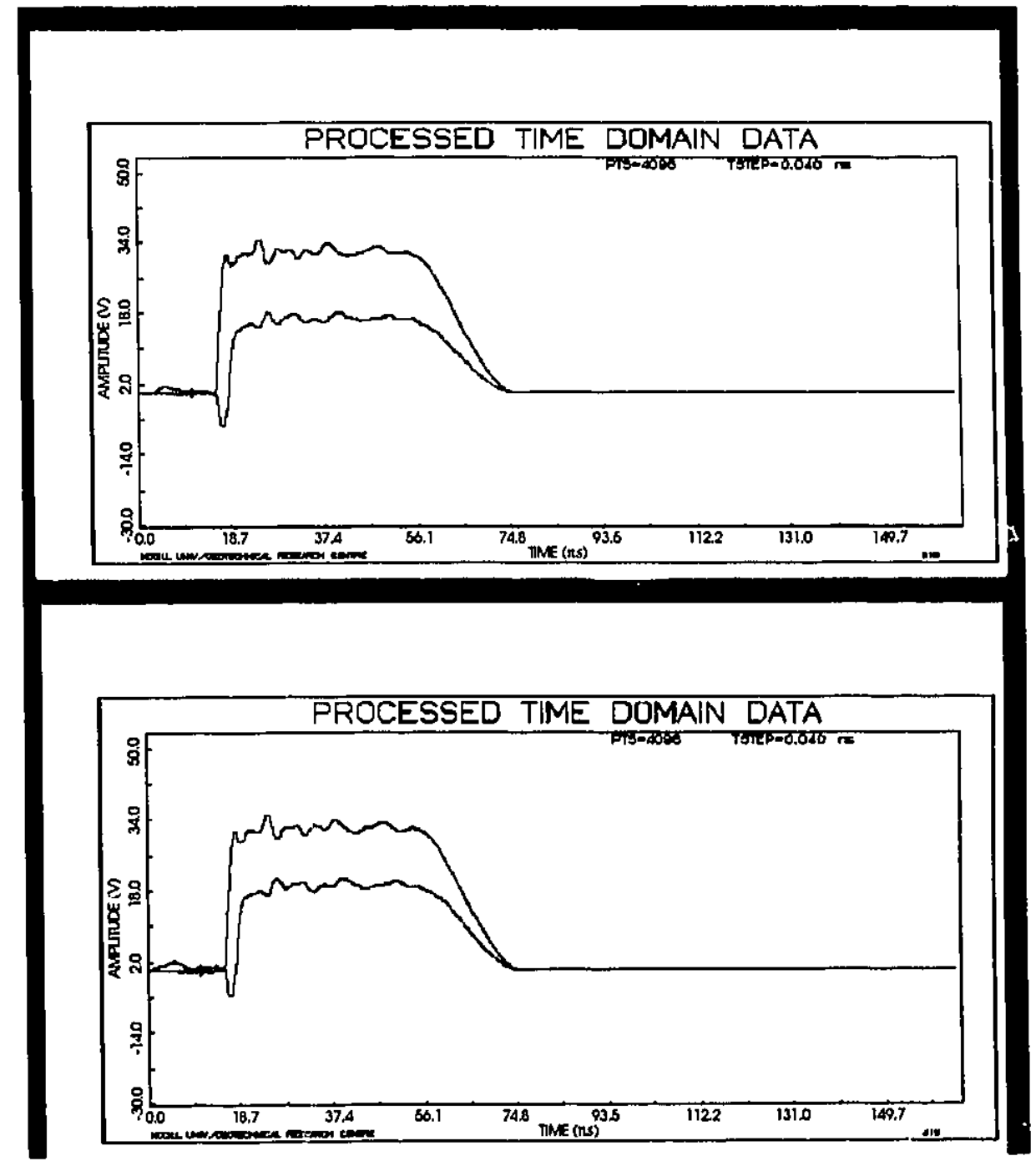

Figure 4.20 Processed Time-Domain Data: LACHENAIE, NACL. 


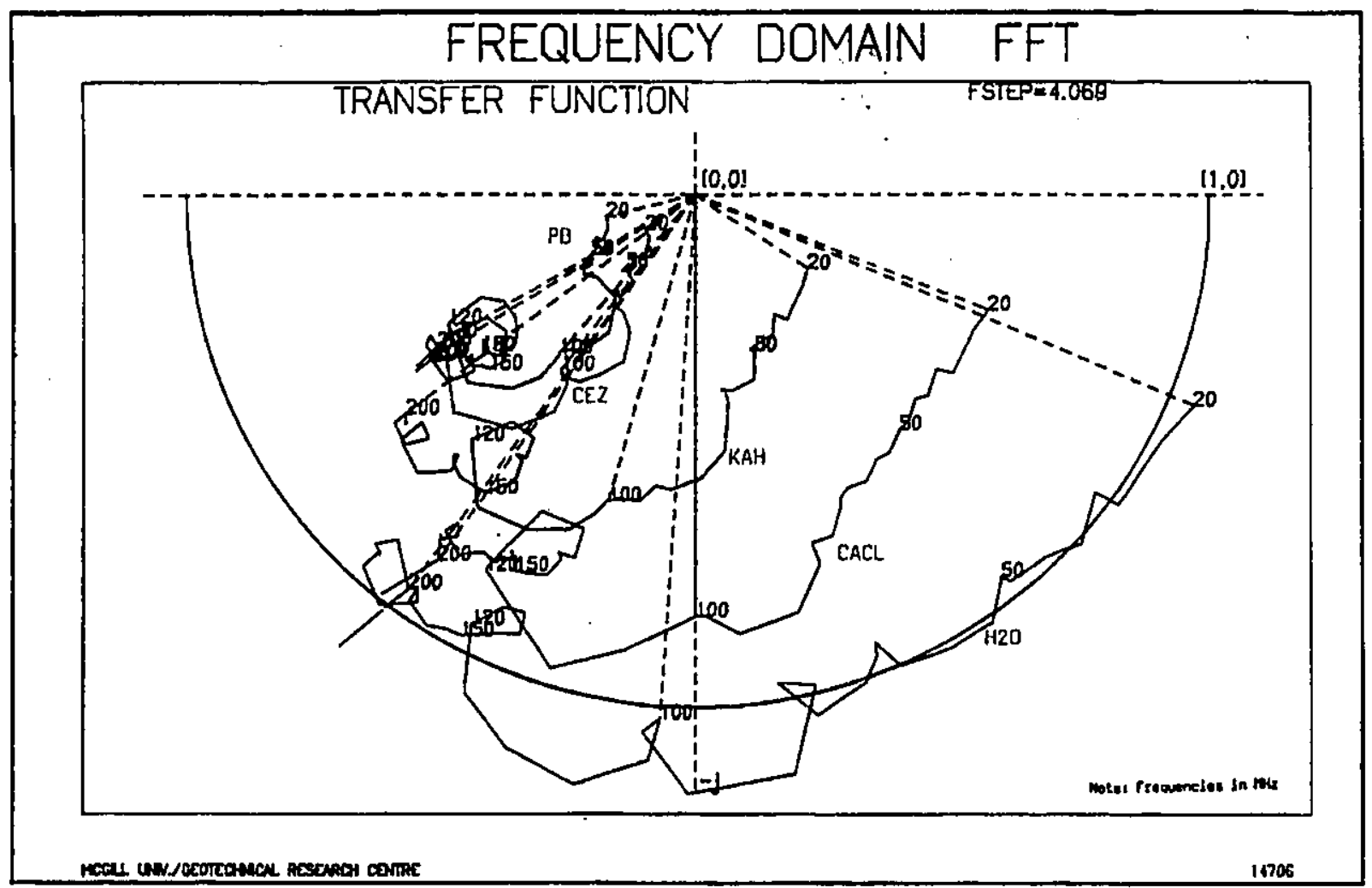

Figure 4.21 Transfer Function : PB, CEZ, KAH, CACL, H2O.

The concept of employing the transfer function in the contaminant detection has been reported by Yong and Hoppe (1989). The previously published material is included in the Appendix 2. It was realized, however, that while a visual presentation in terms of a transfer function expressed by polar coordinates provides a qualitative insight of the polarization phenomenon, it does not render itself well to the task of quantifying numerous test results. It is evident that in polarization measurements both magnitude and phase contain significant information. Much of the useful information is contained in the phase spectrum, yet phase is routinely susceptible to noise, particularly at high frequencies. It leads to a common difficulty in analyzing the polar coordinate transfer function, as manifested by the presence of "loops". Nevertheless, when visually comparing graphs such as Figure 4.23 and Figure 4.24, there appear to be some distinctive 


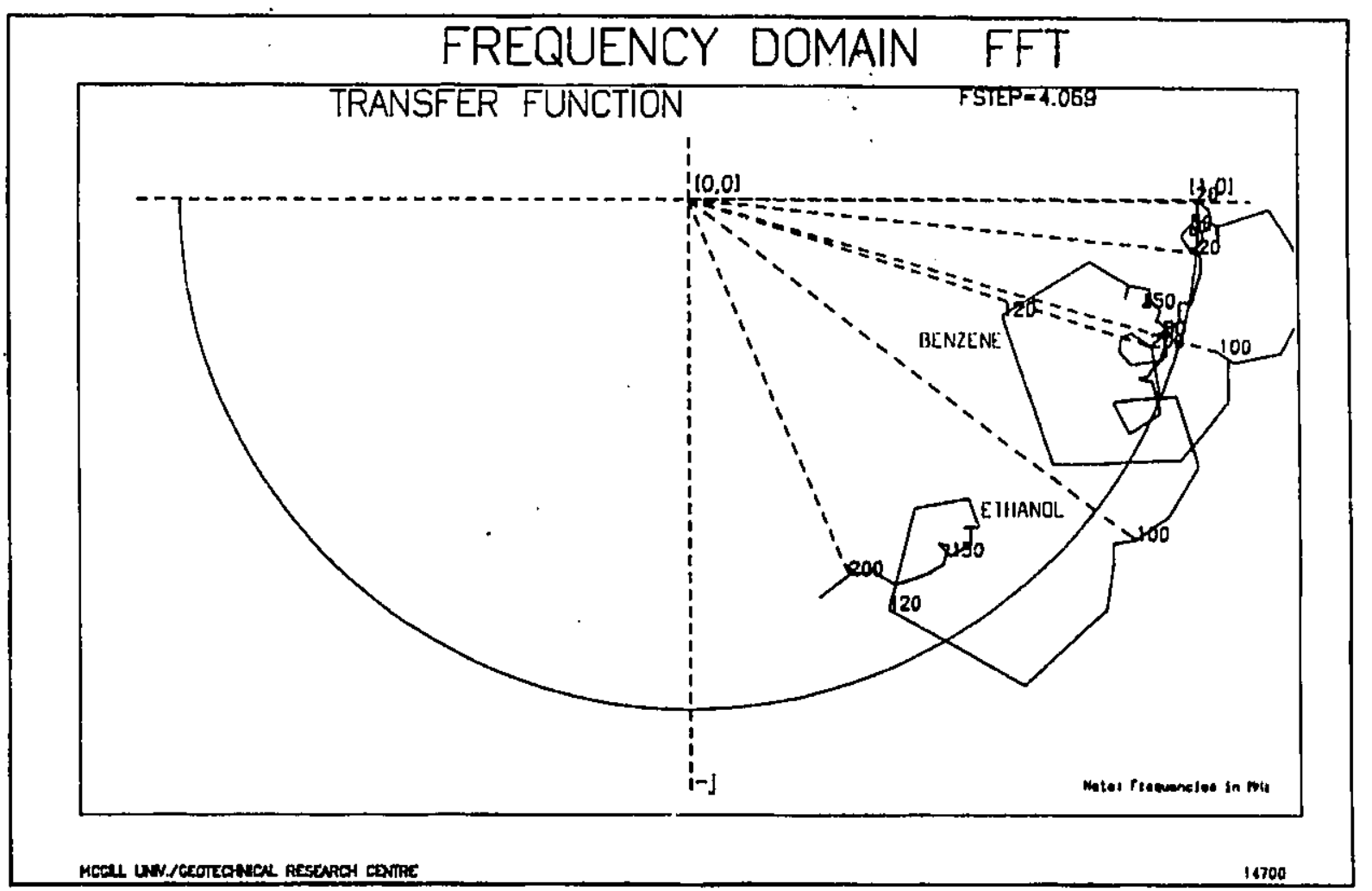

Figure 4.22 Transfer Function : BENZENE, ETHANOL.

similarities amongst each group of "contaminants". Clearly, some systematic approach to quantifying these test results for a subsequent matching of known and unknown responses is needed to facilitate the contaminant detection.

The approach to data analysis proposed in this study involves the application of the coherence function. The complex coherence function is a normalized complex cross power spectral density function (Carter, 1972) given by:

$$
\Gamma(f)=\frac{S_{x y}(f)}{\sqrt{S_{x x}(f) S_{y y}(f)}}
$$

where $S_{x x}(f)$ and $S_{y y}(f)$ are the power spectral densities of $s_{x}(t)$ and $s_{y}(t)$ respectively and $S_{x y}(f)$ is the cross-power spectral density. 


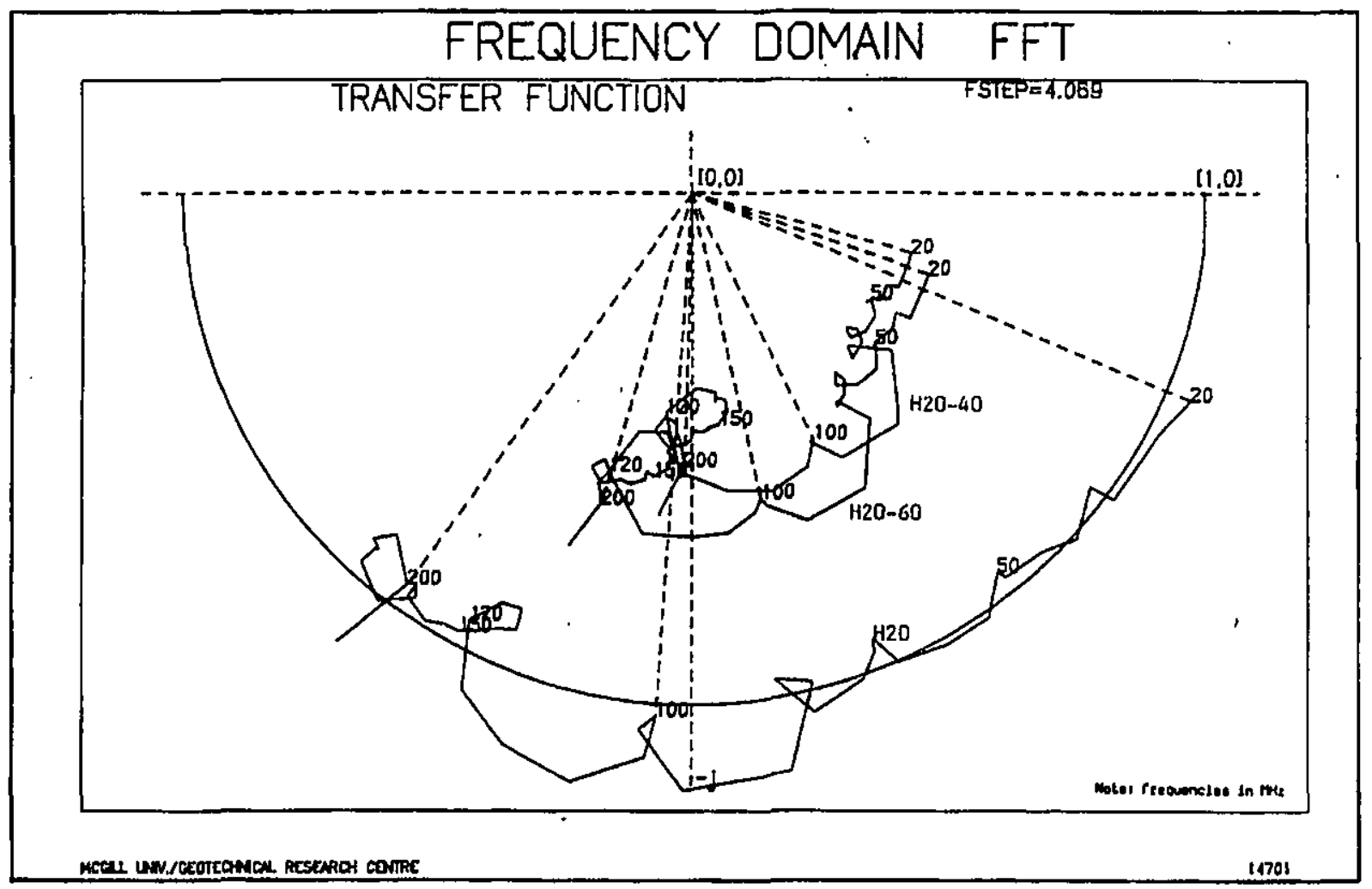

Figure 4.23 Transfer Function : H2O, H2O-40, H2O-60.

The magnitude of the complex coherence function is:

$$
|\Gamma(f)|=\frac{\left|S_{x y}(f)\right|}{\sqrt{S_{x x}(f) S_{y y}(f)}}
$$

It follows directly that the square of the magnitude of the complex coherence function is:

$$
|\Gamma(f)|^{2}=\frac{\left|S_{x y}(f)\right|^{2}}{S_{x x}(f) S_{y y}(f)}
$$

The term "coherence" usually refers to equation 4-7. It should be noted that given only one set of waveforms $s_{x}(t)$ and $s_{y}(t)$ the magnitude-squared coherence $=1$. Consequently, the estimate is biased, depending on the nuraber of sets of waveforms 


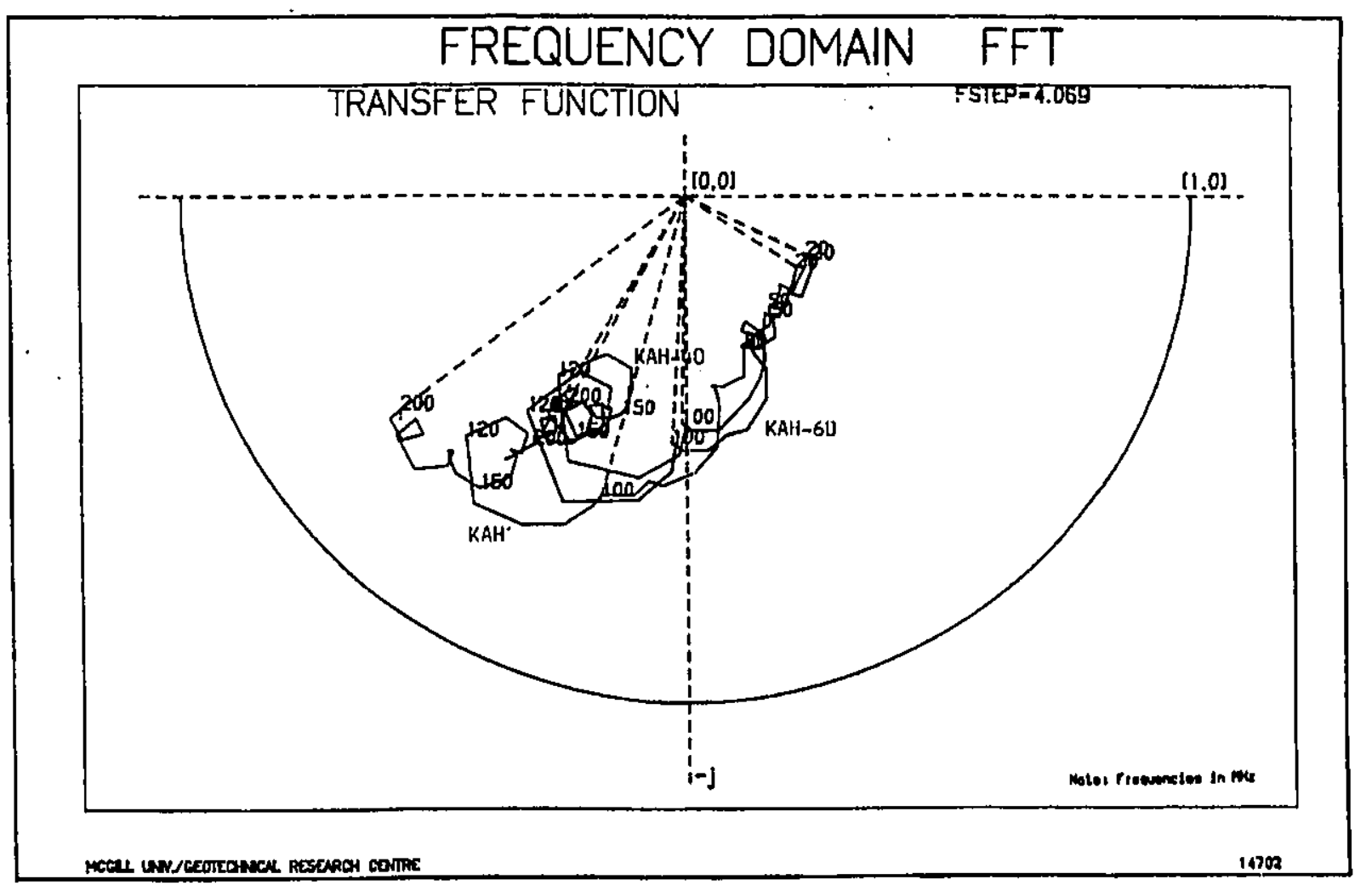

Figure 4.24 Transfer Function : KAH1, KAH1-40, KAH1-60.

that are subsequently averaged. In practice the number of acquisitions of $s_{x}(t)$ and $s_{y}(t)$ from a particular measurement setup should be as large as practicable to produce a meaningful estimate of the magnitude-squared coherence. Thus the magnitude-squared coherence function (MSC) of two signals $s_{x}(t)$ and $s_{y}(t)$ may be expressed as:

$$
\Gamma^{2}(f)=\frac{\left|<S_{x y}(f)>\right|^{2}}{<S_{x x}(f)><S_{y y}(f)>}
$$

where $S_{x x}(f), S_{y y}(f)$, and $S_{x y}(f)$ are each obtained by averaging over a number of data acquisitions.

The MSC always falls between zero and one. It is zero when the waveforms $s_{x}(t)$ and $s_{y}(t)$ are uncorrelated. It is equal to unity if and only if there exists a linear relation between $s_{x}(t)$ and $s_{y}(t)$. The main applications of the MSC function are as follows: 


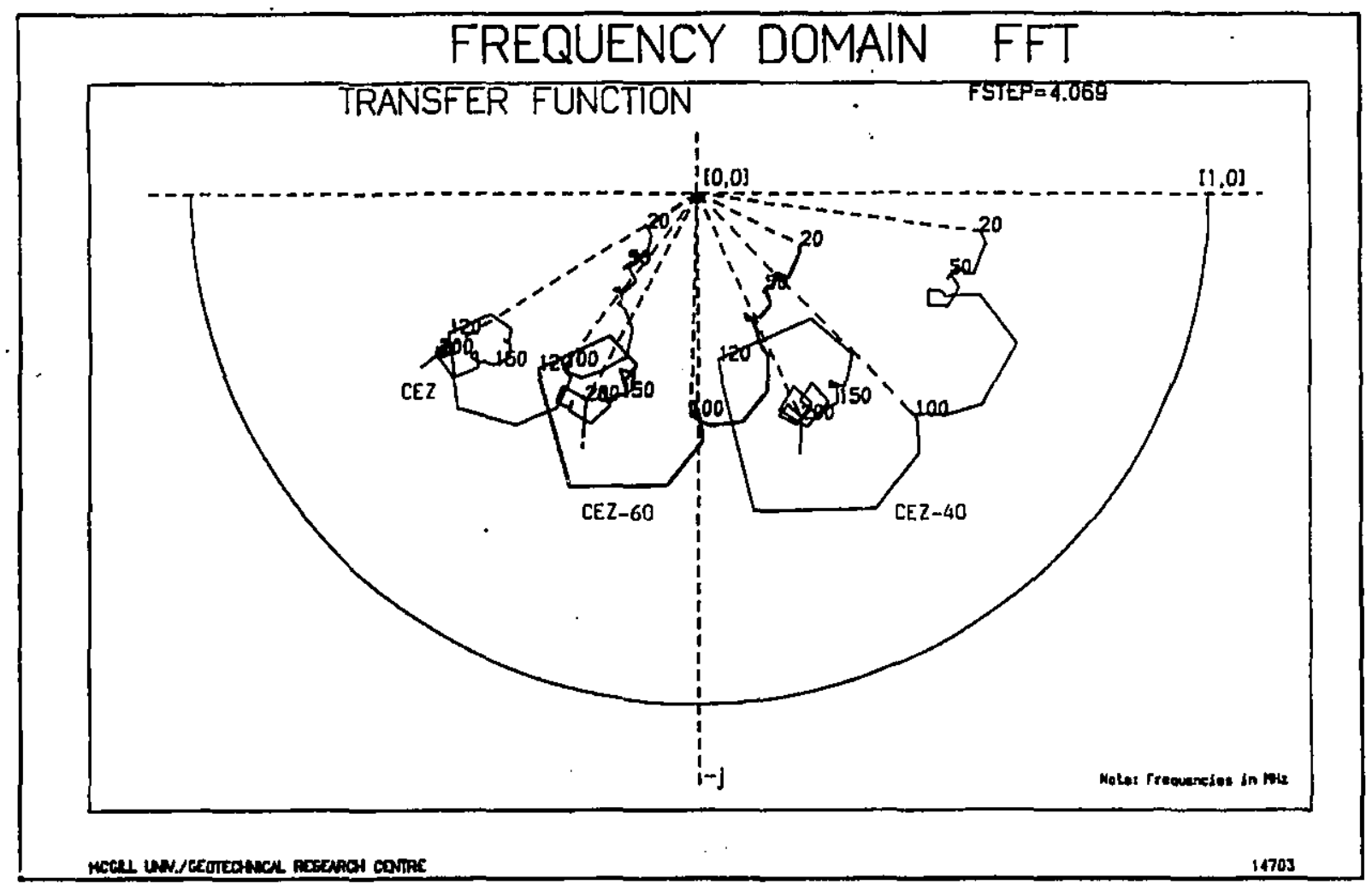

Figure 4.25 Transfer Function : CEZ, CEZ-40, CEZ-60.

- a measure of system linearity.

- a measure of correlation.

- a measure of signal to noise ratio.

The utility of the coherence function is demonstrated in Figures 4.26 and 4.27. It is assumed that a system is subjected to an input signal with a spectral content of $F_{x}(f)$, resulting in a corresponding output signal $F_{y}(f)$. Subsequently, another test is performed on the same system using an input signal $G_{x}(f)$ which results in $G_{y}(f)$. Nonlinearity and phase distortion are introduced to demonstrate the impact on the coherence. It is evident from the hypothetical example that at a given frequency $f$ it is only when the individual estimates of the cross spectrum $S_{x y}(f)$ have exactly the 
same phase angle and the system is linear, that the coherence equals to 1 . In such a case the vector addition used to form the mean of the cross spectrum gives the same modulus as scalar addition of the power spectrum products, resulting in the $\Gamma$ of unity. The practical implication of equation $4-8$ is that if the signals are statistically same then their coherence equals to 1 .

Typical applications of the coherence function in signal processing seek to determine the extent to which the output signal is caused by the input signal, which provides a measure of the validity of the transfer function. The coherence function has been used extensively in the undersea acoustic applications, particularly in situations where a signal source is in motion in a transmission medium (Gerlach, 1980).

A practical linear system is characterized by a coherence function which typically approaches 1 at a wide range of frequencies but eventually departs from unity. This stems from the fact that every practical system exhibits a certain amplitude bandwidth over which all frequency components are amplified or attenuated equally and a certain phase bandwidth over which the phase change is directly proportional to frequency (Lewis and Wells, 1954). Excessive amplitude and phase distortion render the physical interpretation of the measured phenomena unreliable beyond this bandwith.

The application of the coherence function is illustrated in Figures 4.28 through 4.34. Two separate TDR records (Soil 1 and Soil 2), obtained from replicate measurements on a dry soil, are shown and further operations involving preparation of the time-domain data, calculation of the power spectra, cross spectra and transfer functions are illustrated. Figure 4.34 shows the resulting coherence function between the input and the output waveforms (equation 4-8) of both TDR records. The coherence approaches 1 over a frequency range extending from 0 to about $200 \mathrm{MHz}$, which agrees with the bandwith estimate obtained from the risetime of the incident pulse. It may be concluded that the transfer function of this system is valid in the frequency range of 0 to $200 \mathrm{MHz}$ with a given measurement setup. 


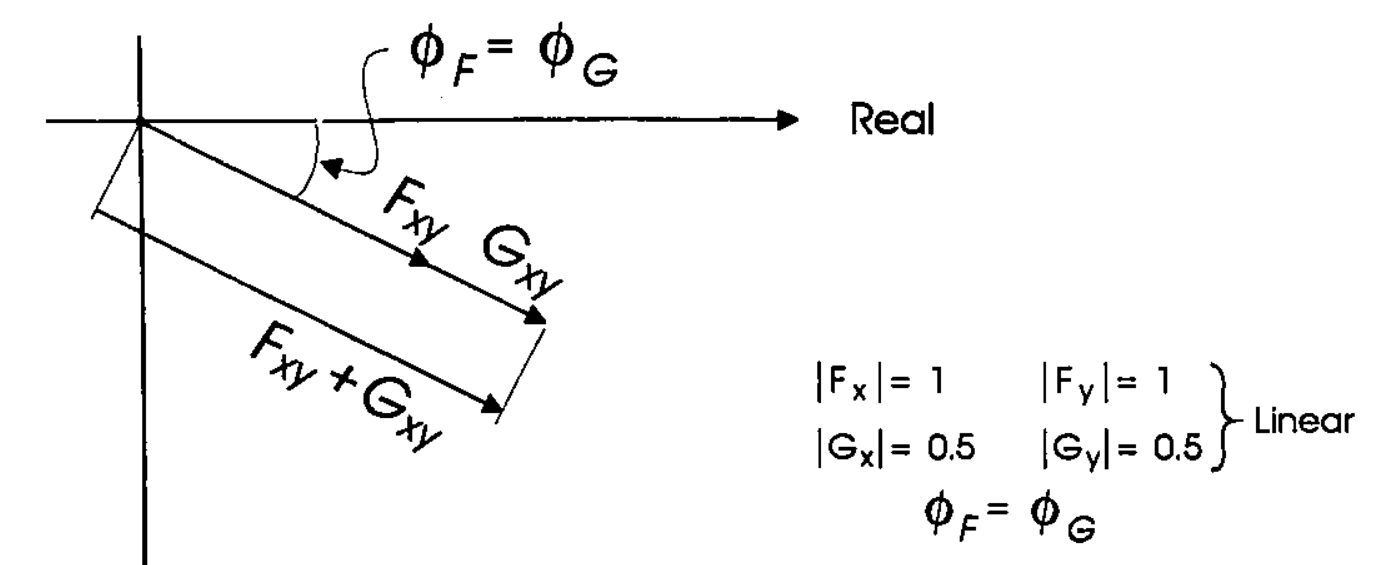

Numerator: $\left|F_{x y}+G_{x y}\right|^{2}=(1+0.25)^{2}=1.25^{2}$

Denominator: $\left[F_{x x}+G_{x x}\right]\left[F_{y y}+G_{y y}\right]=\left[1^{2}+0.5^{2}\right]\left[1^{2}+0.5^{2}\right]=1.25^{2}$

Imaginary

COHERENCE $=1$

(a)

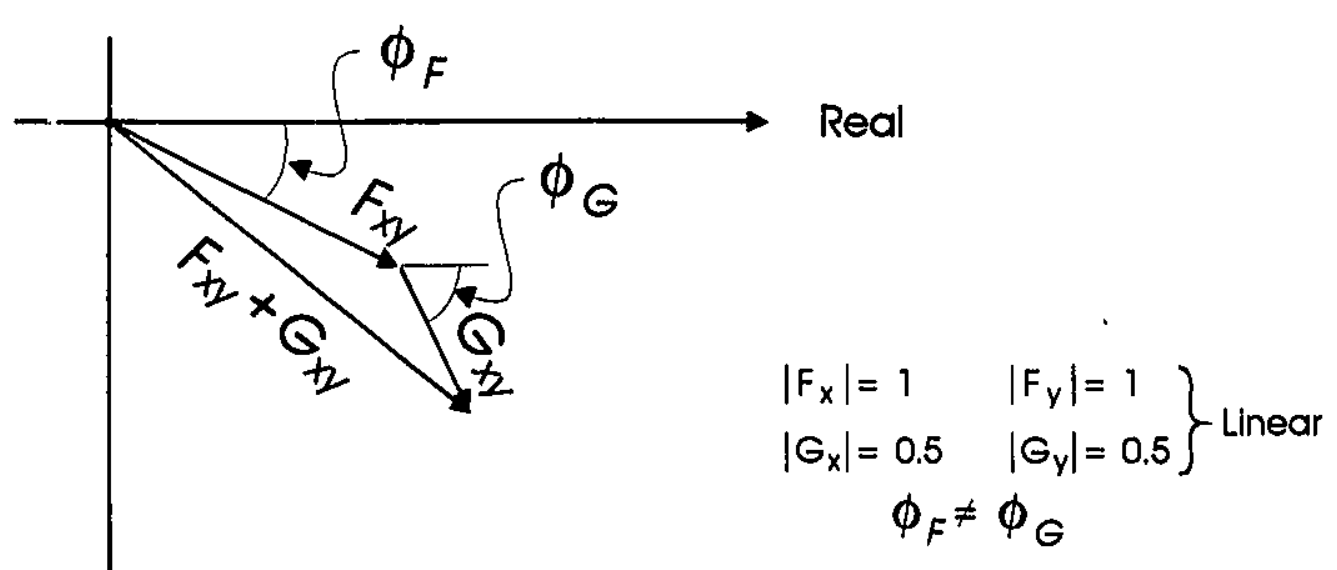

Numerator: $\left|F_{x y}+G_{x y}\right|^{2}<1.25^{2}$

Denominator: $\left[F_{x x}+G_{x x}\right]\left[F_{y y}+G_{y y}\right]=1.25^{2}$

Imaginary

COHERENCE $<1$

(b)

Figure 4.26 The Influence of Phase Angle on Coherence. 


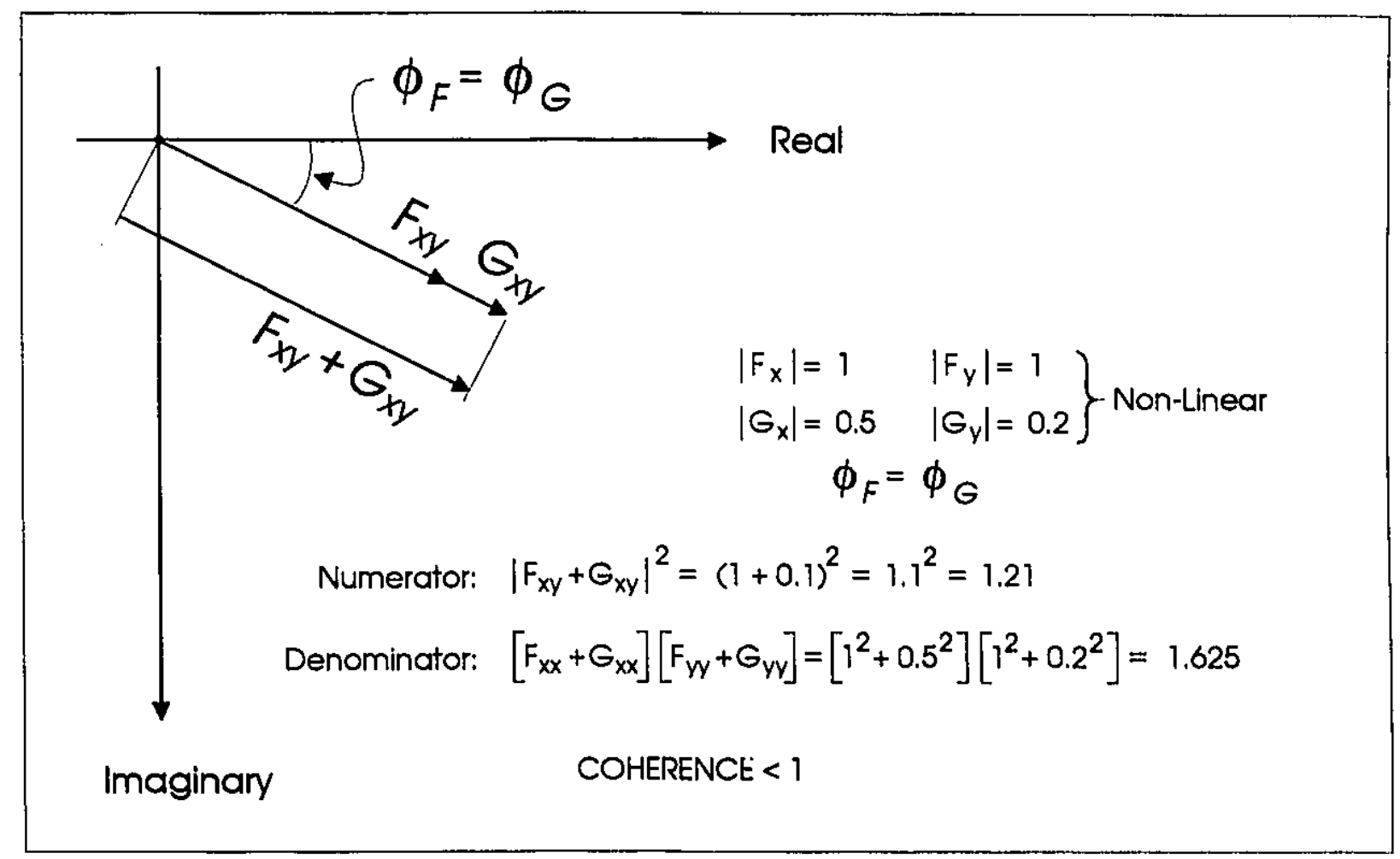

(a)

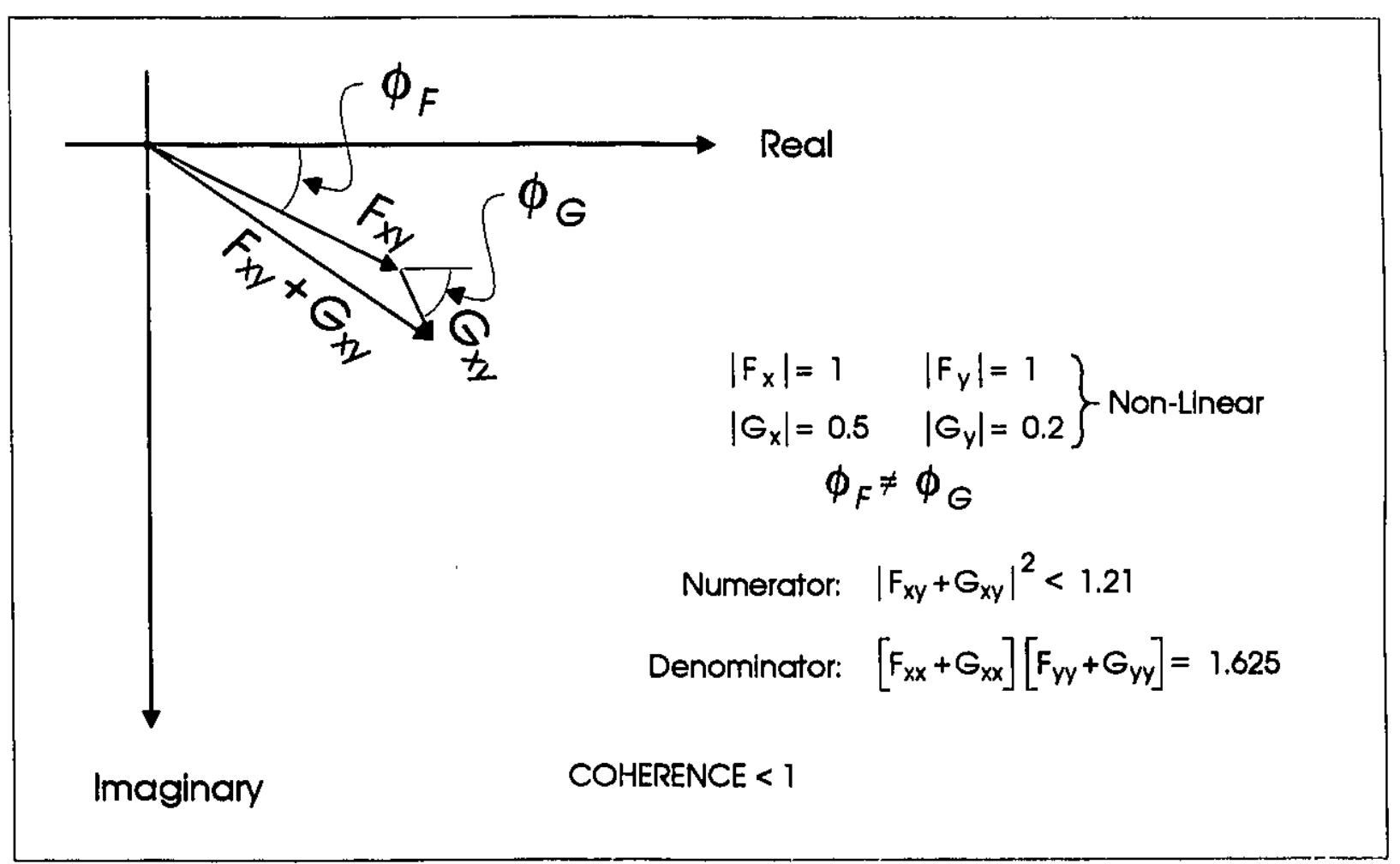

(b)

Figure 4.27 The Influence of Magnitude on Coherence. 

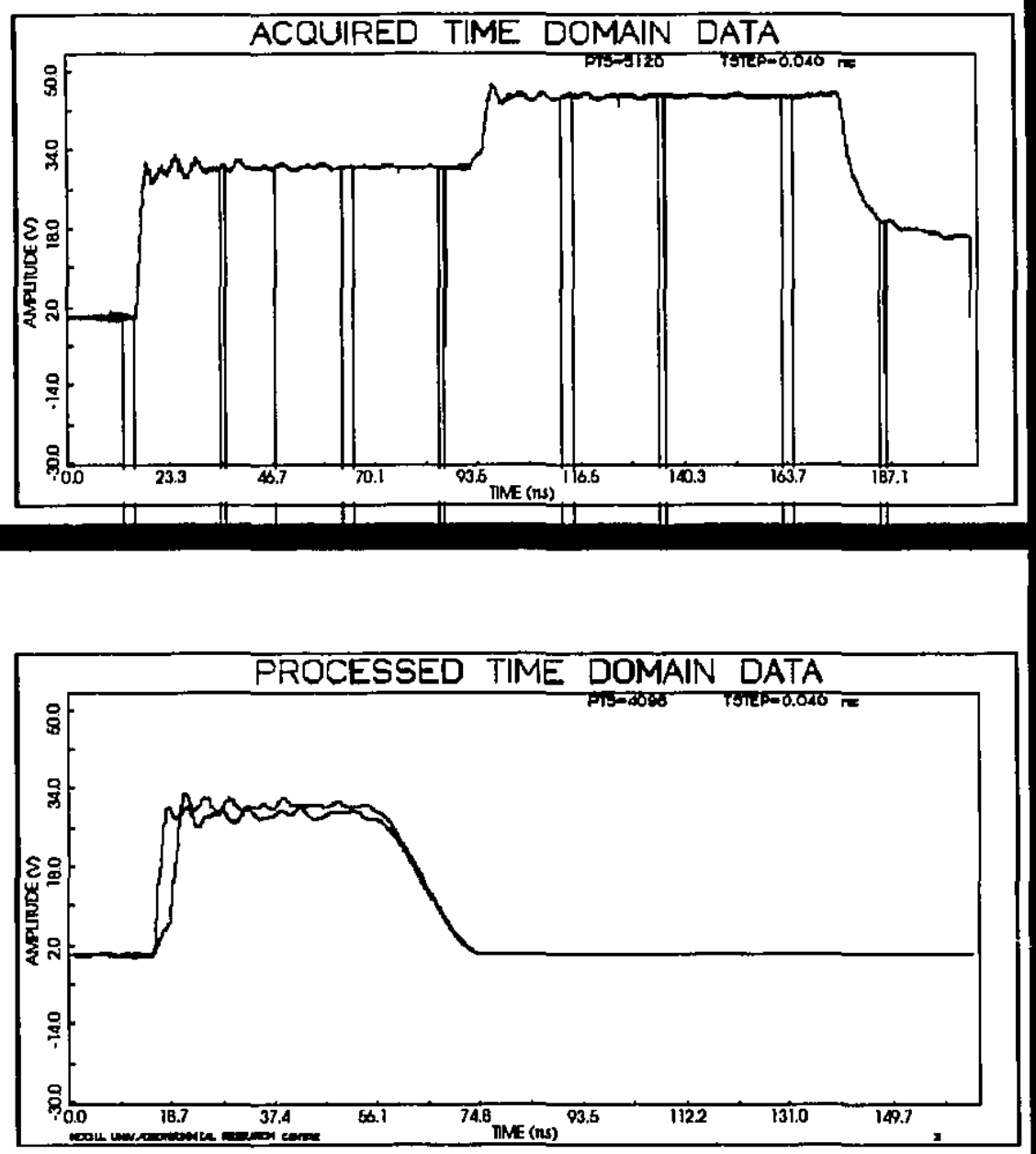

\section{FREQUENCY DOMAIN \\ FFT of Input \\ Soil 1}

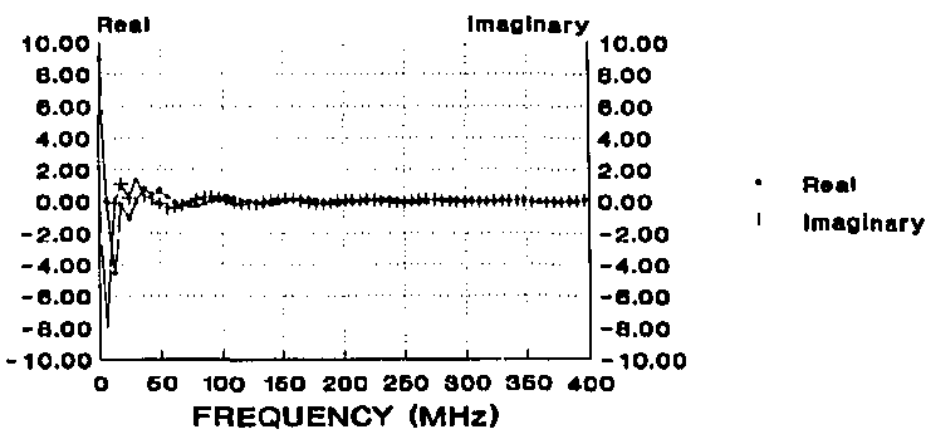

Figure 4.28 Soil 1: Time-Domain Data and FFT of Input. 


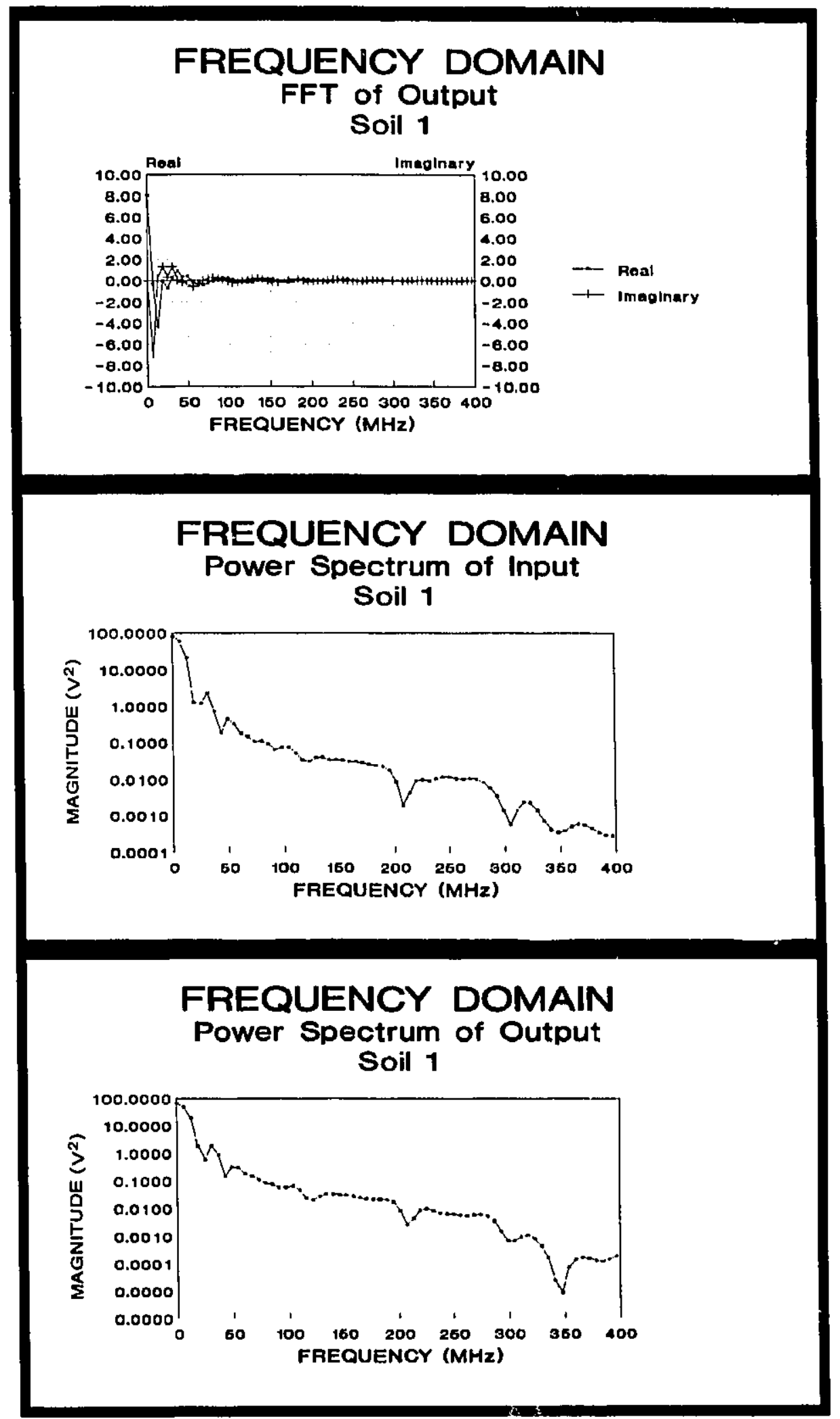

Figure 4.29 Soil 1: FFT of Output and Power Spectra. 


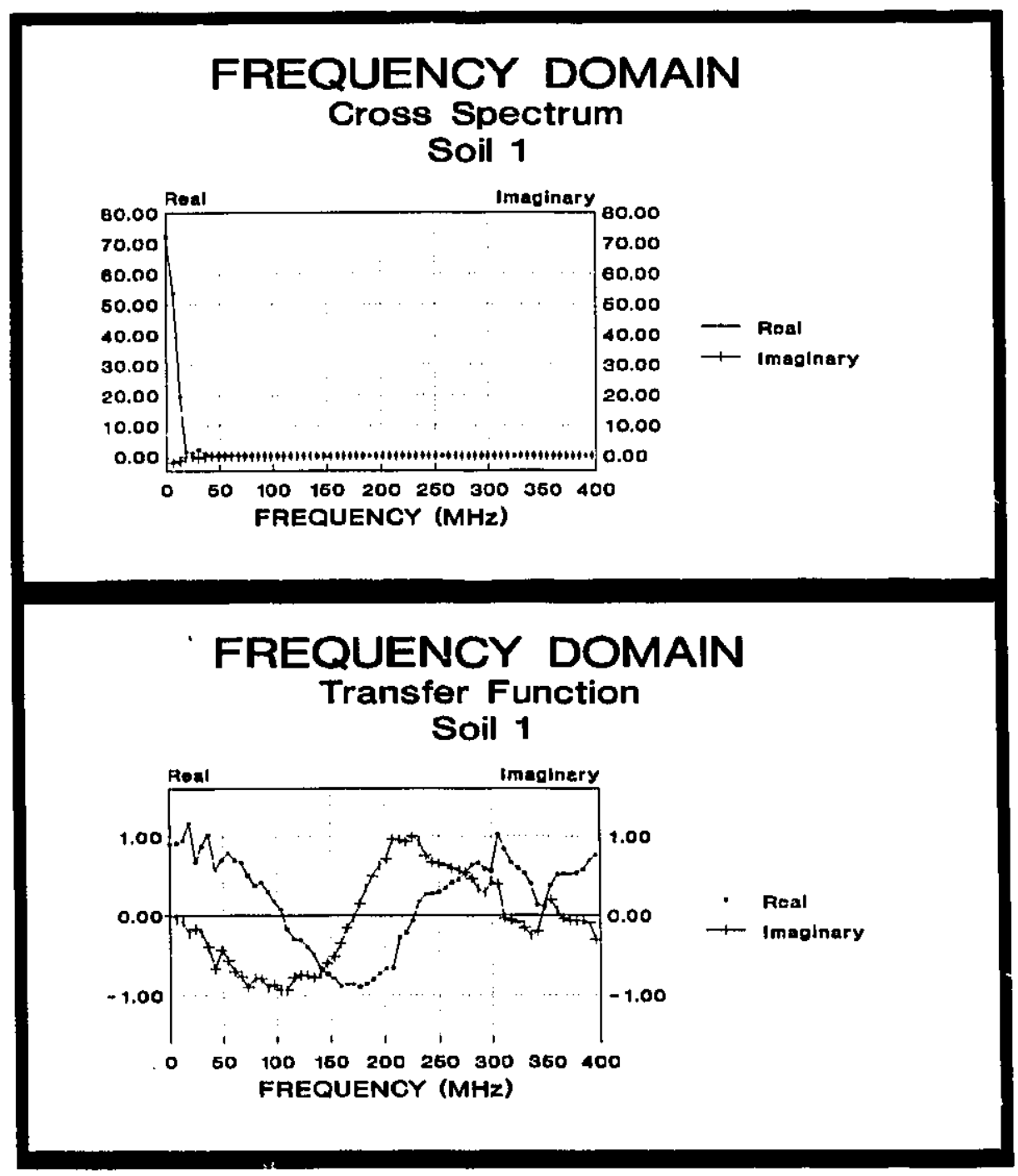

Figure 4.30 Soil 1: Cross Spectrum and Transfer Function. 

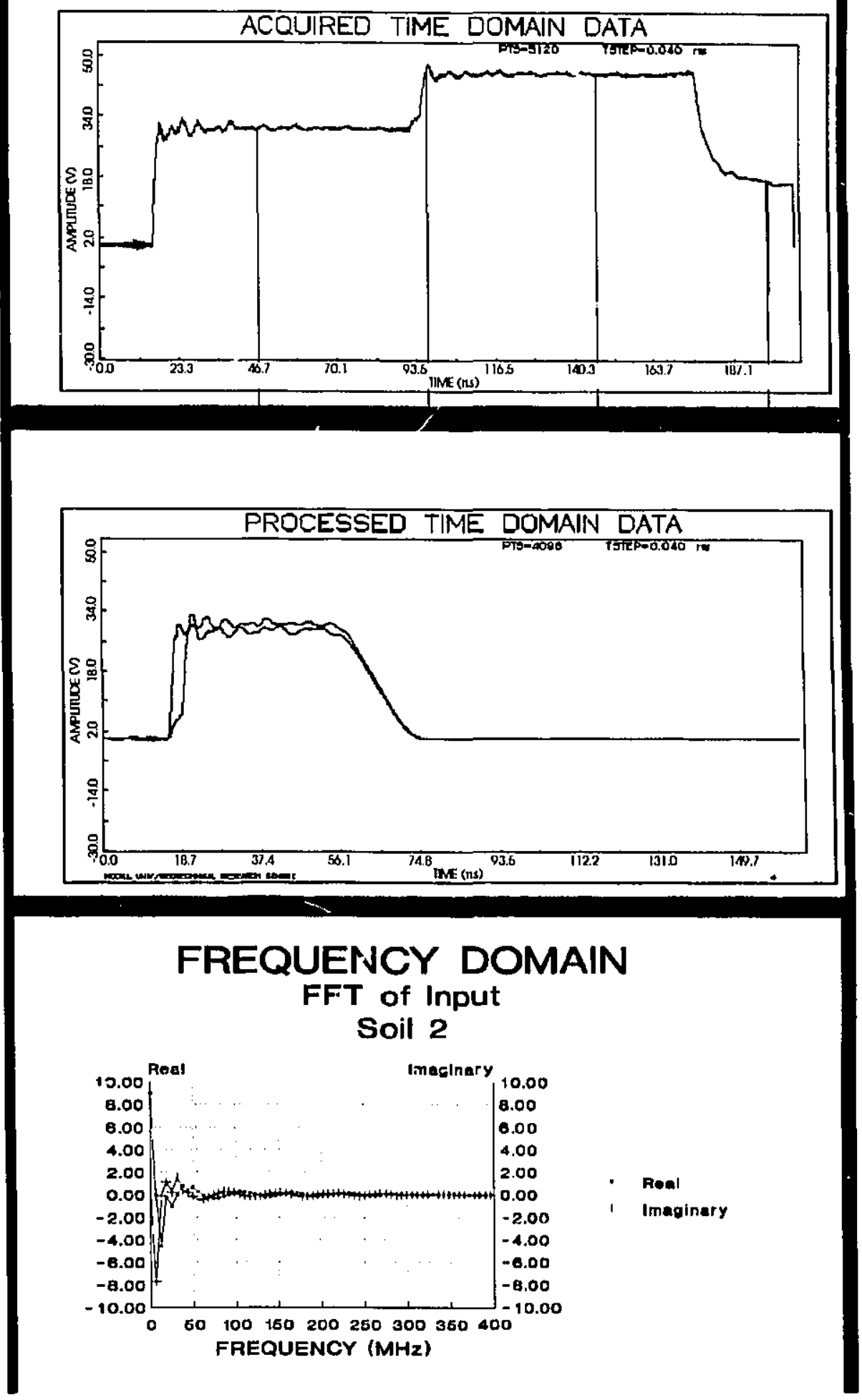

Figure 4.31 Soil 2: Time-Domain Data and FFT of Input. 


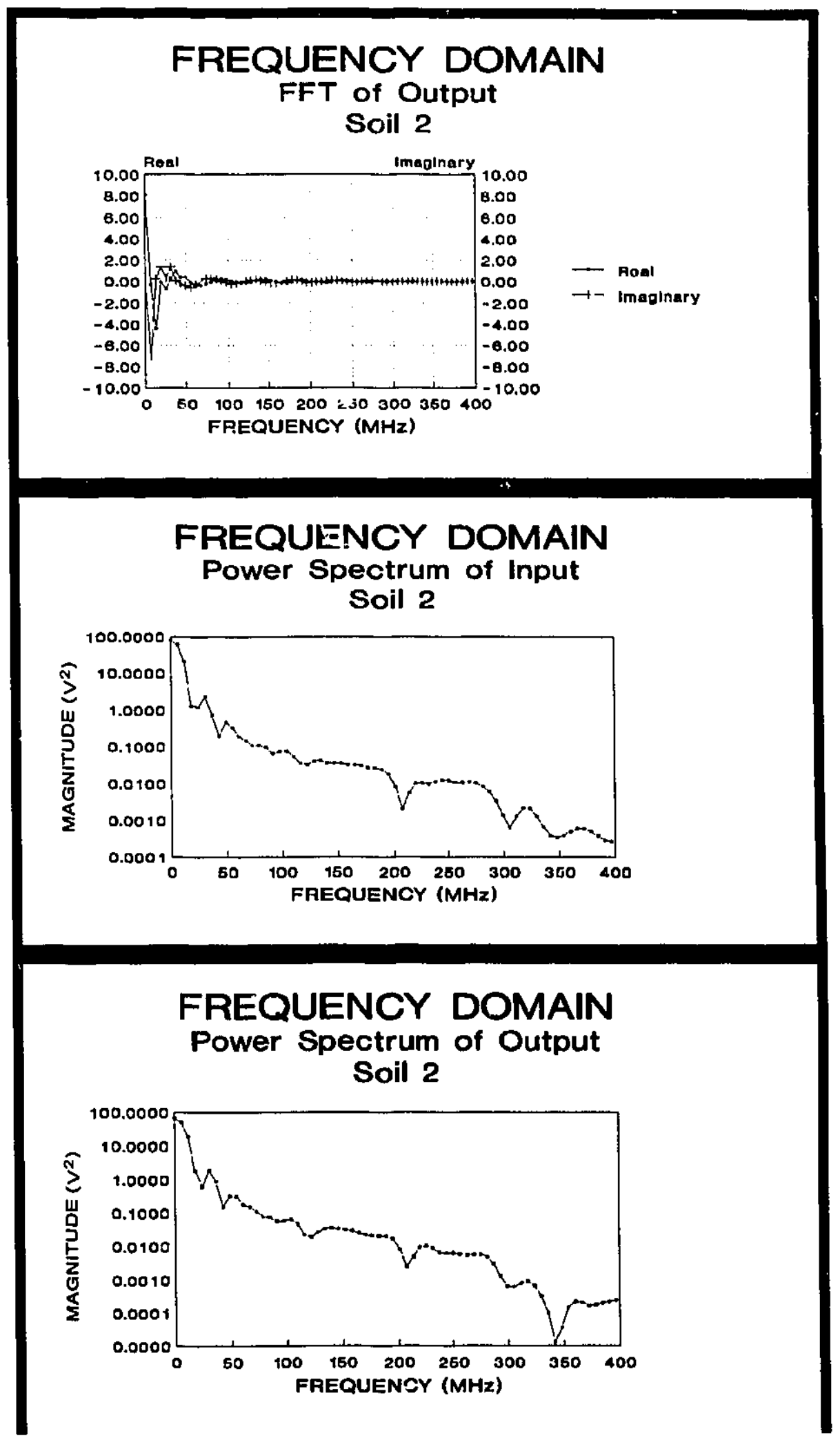

Figure 4.32 Soil 2: FFT of Output and Power Spectra. 


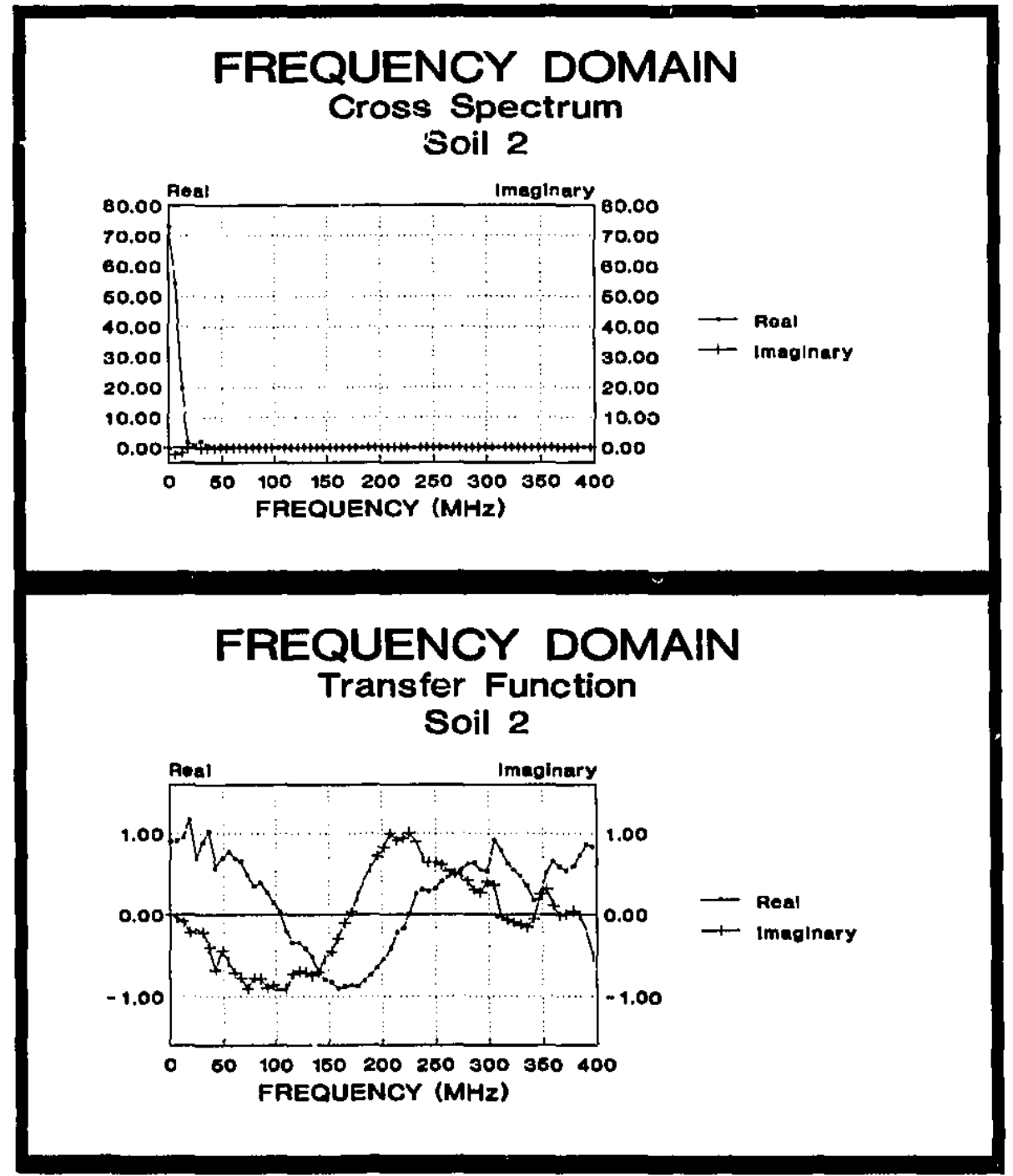

Figure 4.33 Soil 2: Cross Spectrum and Transfer Function. 


\section{FREQUENCY DOMAIN COHERENCE FUNCTION 2 TDR RECORDS OF DRY SOIL}

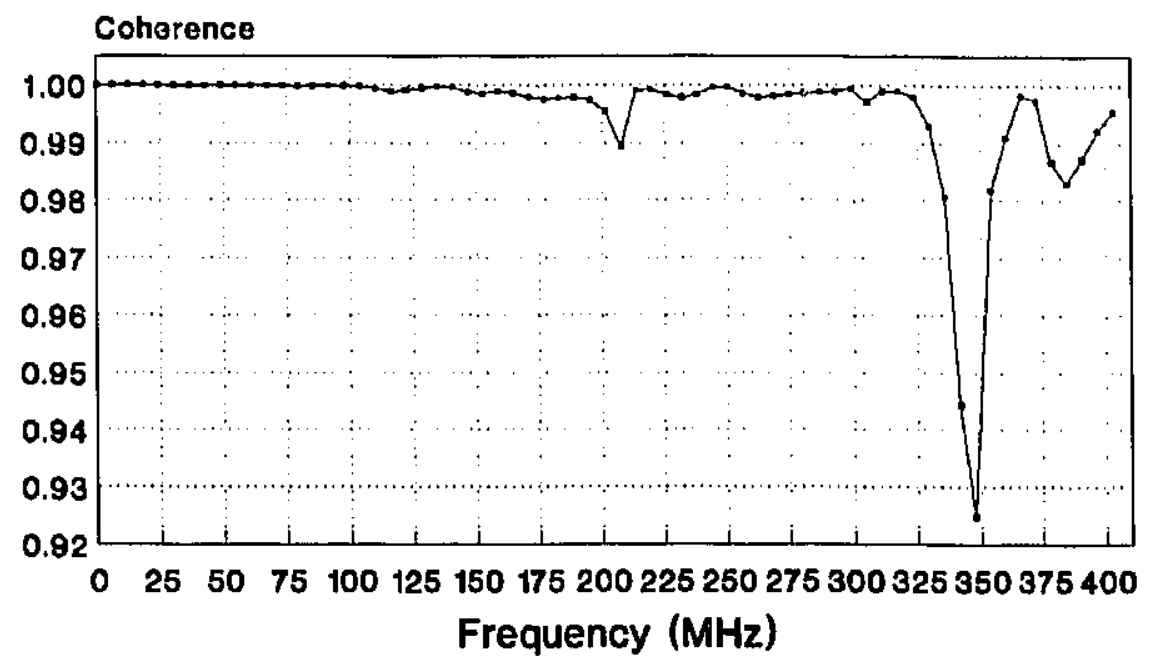

Figure 4.34 Coherence Function Between Dry Soil 1 and Dry Soil 2.

It is also evident that for the coherence to equal unity, the individual transfer functions and hence the systems must have been identical in the corresponding frequency range. Therefore, it follows that a quantitative comparison of transfer functions may be accomplished by computing the coherence between the input and the output waveforms.

In a practical application to a leakage occurring from a point source, a contaminant detection in soil may be achieved as follows:

- obtain representative fluid samples from an underground storage tank or a landfill leachate. 
- obtain representative soil samples.

- conduct laboratory TDR measurements on a number of soil-contaminant mixtures and create a database set of known TDR records.

- conduct field TDR measurements by probing areas suspected of contamination and create a test set of unknown TDR records.

- compute the coherence function using unknown and known records. In a perfect match the coherence would equal to 1 over an effective frequency bandwith.

The principal advantage of the above approach is that the entire process of data analysis can be fully automated using a portable computer. It also climinates the need for a manual handling and the uncertainty of visual comparisons.

In a real life situation no amount of laboratory testing will ever duplicate all the possible permutations encountered in the field. Thus the essence of the matching process is the determination of the most likely association between an unknown TDR "signature" and a waveform traceable to a particular contaminant. Obviously, the closer the match the larger the coherence. The problem entails matching the test signal with a database of signals obtained from known contaminants and soil-contaminant mixtures. Given a field TDR record transformed into its constituent input $G_{x}(f)$ and output $G_{y}(f)$ waveforms, and a known TDR record transformed into $F_{x}(f)$ and $F_{y}(f)$, a calculation of their coherence indicates if the association is likely.

The frequency range used in the matching procedure needs to be established in advance. This may be accomplished by acquiring a number of TDR records from each test and computing the coherence function as defined in equation 4-8. Obviously, the frequency range used to compare different TDR records must not exceed the range over which the ccherence approaches 1 for individual records.

The expected estimation error in coherence is dependent on the number of individual data acquisitions. The relationship for the expected estimation error or bias in 
computing the ISSC was found by Benignus (1969) to be:

$$
\text { Bias }=\frac{1}{n}\left(1-\Gamma^{2}\right)
$$

where $n$ corresponds to a number of records.

It should be noted that:

$$
\lim _{n \rightarrow \infty}(\text { Bias })=0
$$

The application of the coherence function in this study seeks to answer the question: To what extent does a given test TDR record match a given database TDR. record? A flow chart for performing an automated waveform matching based on the above concept is presented in Figure 4.35. The corresponding Fortran computer source code is included in the Appendix 1. In the process of comparing an unknown record ("unknown contaminant") with each database record ("known contaminant") a single parameter descriptor of the fit is introduced. It represents an integration of coherence values substracted from unity, over a frequency range of interest. In a perfect match this descriptor would equal to zero.

The proposed contaminant match procedure addresses a well known TDR problem of identifying an appropriate time reference at which the record is split into its constituent input and output waveforms. This step is essential in accounting for phase differences between various output waveforms. In practical measurements it is often difficult to determine precisely at what point the incident signal ends and the reflected one begins, as illustrated in Figures 4.7 through 4.13. To establish this "cut point", a TDR record of an empty soil probe was analyzed. Since it describes an essentially open circuit termination, involving an infinite resistance and a negligible capacitance, the most appropriate "cut point" is the one that results in a transfer function with minimum phase shifts (all frequencies are transferred in phase in the ideal open circuit termination). After determining this "cut point", it was time referenced to the leading 


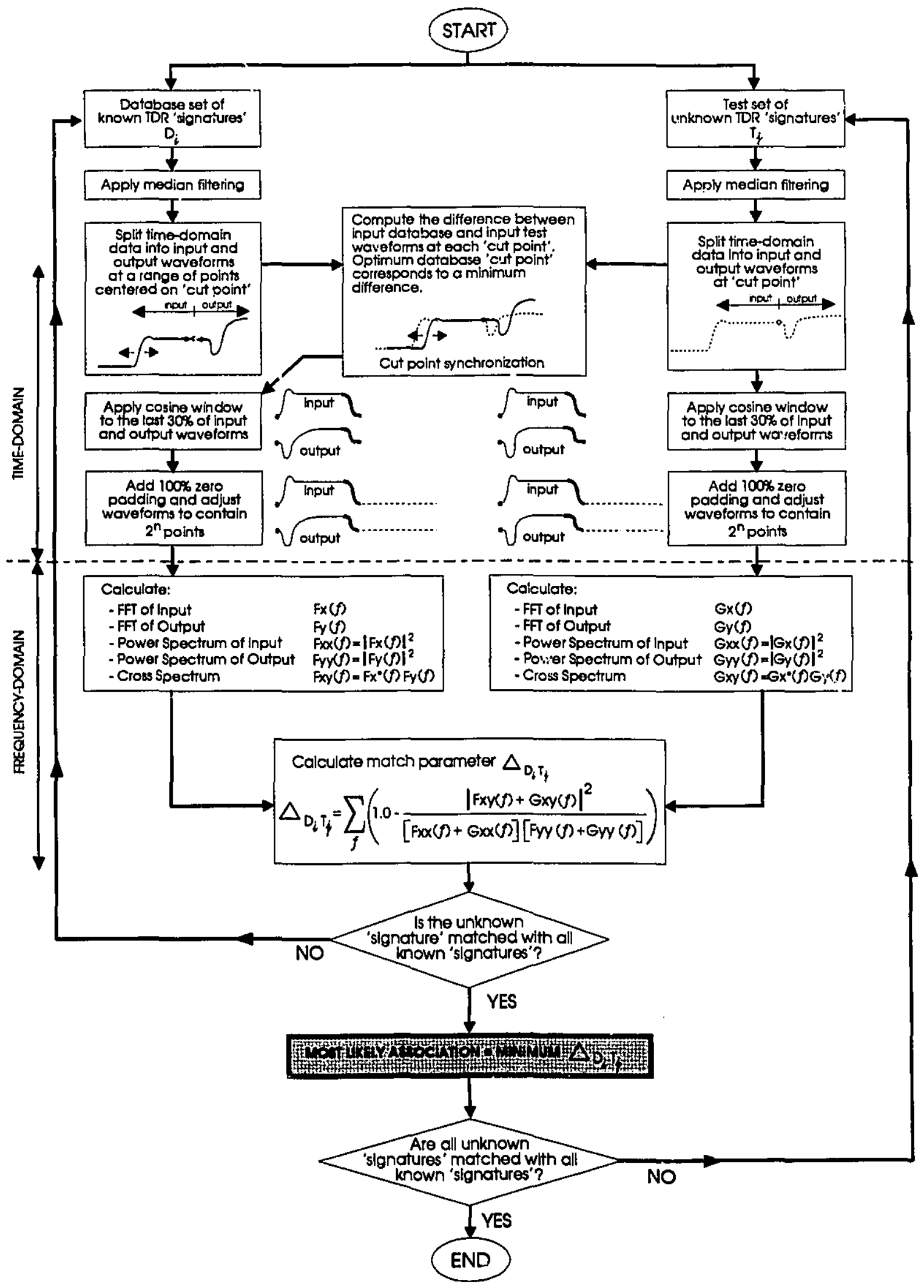

Figure 4.35 Proposed Contaminant Match Procedure. 
edge of the incident pulse. As long as the measuring network maintains its geometry, the time between the leading edge of the incident pulse and the "cut point" will always be the same. Thus, if some TDR records are acquired with a different length of the pretrigger data, they can still be time referenced to each other. The approach described in Figure 4.35 irrvolves time-domain matchirg of the leading edges of incident waveforms. When the leading edges are synchronized so that the difference between the incident waveforms is minimized then their respective "cut points" are also synchronized.

After a TDR record is split at a "cut poini", the resulting input and output waveforms are adjusted prior to implementing the Fast Fourier Transform. These adjustments include windowing, zero padding and appending data to obtain $2^{n}$ data points (4096 in this study). The reasons for these operations were described previously.

The application of the FFT results in the transformation of data into a set of complex numbers expressed as a function of frequency. Additional operations described in Figure 4.35 include the computation of the power spectrum, which involves a multiplication of the FFT output by its complex conjugate and the cross spectrum, or a conjugate multiplication of input and output spectra. These operations constitute intermediate steps needed to compute the coherence.

The coherence is calculated over a specified frequency range. At each of the specified frequencies the value of coherence is substracted from 1 . These values are subsequently integrated to arrive at the single match parameter indicative of the degree of association. The lesser the match parameter the higher the coherence and the closer the association.

To evaluate the concept of coherence matching, two identical sets of data, consisting of the previously acquired TDR records, were created. One set was considered a database of known "signatures" and the other was assumed an "unknown" set. The procedure outlined in Figure 4.35 was subsequently applied. The main objective of this operation was to determine if records from soils containing various concentrations of 
the same contaminant form the most likely associations. Thus, each element $i$ from the "known" set was matched with each element $j$ from the "unknown" set. The output of the coherence matching program is presented in Tables 4.2 through 4.8 . The frequency range of interest is $6.10 \mathrm{MHz}$ (first harmonic) to $201.42 \mathrm{MHz}$ (practical limit of the incident signal bandwidth). In each match the \#1 rank corresponds to the simple case of two identical records. Matches ranked \#2 and greater correspond to the successively less likely associations.

\subsection{DISCUSSION OF RESUL.TS}

The time-domain relationship, shown in Figures 4.7 through 4.13 presents various waveforms acquired by the digitizer. It can be seen that the applied step-function is not perfectly rectangular. The initial stage of the incident impulse is affected by ripples, stemming from imperfections in the impulse generator and unwanted reflections in the measuring circuit. It should be noted, however, that the shape of the incident signal and therefore its spectral composition, remains virtually identical in different tests. This attests to a good reproducibility of pulses produced by the mercury contact relay. The reflected voltage step, commencing after approximately 70 nanoseconds, is characteristic of the material being analyzed. Thus, in non-polar liquids such as benzene or ethanol, the reflected waveform practically mirrors the applied waveform. A substantial signal attenuation occurs in highly conductive liquids, such as in CEZ or PB, which contain ions of heavy metals. The initial dip of the reflected impulse, signifies the capacitive influence. The latter part of each waveform approaches a steady value, indicative of the DC resistivity. This dielectric response appears most predominant in the first 4 ns of the reflected waveform.

After transforming the time-domain data into the frequency-domain, using the Fast Fourier Transform, the transfer function is computed by dividing the spectrum of the reflected signal (Output FFT) by the spectrum of the incident impulse (Input 
FFT). The attenuation and phase shift characteristics of individual contaminants and soil-contaminant mixtures are presented in terms of the material transfer function in Figures 4.21 through 4.25. The results are shown in a polar form, with the modulus being the distance from the point of origin to the particular frequency component of the waveform and with the corresponding phase angle measured relative to the positive $\mathrm{x}$-axis. Each transfer function forms a distinctive and unique representation of a particular soil-contaminant system.

The transfer function representation provides a meaningful insight into the material's dielectric behavior. If the charges contained in the material are free to move under the influence of the electric field, the resistance is effectively independent of the frequency of the applied signal, but if these charges are bound, as in oscillating dipoles, the resistance becomes a characteristic function of frequency. This pattern manifests itself readily in the transfer function. It is worth noting the similarity of Figures 4.21 through 4.25 to the general behavior of the dielectric constant illustrated in Figure 3.3.

It can be seen that the transfer function exhibits a different signature for different contaminants. In a practically non-polar material, such as benzene (Figure 4.22), the phase shift and attenuation of different frequency components are minimal. The transfer function reflects the combined influence of the dielectric constant and resistivity of a given material, and thus the response of benzene $(\epsilon=2.3)$, ethanol $(\epsilon=31.2)$ and distilled water $(\epsilon=80)$ illustrate the trend of an increasing dielectric constant and a decreasing resistivity.

Although the polar plot of the transfer function offers a good visual representation of the polarization phenomena, it does not render itself well to an identification of the most likely matches between various signals. It illustrates, however, that both magnitude and phase contain characteristic descriptions of the tested material. The coherence function may be employed to account for both of these descriptors in a numerical fashion, allowing an effective comparison. 
The results of the proposed contaminant match procedure are presented in Tables 4.2 through 4.8 . The optimum database "cut point" and a match parameter are listed. A perfect match of a test waveform with a database waveform was obtained between the following materials:

- $\mathrm{H} 2 \mathrm{O}-40$ and $\mathrm{H} 2 \mathrm{O}-60$

- $\mathrm{H} 2 \mathrm{O}-60$ and $\mathrm{H} 2 \mathrm{O}-40$

- PB-40 and PB-60

- PB-60 and PB-40

- KAH1-40 and KAH1-60

- KAH1-40 and KAH1

- KAH1-60 and KAH1-40

- KAH1-60 and KAH1

Associations involving BENZENE, ETHANOL, LACHEN, and NACL test waveforms were reasonable given the selection of the database set. BENZENE was matched with OPEN (empty probe), ETHANCL with BENZENE, LACHEN with CACL, and NACL with CACL.

An illustration of the coherence matching concept is presented in Figure 4.36. It demonstrates that a soil contaminated with the leachate collected from the Kahnawaiki landfill site exhibits a higher coherence with the Kahnawaki leachate than with the Lachenaie leachate. As Table 4.6 indicates, KAHi-40 matches most closely with KAH1 when only the contaminants and not the soil-contaminant mixtures are considered in the database set. Relatively poor match results were obtained with soils contaminated by CACL and CEZ. CACL-40 was matched with CEZ-60 and CACL-60 was paired with KAH1-40. A common element in these matches appears to be the $\mathrm{Ca}$ ion in KAH1 and CEZ. Also CEZ-40 was matched with H2O-40 and CEZ-60 with CACL-40. Again, the most common element is the $\mathrm{Ca}$ ion which is the most predominant extractable ion in the soil (see soil description). 


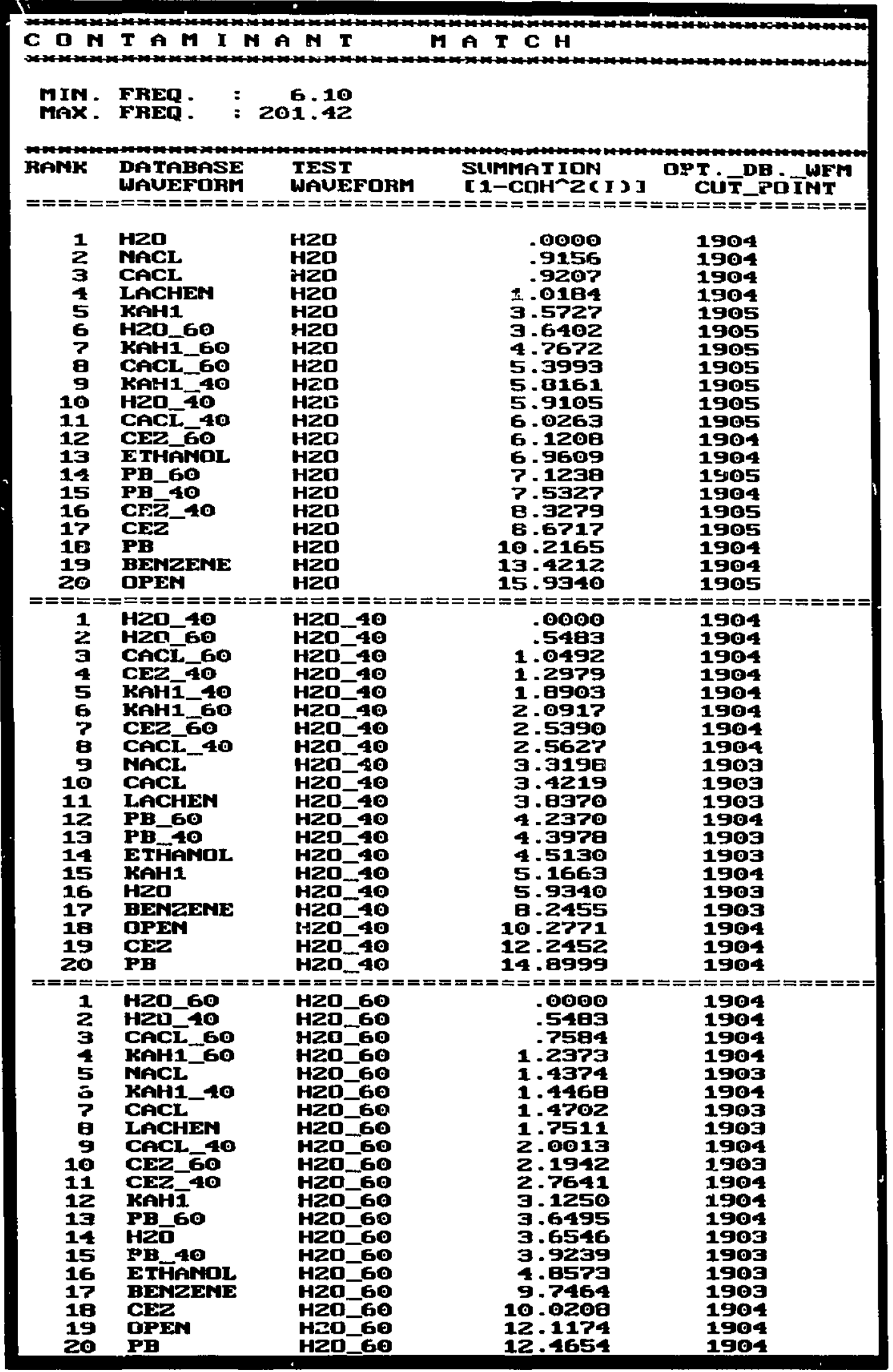

Table 4.2 Contaminant Match Results : H2O, H2O-40, H2O-60. 


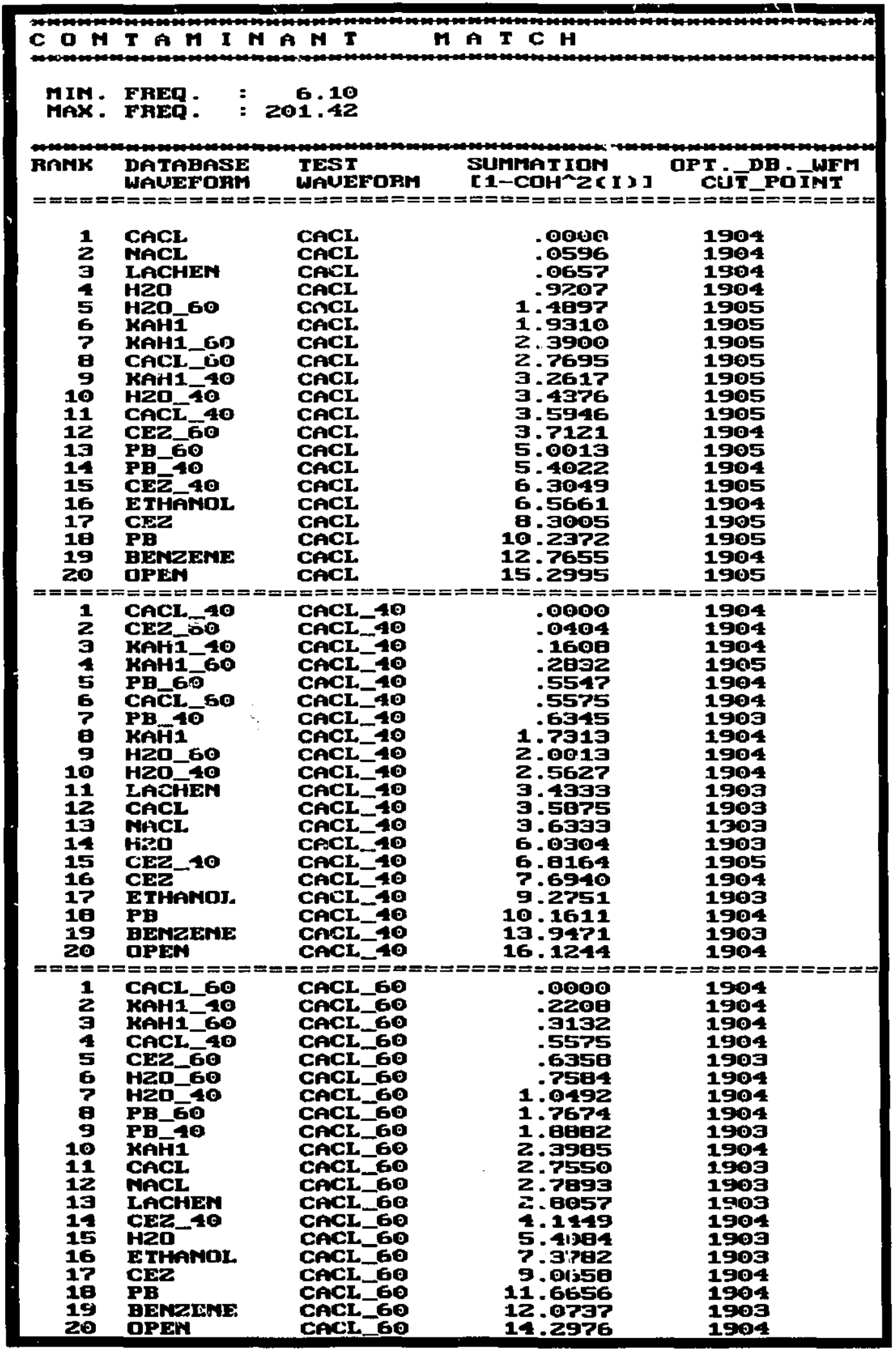

Table 4.3 Contaminant Match Results : CACL, CACL-40, CACL-60. 


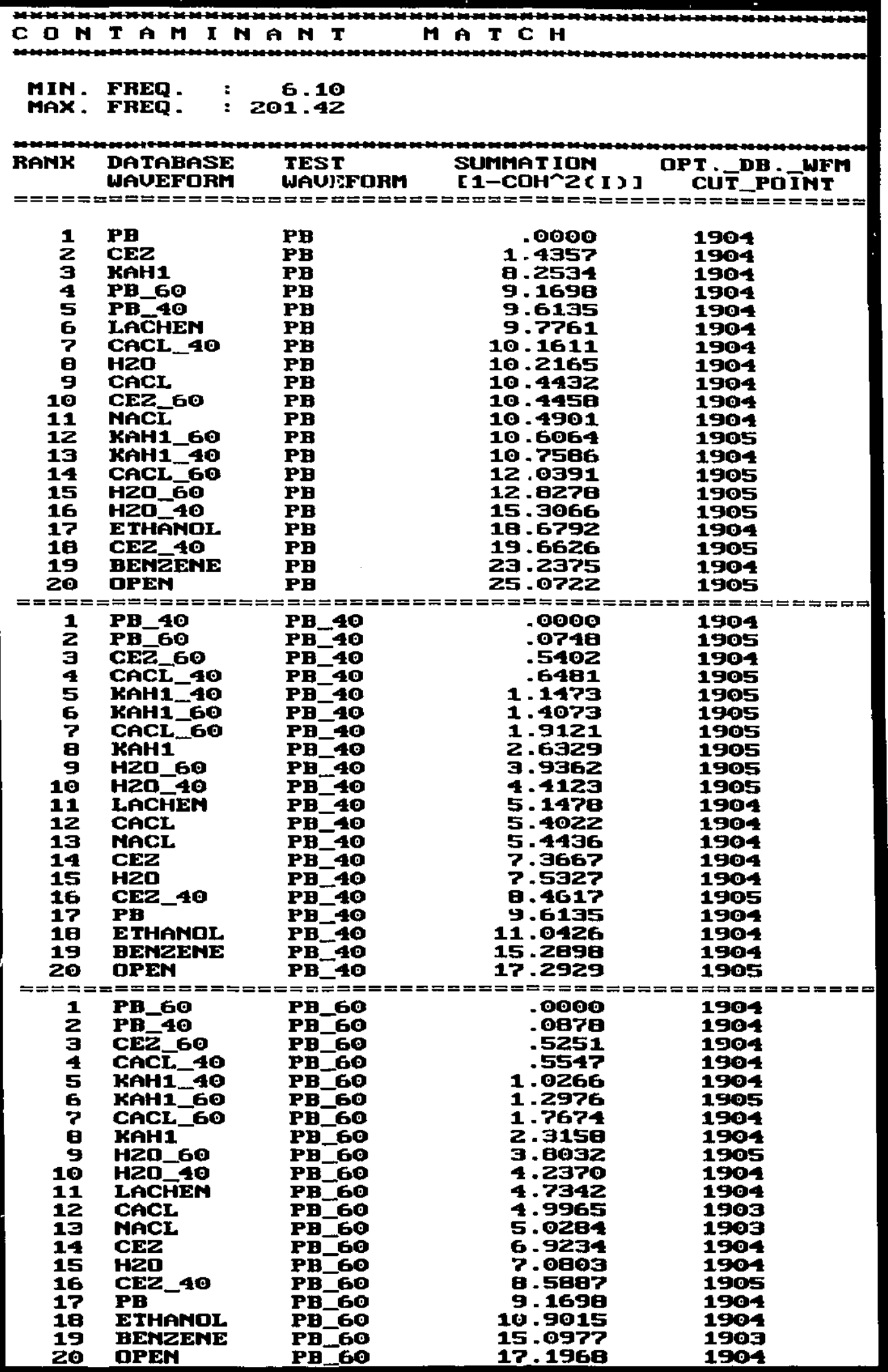

Table 4.4 Contaminant Match Results : PB, PB-40, PB-60. 


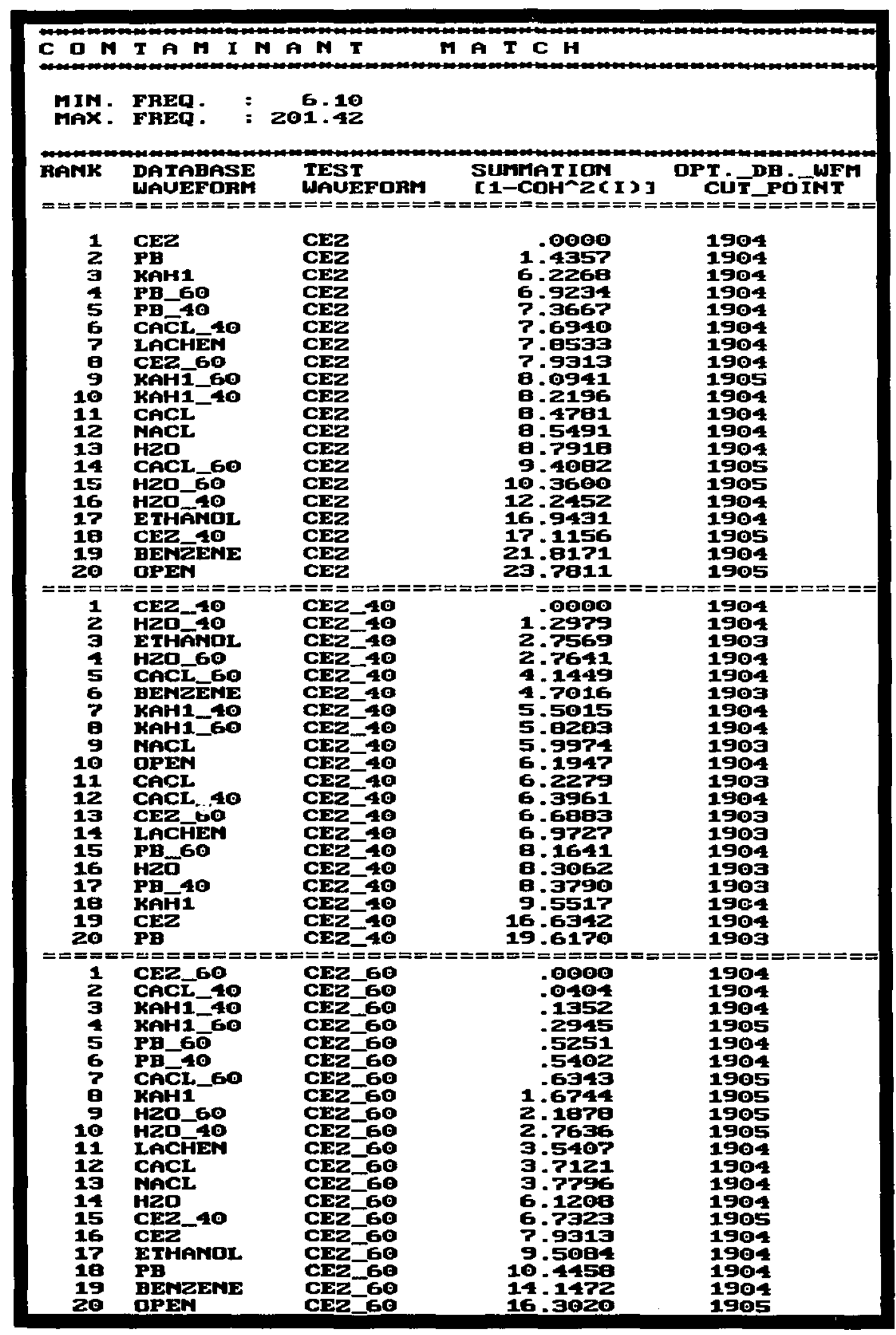

Table 4.5 Contaminant Match Results : CEZ, CEZ-40, CEZ-60. 


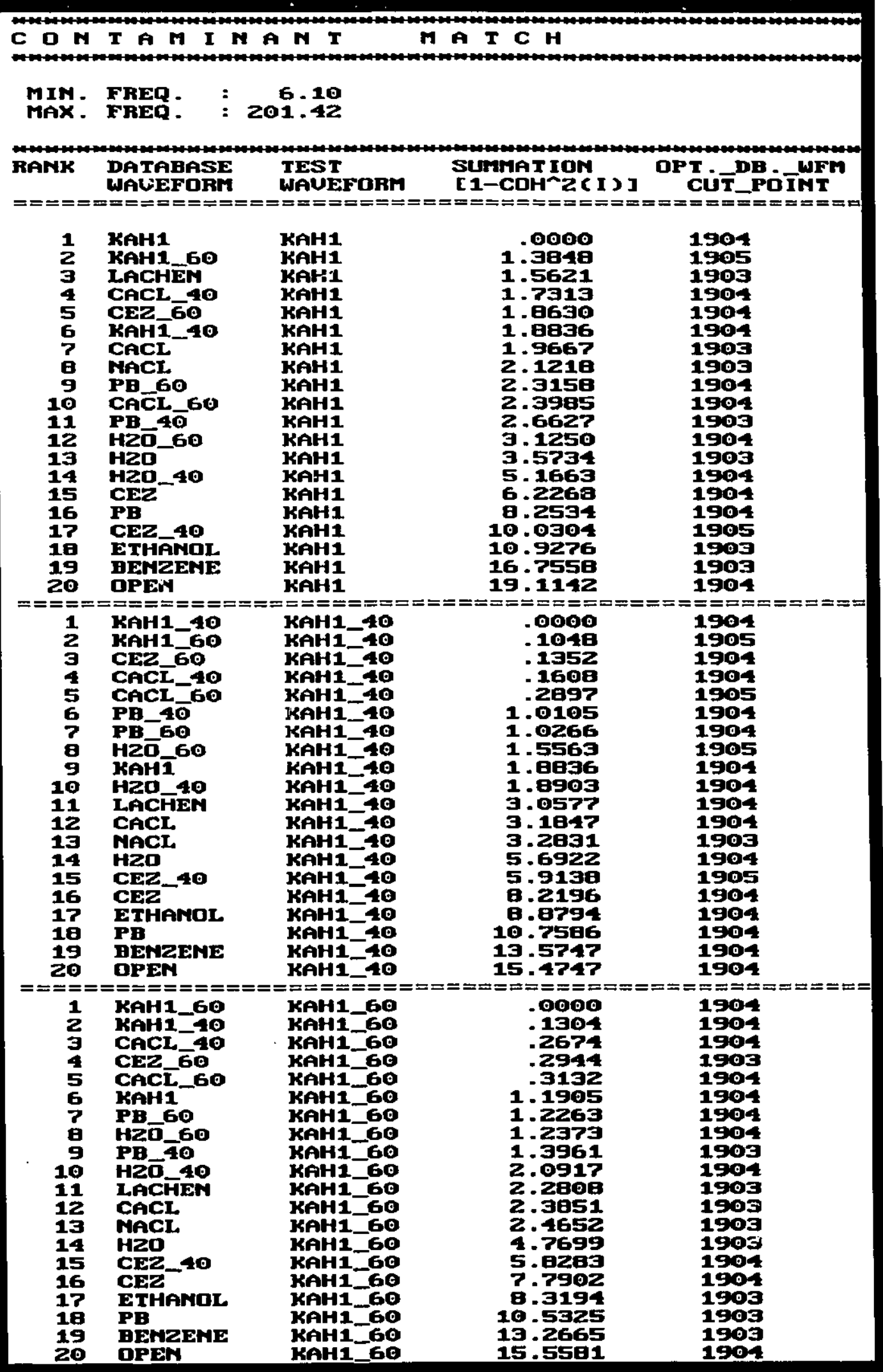

Table 4.6 Contaminant Match Results : KAH1, KAH1-40, KAH1-60. 


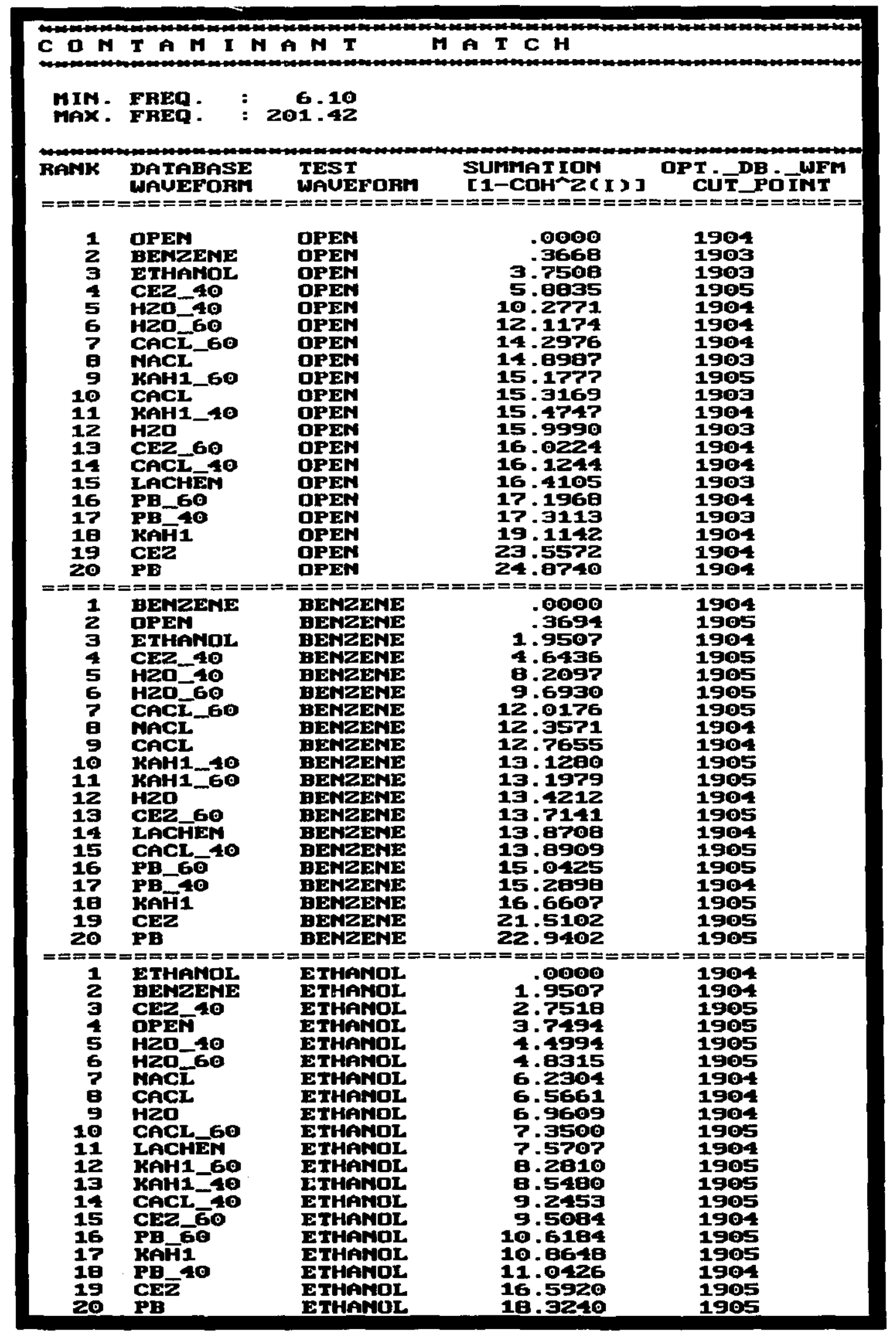

Table 4.7 Contaminant Match Results : OPEN, BENZENE, ETHANOL. 


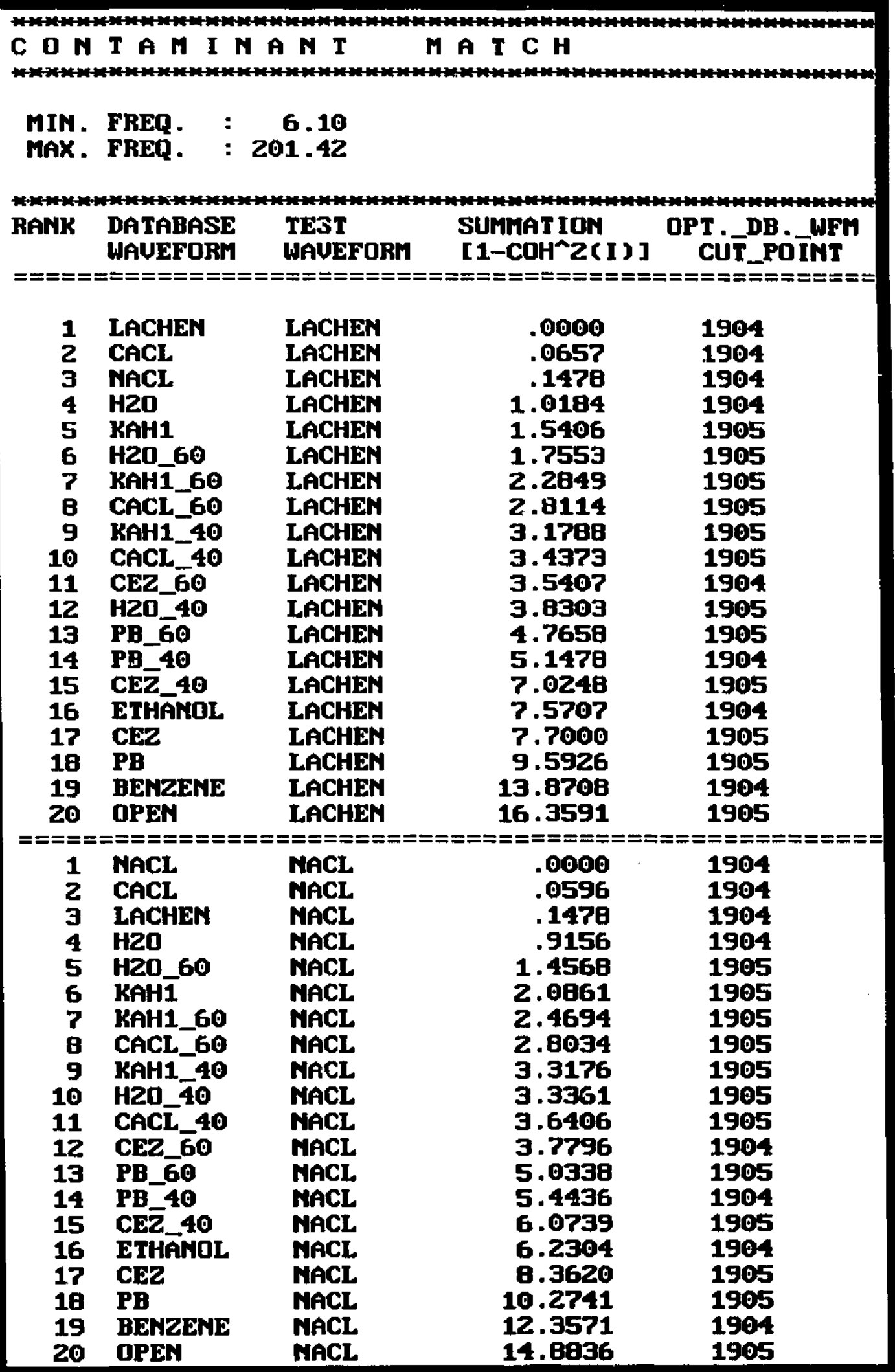

Table 4.8 Contaminant Match Results : LACHENAIE, NACL. 


\section{FREQUENCY DOMAIN COHERENCE FUNCTION $\mathrm{KAH} 1-40$ and $\mathrm{KAH} 1$}

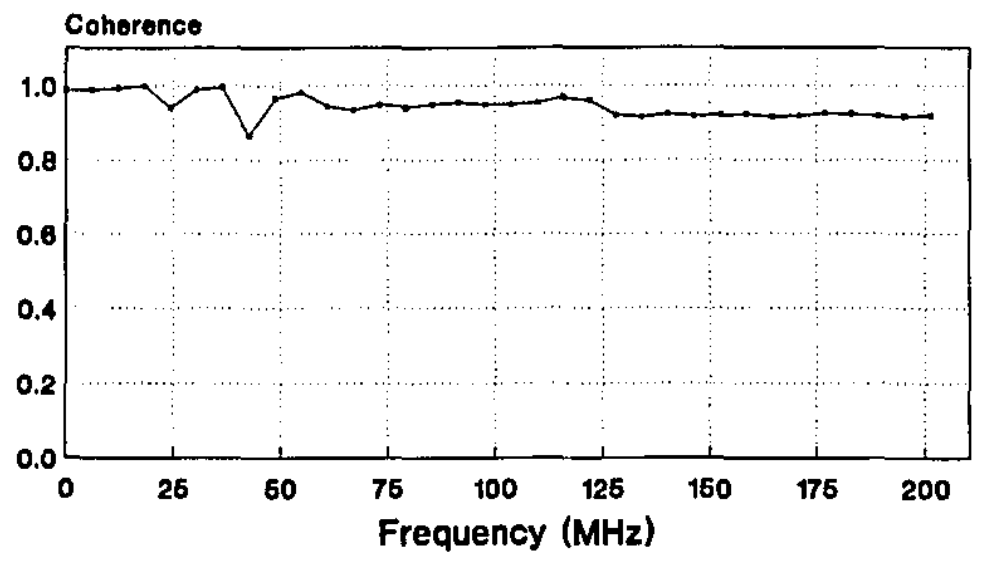

FREQUENCY DOMAIN COHERENCE FUNCTION $\mathrm{KAH} 1-40$ and LACHEN

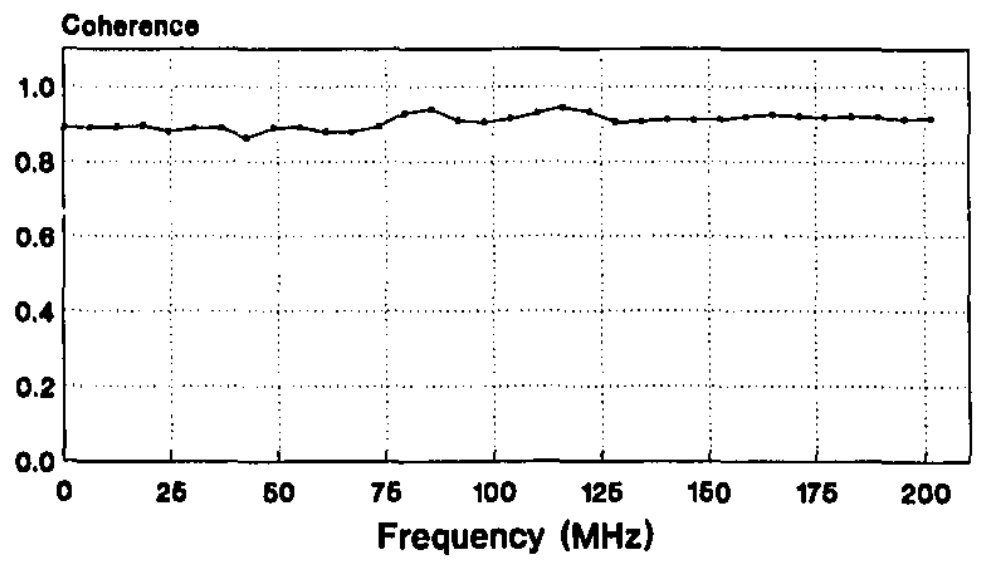

Figure 4.36 Coherence Function Between KAH1-40, KAH1 and LACHEN. 
The results indicate that an unknown, contaminated soil may be matched with a known (database) soil-contaminant mixture through a signal processing of TDR records. A direct match involving a contaminated soil and a database contaminant appears to be more challenging. The only direct association was obtained for KAH1. This may suggest that measurements conducted up to a maximum frequency of $200 \mathrm{MHz}$ reflect mainly the influence of the interfacial polarization occurring in the double layer of the colloidal material. It is worth noting that the PB-contaminated soils were matched with each other despite almost identical conductivity of the CEZ-contaminated soils (Table 4.1). This demonstrates the principal advantage of the polarization versus the conductivity measurement. A number of materials display similar conductivities but. contain different ionic compositions.

Poor matching of CACL and CEZ contaminated soils may be explained by the excessive conductivity of the analyzed material, masking or short-circuiting the polarization phenomena. However, highly conductive contaminants such as CEZ can be easily traced with a conventional resistivity survey. Conversely, low conductivity contaminants such as petroleum by-products are well suited to electric polarization measurements but are difficult to detect with the resistivity survey.

It should be noted that the degree of success in waveform matching is directly proportional to the amount of laboratory work involved in generating a database set of known "signatures". The laboratory testing program may also be used to determine quantitatively what influence a set change in a contaminant concentration exerts on a coherence function of a particular soil-contaminant system. This information may be subsequently used to estimate the contaminant concentration in the field. 


\subsection{PRACTICAL IMPLEMENTATION}

Obviously, technical problems and refinements associated with the digital signal processing need to explored further. Continuous advances in the microcomputer technology and the measurement instrumentation make it increasingly feasible. Extensive experimentation with various soil probes to enhance the measurement sensitivity is also warranted. Additional studies are also needed to explore various low loss coaxial transmission lines and high bandwidth step function generators. The optimal measuring network should cause a negligible degradation of the incident pulse, hence low loss of bandwidth, as the signal propagates through the transmission line.

Much work remains to be done to sort out the specific effects of contaminant-soil interactions, particularly in situations involving multi-component contaminants. It is proposed that further research include "calibration" experiments, seeking to identify before and after contamination scenarios. These are required for classifying various "signatures", especially with reference to a soil type, soil density, moisture content, porosity, contaminant species and ionic concentrations. Efforts need to be directed at uncoupling the effects of a soil from those of a contaminant on the frequency dependent dielectric properties. Existing studies indicate that these effects manifest themselves at different frequency ranges (solids at low frequencies and liquids at high frequencies), but it is conceivable that they may interact in some cases. Also, the interference effects and other possible causes of spectral differences between the incident and the reflected pulses might exist without being indicative of the contaminant presence. Further understanding of the polarization phenomena in contaminated soils may be enhanced by a numerical modeling of the measuring network. 


\section{CHAPTER 5 \\ CONCLUSIONS}

This study demonstrates the feasibility of an effective subsurface contaminant detection method based on the phenomenon of electric polarization in soils. Technically, the instrumentation set-up is relatively simple and borrows from the well established TDR method. Waveform acquisition by a digitizer and its processing by a portable computer can be performed directly on site, with the aid of database of "signatures" generated through the laboratory testing. The spatial extent of an underground contamination can be determined by probing the affected area and analyzing the incident and the reflected signals in the frequency-domain. Currently available test instruments and portable computers are suited for a practical implementation of this task.

The results of this study indicate promising means of identifying contaminants through the application of the coherence function to data analysis. The proposed approach involves utilization of the coherence function in two phases. First, it would be applied to individual measurements in order to check the validity of the transfer function within a set frequency range. Second, it would be applied to establish a degree of association between known and unknown records. It is envisioned that through the systematic means of creating a database of "signatures", an automated measurement and analysis process can be applied to the detection of subsurface contaminants.

The primary task of an in-situ contaminant detection technique is a determination 
of the lateral extent of a contaminant. The approach presented in this study indicates the feasibility of performing this task. The secondary task involves a detailed chemical characterization of a suspected contaminant. It is expected that with a greater variety of test situations a series of "signatures" can be cataloged to permit an effective characterization.

The effectiveness of the subsurface contaminant detection method proposed in this study can be enhanced if it is used in conjunction with other measurement techniques. Thus, an initial site reconnaissance can be rapidly performed with a portable electromagnetic conductivity probe. The area of interest can be subsequently analyzed with the TDR method. Further refinement, if required, can be achieved by a direct sampling from a monitoring well, which at this stage can be judiciously located. 


\section{STATEMENT OF ORIGINALITY}

A technique for a rapid detection and delineation of contaminants in soils is presented. The proposed methodology is based on the principles of electric polarization and the interaction of matter with the electric field. The technique employs time-domain reflectometry (TDR) measurements using a digital oscilloscope for signal recording and a microcomputer for data analysis.

Test results indicate that it is feasible to detect a particular contaminant in a subsurface soil through the observation of its char acteristic dielectric response. The proposed contaminant detection procedure employs the coherence function to match an unknown TDR "signature" with a set of database "signatures" and establish the most likely association. The author is not aware of any previous studies involving the application of both the TDR and the coherence function to a subsurface contaminant detection. 


\section{APPENDIX 1 \\ Computer Source Code Listings}




\subsection{Data Transfer from TEK 11402 to IBM PC}

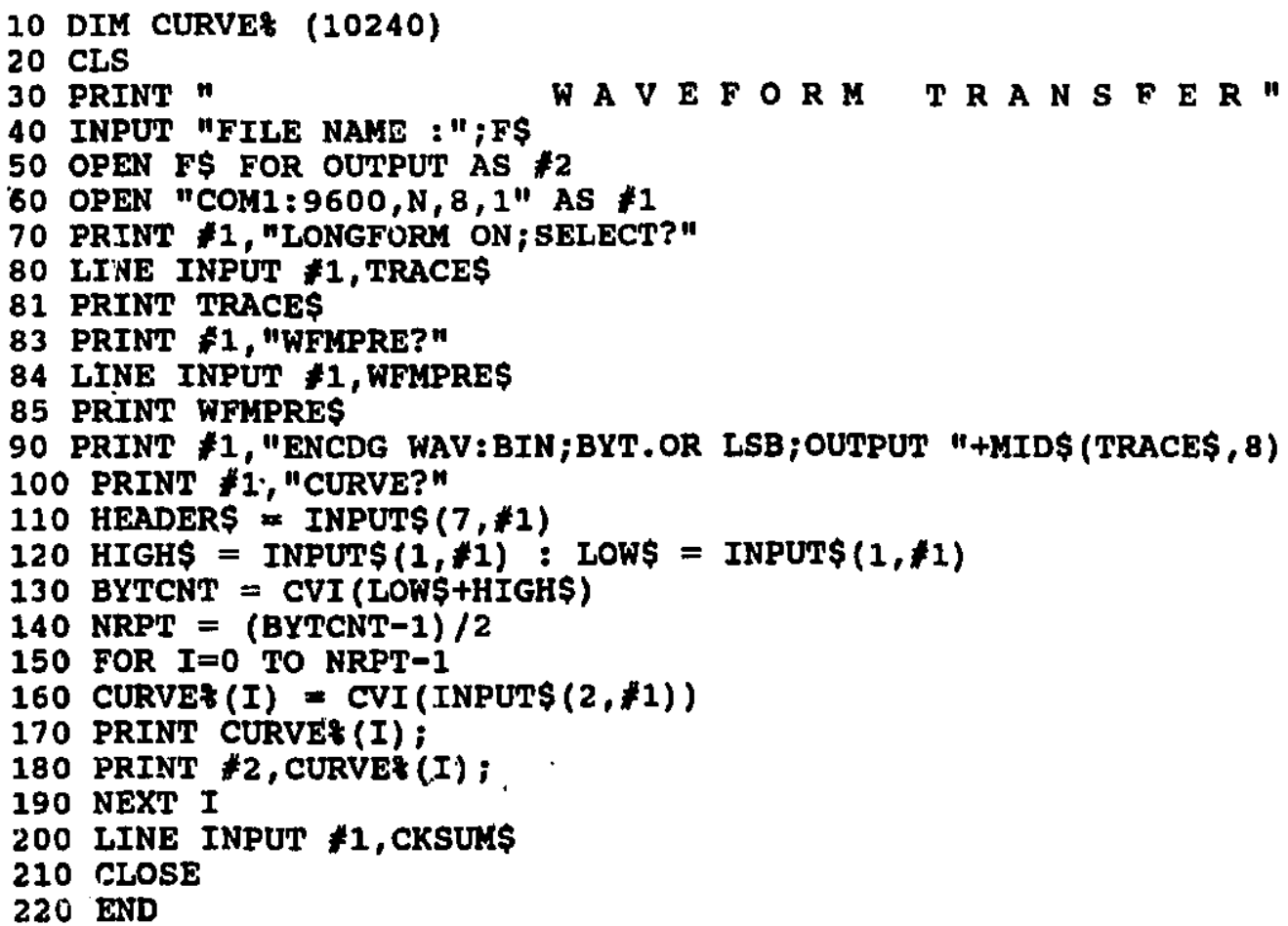




\subsection{Processing of Acquired Waveforms}

DIMENSION $F(2049), A(5200), V(5200)$, MA (200)

CONPLEX $\$ 8$ JN $(4096)$, OU $(4096), 2(4096)$

CHARACTER 10 KNOWN, FNAME

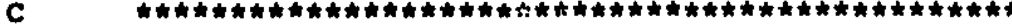

THIS PROGRAY OPERATES ON THE ACQUIRED TIME DOMAIN

DATA FILES AND

PRODUCES PROCESSED TIME DOMAIN DATA AND

PROVIDES CONVERSION TO FREQUENCY DOMAIN

USING THE FFT ALGORITHA

ARRAY DEFINITIONS:

$F()=F R E Q U E N C Y$

A() =PROCESSED TIME DOMAIN OUTPUT

V() =PROCESSED TIME DOKAIN INPUT

MA () =MAGNITUDE OF TRANSFER FUNCTION

$z()=$ COMPLEX TRANSFER FUNCTION

IN () $=$ INPUT FET

OU()-OUTPUT FFT

COMPILE WITH MICROSOFT FORTRAN V.4.01

LAST REVISION 09/22/94 EDWARD J. HOPPE

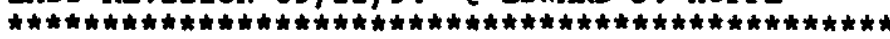

$N D=-1$

$\operatorname{WRITE}(*, *)$

C औ ASK FOR A FILENAME

WRITE $(\star, 890)$

READ ( * 891) KNOWN

890 FORMAT' ' NAME OF FILE SET: ' $\backslash$

891 FORMAT (A)

OPEN (9, FILE-KNOWN)

C $\operatorname{READ}(9, \star)$ FHIN, FMAX

C $\star$ MINIMUM FREQUENCY $=0$, MAXIMUM $=200 \mathrm{MHz}$

FMIN $=0.0$

FMAX $=200.0$

C औ DATA SET WITH 2 TO THE POWER OF 12 (FOR FFT)

$1 \quad \mathrm{LN}=12$

$N=2 \pitchfork \pitchfork \mathrm{LN}$

ND2 $1=N / 2+1$

$P I=3.141593$

$D E G=180.0 / P I$

READ (9,'(A)') FNAME

IF (FNAME. EQ. 'FIN') GOTO 999

WRITE (*, *) FNAME

C $\operatorname{READ}(9, *) \mathrm{J}$

c $*$ DEFINE OPTIMUY CUT POINT

$J=1904$

c

WRITE(*,*) , OPTIMUM CUT_POINT ,

WRITE (*, *)

C * READ AND SCALE INPUT DATA

OPEN (4, FILE-FNAYE)

C * NPT-NUMBER OF POINTS

C * TSTEP-SAMPIING INTERVAL

C * XZERO=INITIAL TIKE

READ (4, *) NPT,TSTEP, XZERO

TSTEP-(TSTEP/1.333)*1.0E9

XZERO $=(X 2 E R O / 1.333) \star 1.0 E 9$

$\operatorname{READ}(4, *) \quad A(1)$

$\operatorname{IF}(A(1) \cdot L T .-1.0) A(1)=0.0$

DO 2 I $=2$, NPT

$\operatorname{READ}(4, *) \quad A(L)$

C $\operatorname{IF}(\mathrm{A}(\mathrm{L}) \cdot \mathrm{LE} .-50.0) A(\mathrm{~L})=\mathrm{A}(\mathrm{L}-1)$

2 CONTINUE 


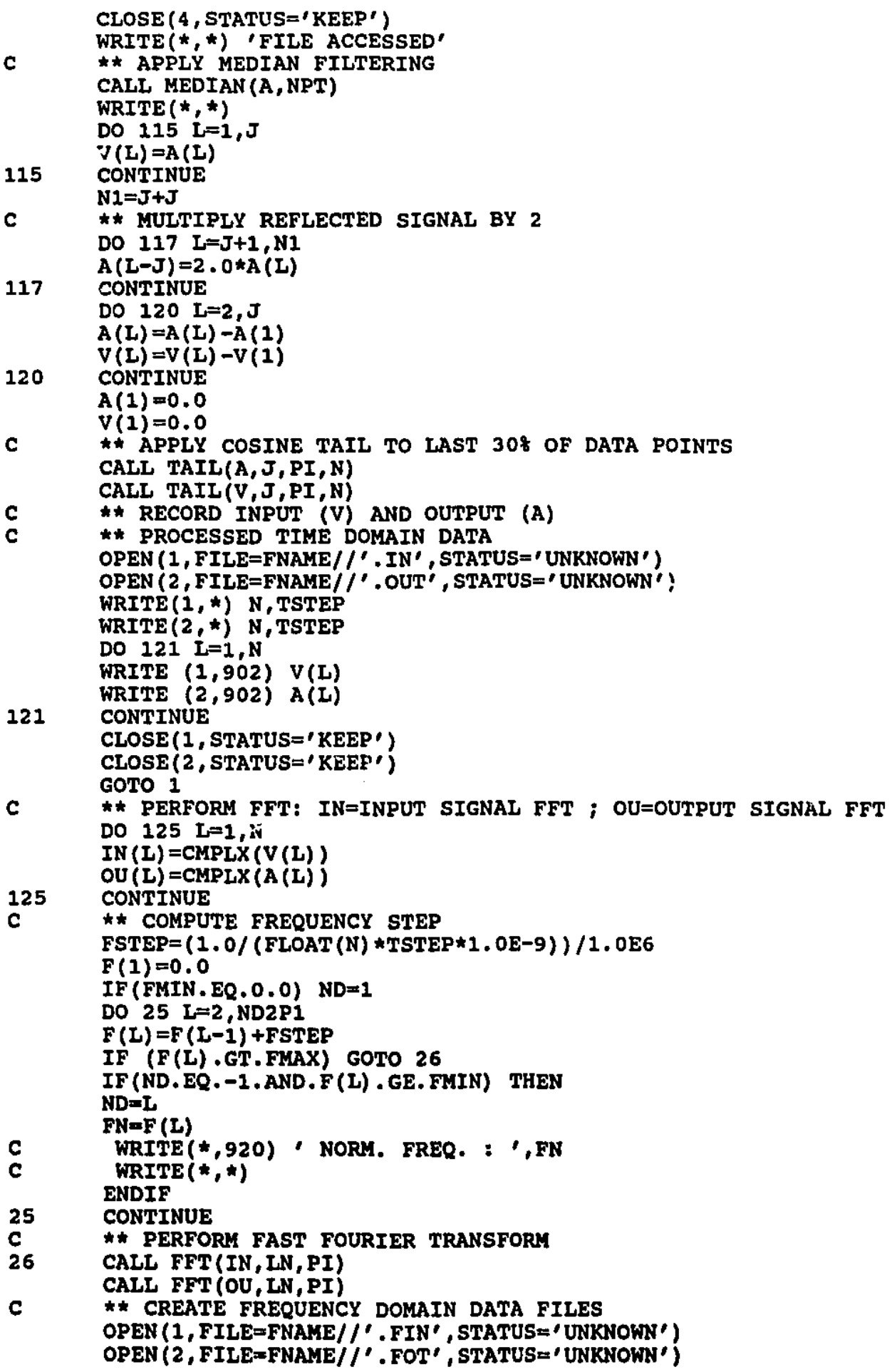




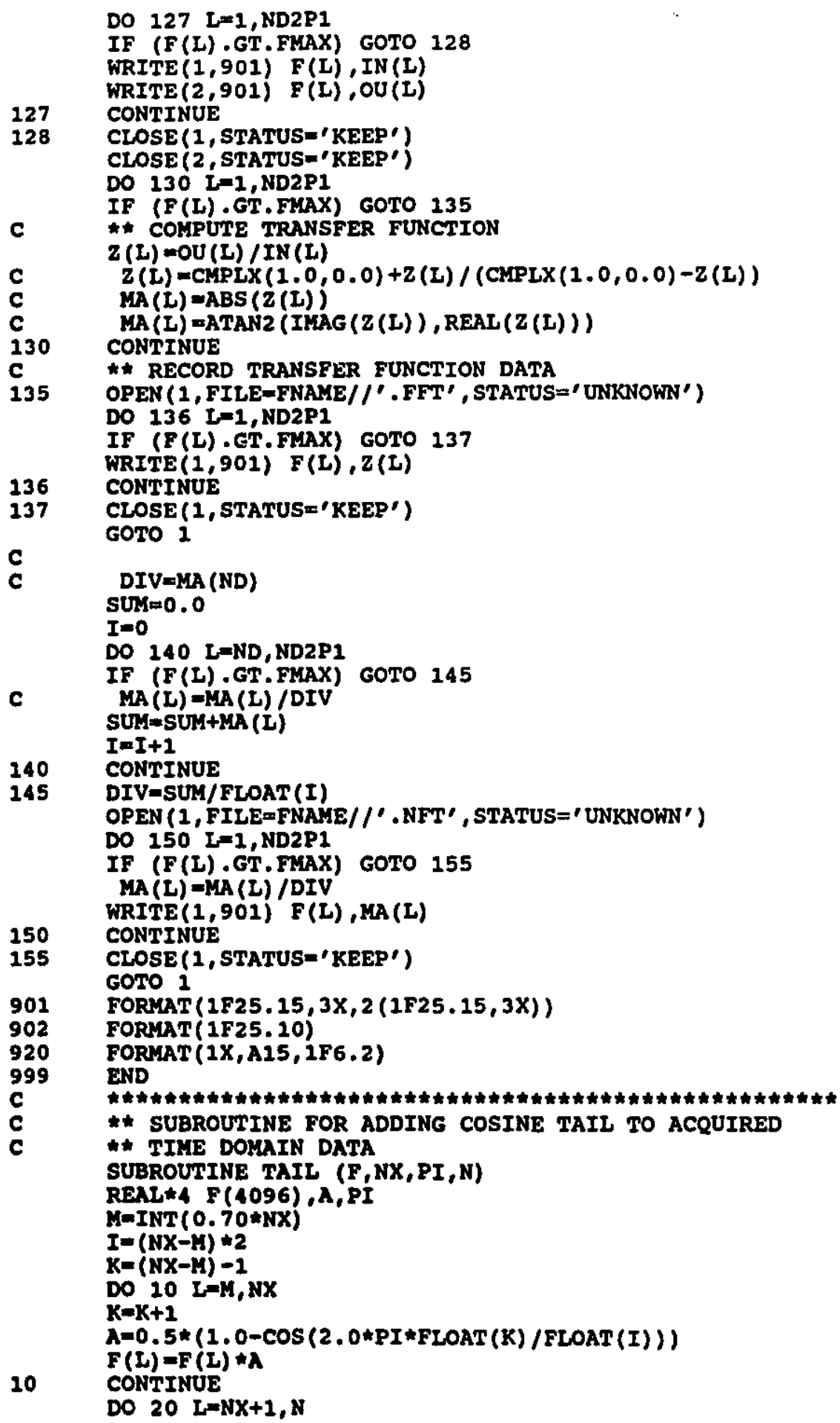




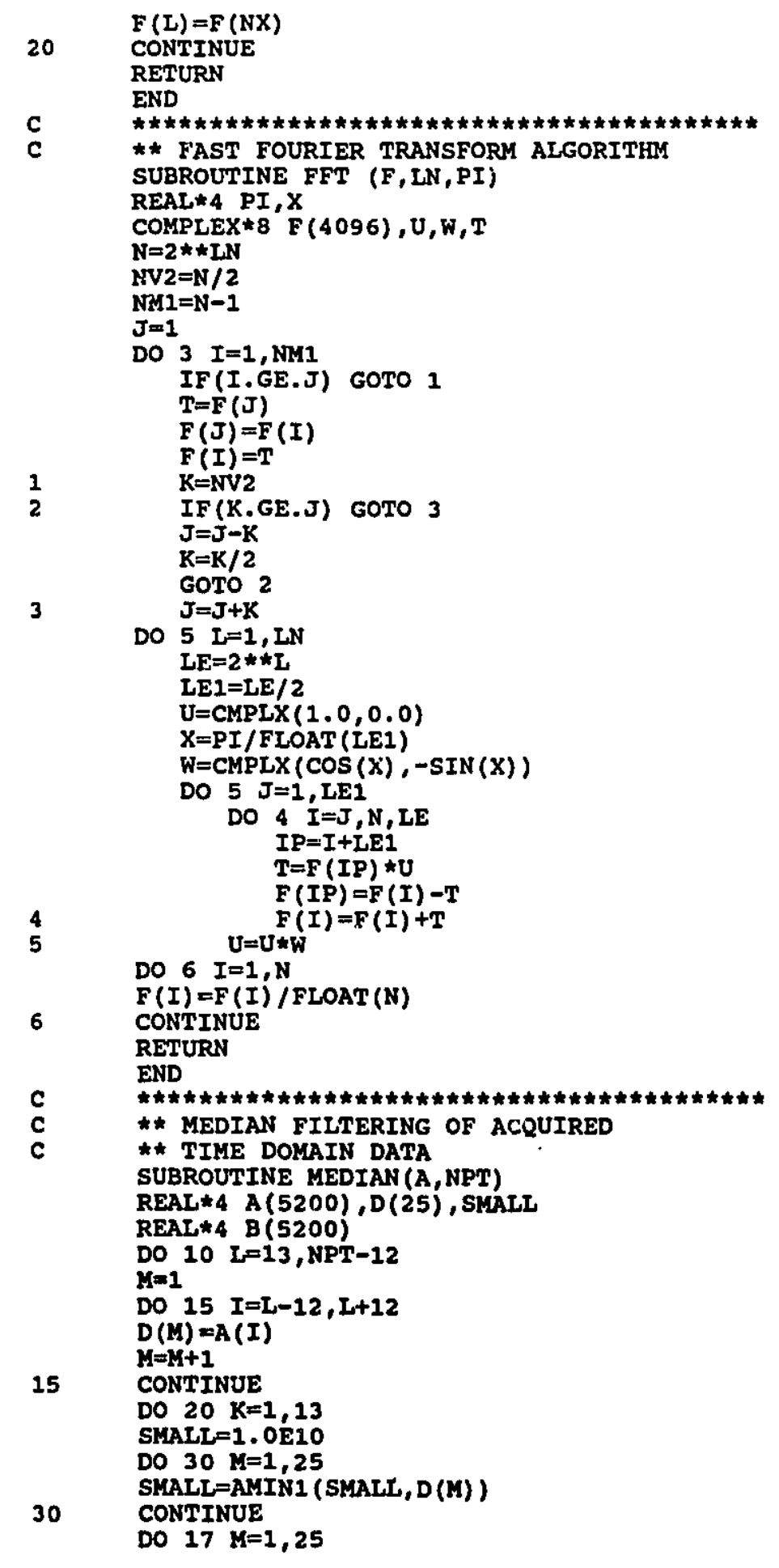




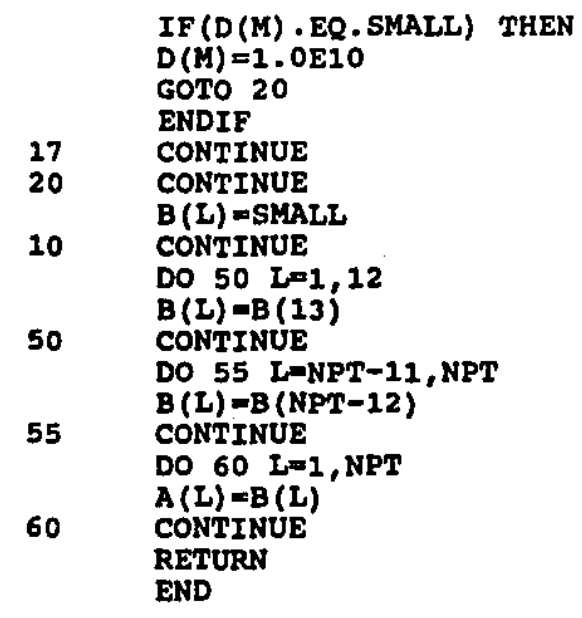




\subsection{Display of Time-Domain Waveforms}

DIMENSION TA $(6000), A(6000), V(6000)$

CHARACTER $* 30$ FNAME, ARG

INTEGER DEV

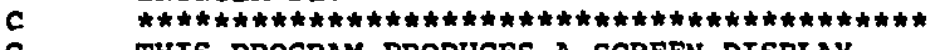

C THIS PROGRAM PRODUCES A SCREEN DISPLAY

C OF TIME DOMAIN DATA USING MCGILL FORTRAN

C PLOTTING SUBROUTINES

C ARRAY DEFINITIONS:

C TA ()$=$ TIME

C $\quad$ V( $)=$ FIRST DATA FILE

C. $\quad A()=S E C O N D$ DATA FILE

C COMPILE WITH MICROSOFT FORTRAN V.4.01

C AND MCGILL PLOTTING SUBROUTINES

C LAST REVISION $9 / 22 / 94$ Q EDWARD J. HOPPE

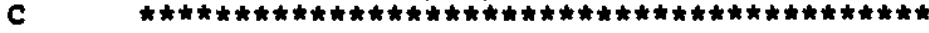

* * TAG MARKS EACH PLOT

WRITE $(*, *)$ 'PLOT ID NUMBER'

$\operatorname{READ}(*, *)$ TAG

WRITE(*,'(AI)') , VIEW OR FILE ? ( 1 or 2$):$ '

$\operatorname{READ}(*, *)$ NDEV

IF (NDEV.EQ.2) THEN

WRITE $\left.(*, '(A))^{\prime}\right)$ ' OUTPUT FILE NAME ? '

$\operatorname{READ}(*, '(A) ')$ ARG

ENDIF

WRITE $\left(*, '(A \mid)^{\prime}\right)$ ' NUMBER OF WAVEFORMS (1 or 2) : '

READ $(*, *)$ NFILES

WRITE $\left(*, '(A \backslash)^{\prime}\right)$, NUMBER OF POINTS TO DISCARD (TAIL) : '

$\operatorname{READ}(*, *)$ NDISC

WRITE $\left(*, '(A \backslash)^{\prime}\right)$ ' WAVEFORM PLOT ONLY (1=YES) : '

$\operatorname{READ}(*, *)$ NPLOT

XZERO $=0.0$

DO $13 \quad I=1$, NFILES

c

WRITE (*,'(A)')', TIME DOMAIN FILE : '

** READ TIME DOMAIN FILE

READ (*,'(A)') FNAME

OPEN (4, FILE=FNANE)

READ $(4, *)$ NPT, TSTEP, XZERO

IF (XZERO.EQ.0.0) GOTO 1

TSTEP $=($ TSTEP $/ 1.333) * 1.0 E 9$

XZERO $=(X Z E R O / 1.333) * 1.0 E 9$

1

NPT $=$ NPT-NDISC

WRITE $(*, *)$

WRITE $(*, *)$ NPT TSTEP (ns) ,

WRITE $(*, *)$ NPT, TSTEP

$\operatorname{WRITE}(*, *)$

$T A(1)=0.0$

DO $7 \mathrm{~L}=1$, NPT -1

$\operatorname{READ}(4, *) \quad A(L)$

7

TA $(L+1)=T A(L)+T S T E P$

CONTINUE

CLOSE (4, STATUSm ' KEEP')

C

WRITE $(*, *)$ 'FILE ACCESSED'

IF(I.EQ.2) GOTO 19

DO $250 \quad L=1$, NPT

$V(L)=A(L)$

250

CONTINUE

18 CONTINUE

C $\quad$ C

19 IF (NDEV.EQ.1) CALL PLOTON $\left(9,8^{\prime}\right.$ ) 


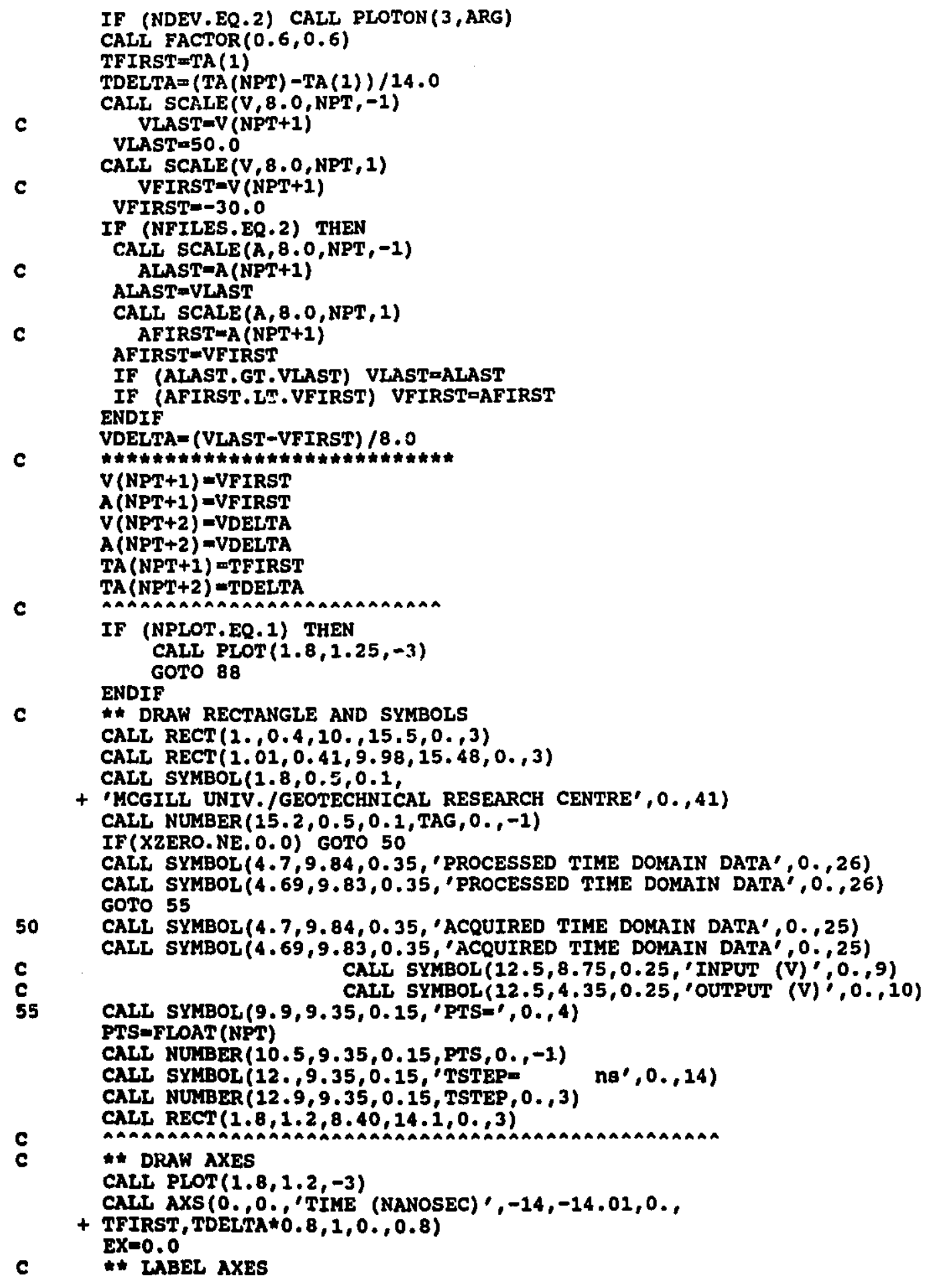




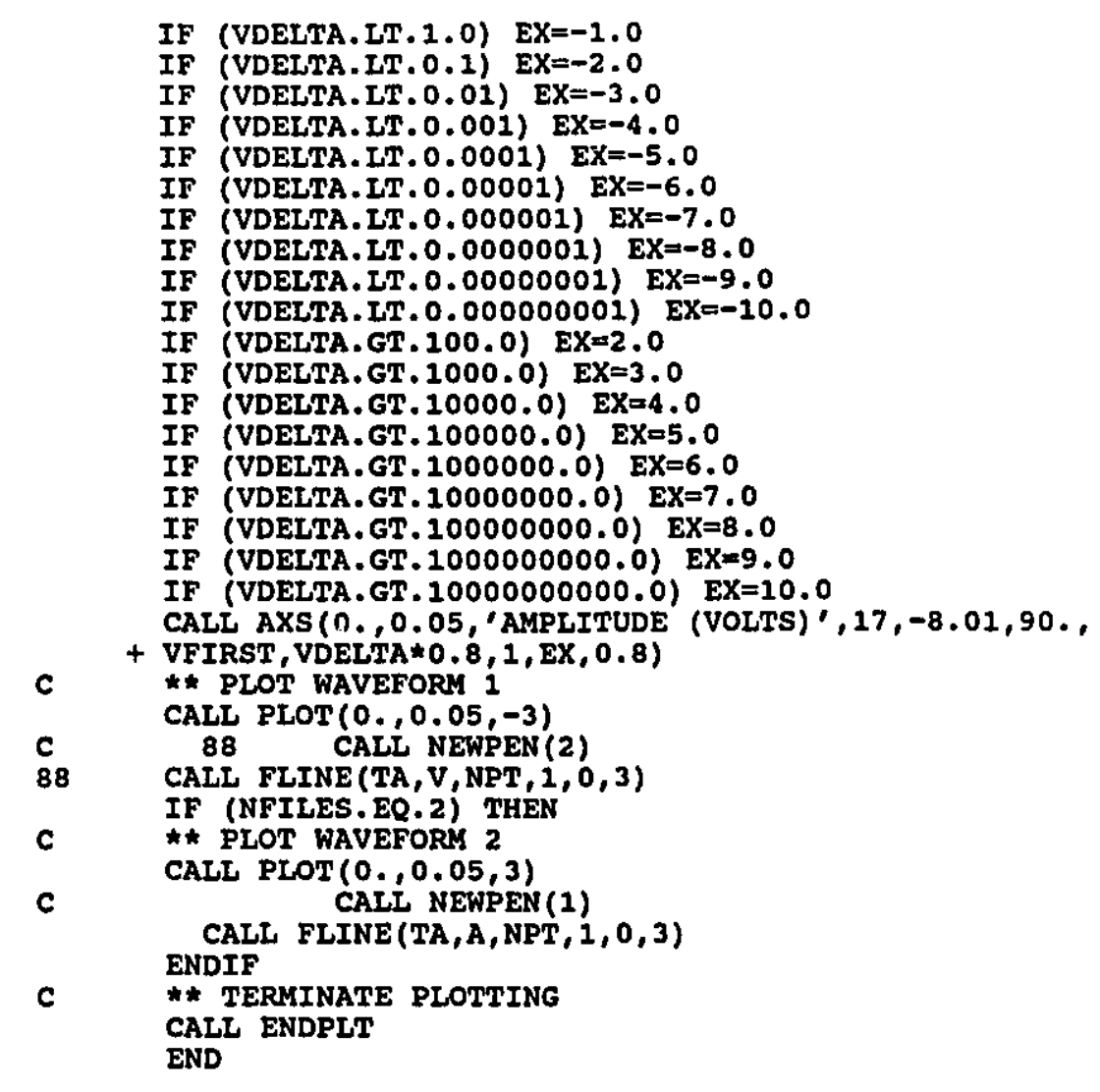




\subsection{Display of Frequency-Domain Waveforms}

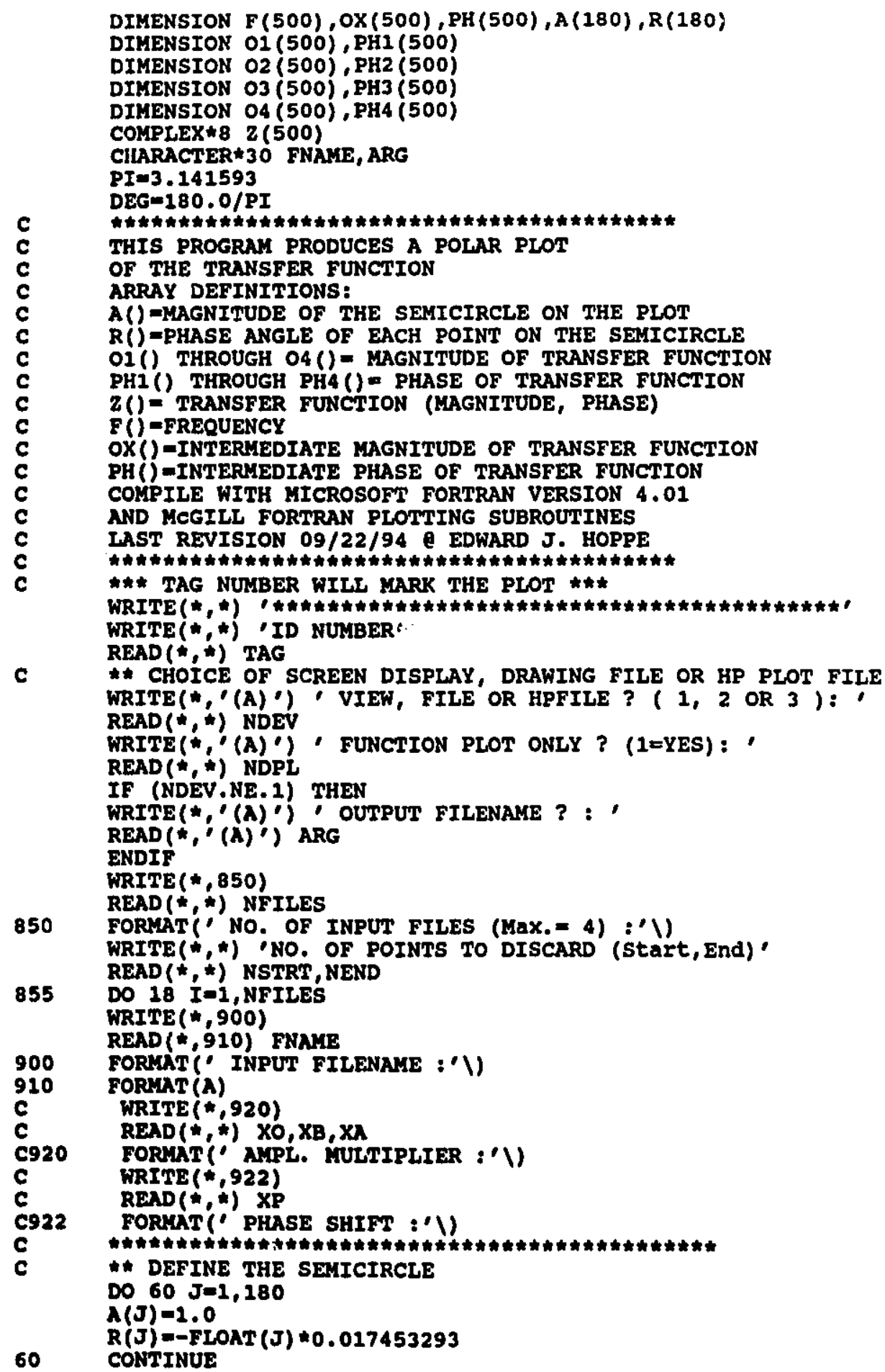




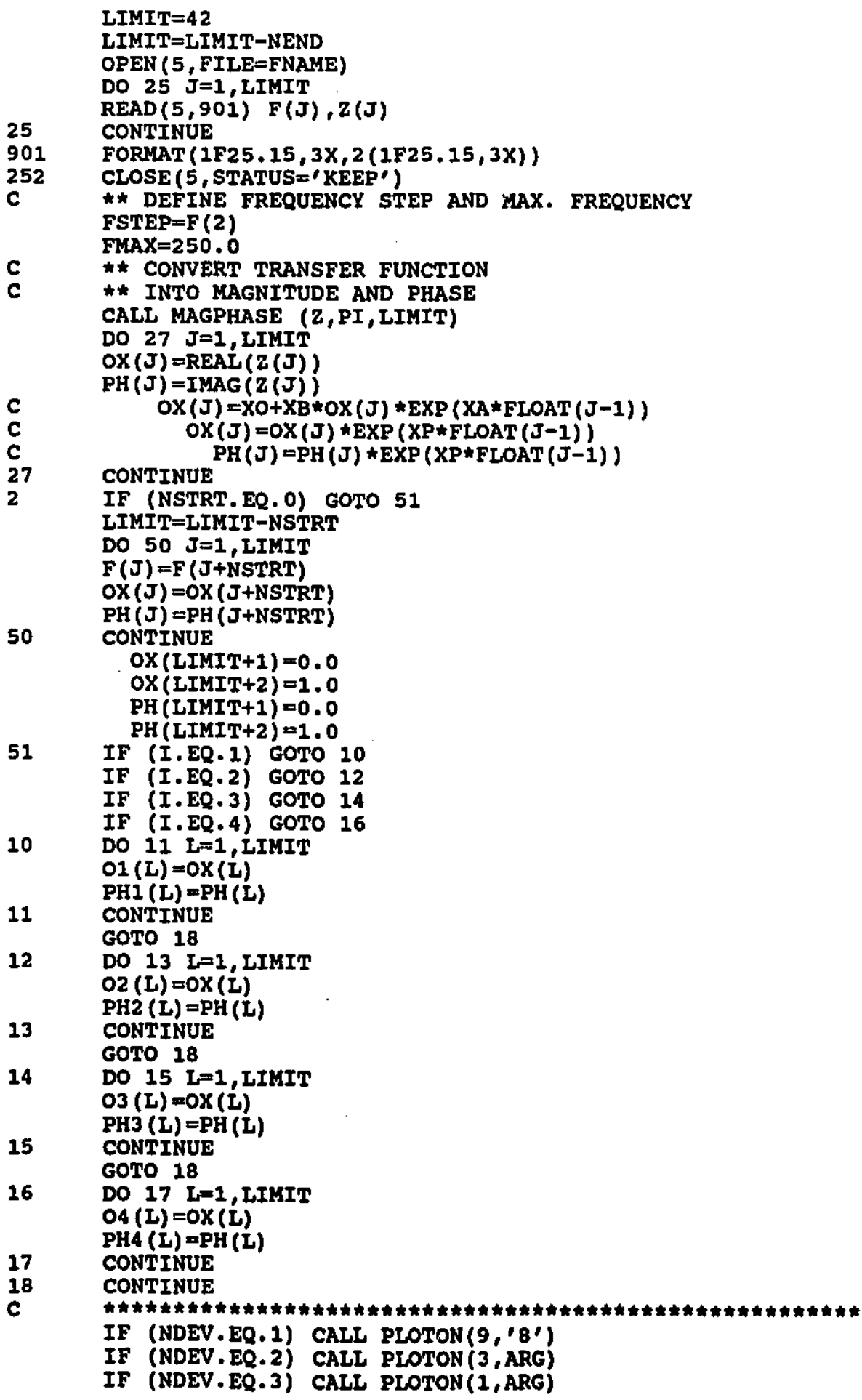

2 IF (NSTRT.EQ.0) GOTO 51

LIMIT=LIMIT-NSTRT

DO $50 \mathrm{~J}=1$, LIMIT

$F(J)=F(J+N S T R T)$

$\operatorname{OX}(J)=O X(J+N S T R T)$

$50 \quad$ PH (J) $=$ PH

$\operatorname{OX}($ IIMIT +1$)=0.0$

OX (IIMIT+2) $=1.0$

PH (LIMIT+1) $=0.0$

PH (LIMIT+2) $=1.0$

51 IF (I.EQ.1) GOTO 10

IF (I.EQ.2) GOTO 12

IF (I.EQ.3) GOTO 14

IF (I.EQ.4) GOTO 16

DO $11 \mathrm{~L}=1$, LIMIT

$01(L)=0 \times(L)$

PHI (L) $=$ PH (L)

11 CONTINUE

GOTO 18

12 DO $13 \quad \mathrm{I}=1$, LIMIT

02 (L) $=0 \times(L)$

PH2 (L) $=$ PH (L)

13 CONTINUE

GOTO 18

14 DO $15 \mathrm{I}=1$, LIMIT

03 (L) =0X (L)

PH3 (L) $=$ PH (L)

15 CONTINUE

GOTO 18

16 DO $17 \mathrm{I}=1$, LIMIT

$04(L)=0 X(L)$

PH 4 (L) $=$ PH (L)

17 CONTINUE

18 CONTINUE

IF (NDEV. EQ.1) CALL PLOTON $\left(9,18^{\prime}\right.$ )

IF (NDEV. EQ.2) CALL PLOTON $(3$, ARG)

IF (NDEV. EQ.3) CALL PLOTON(1,ARG) 
CALL RECT $(1,0.4,10 ., 15.5,0 ., 3)$

IF (NDPL. EQ.1) GOTO 44

CALL RECT $(1.01,0.41,9.98,15.48,0 ., 3)$

CALL SYMBOL $(1.8,0.5,0.1$,

+ 'MCGILL UNIV. /GEOTECHNICAL RESEARCH CENTRE',0.,41)

CALI NUMBER (15.2, $0.5,0.1$, TAG, $0 .,-1)$

CALL SYMBOL $(6 ., 9.85,0.35$, 'FREQUENCY DOMAIN FFT', 0.,21)

CALL SYMBOL $(5.99,9.84,0.35, '$ FREQUENCY DOMAIN FF', $0 ., 21)$

CALL SYMBOL $(4.7,9.25,0.25$, TRANSFER FUNCTION',0.,17) CALI SYMBOL $(12,9.4,0.15$, 'FSTEP=

CALL RECT $(1.8,1.2,8,40,14,1,0,3)$ CALL SYMBOL $(12,8,4,0.15$, FMAX $=$
CALL NUMBER $(12,9,8.4,0.15$, FMAX, $0 ., 3)$

CALL DASH $(8.85,9.0,8.85,1.5,0.5)$

CALL SYMBOL $(8,9,8,4,0.15,(0,0\}, 0 ., 5)$

CALL SYMBOL $(14,6,8.4,0.15,[1,0], 0 ., 5)$

CALL SYMBOL $(2.5,8.4,0.15, '[-1,0], 0 ., 6)$

CALL SYMBOL $(8.9,1.5,0.15,-j, 0 ., 2)$

44

CALL PLOT $(8.85,8.3,-3)$

CALL GETWDW (XMIN, XMAX, YMIN, YMAX) YMAX $=8,3$

CALL PLTSZE $(7,0,7,0,126)$

\section{LIXE179}

C $\quad *$ PLOT TRANSFER FUNCTIONS

CALL $\operatorname{POLAR}(A, R$, LIM $, 1,0,3,0.0,0.17)$

CALL NEWPEN (1)

CALL POLAR(01, PH1, LIMIT, 1, 5, 0, 0, 0, 0.17)

CALL PLOT $(-8,5,-6.0,-3)$

CALL POLAR(01, PH1, LIMIT, 1, 0, 03, 0.0,0.17)

CALL FLINE(01, PH1, -LIMIT, 1,0) GOTO 800

* COMPUTE LOCATIONS OF VARIOUS

* FREQUENCY COMPONENTS $\mathrm{F} 12 \mathrm{X}=01(1) * \operatorname{COS}(\mathrm{PH} 1(1)) * 5.882352941$

$F 12 Y=01(1) \star S I N(P H 1(1)) \star 5.882352941$

CALL SYMBOL(F12X, F12Y, 0.13, $12,0 ., 2$ )

$F 20 X=01(1) \star \operatorname{COS}(\mathrm{PH1}(1)) \star 5.882352941$

F2OY $=01(1) \star S I N(P H 1(1)) * 5.882352941$

CALL DASH $(0.0,0.0$, F2OX, F2OY, 0.5)

CALL SYMBOZ (F20X, F20Y, $0.13,20,0 ., 2)$

$F 50 X=01(8) \star \operatorname{COS}(\mathrm{PHI}(8)) \star 5.882352941$

F5OY $=01(8) * S I N(P H 1(8)) * 5.882352941$

CALL SYMBOL $\{550 X$, F5OY, $0.13,(50,0,2$ )

F100X-01 (21)*COS (PH1 (21))*5.882352941

FIOOY $=01(21) * S I N($ PHI $(21)) * 5.882352941$

CALL DASH $(0.0,0.0$, F100X, F100Y, 0.5)

CALL SYMBOL (F100X, F100Y, $0.13,1100,0,13)$

F120X $=01(26) * \cos ($ PHI (26) $* 5.882352941$

F120Y-01 (26) *SIN (PH1 (26) $) * 5.882352941$

CALL SYMBOL (F120X, F120Y, $0.13,1120,0,03$ )

F150X $=01(33) * \cos (\mathrm{PH1}(33)) * 5.882352941$

F150Y=01 (33) «SIN (PHI (33) $\pitchfork 5.882352941$

CALL SYMBOL (F150X, F150Y,0.13, $\left.150^{\prime}, 0,3\right)$

IF (F (LIMIT+NSTRT). GT.200.0) THEN

F200X $=01(45) * \operatorname{COS}(\mathrm{PH1}(45)) \star 5.882352941$ 


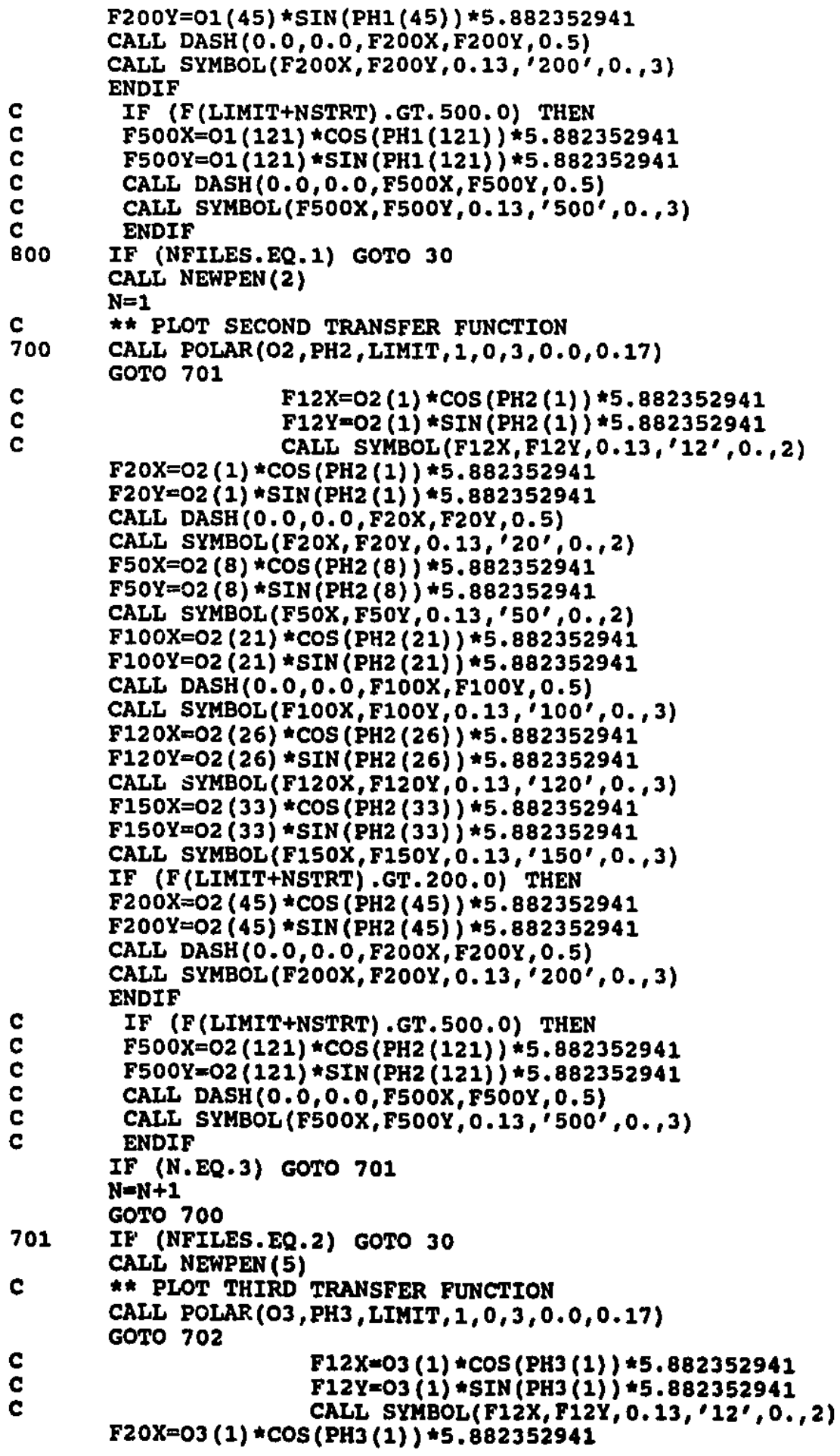


F2OY $=03(1) * \operatorname{SIN~(PH3~(1))~} \$ 5.882352941$

CALL DASH $(0.0,0.0$, F2OX, F2OX, 0.5)

CALL SYMBOL (F2OX, F2OY, $0.13,{ }^{\prime} 20,0,2$ )

F50X $=03(8) \star \operatorname{COS}(\mathrm{PH} 3(8)) \star 5.882352941$

F5OY $=03(8) *$ SIN $(\mathrm{PH} 3(8)) \star 5.882352941$

CALL SYMBOL (F50X, F50Y, $0.13,150,, 0,2$ )

$\mathrm{F} 100 \mathrm{X}=03(21) \star \operatorname{COS}(\mathrm{PH} 3(21)) \star 5.882352941$

F10OY $=03(21) \star S I N($ PH3 (21) ) *5.882352941

CALL DASH $(0.0,0.0$, F100X, F10OY, 0.5)

CALL SYMBOL (F100X, F100Y, $0.13,100,0 ., 3$ )

$\mathrm{F} 120 X=03(26) * \operatorname{COS}(\mathrm{PH} 3(26)) \star 5.882352941$

F120Y $=03(26) * S I N(\mathrm{PH} 3(26)\} \star 5.882352941$

CALL SYMBOL (F120X, F120Y, $0.13,1120,0 ., 3)$

F150X $=03(33) * \cos (\mathrm{PH} 3(33)) \star 5.882352941$

F150Y $=03(33) *$ SIN $($ PH3 $(33)) * 5.882352941$

CALL SYMBOL (F150X, F150Y, $\left.0.13,150^{\prime}, 0,3\right)$

IF (F(IIMIT+NSTRT) , GT.200.0) THEN

F200X $=03(45) \star \cos (\mathrm{PH} 3(45)) \star 5.882352941$

F20OY $=03(45) *$ SIN $($ PH3 $(45)) \star 5.882352941$

CALL DASH $(0.0,0.0$, F200X, F200Y, 0.5)

CALI SYMBOL (F200X, F200Y, $0.13,2_{20}^{\prime}, 0 ., 3$ )

ENDIF

C IF (F (IIMIT+NSTRT) . GT.500.0) THEN

C F500X $=03(121) * \operatorname{COS}(\mathrm{PH} 3(121)) * 5.882352941$

FSOOY $=03(121) \star$ SIN (PH3 $(121)) \star 5.882352941$

CALI DASH $(0.0,0.0$, F5OOX, F5OOY, 0.5)

CALL SYMBOL (F500X, F500Y, 0.13, 500, 0.,3) ENDIF

IF (NFILES. DQ.3) GOTO 30

CALL NEWPEN (6)

$\mathrm{N}=1$

C $*$ PLOT FOURTH TRANSFER FUNCTION

705 CALL POLAR (04, PH4, LIMIT, 1, 0, 3, 0.0, 0.17)

c

c

$\mathrm{F} 12 \mathrm{X}=04(1) * \operatorname{COS}(\mathrm{PH} 4(1)) \star 5.882352941$

F12X $=04(1) *$ SIN $($ PH4 (1) $) \star 5.882352941$

GoTn 30

CALL SYMBOL $(F 12 X, F 12 Y, 0.13, ' 12,, 0,2)$

$\mathrm{F} 20 \mathrm{X}-04(1) * \cos (\mathrm{PH} 4(1)) \star 5.882352941$

$F 20 Y=04(1) * S I N(P H 4(1)) * 5.882352941$

CALL DASH $(0.0,0.0$, F2OX, F2OY, 0.5)

CALL SYMBOL (F20X, F2OY, $0.13,20,0,2$ )

F50X $-04(8) * \operatorname{COS}($ PH 4 (8) $) \star 5.882352941$

F5OY $=04(8) *$ SIN $($ PH4 $(8)) \star 5.882352941$

CALL SYMBOL (F5OX, F5OY, $0.13,50 \prime, 0,2$ )

$\mathrm{F} 100 \mathrm{X}=04(21) \star \operatorname{COS}(\mathrm{PH} 4(21)) \star 5.882352941$

F100Y $=04(21) *$ SIN (PH4 (21) $* 5.882352941$

CALi DAsh $(0.0,0.0$, F100X, F100Y, 0.5)

CALI SYMBOL (F100X, F100X, $0.13,100,0 ., 3$ )

F120X $=04(26) * \operatorname{COS}(\mathrm{PH} 4(26)) \star 5.882352941$

$F 120 Y=04(26) * S I N($ PH4 $(26)) * 5.882352941$

CALL BYABOL (F120X, F120Y, $\left.0.13,120^{\prime}, 0,3\right)$

F150X $-04(33) \star \operatorname{COS}(\mathrm{PH} 4(33)) \star 5.882352941$

F15OY $=04(33) * S I N($ PH4 (33) $) \star 5.882352941$

CALL SYMBOL (F150X, F150Y, 0.13,'150',0, 3)

IF (F (LIMIT+NSTRT).ET.200.0) THEN

F200X $=04(45) * \cos ($ PH4 (45)) *5.882352941

F20OY $=04(45) *$ SIN $($ PH4 $(45)) * 5.882352941$

CALL DASH $(0,0,0.0$, F2OOX, F2OOY, 0.5)

CALL SYMBOL (F200X, F200Y,0.13, $200,0 ., 3)$

ENDIF 


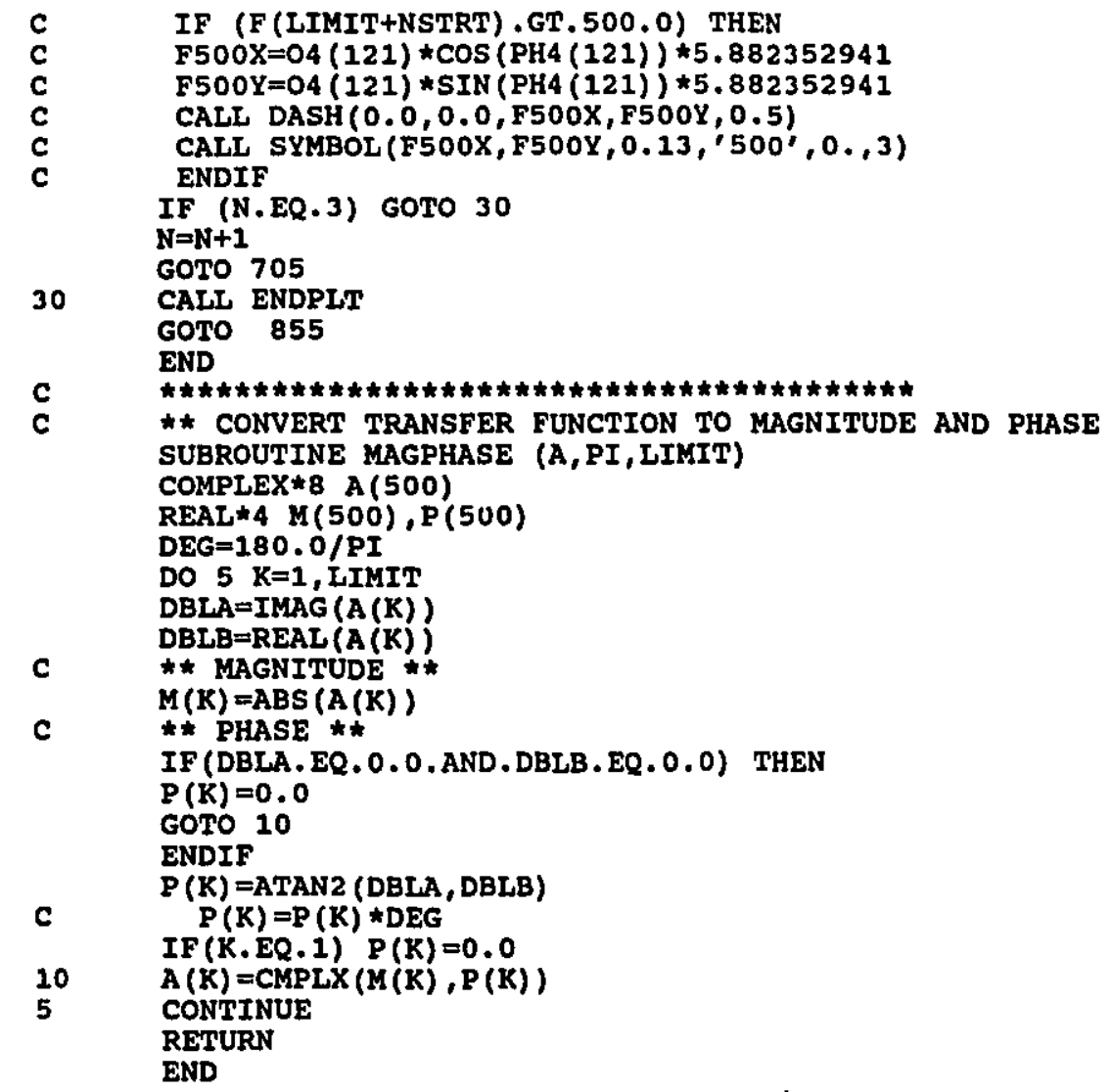




\subsection{Matching of Database and Test Waveforms}

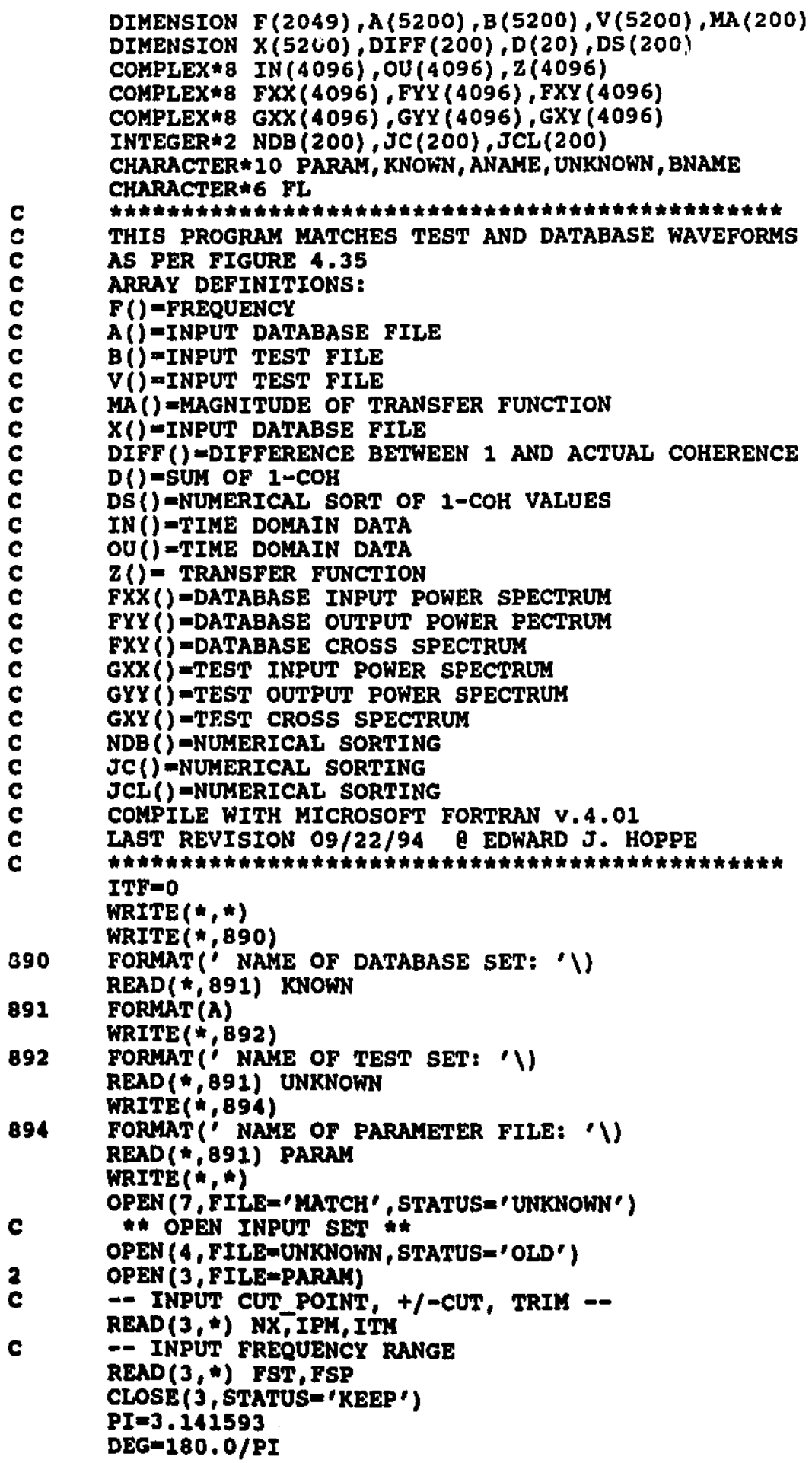


$\mathrm{LN}=12$

$\mathrm{N}=2 * * \mathrm{LN}$

$N D 2 P 1=N / 2+1$

$\mathrm{IDB}=0$

INP $=0$

c

** READ INPUT FILENAME * *

READ (4,'(A)') BNAME

IF (BNAME. EQ .'FIN') THEN

CLOSE (4, STATUS=' KEEP')

CLOSE (7, STATUS='KEEP')

GOTO 999

C $\star$ \# OPEN INPUT FILE **

OPEN (2, FILE=BNAME, STATUS= ' OLD')

INP $=I N P+1$

$\operatorname{READ}(2, *)$ NPT, TSTEP, XZERO

TSTEP $=(T S T E P / 1.333) * 1.0 \mathrm{E} 9$

XZERO $=(X 2 E R O / 1.333) * 1.0 E 9$

$\operatorname{READ}(2, *) \quad B(1)$

$\operatorname{IF}(B(1) . \operatorname{IT} .-1.0) \quad B(1)=0.0$

DO $11 I=2, N P T$

$\operatorname{READ}(2, *) \quad B(L)$

C IF(B (L).LE. -50.0$) \quad B(L)=B(L-1)$

11 CONTINUE

CLOSE $(2$, STATUS='KEEP')

CALL MEDIAN (B, NPT)

WRITE $(*, *)$

DO $12 L=1, N X$

12 CONTINUE

$\mathrm{N} 1=\mathrm{NX}+\mathrm{ITM}$

$\mathrm{N} 2=\mathrm{NX}+\mathrm{NX}$

N3 $=\mathrm{NX}-\mathrm{ITM}$

DO $15 \mathrm{~L}=\mathrm{N} 1+1, \mathrm{~N} 2$

15 CONTINUE

DO $16 \quad \mathrm{~L}=\mathrm{ITM}+1, \mathrm{NX}$

$V(L-I T H)=V(L)$

16

CONTINUE

DO $17 \mathrm{~L}=2, \mathrm{~N} 3$

$B(L)=B(L)-B(1)$

$V(L)=V(L)-V(1)$

17

CONTINUE

$B(1)=0.0$

$V(1)=0.0$

DO $171 \mathrm{Lm} 1, \mathrm{~N} 3$

$\mathrm{X}(\mathrm{L})=\mathrm{V}(\mathrm{L})$

171 CONTINUE

CALL TAIL (B,NX, ITM, PI,N)

C CALL TAIL (V,NX, ITM, PI,N)

DO $22 I=1, N$

IN (L) $=$ CMPLX (V (I))

22

OU (L) $=$ CMPLX (B (L))

CONTINUE

FSTEP $=(1.0 /($ FLOAT $(N) \star T S T E P \star 1.0 E-9)) / 1.0 E 6$

IST $=-1$

ISP=-1

IF (FST. EQ.0.0) IST=1

$F(1)=0.0$ 
DO $25 I=2, N D 2 P 1$

$F(L)=F(L-1)+F S T E P$

IF(IST.EQ.-1.AND.F(L),GE.FST) THEN

IST $=\mathrm{L}$

FST $=F(L)$

ENDIF

IF (ISP. EQ. -1.AND.F(L) .GE.FSP) THEN

ISP=L

$F S P=F(I)$

25 CONTINUE

CALL FFT (IN, LN, PI)

CALI FFT (OU,LN,PI)

DO $30 \mathrm{~L}=1$, ND2P1

IF (F(L).GT.FSP) GOTO 45

$Z(L)=O U(L) / I N(L)$

$\operatorname{GXX}(L)=\operatorname{CONJG}(I N(L)) * I N(L)$

GYY (L) $=$ CONJG (OU (L) ) *OU (L)

$30 \quad \operatorname{GXY}(L)=\operatorname{CONJG}($ IN $(L)) * O U(L)$

C $\star \star$ OPEN DATABASE SET $\star \star$

45 OPEN (5, FILE=KNOWN, STATUS='OLD')

1 IDB $=I D B+1$

OPEN (10, FILE= 'TMP' , STATUS= ' UNKNOWN')

IF $=100+I D B$

$J F=200+I N P$

WRITE $(10,903)$ IF, JF

C CLOSE (10, STATUS = KEEP')

C * READ DATABASE FILENAYE * * $\operatorname{READ}\left(5, '(A)^{\prime}\right)$ ANAME

IF (ANAME. EQ.' FIN') GOTO 200

* * OPEN DATABASE FILE * *

OPEN (1, FILE=ANAME, STATUS=' OLD')

WRITE $(*, *)$ ANAME, BNAME

READ $(1, *)$ NPT, TSTEP, XZERO

TSTEP $=($ TSTEP/1.333)*1.0E9

XZERO $=(X Z E R O / 1.333) * 1.0 E 9$

$\operatorname{READ}(1, *) \quad A(1)$

$\operatorname{IF}(A(1) \cdot L T \cdot-1.0) A(1)=0.0$

DO $10 \mathrm{~L}=2$, NPT

$\operatorname{READ}(1, *) \mathrm{A}(\mathrm{I})$

C $\quad \operatorname{IF}(A(L) . L E .-50.0) A(L)=A(L-1)$

10 CONTINUE

CLOSE $(1$, STATUS $=$ 'KEEP')

CALL MEDIAN (A, NPT)

$\mathrm{IK}=0$

DO $100 \mathrm{~K}=I T M-I P M, I T Y+I P M$

$I K=I K+1$

DO $50 \mathrm{~L}=1+\mathrm{K}, \mathrm{N} 3+\mathrm{K}$

50 CONTINUE

CONTINUE
SUX $=0.0$

DO $55 \mathrm{~L}=1, \mathrm{N3}$

SUM $=S U M+(V(L)-X(L)) \star \star 2$

55 CONTINUE

DIFF (IK) = SUN

CONTINUE

SMALI=1.0E6

DO $110 \quad L=1, I K$

SMALIMMIN (SMALL, DIFF (L)) 


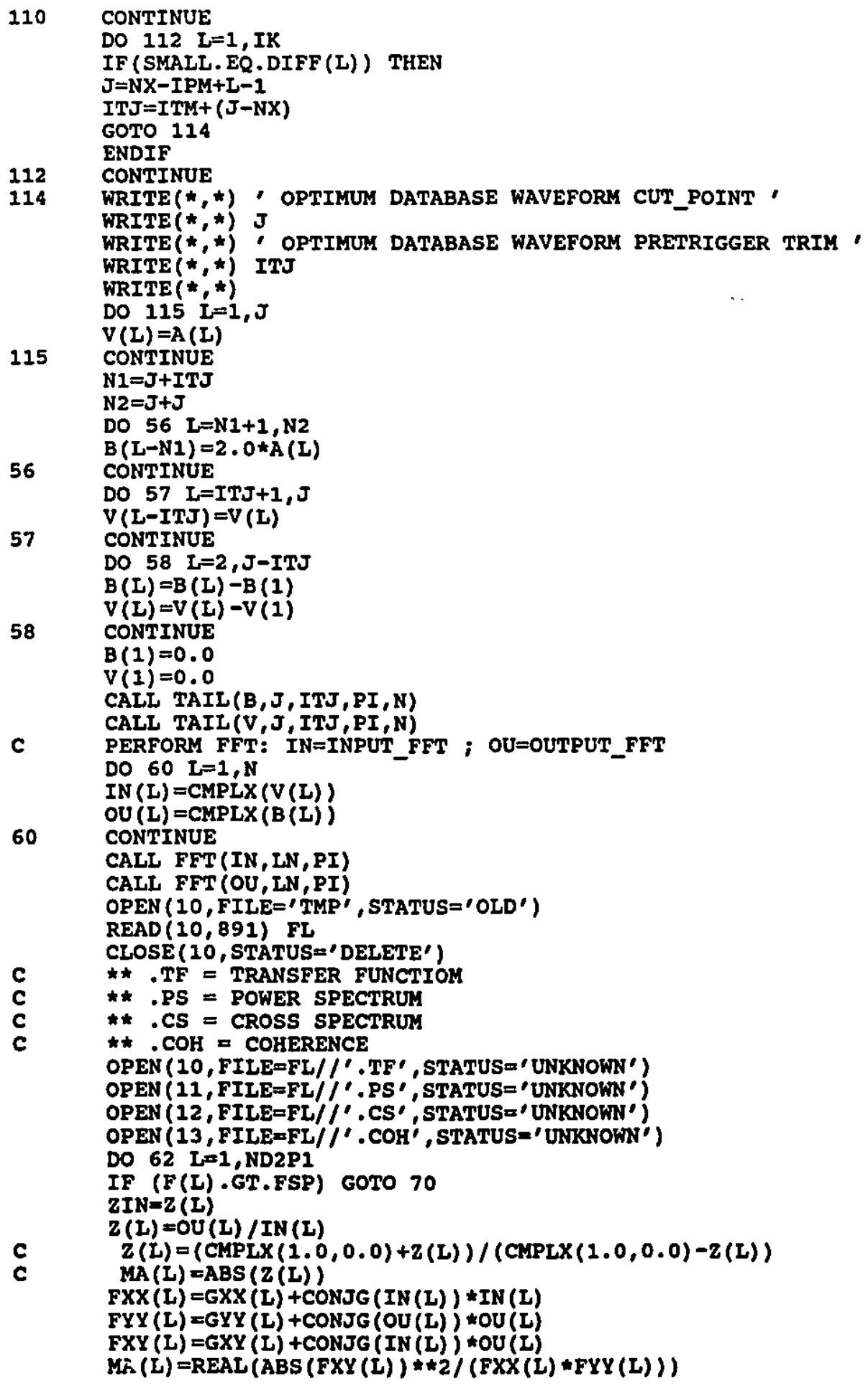




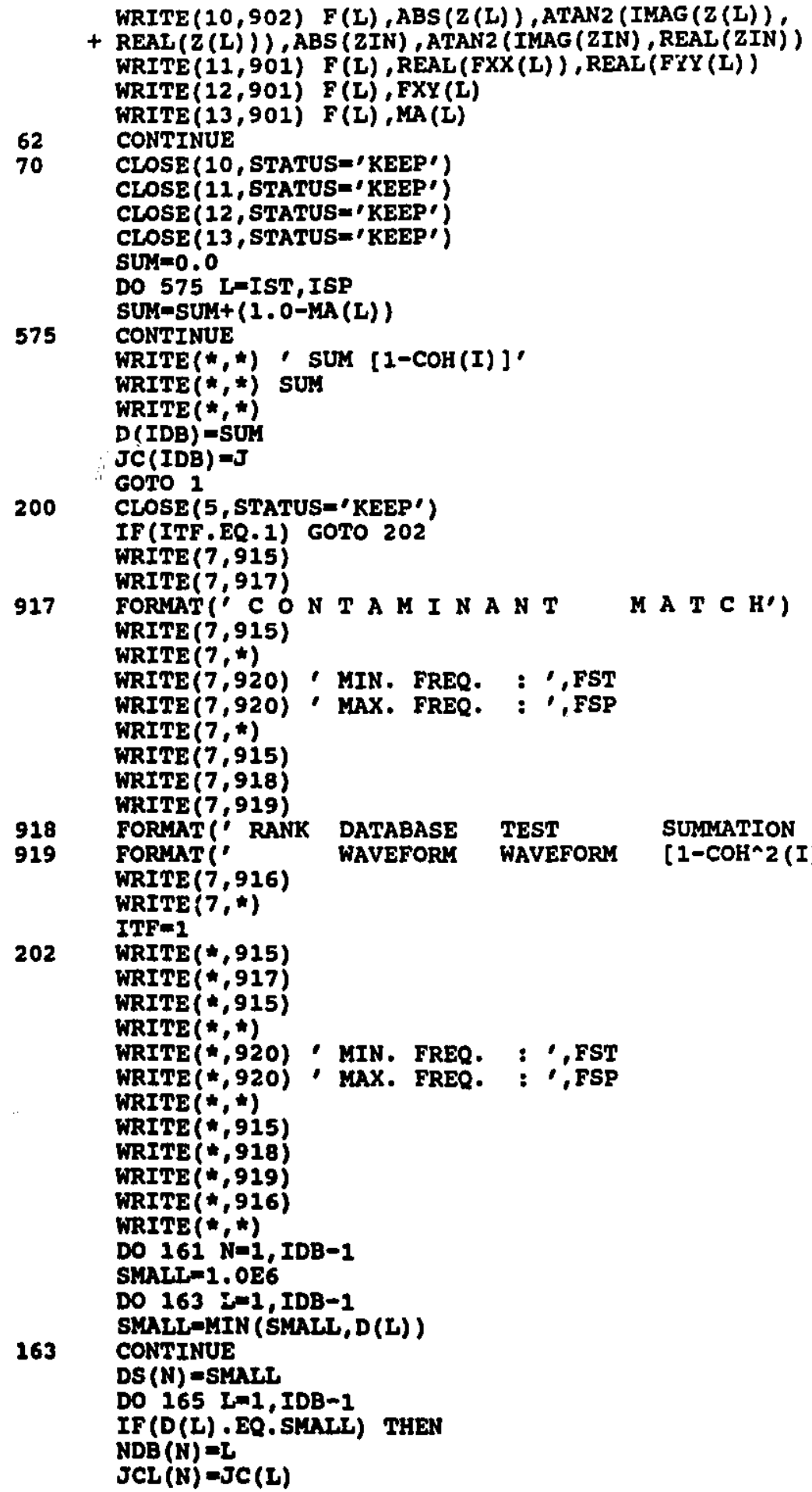




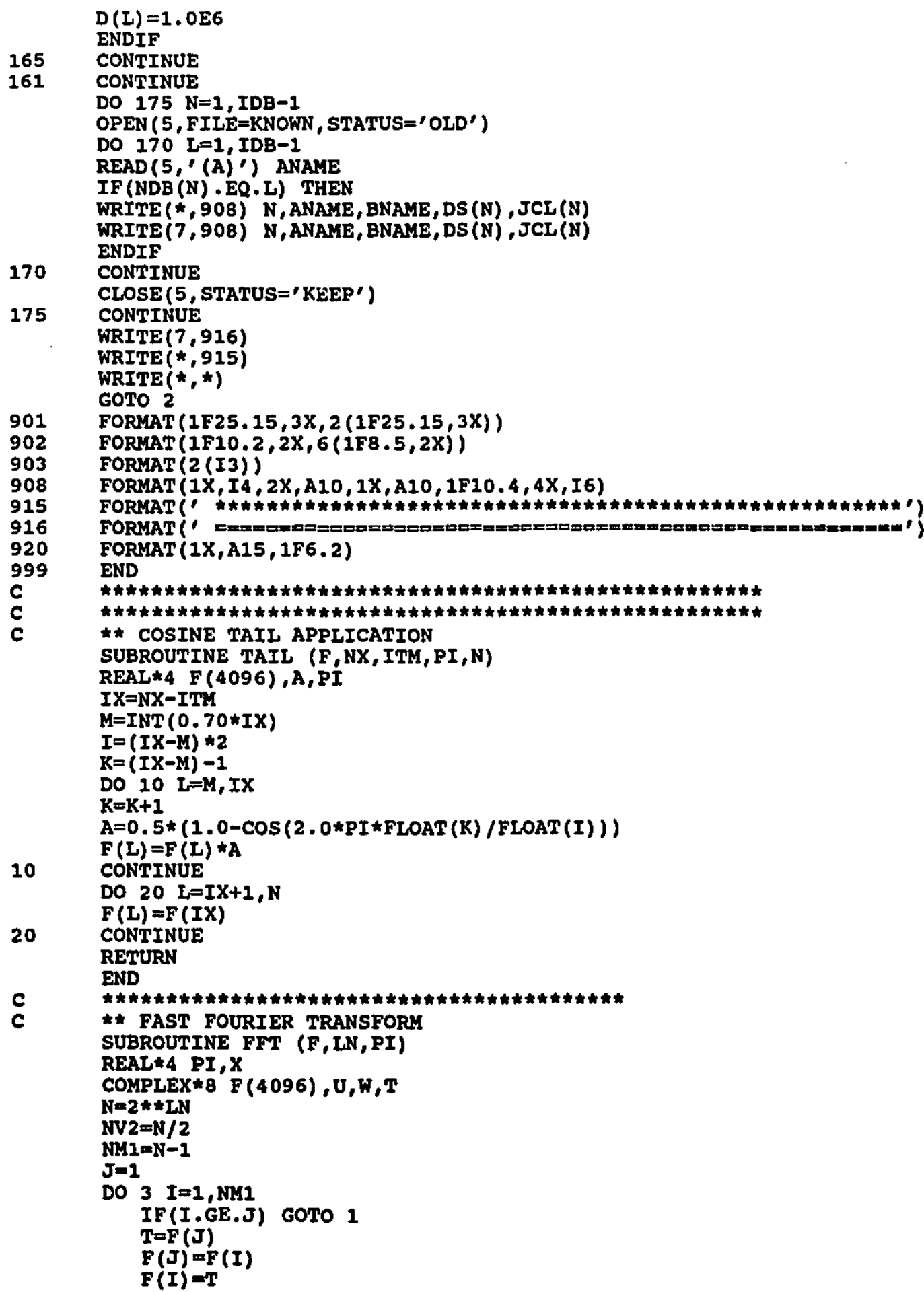




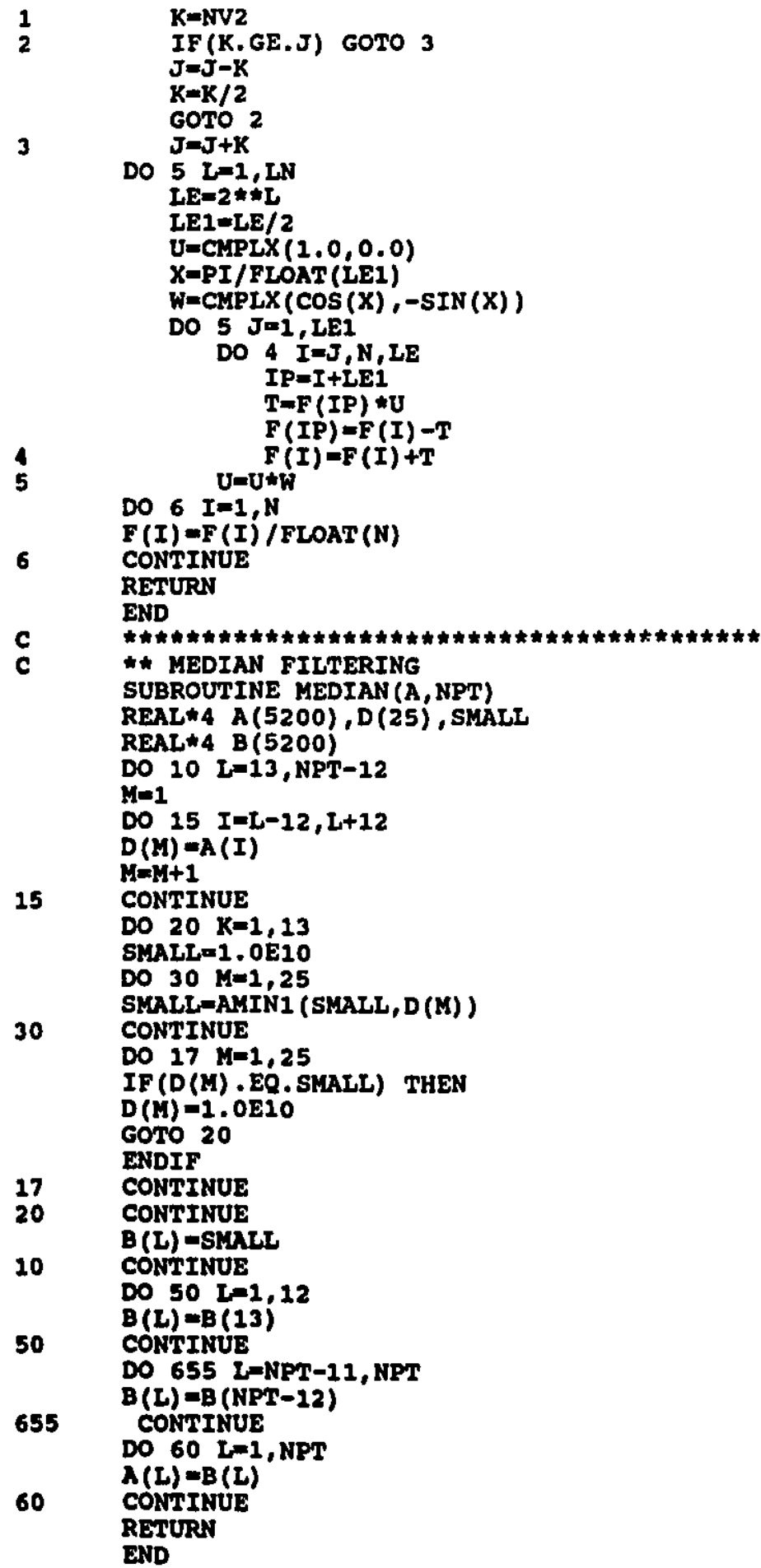




\section{APPENDIX 2}

\section{Previously Published Material}


Canadian

Geotechnical Journal

\section{canadienne de \\ Revue géotechnique}

Appiization of electric polarization to contaminant detection in soils

RAYmond N. Yong and EDWARd J. Hoppe

Volume $26 \bullet$ Number $4 \bullet 1989$

Pages 536-550 


\title{
Application of electric polarization to contaminant detection in soils
}

\author{
RAYMIOND N. YONG ANI EDWAKI) J. Il(olיונ:

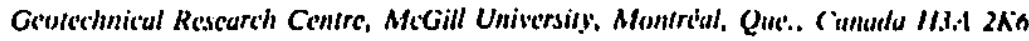 \\ Received November 24, 1988 \\ Accepted April 18, 1989
}

\begin{abstract}
D'reliminary experiments indicale the feasibility of consiructing for field use a comaminant-delection instruncntatiun based on diclestric measurements. This :tudy applies the technique of time-dumitin reflectometry to assess characteristic "signatures" of some selteited contaminants and soil-contaminant mixtures. The results imply that a proper differentiation between various signatures can be altained, allowing an assessnemt in regard to soil-cuntoniunant stalus. Flac profwesed teclnique is similar in principle to the induced-polarization method applied in mincral exploration.
\end{abstract}

Key' words: clectric polarization, contaminant transport, dielectrics, induced polarization, nonnolar liquids, limts. domain reflcctometry, relaxation, contaminant-soil interaction.

Des expériences préliminaires indiquent la faisabilité de la construction d'une isstrumentation nour la délection de contaminausts sur le terrain basée sur les mesures dičlectriques. Cette ćtude utilise la teclınique de reflectométrie à plage temuporelte pour évaluer les " signatures " caratéristiques de contaminants sélectionmés el de mélantes sul-contianintant. l.es résultats impliquent que l'on peut obtenir une différentiation entre les diverses sigualures suffisanle pour permıttre

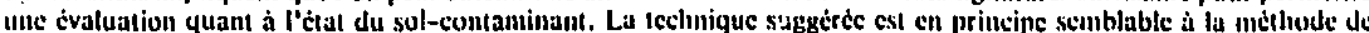
polarisation induite utilisće pour l'exploration minikre.

Mots clés : polarisation èlectrique, transport de contaminant, diélectriques, polarisittion induile, liqusides ntun polaires, réflectomćtric à plage temporelle, relaxation, interaction sol-contaminant.

[Traduit par la revie)

(ans. (iecutcth. J. 26, 536-550) (19R9)

\section{Introduction}

In the last decade, mounting environmental concerns have forced goveruments of the United States and Canada to pass a scries of regulatory legislations, aimed at protecting the groundwater supply. These actions have resulted in a substantial decrease of waste water discharges into lakes and strcams, but the use of land as a major repository of hazardouts waste still continues. According to the United States Lnvirommental Prolection Agency, American industry produces approximatcly 35 million metric tons of toxic waste cach ycar (Waller and Davis 1984). Much of this waste is disposed in land impoundments contained within man-made or natural matcrials, such as synthetic and clay liners. The single, most important requirement for these liners is that they act as barriers to fully contain hazardous wastes or leachates within the disposal sitc. In many instances, as for example in the Province of Quebec, Canada, the use of clay liners as batriers has become a mandatory requirement on all newly constructed land fill sitcs (ministċe de l'Environne. ment du Québec $1987 a, b)$.

The use of low-permeability lining matcrials has bcen proven an effective method for containment of many types of waste leachates and could bencfit from the use of an in situ detection lechinique to monitor the performance of these litsers. Current monitoring procedures, which generally rely upon groundwater-quality monitoring or use of suction lysimeters, are not totally satisfactory in pinpointing the location of a liner failure or in evaluating the extent of movement of a contaminant plume in the liner or in the subsurface. Obviously, detection of a plume advance between wells can pose a scrious challenge, particularly if the wells are not "properly" placed.

The aim of this study centers on the development of a viable fictd monitoring technique capable of detecting the advance of a contaminant plume in the substrate soil material. The proposed method involves an application of phenomena associated with the electrical polarization of diclectrics. The measurement of frequency-dependent electrical properties of a contaminated soil can provide a claracteristic "signature" sufficiently different from that of an uncontaminated soil to pernit detection of a plume advance.

Before providing an accounting of the development of the technique and of the obtained results, it is useful to review the diclectric behaviour of materials and stress its relevallcc to the problem at hand.

\section{Theory}

In dealing with subsurfacc contamination, it is informative to relate the level of soil contamination to the chatuge in electrical properties of the soil. These properties may be substantially affected by the introduction of liquid contaninant into the soil pores: In the initial approacli to the prob. $1 \mathrm{em}$, it is common to resort to a de resistivily survey in siru. This method can provide a quick and inexpensive way of locating a subsurface contamination, provided that the geological cross section is fairly uniform. In areas of complex lithology, however, such an approach cannot readily discern between the resistivity of a particular soil type and that of a pore fluid. In ract, a varicty of chemically different matcrials exhibil essculially similar de resistivities. I'o address this lack of selectivity, one may consider moniloring the resistivity not only at zero frequency (dc) but also over a very wide range of electrical frequencies. From the measurement standpoint, contantinated soils can be regarded as diclectric matcrials, with charactcristic resistivities and dielectric constants influenced by the chemical nature of the contaminant. The problem entails the interaction of these dielectric materials with an electric or a magnetic ficld.

When a time-dependent voltage $V(I)$ is applied to the diclectric, it causes a charge $Q$ to vary with lime, resulting in a flow of current $\boldsymbol{l}$. Dielectric relaxation concerns the tim- 


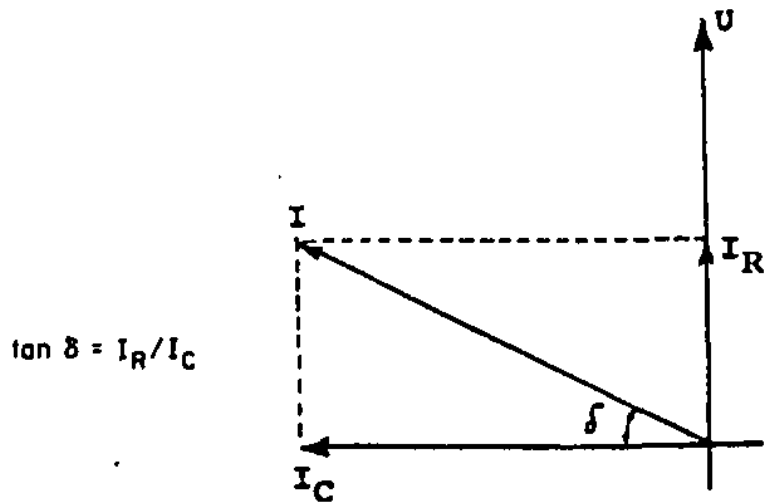

Hitt. I. Phase relaliunship between vollage $(C)$ and current in in at res Jislectric. $I_{k}$. resistive component of curremt; $I_{t}$.

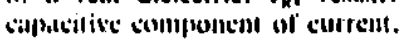

itig of this electrical response, which reflects the specific relationslipip between $V(t), Q(t)$, and $I(t)$ for various matcrials. This relationship applies to a linear system, where a response ald a stimulus are proportional to each other. Relaxation constitutes a delayed response 10 a changing stinulus. The stimulus is usually an clectrical ficld, whilc $Q(I)$ and $/(I)$ (Danicl 1967) form the response.

The relationship of $V(t), Q(t)$, and $I(t)$ can be considered by atn analogy to an electrical circuit consisting of a (a)pacitance $C$ and a resistance $R$. When a step-runction vollatge is applied lo a capacitor (connected in scries with a resistor), the charge rises exponentially form $Q=0$ at $t=0$ lo a fraction $1 / c$ of its final value at a time $\tau=R C$ : (I) $Q=C v(1-a \cdot t)$

The delay time $r$ is called a "time conslant" in electrical engintering and a "relaxation lime" in physics and chemistry. The ceapacitance of the diclectric is equal to the product of the geometrical component $C_{v}$ and the diclectric collstumt . Diclectric relaxation is the manifestation of a phituonetuon whereby the material constant $f$ is variable over at wide ratrec of frequentics. Thereiore, the capacitance of a reil tapacitor actually varies as the time-dependent voltage is imposed on its terminals.

When the excitation voltage is sinusoidal, with a given frefueticy $f$, and the recorded response forms a current $I$, then the plitse relationship between these quantities reflects the diclectric properties of the matcrial. In a textbook exaumple of a pericet diclectric placed in an electric field, Ilse current leads the voltage by $90^{\circ}$ and no power is being dissipalid. Al the other exireme, ill a condutior, the drift of lire clectrons forms a conduction current in phase with the ilppliced voltage. It has been documented that in practical diclectric nualcrials there is always a detectable conduction curicill, which in the calse of a good insulator has a very smill value (von Hippel 1954). Thus, in real dielectrics the r'sultanl current no longer leads the voltage by $90^{\circ}$ but by

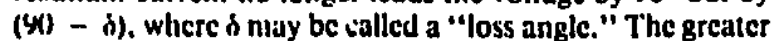
the value of $b$, the greater the power loss in the dielectric (lïg. I).

There are stveral mechanisms ol polarization that cause a Prequency dependence of electrical properties. Contribufions to this polarization arise from the displacement of ele:trons relalive to the nucleus of an atom (electronic

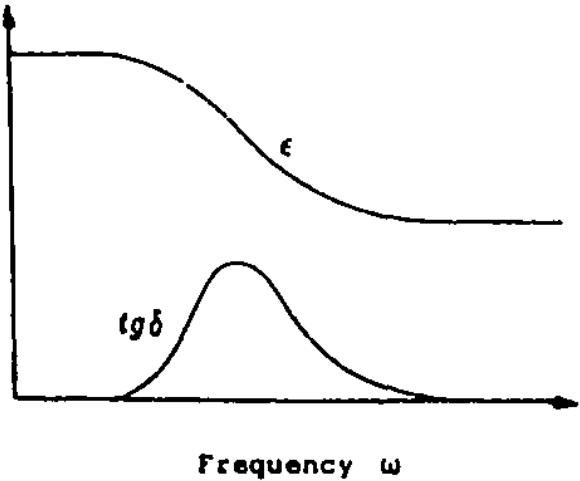

Fisi. 2. Idealias locyucency dependellec of dielectric constant and loss angle (afler Cicmiant 1433).

polarization), the movensent of onc atomic nueletes relitive to another in the sanie molecule (alomic polarization), lice alignment of molecular dipoles in the directions of applied clectric lield (oriemtational polarisat iont), and the accousulas tion of charges at intcrlaces between materials with differellt clectrical propertics.

It has been observed that, duc to polarization phenoniena, $\delta$ is not a constant for a particular matcrial but varics with the freyuency. The behaviour of the naterial tun be visualized in terms of a molecular dipole rotating into the direction of the electric field. When the speced of lield reversal becomes faster that the rate of dipolar reorientation, rotation of tlis molecules cannot occur. At this relaxation frequency the material's diclectric constant drops in value, since there arc rewer available charges that can be displaced by the elect ric ficld. Simultancously, the loss angle $\delta$ increases markedly, signifying a substantial rise in chergy dissipation (Fig. 2). The variability of diclectric constant with frequency is known as dispersion. Thus, the time or frequellicy dependence of the dielectric constant can be used to provide information on the rate of dipolar reorientation in the material. The relixation frequency is found in be characteristic of the particular polar moleculc.

The geophysical icchnique of indueed polarization (II') detects phenomena primarily associatej with interfacial polarization. Recent work suggests that organite chemicuals can interfere with the exchange process in clays, permitting direct detection of these organics (Olhoeft 1986). This mechanism has been a subject of particular interest to chemists and molecular plyysicists performing laboratory studies on material propertics.

Gencrally, molarizalion can be attributed to a nution ol jons, a motion of molecular dipoles, or al motion of elte'crenss in a molecule. The lirst group of causes occurs al the low end of the spectrum, typically al so-called power frequencies. A dipole action is conmonly observable at microwave frequencies, whereas a motion of electrons is associaled with optical frequencies. The polarization phenumenon due to ionic displacement was investigated extensively by Maxwell (1854) and Wagner (1913). Credit belongs to Debye (1929) for exploring the mechanism of dipole polarization and 10 Lorentz (1915) for work on electronic polarization.

In studying the selaxation properties of various materials it is imperative to find a frequency range of interest where the effects are most pronounced. As pointed out by Cole, 

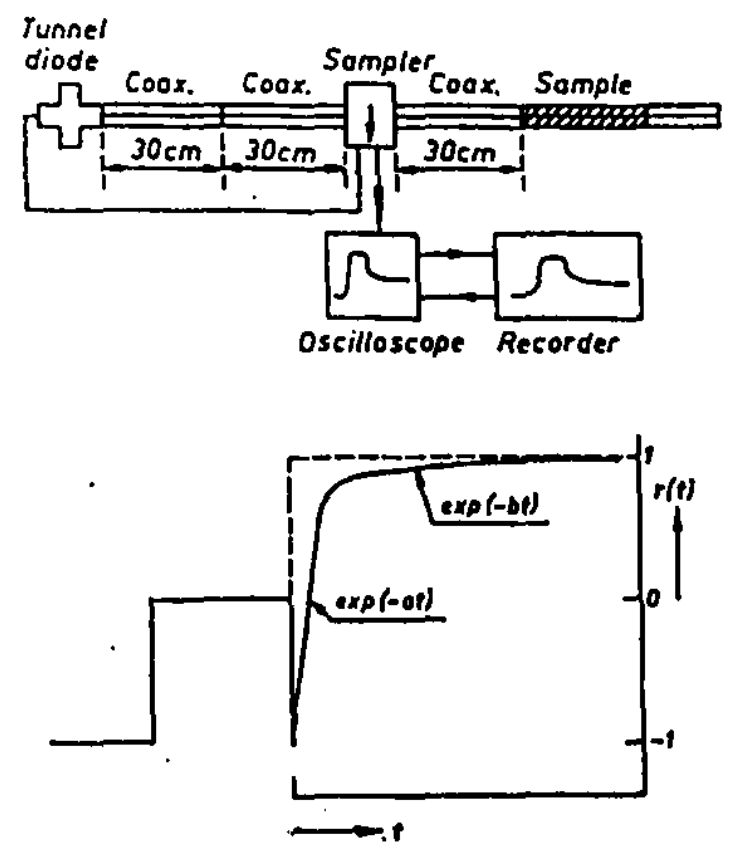

Fili. 3. Typical sctup for the TDR method and a schemalic form of the step response for a Debye relation; the cunnel diode nroduces a step impulse (after van Gemert 1973).

this frequency range is often as awkwardly low for solids as it is awk wardly high for liquids. The reason for such disparity is that the charge displacement is much more constrained in a solid matrix than in a liquid. For example, water molecules in a liquid statc become aligned with an clect ric field in about 30 ns (kicller and Firischknecht 1966). The anount of polarization is fairly large, as water exhibits the diclectric constant of 81.5 at low frequencies.

A study conducted by Hockstra and Delancy (1974) indicates that in geological matcrials the relationship between water content, conductivity, and diclectric constant is a strong function of the soil type from de levels up to about I MHz. Olhocft (1987) shows that in clay-water systems, there are significant effects of the clay up to $100 \mathrm{MHz}$. At higher frequencies the influence of the pore fluid becomes dominant. It is also observed that the frequency of maximum dielectric loss is appreciably lower in a soil-water mixture than in bulk water because of the constraints on charge displacement, attributable to the double layer. It is envisaged that the problem might become more significant in active clay soils where double-layer effects and influences are more pronounced. A study by Bockris et al. (1966) indicales that liquid molecules of the double layer are severely restricted in their motion, and their relaxation frequency is lowered. Work involving measurements on packed protein powders with adsorbed water, conducted by Harvey and Hoekstra (1972), reports two distinct relaxation frequencics, corresponding to two layers of adsorbed water.

\section{Avallable measurement techniques}

The traditional four-electrode arrangement used in the IP method is capable of detecting low-frequency relaxations, which are commonly associated with the interfacial polariza- tion. While effective for mineral exploration, this setup is not designed io detect relaxations of orientational polatization occurring in pore Muid. $\wedge$ majority of high-frequency dielectric measurements have been confined to a laboratory environment; however, as with the IP in situ technique, the objective of cach method of measurement was detection of the electric polarization phenomena. To perform high. frequency measurements, the inonitoring circuit must be properly shiclded from, for example, inductive coupling in IP between the transmitter and recciver.

To investigate the relaxation pattern of an analyzed material, the dispersion of clectric propertics of dielectries is usually evaluated over several decades of frequency. Since the transient technique covers a broad frequency spectrum with a single impulse, it is often judged more expedient than the altcrnative of performing a multitude of frequencydomain measurements. Many rescarchers favour the applicition of a transient method over the "point-hy-poinl" approach required in the frequency domain. $\wedge$ Fourier sjucetrum of such an impulse contains a wide range of frequencies. A single impulsc, applied to a diclectric malerial, yiclds. a time-domain response. When lic liourier spectral of the input and the response signal are calculated, it is possible to arrive at the same outcome as obtained with the frequency-domain approach. The experimental results are often displayed in the form of a Cole-Cole plot (Cole and Cole (941).

Following the work of Fellner-Feldegg (1969), pulse transient methods have found a widespread use in the study of fast relaxation processcs appearing al microwave frceuencies. These methods commonly originate from the lield of study called time-domain reflectometry (TDR), developed in electrical engineering. Typically, an electrical impulse with a fast rise time is sent into a coaxial cable. Upon reaching the cha of the cable cenbedded in the analyzed material, the impulse is reflected in a manner indicating the characteristic spectral signature of the sample material (F̈ig. 3). The reflected signal can range in magnitude from $+100 \%$ to $-100 \%$ of the incident signal. These two extremes correspond to conditions of open-circuit and short-circuil resistivily of tlic sample material. The shape of the wave form at carly times is indicative of capacitive propertics of the matcrial. In the case of an idcal capacitor terminating the costuial cable, the reflected wave form ofrops rapidly to zero potential, before increasing exponentially towards the level of twice the amplitude of the incident wave form. This lype of behaviour represents the capacitor's property of being a virtual conductor at high frequencies and behaving like an insulastor at a de level. In the case of a practical diclectric malerial, the reflected signal does not exhibit a purcly exponential rise, because of polarization plenomena and variation in diclectric constant and capacitance. $\Lambda$ good review of the application of TDR techniques to soils can be found in Davis ef al. (1977).

Dielectric relaxation has long been recognized as a power. ful tool for analyzing the physical statc of a systcm containing polar molecules or groups. Historically, onc of the methods for studying the behaviour of polar molecules has been by measuring the complex diclectric constunt $\epsilon(i \omega)=\epsilon^{\prime}(\omega)-i \epsilon^{\prime \prime}(\omega)$ over the frequency range of in:srest. The results are commonly expressed cither as a diclectric constant versus frequency graph or as a Cole-Colc plot of a dielectric loss versus dielectric constant. Diclectric spec- 
troscopy covers an unusually wide range of frequencics, from the $10^{-4} \mathrm{~Hz}$ to the high GH\% region, with geologial malerials typically analyzed in the lower end of this spreciruulı.

\section{Experimental study}

In the present study, both time-domain and the frequencydomain approaches were evalunted and the time-domain leclinique was selected. In time-domain measurement the distribution of high-frequency components of an inpulse is dependent on the signal's rise time. Thus, a stecply rising impulse cxhibits a wide spectrum.

To assess the practicality of applying a TDR method to contaminant detection, a series of laboratory experiments was conducted. The instrumentation setup is shown in lijg. 4. The main components include the step-function generator, coaxial cable terminated by a probe, digital waveform recorder, and portable computer to analyze the ikçuired dala. The recording deviec selected was a Tektronix 11402 digiticing uscilloscone llat has a bandwidth of I GHz. The impulse signal trausmitted by the generator is split as it travels past point A. Half of this signal is detected by the digitizing oscilloscope, while the other half reaches the diclectric matcrial at point $B$, where it is reflected. Because the relurn signal is also split in hair al point $A$, its amplitude ranzes from $-50 \%$ to $+50 \%$ of the incident signal.

The step-function generator uses a mercury-wetted contact relay, which delivers reproducible pulses with subnanosecond rise times (Andrews 1973). The step-function generator cliarges a section of RG 58 coaxial cable, acting as a capacilor, and distharges it through the mercury switch to a low-loss RG, 214 cable, where it propagates with minimum distortion.

To simulate field conditions, the length of the RG 214 cable was selected as $7 \mathrm{~m}$. In the field, a probe would be drilicd or pushed into the soil and the recording instruments placed at the surface. A substantial length of coaxial cable results in impulse deterioration. The efrect of pulse degradation is illustrated in Fig. 5. The attenuation characteristics of the initial signal are compared with those of the signal reflected trom point B, measured at point $A$. In the range of 0-200 MHz the RG 214 coaxial cable does not significantly itlenuate the signal. Furthermore, it can be seen that the $200 \mathrm{MHz}$ frequency component exhibits about $\mathbf{4 0} \mathrm{dB}$ attenualion, which translates into a signal strength of 0.01 of the de component. This signal level is well within the resolution cupability of Tektronix $1 / 402$.

The concept of an extended central electrode, surrounded by a diclectric matcrial, borrows from the lumped capacitance melhod of Iskander and Stuchly (1972). Electrically, the equivalent circuil may be represented by a sliunt capacilor terminuting the couxial line. The reflection coefficient I' for a Iransmission line of impendance $Z_{0}$ terminated by the loud impedance $Z_{1}$ can be expressed as

[2] $r=\frac{Z_{1}-Z_{10}}{Z_{1}+Z_{11}}=\frac{V_{\text {ref }}}{V_{\text {iw }}}$

In the time domain, the input signal, system response, and output signal are related through the Duhamel convolution integral:

[3] $y(t)=\int_{-\infty}^{\infty} h(r) h(t-\tau) d r$

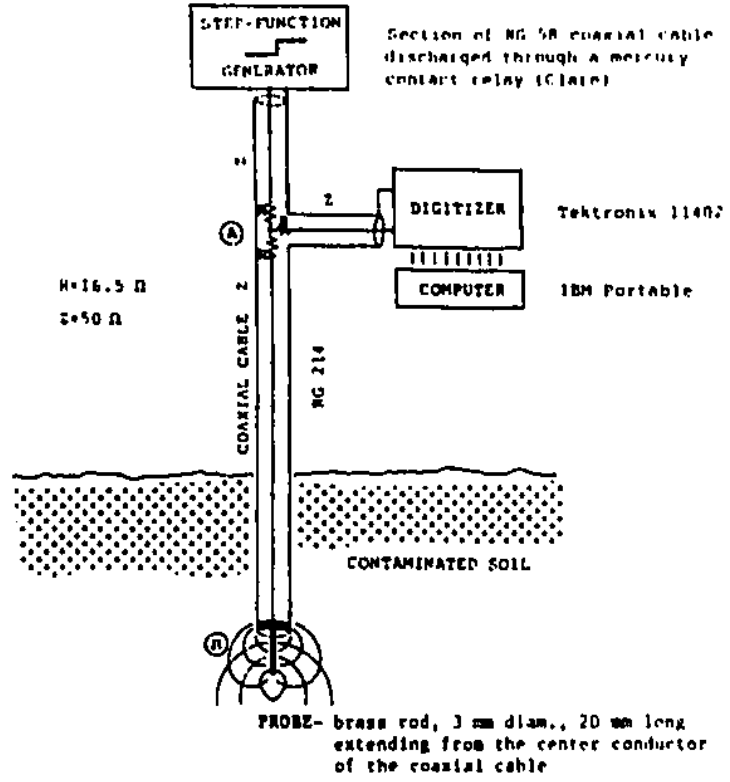

Fici. 4. Experimental setup smployed in this study.

In principle, the convolution may be seen as a process of correlating one time series with another that has been reversed in time. The input and the output signals can be transformed into the frequency domain through the use of fast fourier Iransform (FFT). Subsequently, the trans [er function $H(N)$ of a system may be deconvolved by dividing the spectrum of the output by the spectrum of the input waveform:

[4]

$$
Y(\Omega)=H(\Omega) \cdot X(\Omega)
$$

$$
H(\Omega)=\frac{Y(n)}{X(f)}
$$

What usually needs to be established is how a given system responds to each frequency component of an arbitrary input signal. In a lincar, time-invariant system, such a response, referred to as a transfer function, offers a complete circuit characterization (Ramircz 1985). Proper application of the spectral analysis demands that a wave form to be transformed begins and ends at the' same amplitude. Steplike wave forms produce a well-known truncation error, if they are directly treated by the FFT algorithm. Scveral methods addressing this particular problem have been published (c.g., Waldemeyer 1980).

Tests were performed on several arbitrarily chosen "tontaminants" and on soil-contaminant nixtures. The soil used to creale these mixtures (simulating a typical sandy clay) consisted of $60 \%$ Lake Agassiz clay and $40 \%$ crushed granodiorite passing sieve No. 50 and retained on sicve No. 16. Samples were prepared with 60 and $40 \%$ fluid content, representing fully saturated and unsaturated soil conditions. Table I summarizes the chemical composition of fluids usedi in the experiments.

Lake Agassiz clay was collected from St. Boniface, Manitoba. Its mineral composition, in decreasing order of abundance, is montmorillonite, illite, quartz, kaolinite, feldspar, and dolomite (Yong et al. 1986). Based on the saturation extract analysis, the main water-soluble ions were classified as $\mathrm{Na}^{+}, \mathrm{Ca}^{2+}, \mathrm{HCO}_{3}^{-}$. The predominant extract- 


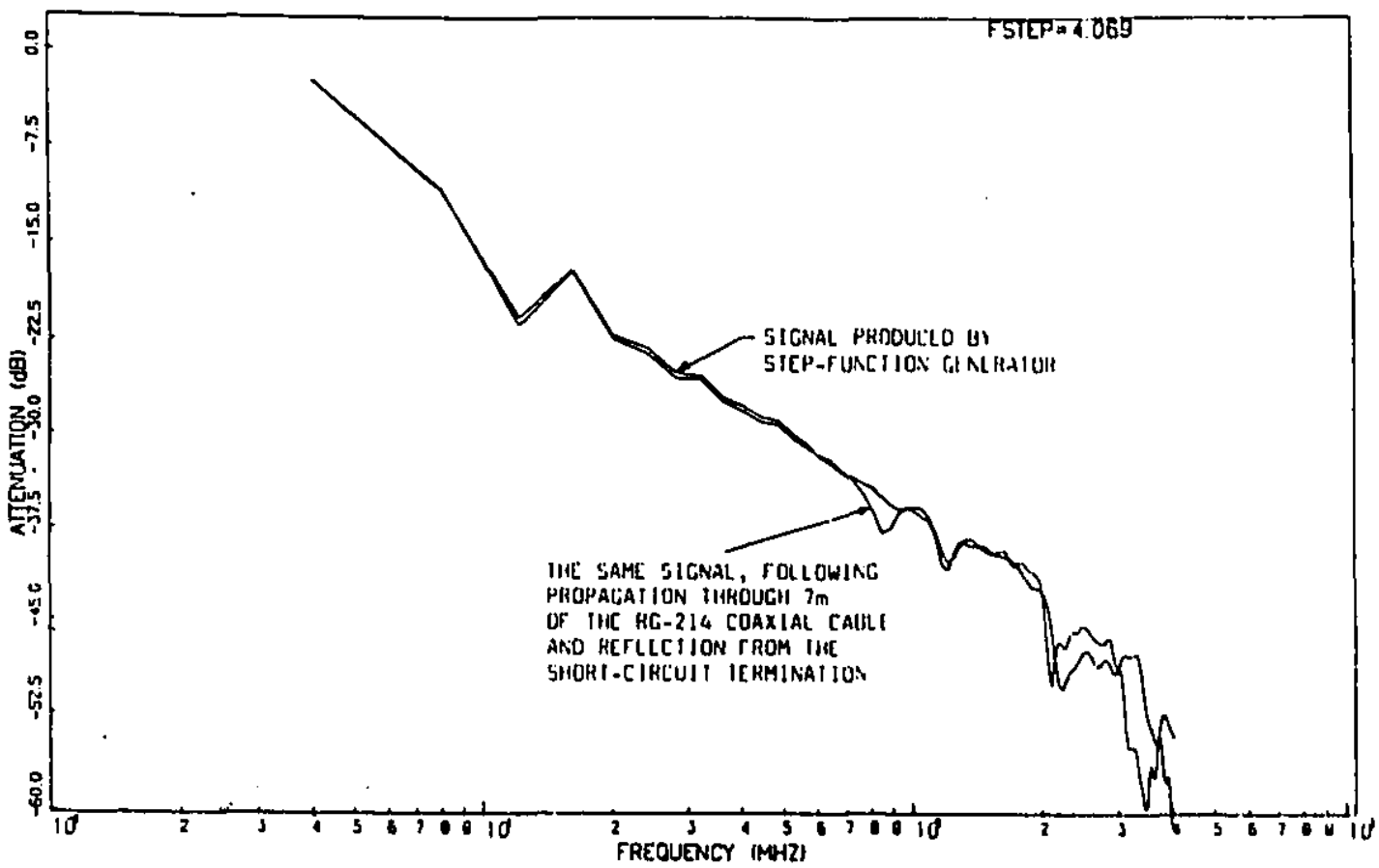

Fic. S. Effect of pulse propagation through the coaxial cable on llie signal altenuation (frequency domain fir.

Taul.: 1. Chemical characteristics of jiquids used in experiments

Pullutant
$\mathrm{pH}$

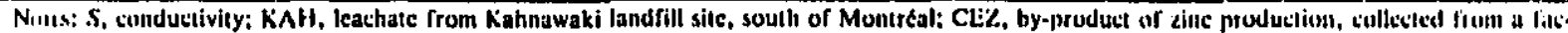

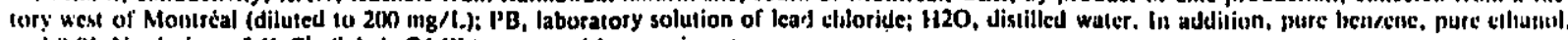
and $0.01 \mathrm{~N}$ sthlitun of (aCl, (label: CACL) were used in experiments.

able ion was found to be $\mathrm{Ca}^{21}$ and the cation exchange capatily (CEC) was decrmined as $71.4 \mathrm{mg} / 100 \mathrm{~g}$. The liquid and plastic limits were $112 \%$ and $28 \%$ respectively. The crushed granodiorite originated from Cold Springs Quarry in Lac du Bonnet, Manituba. Its mineralogical composition was found to include quartz (28\%), feldspar plagioclase (35\%), and microcline $(20 \%)$.

\section{Time demain}

\section{Experimental results}

Measurements were performed on contamimants and on soil-contaminant mixtures, prepared $24 \mathrm{~h}$ in advance of testing. During the $10 \mathrm{~h}$ testing period, no significant scatter in cath matcrial's response was observed. Figures 6-8 display the experimental results obtained with a circuit as shown in Fig. 4. Figure 6 shows the wave forms obtained from lests on comtarninants themselves, whereas Figs. 7 and 8 portray the wave forms of soils laced with the individual cortuminants. Each wave form, sampled at a 40 ps time stcp, consists of $\mathbf{4 2 2 0}$ data points and ilfustrates the initial voltage step as the impulse reaches the digitizing oscilloscope and a subsequent reflection from the sample material localed at the end of the coaxial cable. The time $t$ - 0 signifies the triggering point for the wave form acquisition to the digitizer's memory. The negative lime range represents pretrigger events. Alter about 71 iss following tlec starl ol' incident impulse acquistion, the rellected sigual reaches the digitizer. This time lag is governed by the lenglh of eable between the sampling point and the probe.

Data can also be conveniently presented in terms of the load impedance of various diclectric materials. The transfiormation, based on the relationship between the rellection cocfricient and llie load inpedanee $([2])$ is shown in Figs. 9-11. These figures portray the time dependentet of the load impedance $Z_{\mid}$, departing from the so a conxial cable impedance $Z_{10}$.

\section{Frequency domain}

The relationship between applied signal and observed response is commonly analyzed in the frequency domain. The technique used for processing of time-domain data in this sludy involves application of a Hanning window to the last $50 \%$ of data points. Additional preprocessiug of wave forms includes treating data with a smooth, nonrecursive filter, passing the lower one-third of the Nyquist interval (Hamming 1977). Furthermore, 100\% zero padding is applied, so thal 


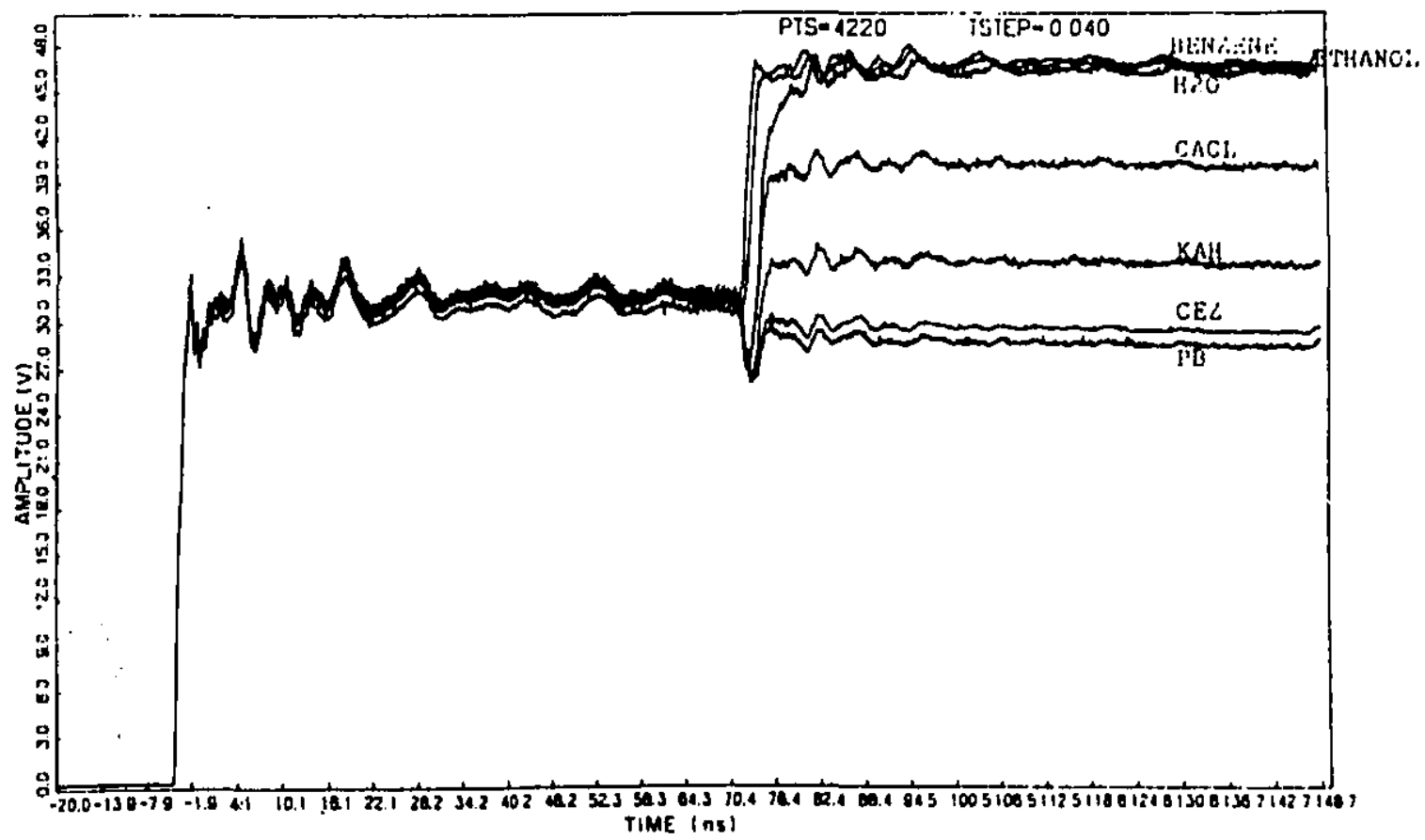

Fici. 6. Time-domain response of various contaminats (time domain).

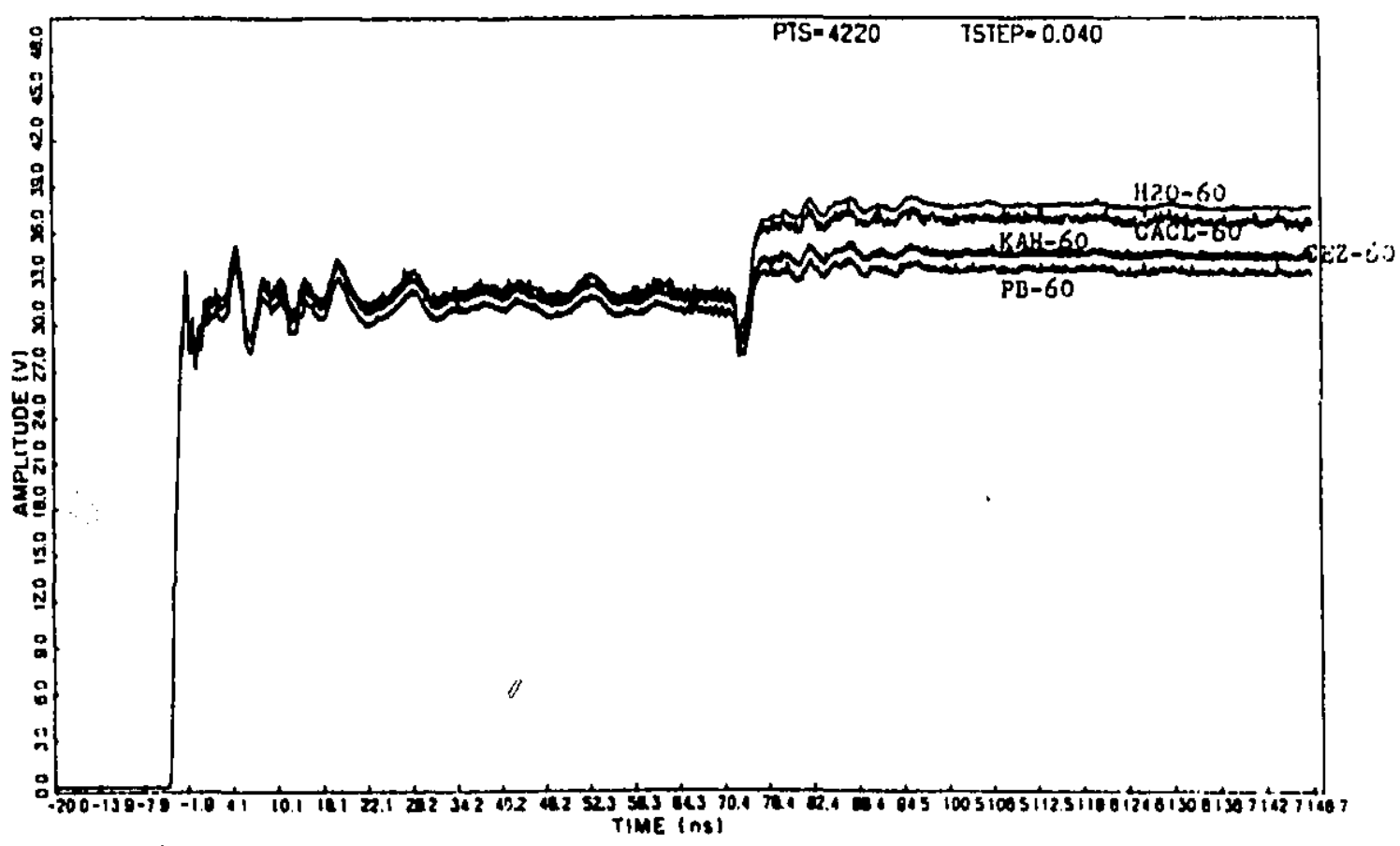

Heti. 7. Time-donain response of soils saturated with contaminants; $n=60 \%$.

the analyzed impulse signal appears to the FFT algorithm as a repetitive wave form. The transfer funclion or the lirequency respensse, compuled by dividing the output wave form by the input in frequency domain, represents the characteristic reflection coefficient for a given dielectric. The spectrun of the input impulse is based on ilhe short-circuit reflection, while the wave form reflected from an analyzed matcrial is taken as an output signal.

Figure 12 illustrates some typical examples of the responsc to a step-iunction excilation in a coaxial line terminated by resistunce and capacitance. Each time-domain wave form represents a mathematical idealization of the real signul (i.s., 


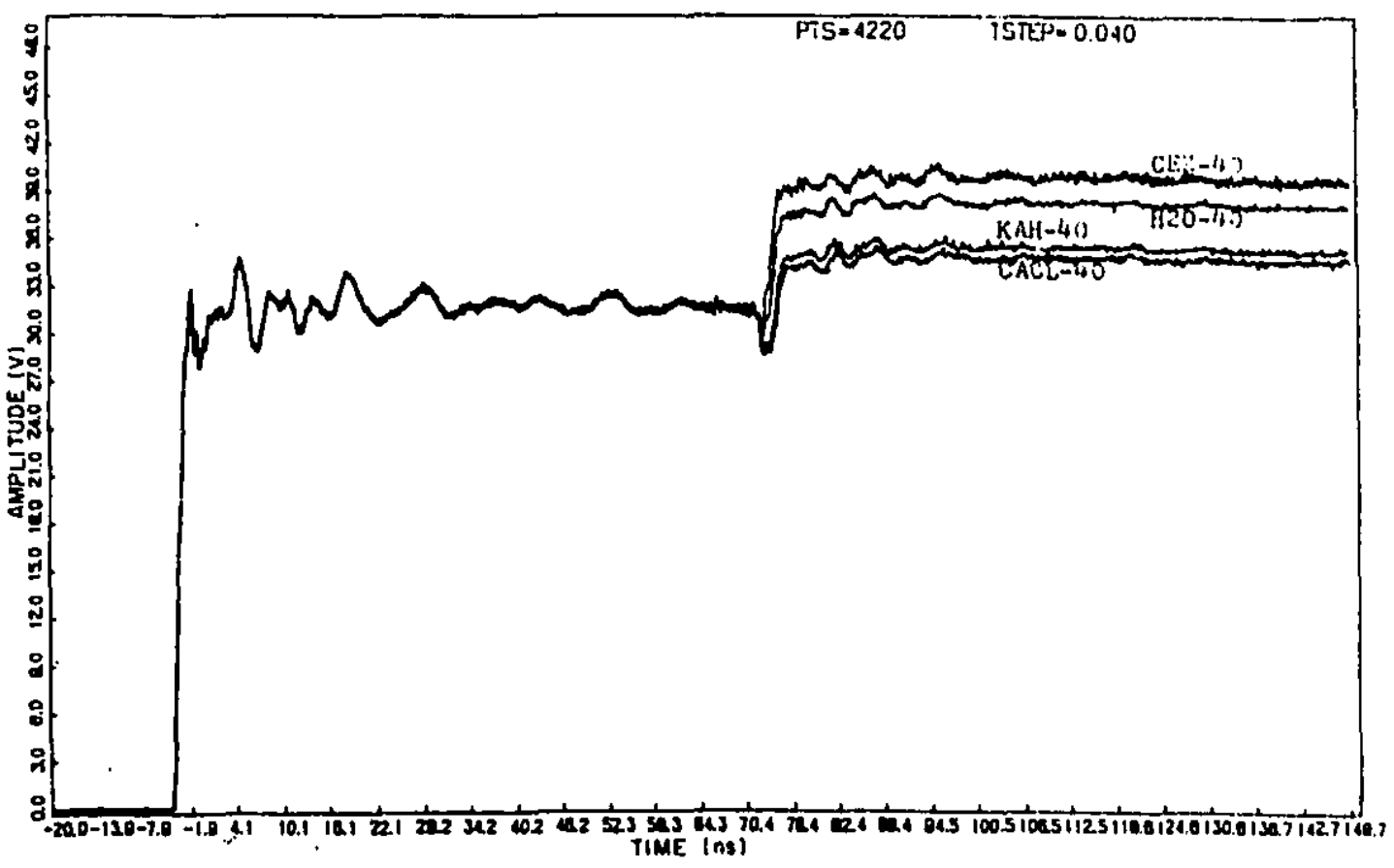

fici. 8. Time-domain response of soils saturaled with combunisanls; iv :40\%\%.

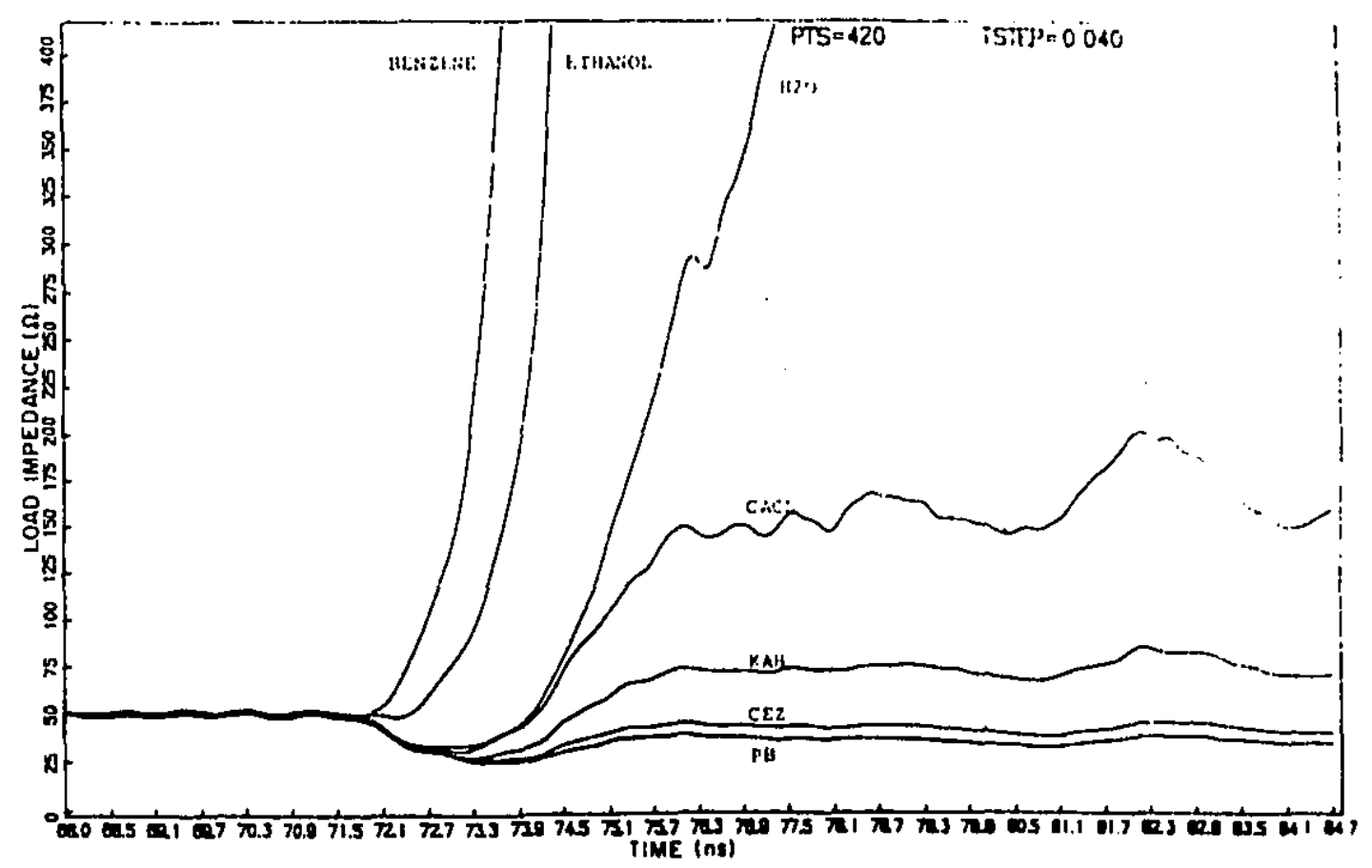

liki. 9. Load inspeciance of various contaminates (tintc domaitt).

no ripples or distortions), whilc the corresponding frequencydomain 1 ansfer function results from the actual processing technique used in this study. The relationship between the tine domuin and the frequency domain may be regarded as reciprocal, meaning that at short times the wave form is described by the high-frequency harmonics, while at longer times it is shaped by the low frequencies and a de component of the insulse. It can be observed that the intilial tirnedomain response of tlac capacitor corresponds to that uf a short circuit $(K=0)$, while in the latter stuges it approuclies exponentially the behaviour of an open circuit $(R=\infty)$. This phenomenon reflects the capacilor's property of con- 


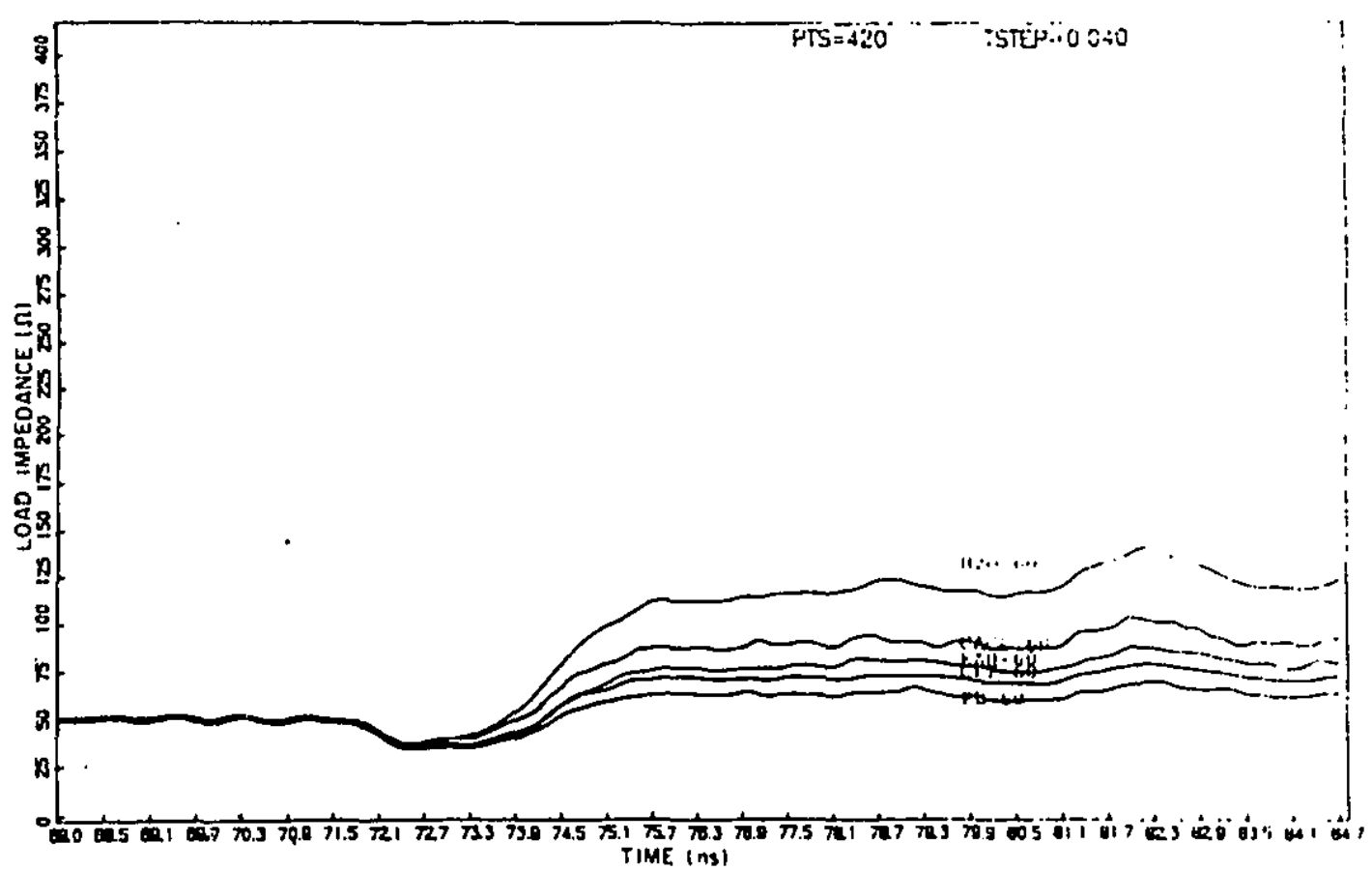

Fici. 10. Load impedance of soils saturated with contaminants (time domain); $w=60 \%$.

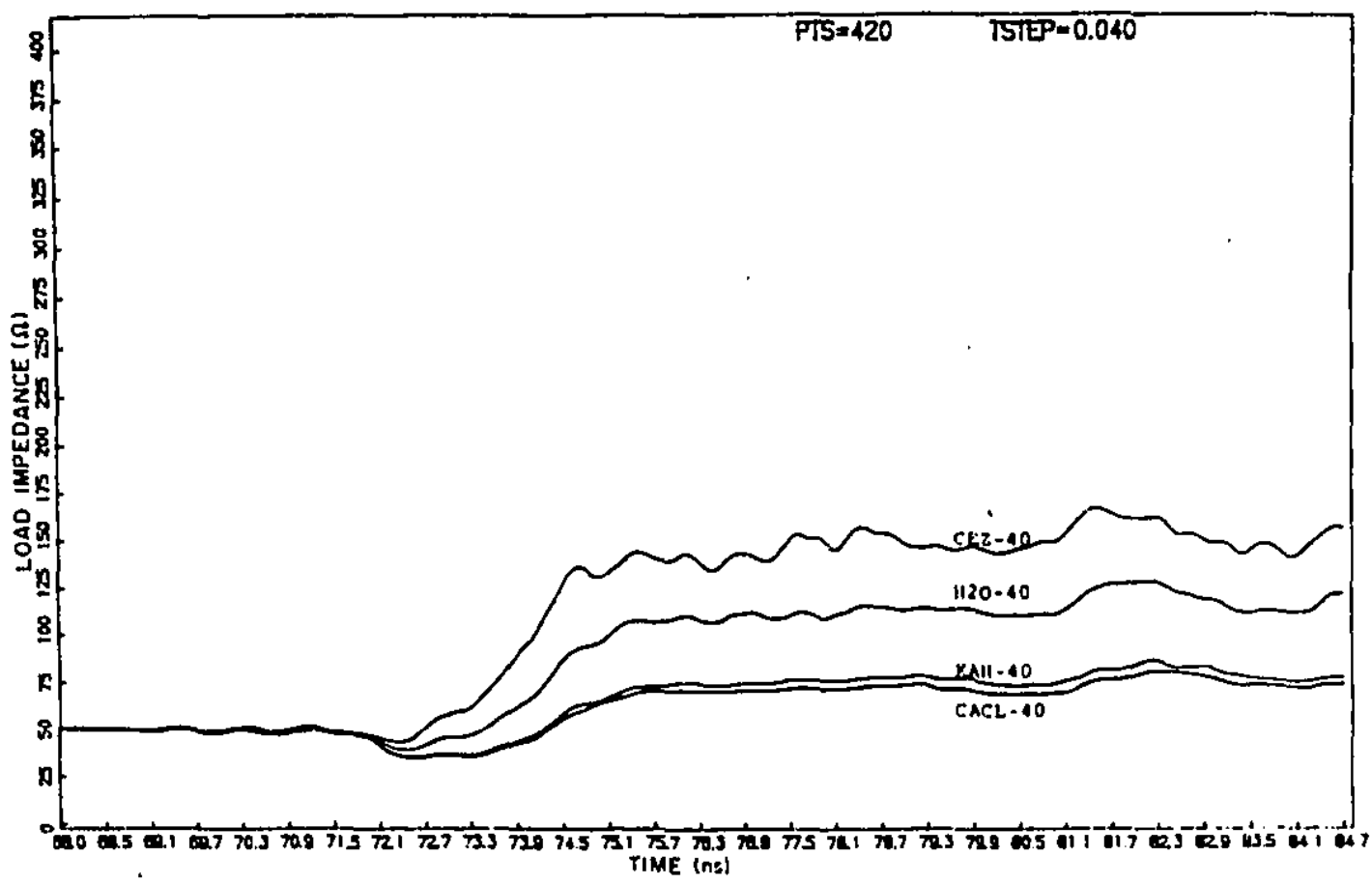

Fits. 11. Luad impedance of soils saturated witl contaminants (time domain); $w=40 \%$.

ducting at high frequelcies while blocking any current at a dic level. Thus, the transfer function of a capacitor indicates a relative phase shift and attenuation of the multitude of frequency components of the applied impulse. By contrast, the resistor transfers all frequencies of the input sigital equally, both in magnitude and in phase. In the open- circuit termination (infinite resistance) all frequency consponents of the output signal appear in phase with the spectrum of the incident signal. In the short-circuit termination (zcro resistance) the transfer occurs in antiphase.

$A$ contaminated soil can be viewed as a complex collection of resistors and imperfect capacitors exerting a combined 


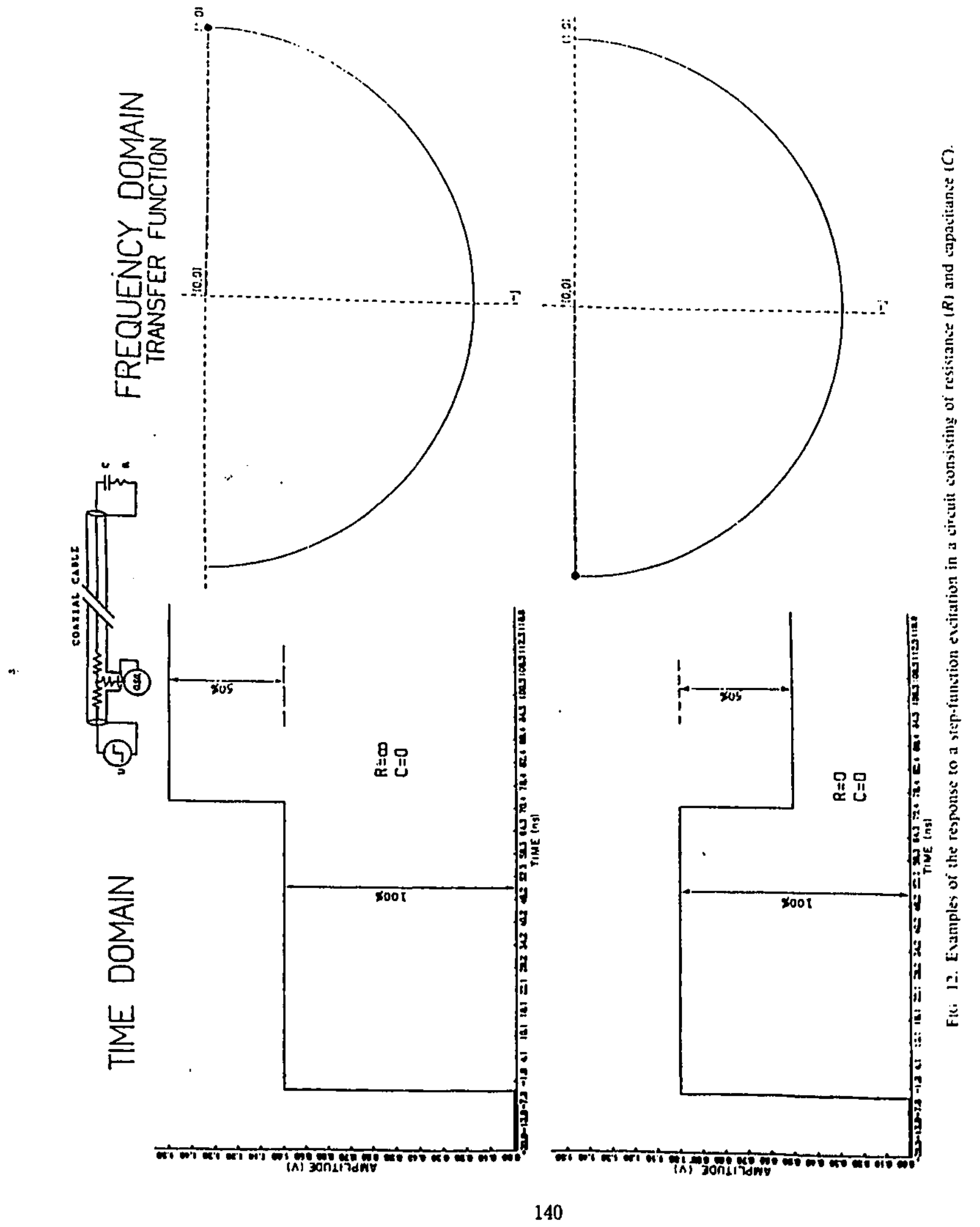




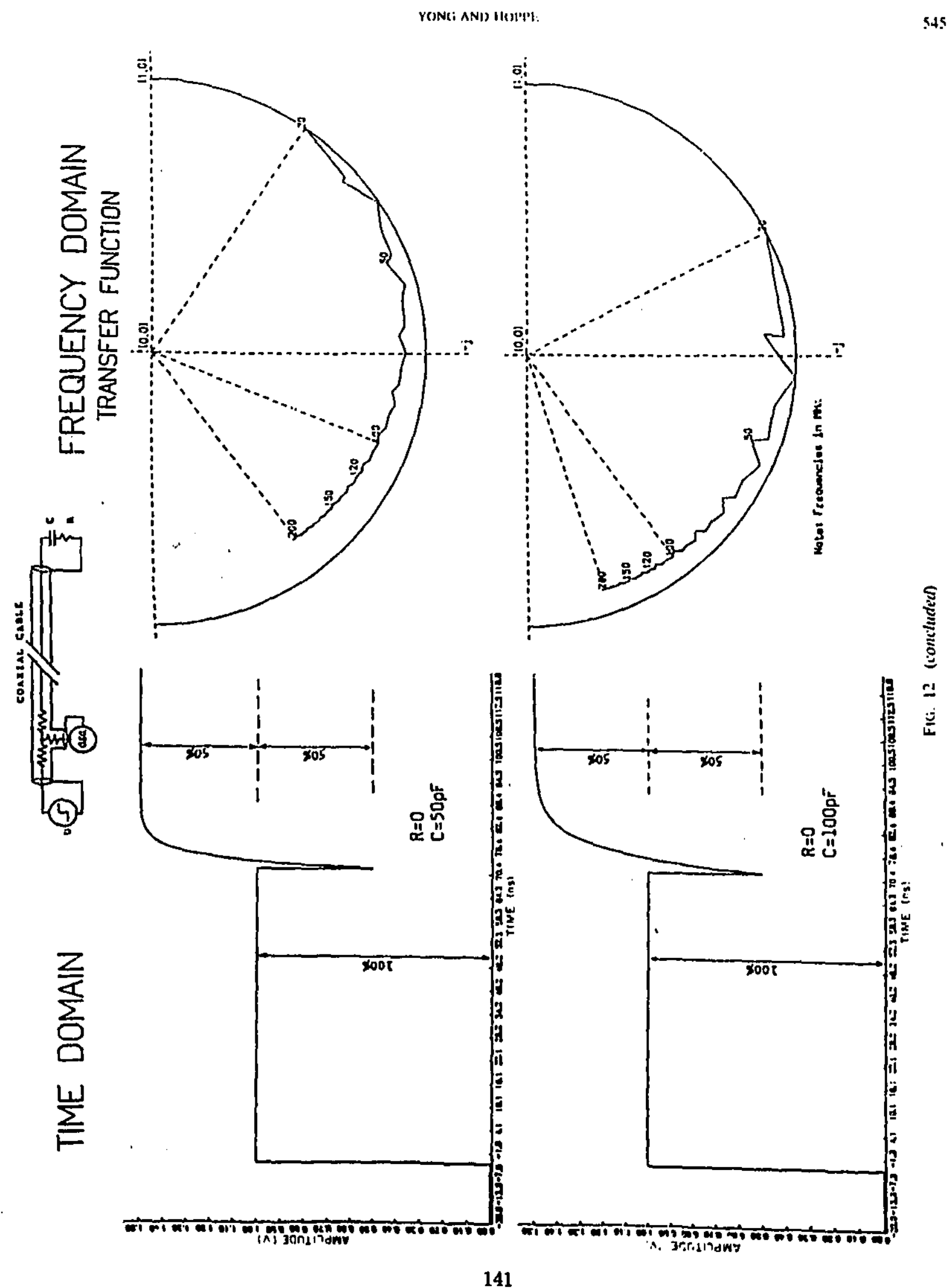




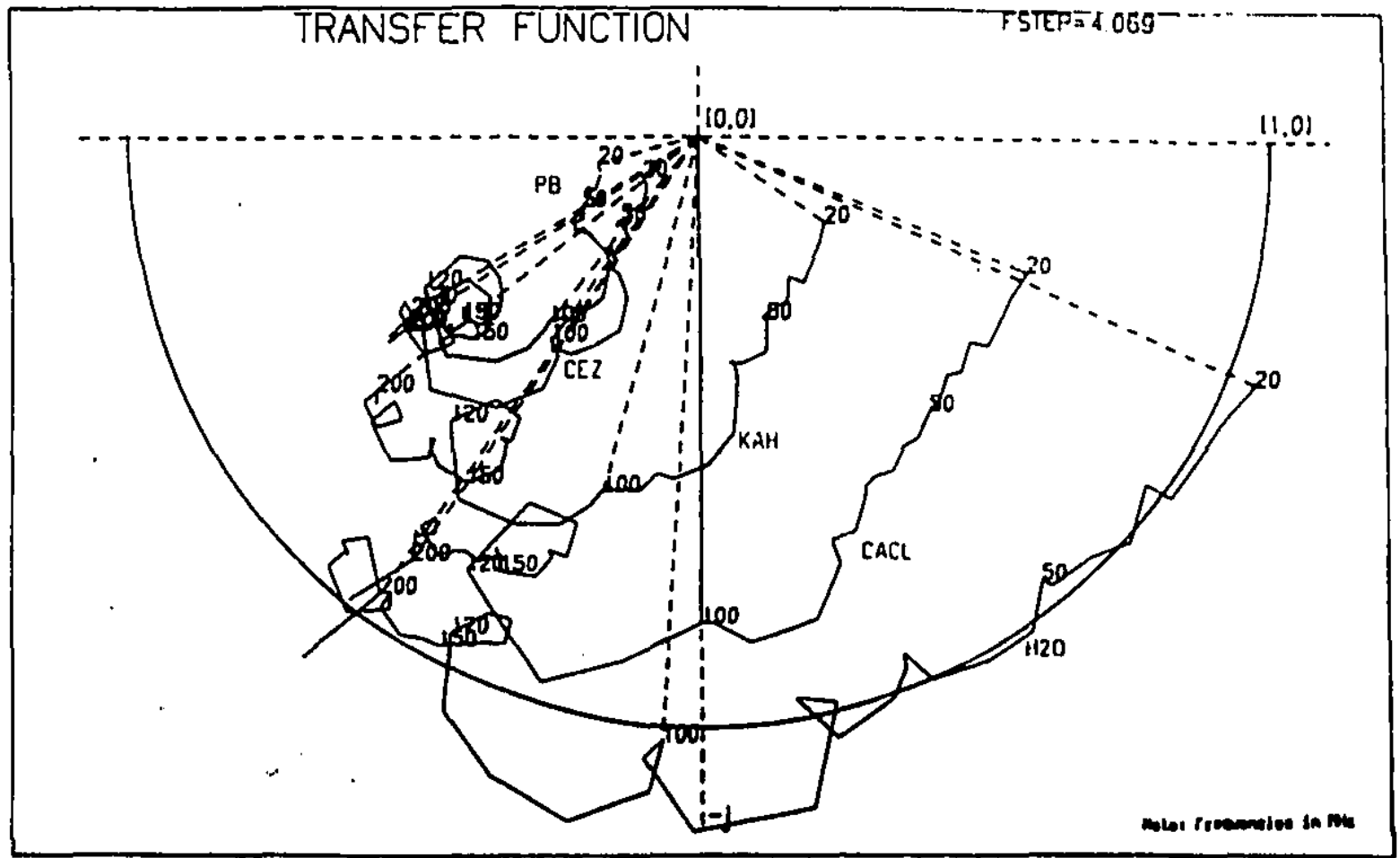

Fisi. 13. Frequency response (lilit) of various contaminants.

influence on the overall clectrical response. Some representative frequency-domain results are shown in Figs. 13-17. Transfer functions for contaminants and soil-contaminant mixtures are computed in the spectral range of $20-200 \mathrm{MHz}$, in $4 \mathrm{MHz}$ frequency intrements, and are expressed in polar coordinates. The upper limit is governed by the attenuation of the incident impulse in the analyzed material and by the initial spectral composition of the generated signal.

It will be noted that distinct transfer-function signatures cun be oblained for the various iest cases studied. The exact quanlitative determination of individual chemical components cannot be made at this stage; however, it is expected that with a greater varicly of test situations, a scrics of cliaracteristic signatures can be catalogued to permit rapid qualitalive analysis.

\section{Discussion}

The lime-domain relationship, shown in Figs. 6-8, reveals various wave forms as they are acquired by the digitizer. It can be seen that the applied step function is not perfectly rectangular. The initial stage of the incident impulse is af'fected by ripples, stemming from imperfections in the impulse generator and from unwanted reflections in the measuring circuit. However, the shape of the incident signal, and therefore its'spectral composition, remains virtually identical in different tests. The reflected voltage step, comniencing at about $71 \mathrm{~ns}$, is characteristic of the matcrial being analyzed. Thus, in nonpolar liquids, such as benzene or cthanol (Fig. 6), the reflected wave form practically mirrors the applied step voltage. A substantial signal attenuation ociurs in conductive liquids, such as CEZ or PB (sec Table I for explanation of terins). The initial dip of the reflected impulse signifies capacitive effects. The laller parı of each wave form appronches a steady value, indicative of the DC resistivity. It appears that the transition period bet ween thic initial and final amplitude of the reflected sjenal is not purely exponential, signifying a phenomenon of more complex nature than the charging of an idcal capacitor. This diclectric response is most predominant in the first $4 \mathrm{JS}$ of the reflected wave form.

Graphs displaying the load impchance of various matcrials. (Figs. 9-11) portray differences in the dielectric response of highly conductive fluids, such as CEZ or PB, as compared with virtual insulators, such as benzenc. Soil-conlamisant mixtures (Figs. 10, I1) produce more attenuated reflections, stemming from the conductivity contribution of soil parlicles. However, wave forms of a pure contaminanl and of a corresponding soil-contaminant mixture indicate some resemblance in the initial stages of the acquisition (i.c., at high frequencies).

Since in the tinse-domain relationship the sliape of the initial stage of each wave form is governed by its higli. frequency content, while the final stage relates to a $D C$ terin. it is meaninglul to look at results in the frequency dontain. as displayed in Figs. 13-17. In these figures llie altentual iont and phase-shift characteristics of individual contaminants and soil-contaminant mixtures are presented as mattrial Iransfer functions. They are computed by dividing the spectrum of the reflected signal (output FFT) by the spectrum of the incident impulse (inpul FFT). The results are slown in a polar form, with the modulus being the distance from the point of origin to the particular frequency component of the wave form and the corresponding phase angle measured relative to the positive $x$-axis. With reference to 


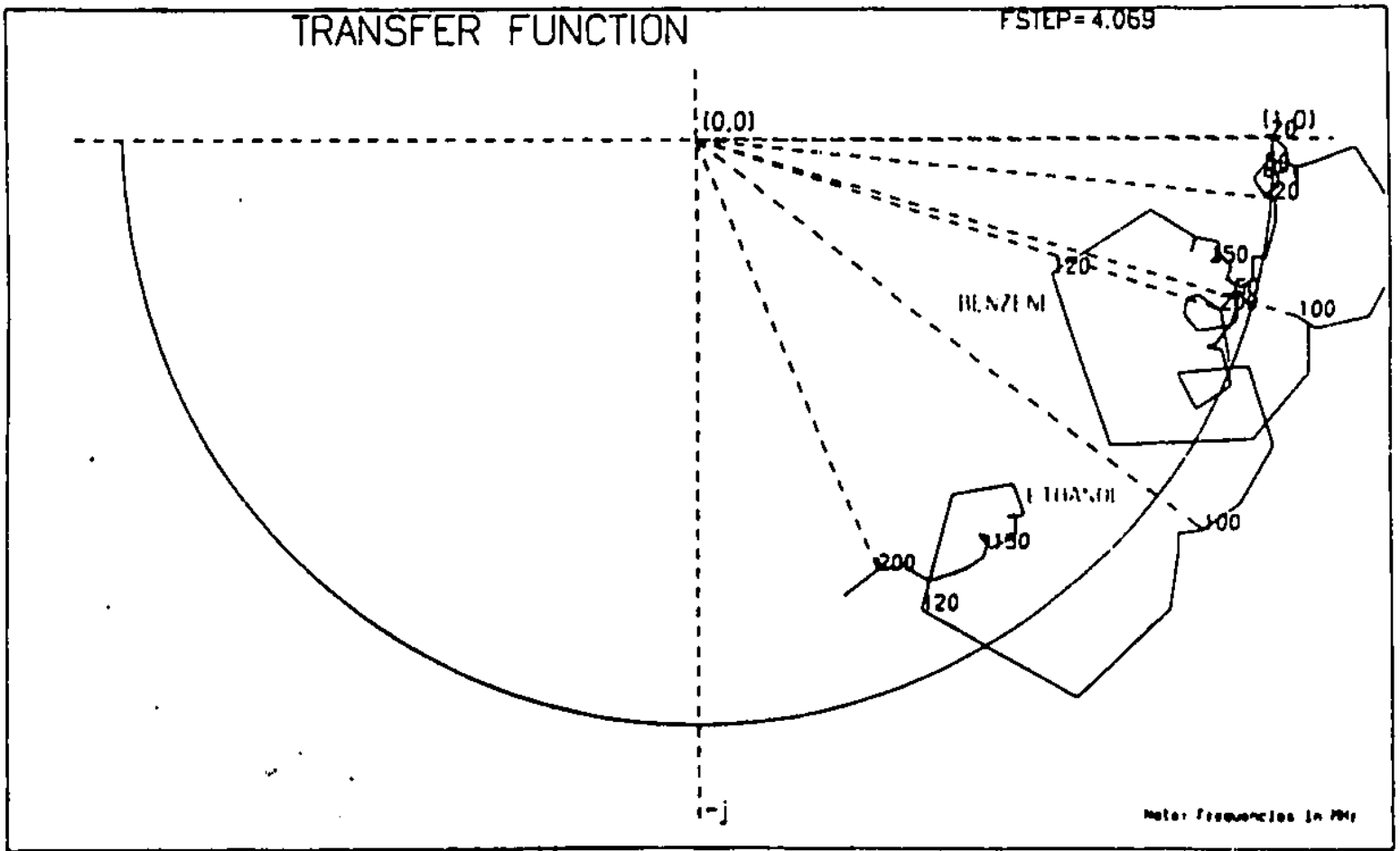

Fig. 14. Frequency response (FFT) of benzene and ethanol.

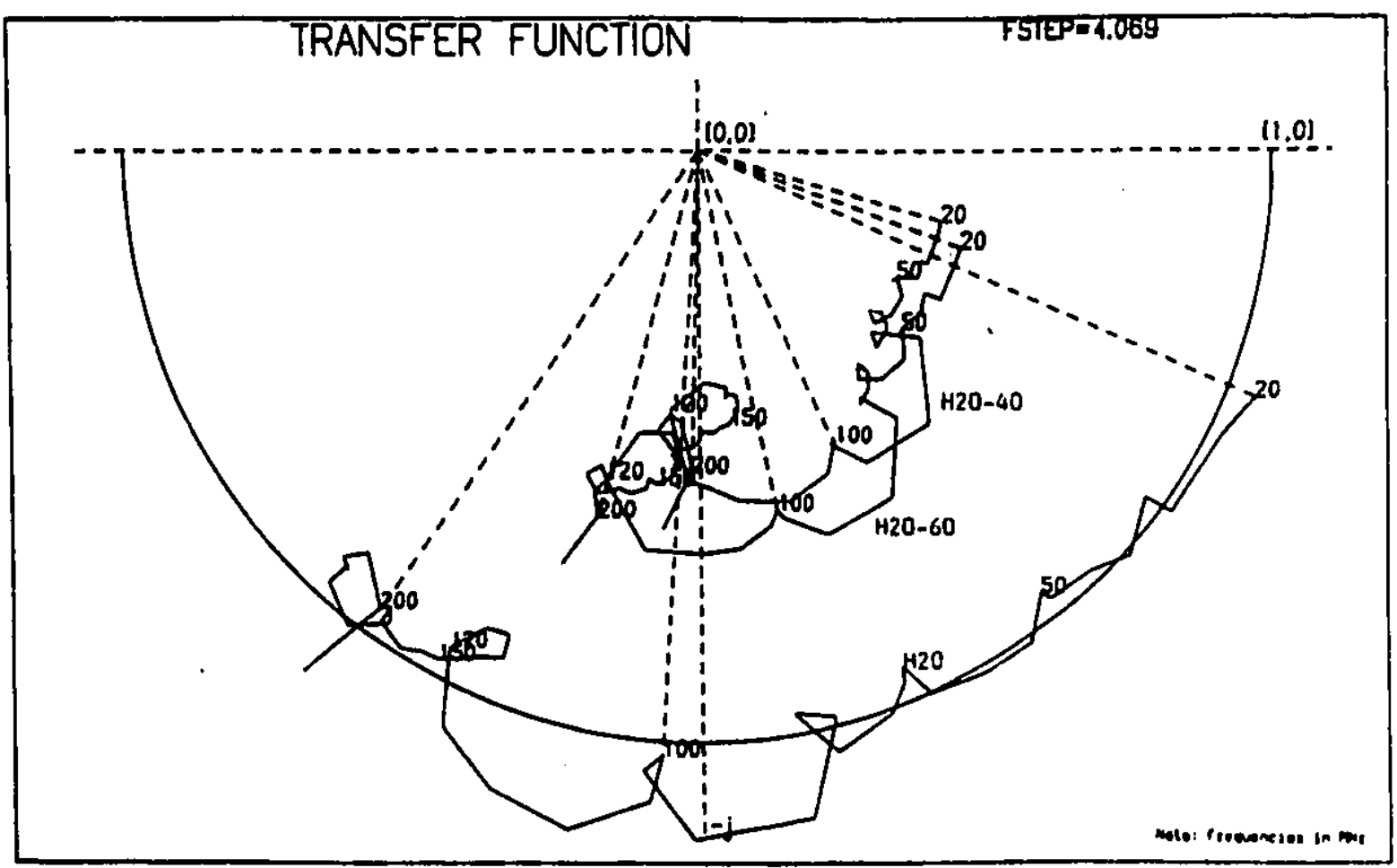

Fiki, 15. Irequency response (FFT) of $H 20$ and of soils conlainine 60 and $40 \%$ of $\mathrm{H} 20$. 


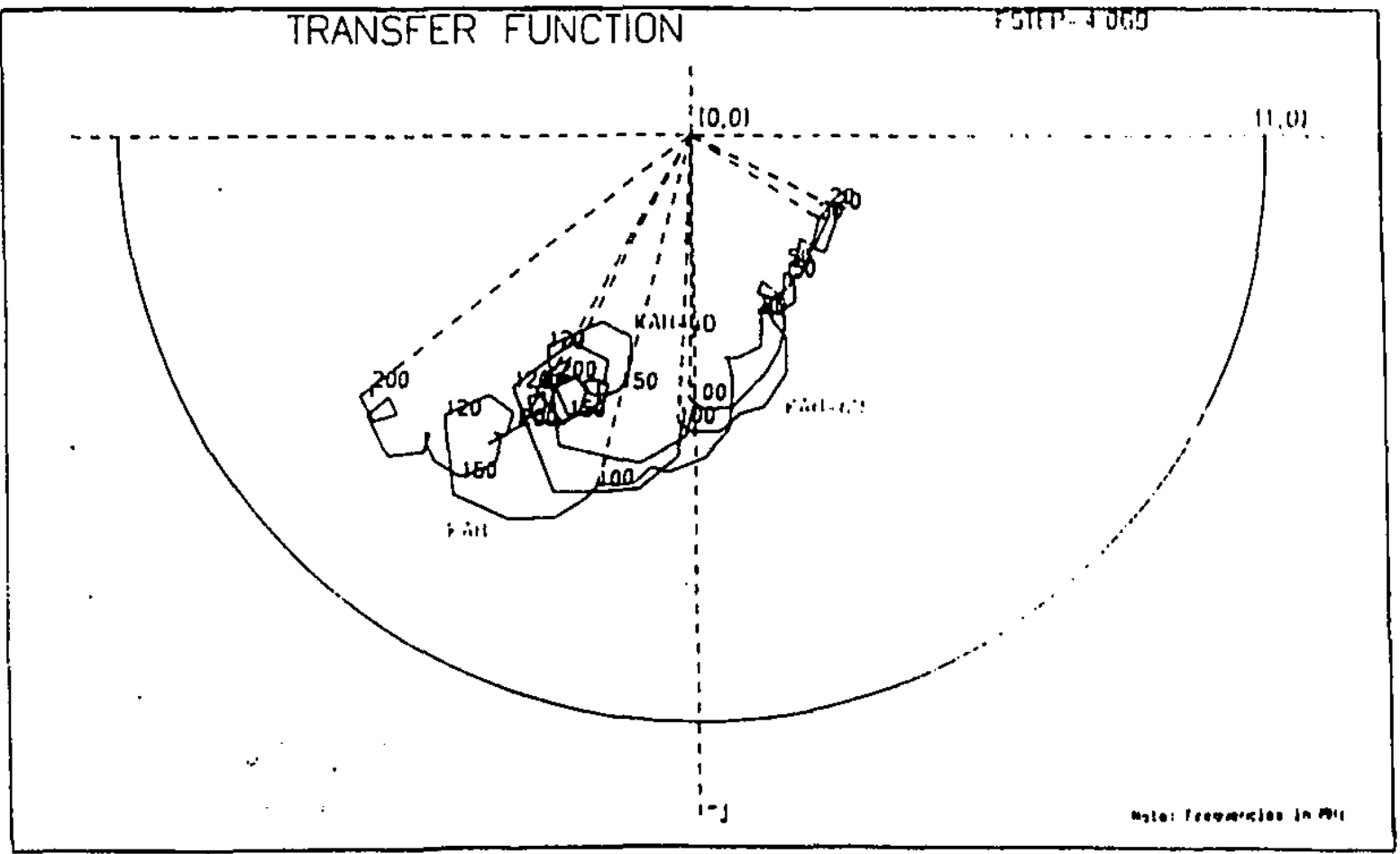

Fiki. 16. Frequency response (FFT) of KAH and of soils containing 60 and $40 \%$ of KAHI.

lig. 12, while it would appear that the matcrial's resistivity (or conductivity) affects the transfer-function position along the $x$-axis, and that its diclectric constant causes the relative pliase shift of various frequencies, it is likely that the processes contributing to the results shown are more complicated. The real part of the resistivity (or imaginary part of $\epsilon$ ) would also affect the phase shift.

The trans/cr-function representation provides a meaningful insight into the material's diclectric behaviour. When the sample material is either conductive or polar, or possibly both, it does not behave like a perfect capacitor (as in Fig. 12), leading to a particular phase shift of various harmonics. If the charges contained in the material are free to move' under the influence of an electrical field, the resistance is effectively independent of the frequency of the applicd signal, but if these charges are bound, as in oscillating dipoles, the resistance becomes a characteristic function of frequency. This pattern manifests itself readily in lïigs. 13-17.

ll can be scen that the transfer function exhibits a different signature for difrerent contamitants. In a highly conJuctive liquid, such as CliZ (Fig. 17), it appronches the response of a short circuit (Fig. 12). In a practically nonpolar niaterial, such as benzene (Fig. 14), the phase shirt and attenuation of different frequency components are minimal. The transfer function reflects the combined infuence of the diclectric constant and resistivity of a given material, and thus the response of benzene $(\epsilon=2.3)$, cthanol $(\epsilon=31.2)$, and distilled water $(\epsilon=80)$ illustrate the trend of increasing diclectric constant and diminishing resistivity.

\footnotetext{
"Iuterfacial polarization is from "free" charge movemenl, and
} is signifficaul at these frequencies.
In general, the signature of the transfer function ol a pure contaminant resembles the corresponding transfer lunction of a soil-contaminant mixture. It appears that at higher frequencies the transfer function is influenced predominantly by the dielectric properties of a liquid. This phenomenon can be exploited to trace the extent of a subsurface contaminarit plume and its approximate concentration.

As stated previously, a greater collection of information from various before and after (contamination) situations. would provide one.with the basis for establishing a gencral catalogue of signatures. It is hoped that through systematic amassing of data a qualitative approach can be developed to permit one to deduce the presence of contaminants in soils. Further work also remains to be done on tlic cvalualion of the effects of chemical interaction between the contani. nant and the soil vis-a-vis alteration of the diclectric properties of the contaminant fluid (sec, for example, Olhoeft 1987). Obviously, other factors that need full consideration include clay type, contaminant species and concenteation, multispecies contaminants, etc. The list is endless. However, it is hoped that a demonstration of the ability of Ile fectonizinc presented would spur others to pursue lurilier (isdded) documentation of signatures.

\section{Conclusions}

This study is intended to demonstrate the feasibility of constructing an effective in situ contaminant-detcction technique based on the phenomenon of clectrical polariyation. In principle, the proposed approach is similar to the presently utilized geophysical technique of induced polariza. tion. The main difference stems from the necessily of delecting high-frequency polarization phenomena oceurring in lie 


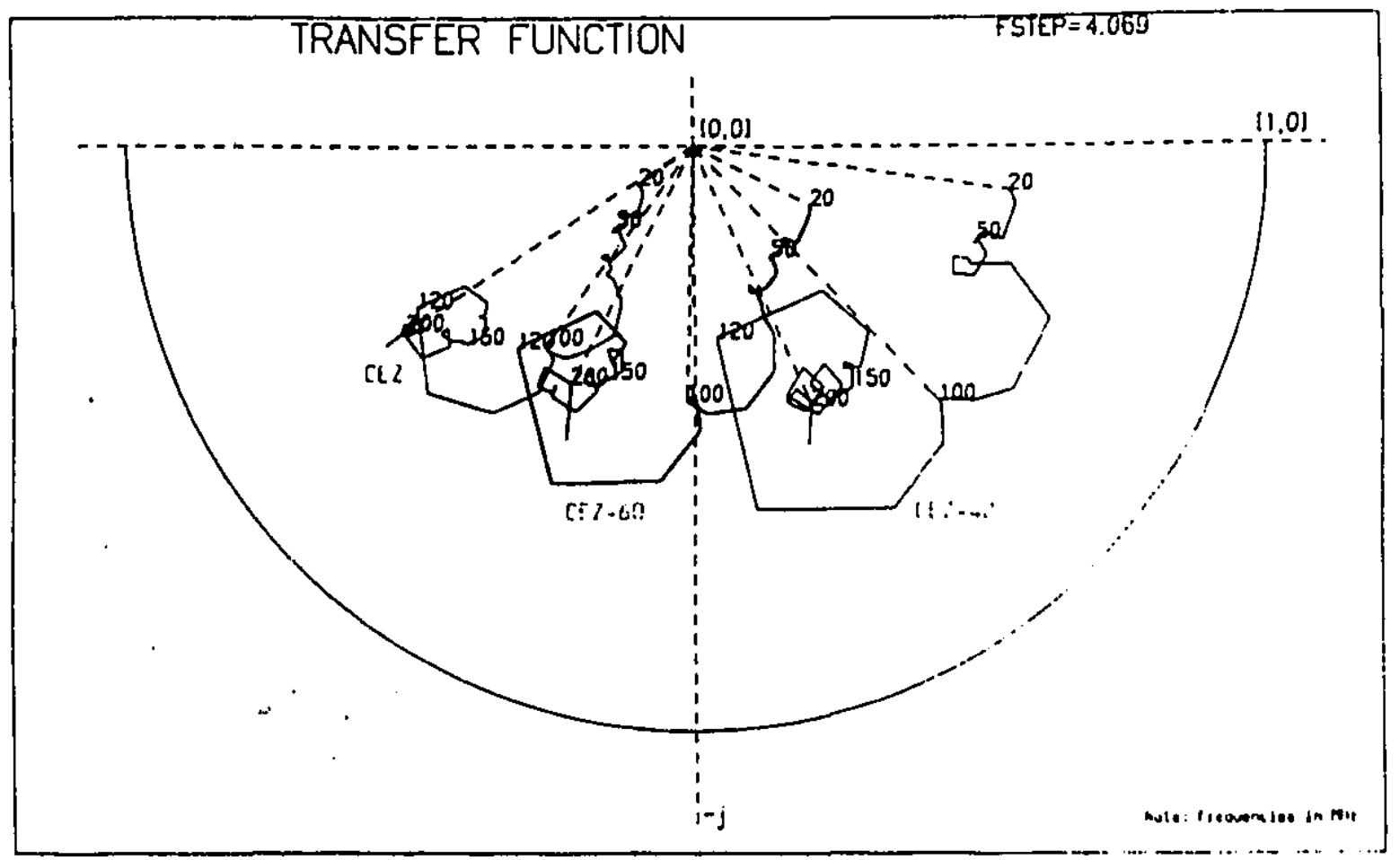

Fici. 17. Frequency response (FFT) of CEZ and of soils containing 60 and 4 no\% of CEZ.

pore Muid, as opposed to low-frequency interfacial polarization indicative of mineral content. Technically, the measuring sclup is relatively simple, scquiring only one cable to be inserted into the soil. Wave-form acquisition by a digitizer alld its processing by a portatle computer can be performed direcily in silu, with the aid of a database of signatures cstablished from more delailed laboratory testing. The extent of an underground contamination can be detected by probing the alfected area and analyzing the spectral signature of a subsurface pore fluid for the presence of a contaminant. Presentation of results in terms of a transfer function, expressed in polar coordinales, facititates the task of conIaminamit detection and moniloring. This task can be fusther enluanced if the technique proposed in this study is used in conjunction with other monitoring methods. Thus, an initial sitc reconnaissance can be rapidly performed with a portable electromagnetic conduclivity instrument. The area of interest cull be subscquently narrowed down with the aid of the electrical polarization method. Irurther refinement, if required, ealis be ichieved by a direct drillimg and sampling from a monitoring well, which at this stage can be judiciously loculed. Currently, there is a growing need for a quick and efficient technique to assess the extent of a localized ground conlamination and it is cnvisaged that this study can lead (1) further work, which would be applied to the development of a mobile cuntaminani-detection system.

Much work reinains to be done to sort out specifie effects of contaminant-soil interaction-particularly for situations involving multicomponent contaminants. "Calibration" experiments that seek to identify before and after (contamination) situations are needed for cataloguing of signalures-especially with reference to soil type, contami- nant species, and concentration. For the present, the results obtained indicate the uscfulness and ability of this technique for detection of contaminant presence.

\section{Acknowledgments}

The authors with to express their gratitude to Dr. Kyszard Malewski of the Hydro-Québec Research Institutc (IREQ). for his constructive comments and helpful guidance in performing measurements. Furthermore, the Iechnical assistance of Messrs. Jean Douville and Louis Lavallée of IREQ is gratefully acknowledged. Critical comments from! Mr. Danicl Tschudi of Asca Brown Boveri are also appreciated. The authors also wish to thank the reviewers for their very constructive inputs for improvement of the paper. This study was supported by grants from the Ministere de l'Éducation du Québec (FCAR/MESST) and the Natural Sciences and Enginecring Rescarch Council of Canada (grant No. A-882).

ANukLws, J.K. 1973. Kandom sampling oscilloscope for the observation of mereury switch closure transition times. IEtal: Transactions on Instrumentation and Measurement, iMe-22: 375-381.

BOCKRIS, J.O'M., GILLAIM, E., and MÜLI.I:K, K. 1\%(6. Diclectric relaxation in the electric double layer. Journal of Chemical Physics, 44: 1445-1456.

Coll, K.S., and Col.E, R.H. 1941. Dispersion and absurption in dielectries. Journal of Chemical Physies, 9: 34/-353.

DANiti., V.V. 1967. Dielectric relaxation. Acadenic l'ress, New York, NY.

DAvits. "J.L., ToP1, G.C., and ANNAN, A.P. 1977. Messuring soil water content in silu using lime-domain reflectonitiry 
techniques. Gcological Survcy of Canada, Report on Activities, I'art B, Paper 77-1B.

1)1:IYI:, P. 1929. P'olar molecules. ('hemical Catalogue Conıpany, New York. NY.

Fti.LNES-FitLLI:Ci(i, H: 1969. The measurement of dielectrics in time domain. Journal of Physical Chemistry, 73: 616-623.

GilininI, A. 1933. Liquid diclectries. John Wiley, New York, NY.

Hansalinci, R.W. 1977. Digital fitters. Prentice-Hall, Englewood Clifrs, NJ.

HAkVtir, S.C., and Holsestra, P. 1972. Diclectric rclaxation spectra of water adsorbed on lysozyme. Journal of Physical Chemistry, 76: 2987-2994.

HetekstrA, $P$., and DEi.ANEY, A. 1974. Dielectric propertics of soils al UHF and microwave frequencies. Journal of Geophysical Rescarch. 79: 1699-1708.

ISKANIJ:R, M.F., and STUChLY, S.S. 1972. A time domain Icchnique for measurement of the dielectric propertics of biological substances. IEEEE Transactions on Instrumenlation and Measurement, IM-21: 425-429.

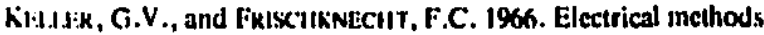
in geophysical prospecting. P'ergamon P'ress, Lilussford, NY.

I. IIKI:NT\%. H.A. 1915. Thic theory of electrons. Dover P'ublications, New York, NY.

Maxu't:1., J.C. 1854. Treatise on clectricity and magnelism. Vol. I Dover Publications, New York, NY, p. 452. 1987a. Ministère dé I'Enviromemesu du Qućbec. Kćglements sur les déchets solides.

1987b. Guide technique pout l'implentation el la gestion de licu d'enfuissentent des sols contaminés.
Ot.hotelr, G.R. 1986. Direct deccition of hydrocarbon and orgausic chemicials with ground penelrating radar and cimullex resistivity. Procecdings, National Well Water Asscriationn American Petroleum Instilute Conference on Petroleun Hydrocarbons and Organic Chemicals in Groundwater I'revention, Detection and Restoration, NWWA, op. 284-305. i987. Electrical propertics fromt 10 ' 10 io and chemistry. Procecdings, 2nd Ineenational Symposium on the Pliysies and Cluemissry of Porous Media. Americuln lostifule of Physies Conference, P'roceeding 154, pp. 281-298.

Ramiktz, R.W. 1985. The FIF fundamentals and comicpls. Prentice-Hull, Englewood Clirss, N.I.

van GEmé'T, M.J.C. 1973. High frequency lime domain methods in dielectric spectroscopy. Philips Kesearch Reports, 2n: 530 -572. von Hippet, A.R. 1954. Dislectrics and waves. The M.I.T. Press, Cambridge, MA.

Watintek, K.W. 1913, Amalen der Physik (1 cipring, Sterien 4, 40: 817-855.

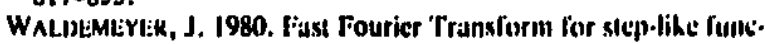
lions: the synthesis of three apparenty differem mellods, Hi:li: Transactions on lnstrumentalion and Measuremsent. IM-29: 36-39.

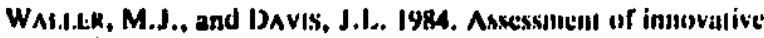
techniques lo detect wasle inapoundment liner failures. Natioulual Technical Information Service, Springfield, VA.

YoNCi, R.N., BOONSINSUX, P., and WoNki, Ci. 19\%6. Jiormulaliun of backfill material for a nuclear fucl waste disnosal vault. Canadian Geotechnical Journal, 23: 216-228. 


\section{REFERENCES}

Adam, J.A. 1988. Soviets Arrive in Nevada for Blast. The Institute, vol. 12, no. 10, pp. 1-4.

Al'pin, L.M., and Berdichevskii, M.N. 1966. Dipole Methods for Measuring Earth Conductivity. Consultants Bureau Enterprises, Inc., New York.

Andrews, J.R. 1973. Random Sampling Oscilloscope for the Observation of Mercury Switch Closure Transition Times. IEEE Transactions on Instrumentation and Measurement, vol. IM-22, no. 4, pp. 375-381.

Arulanandan, K., and Mitchell, J.K. 1968. Low Frequency Dielectric Dispersion of Clay-Water-Electrolyte Systems. Clays and Clay Minerals, vol. 16, pp. 337-351.

Benignus, V.A. 1969. Estimation of Coherence Spectrum and Its Confidence Interval Using the Fast Fourier Transform. IEEE Transactions on Audio and Electroacoustics, vol. AU-17, no. 2, pp. 145-150.

Bleil, D.F. 1953. Induced Polarization: A Method of Geophysical Prospecting. Geophysics, vol. 18, no. 3, pp. 636-648.

Bockris, J.O'M., Gileadi, E., and Müller, K. 1966. Dielectric Relaxation in the Electric Double Layer. The Journal of Chemical Physics, vol. 44, no. 4, pp. 1445-1456.

Boraiko, A.A. 1985. Hazardous Waste. National Geographic, vol. 167, no. 3, pp. 319351.

Bose, T.K., Bottreau, A.M., and Chanine, R. 1986. Development of a Dipole Probe for the Study of Dielectric Properties of Biological Substances in Radiofrequency and Microwave Region with Time-Domain Reflectometry. IEEE Transactions on Instrumentation and Measurement, vol. IM-35, no. 1, pp. 56-60.

Bowders, J.J., Jr., Lord, A.E., Jr., and Koerner, R.M. 1982. Sensitivity Study of a Ground Probing Radar. Geotechnical Testing Journal, vol. 5, no. 3/4, pp. 96-100.

Brown, J.T.L., and Pollard, C.E. 1947. Mercury Contact Relays. Electrical Engineering, vol. 66, pp. 1106-1108.

Carter, G.C. 1972. Estimation of the Magnitude-Squared Coherence Function (Spectrum). Technical Report 4343, Naval Underwater Systems Center, Newport, Rhode Island.

Cole, K.S., and Cole, R.H. 1941. Dispersion and Absorption in Dielectrics. Journal of Chemical Physics, vol. 9, pp. 341-353.

Davis, J.L., and Annan, A.P. 1977. Electromagnetic Detection of Soil Moisture: Progress Report I. Canadian Journal of Remote Sensing, vol. 3, pp. 76-86.

Debye, P. 1929. Polar Molecules. Chemical Catalogue Company, New York.

Dev, S.B., North, A.M., and Pethrick, R.A. 1972. Computational Techniques in the Analysis of Dielectric Relaxation Measurements. Advanced Molecular Relaxation Processes, vol. 4, pp. 159-191. 
Fellner-Feldegg, H. 1969. The Measurement of Dielectrics in Time Domain. The Journal of Physical Chemistry, vol. 73, no. 3, pp. 616-623.

Gajda, B.G., and Stuchly, S.S. 1983. Numerical Analysis of Open-Ended Coaxial Lines. IEEE Transactions on Microwave Theory and Techniques, vol. MTT-31, no. 5, pp. 380384.

van Gemert, M.J.C. 1973. High Frequency Time Domain Methods in Dielectric Spectroscopy. Philips Research Reports, vol. 28, pp. 530-572.

Gerlach, A.A. 1980. Role of the Sectionalized Fourier Transform in High-Speed Coherence Processing. Technical Report 8438. Naval Research Laboratory, Washington, D.C.

Gonzalez, R.C., and Wintz, P. 1987. Digital Image Processing. Addison-Wesley, Reading.

Gooch, D.W., Harrison, C.W., King, R.W.P., and Wu, T.T. 1963. Impedances of Long Antennas in Air and in Dissipative Media. Journal of Research of National Bureau of Standards, vol. 67D, pp. 355-360.

Gouy, G. 1910. Sur la Constitution de la Charge Electrique à la Surface d'un Electrolyte. Ann. Phys., Paris, Série, vol. 4, no. 9, pp. 457-468.

Greenhouse, J.P., and Harris, R.D. 1980. Hydrogeological Studies of a Sandy Acquifer at an Abandoned Landfill, Part 8, DC, VLF and Inductive Resistivity Surveys. Department of Earth Sciences, University of Waterloo, Waterloo, Ontario.

Halverstadt, I.F., and Kumler, W.D. 1942. Journal of American Chemical Society, vol. 64 , pp. 2988-3007.

Harvey, S.C., and Hoekstra, P. 1972. Dielectric Relaxation Spectra of Water Adsorbed on Lysozyme. The Journal of Physical Chemistry, vol. 76, no. 21, pp. 2987-2994.

Hasted, J.B., Ritson, D.M., and Collie, C.H. 1948. Journal of Chemical Physics, vol. 16, pp. 1-14.

Hedestrand, G. 1929. Z. Physik. Chem., vol. 2B, pp. 428-442.

Hoekstra, P., and Delaney, A. 1974. Dielectric Properties of Soils at UHF and Microwave Frequencies. Journal of Geophysical Research, vol. 79, no. 3, pp. 1699-1708.

Hoekstra, P., Mills, T., Blohm, M., and Evans, L. 1988. Time Domain Electromagnetic Soundings for Mapping Sea-Water Intrusion in Monterey County, California. Ground Water, vol. 26, no. 6, pp. 771-782.

Iskander, M.F., and DuBow, J.B. 1983. Time- and Frequency-Domain Techniques for Measuring Dielectric Properties of Rocks: A Review. Journal of Microwave Power, vol. 18, no. 1, pp. 55-73.

Jackson, H.W. 1976. Introduction to Electric Circuits. Prentice-Hall, Englewood Cliffs.

Karably, L.S., and Babcock, K.B. 1989. The Effects of Environmental Variables on Soil Gas Surveys. Hazardous Materials Control, vol. 2, pp. 36-43. 
Keller, G.V., Frischknecht, F.C. 1966. Electrical Methods in Geophysical Prospecting. Pergamon Press, Elmsford.

Koerner, R.M., McCabe, W.M., and Lord, A.E. 1981. State of the Art Lectures: Acoustic Emission Behavior and Monitoring in Soils. ASTM Symposium on Acoustic Emission in Geotechnical Engineering Practice, Detroit, Michigan.

Lewis, I.A.D., and Wells, F.H. 1954. Millimicrosecond Pulse Techniques. McGraw-Hill, New York.

Look, B.G., and Reeves, I.N. 1992. The Application of Time Domain Reflectometry in Geotechnical Instrumentation. Geotechnical Testing Journal, vol. 15, no. 3, pp. 277-283.

Maxwell, J.C. 1854. Treatise on Electricity and Magnetism. Dover Publications, New York.

Ministère de l'Environnement du Québec, 1987. Guide technique pour l'implentation et la géstion de lieu d'enfuissement des sols contaminés.

Ministère de l'Environnement du Québec, 1987. Règlements sur les déchets solides.

Okrasinski, T.A., Koerner, R.M., and Lord, A.E. 1978. Dielectric Constant Determination of Soils at L Band Microwave Frequencies. Geotechnical Testing Journal, vol. 1, no. 3, pp. 134-140.

Olhoeft, G.R. 1985. Low Frequency Electrical Properties. Geophysics, vol. 50, pp. 24922503.

Olhoeft, G.R. 1986. Direct Detection of Hydrocarbon and Organic Chemicals with Ground Penetrating Radar and Complex Resistivity. Proceedings of the NWWA/API Conference on Petroleum Hydrocarbons and Organic Chemicals in Ground WaterPrevention, Detection and Restoration, National Water Well Association, Dublin.

Olhoeft, G.R. 1987. Electrical Properties from $10^{-} 3$ to $10^{9}$ - Physics and Chemistry. Proceedings of the 2nd International Symposium on the Physics and Chemistry of Porous Media, American Institute of Physics Conference Proceedings, pp. 281-298.

Onsanger, L. 1936. Journal of American Chemical Society, vol. 58, pp. 1486-1498.

Ramirez, R.W. 1985. The FFT Fundamentals and Concepts. Prentice-Hall, Englewood Cliffs.

Ryu, J., Morrison, H.F., and Ward, S.H. 1972. Electromagnetic Depth Sounding Experiment Across Santa Clara Valley. Geophysics, vol. 37, pp. 351-374.

Sachs, S.B., and Spiegler, K.S. 1964. Radiofrequency Measurements of Porous Conductive Plugs. The Journal of Physical Chemistry, vol. 68, no. 5, pp. 1214-1222.

Saunders, W.R., and Germeroth, R.M. 1986. Electromagnetic Measurements for Subsurface Hydrocarbon Investigations. Report to Port Authority of New York and New Jersey by Camp Dresser \& McKee Inc.

Schlumberger, C. 1920. Etude sur la Prospection electrique du sous-sol. GauthierVillars et Cie., Paris. 
Sumner, J.S. 1976. Principles of Induced Polarization for Geophysical Exploration. Elsevier, Amsterdam.

Tarrer, A.R. 1993. Impacts of Environmental Regulations on Highway Maintenance. TR News, no. 167, pp. 11-15.

Topp, G.C., Davis, J.L., and Annan, A.P. 1980. Electromagnetic Determination of Soil Water Content: Measurement in Coaxial Transmission Lines. Water Resources Research, vol. 16, no. 3, pp. 574-582.

Ulriksen, P.F. 1982. Application of Impuse Radar to Civil Engineering. Lund University, Department of Engineering Geology, Lund.

Wagner, K.W. 1913. Annalen Phys., vol. 40, no. 4, pp. 817-836.

Wait, J.R. 1959. Overvoltage Research and Geophysical Applications. Pergamon Press, London.

Wait, J.R., 1971. Electromagnetic Probing in Geophysics. The Golem Press, London.

Waldmeyer, J. 1980. Fast Fourier Transform for Step-like Functions: the Synthesis of Three Apparently Different Methods. IEEE Transactions on Instrumentation and Measurement, vol. IM-29, no. 1, pp. 36-39.

Waller, M.J., and Davis, J.L. 1984. Assessment of Innovative Techniques to Detect Waste Impoundment Liner Failures. NTIS, Springfield.

Winter, T.G. 1973. A Survey of Sound Propagation in Soils. Acoustical Holography, vol. 5, pp. 197-216.

Yong, R.N., and Warkentin, B.P. 1975. Soil Properties and Behaviour. Elsevier Scicntific Publishing Co., Amsterdam.

Yong, R.N., Boonsinsuk, P., and Wong, G. 1986. Formulation of Backfill Material for a Nuclear Fuel Waste Disposal Vault. Canadian Geotechnical Journal, vol. 23, no. 2, pp. 216-228.

Yong, R.N., and Hoppe, E.J. 1989. Application of Electric Polarization to Contaminant Detection in Soils. Canadian Geotechnical Journal, vol. 26, no. 4, pp. 536-550.

Yong, R.N., Mohamed, A.M.O., and Warkentin, B.P. 1992. Principles of Contaminant Transport in Soils. Elsevier Scientific Publishing Co., Amsterdam.

Zonge, K.L., and Hughes, L.J. 1980. The Complex Resistivity Method. Zonge Engineering and Research Organization, Inc., Tucson. 